\title{
Performance de IEEE 802.15.6 en coexistencia con IEEE 802.15.4 e \\ IEEE 802.11.
}

Tesis para obtener el grado de Magister en Redes de Datos

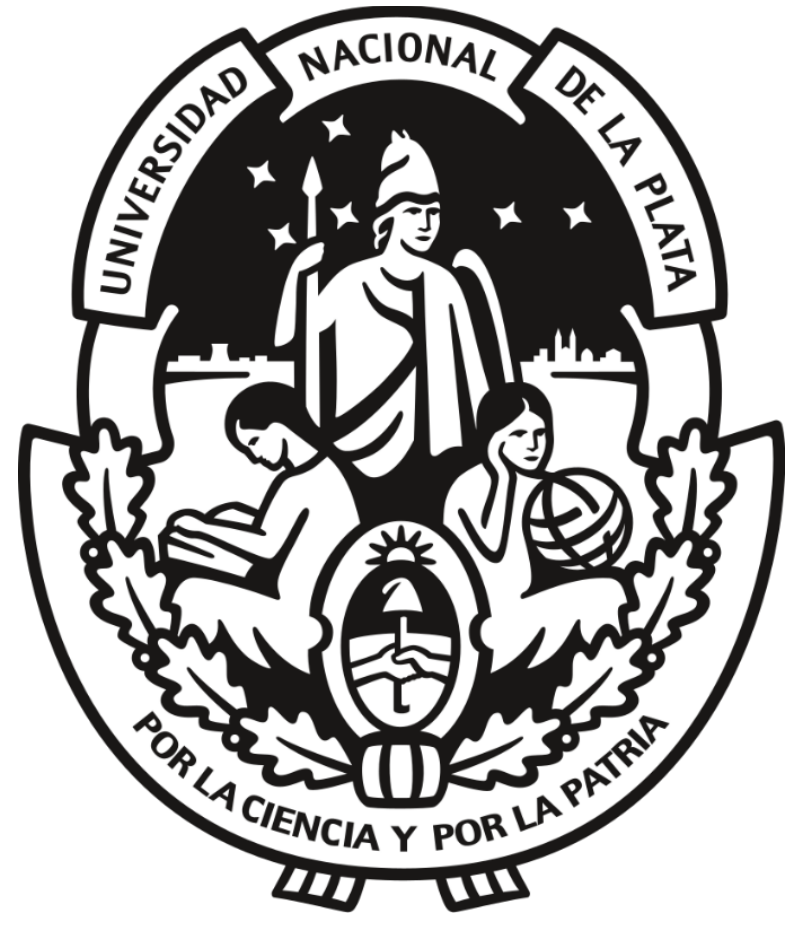

Universidad Nacional de La Plata Facultad de Informática

Autor: Ing. Juan Pablo Michelino Director: Ing. Luis Marrone

Diciembre 2020 


\section{Contenido}

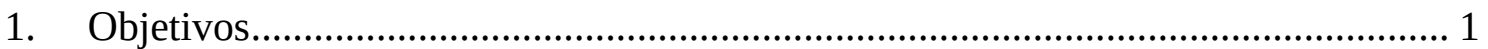

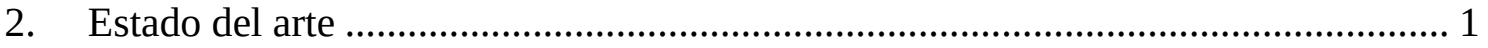

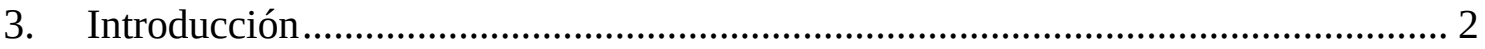

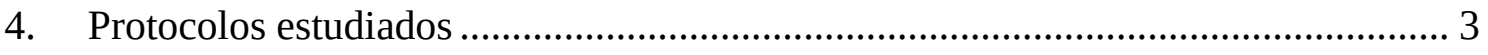

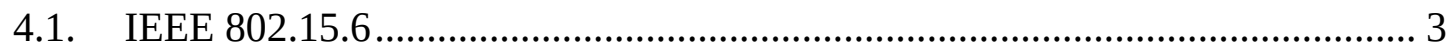

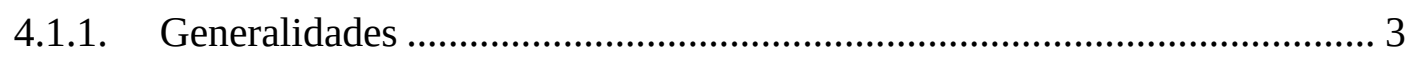

4.1.2. Capa de Acceso al Medio: Formato de trama........................................... 6

4.1.3. Capa de Acceso al Medio: Funciones MAC............................................ 23

4.1.4. Extensión en dos saltos de topología estrella ........................................... 29

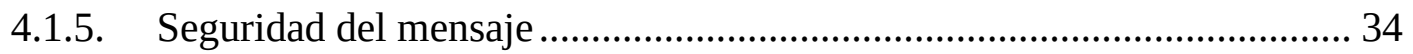

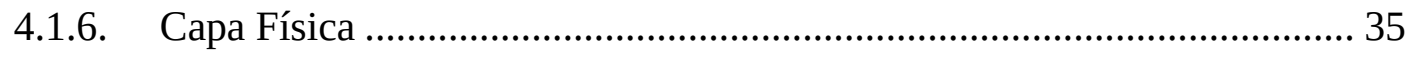

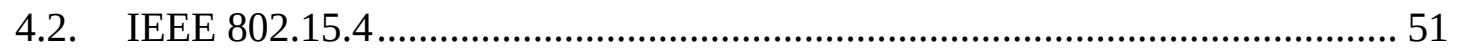

4.2.1. Capa de acceso al medio: Formato de trama........................................ 51

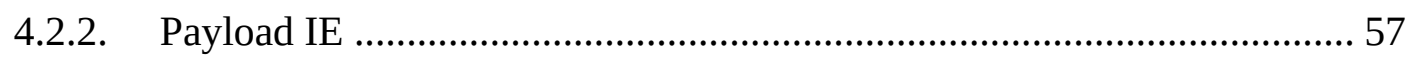

4.2.3. Capa física: Requerimientos generales.................................................. 57

4.2.4. Capa física: Modulación O-QPSK ........................................................ 65

4.2.5. Capa física: Modulación: Chirp spread spectrum (CSS)......................... 67

4.2.6. Capa física: Minimum Shift Keying (MSK) ............................................ 70

4.2.7. Capa física: Smart Utility Network (SUN) Frequency Shift Keying (FSK) 71

4.2.8. Capa física: Low Energy Critical Infrastructure Monitoring (LECIM) Direct Sequence Spread Spectrum (DSSS) ........................................................ 74

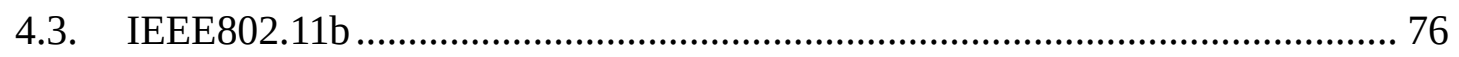

4.3.1. Formato de PSDU de datos ................................................................ 76

4.3.2. Descripción funcional de la subcapa MAC ............................................. 77

4.3.3. Capa Física: Formato de PPDU ............................................................... 83

4.3.4. Subcapa de High Rate PMD .............................................................. 84

4.3.5. Especificaciones de transmisión de PMD ............................................... 86

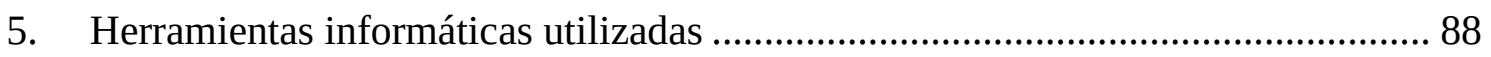

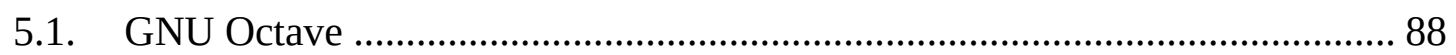

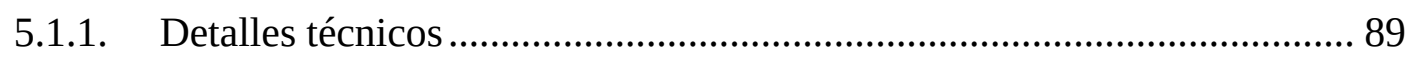

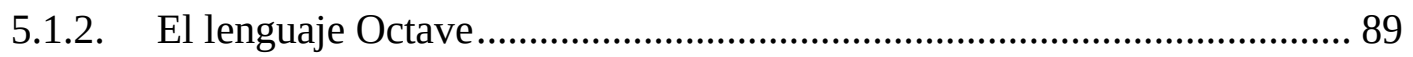

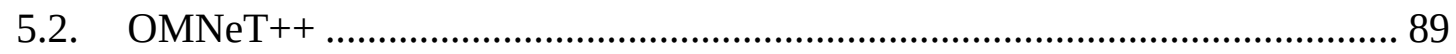

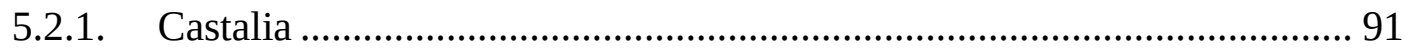

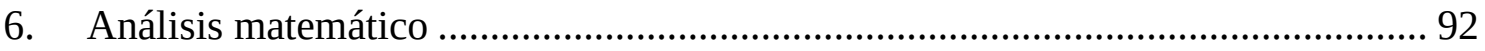

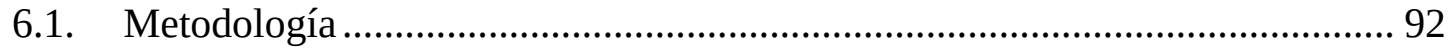




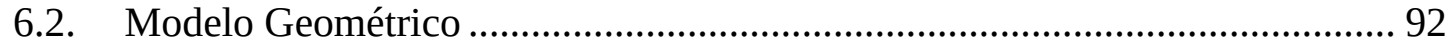

6.3. Modelo de pérdida por recorrido de señal (Path-loss model) .......................... 93

6.4. Modelo de capa físico (Physical layer model) ................................................... 94

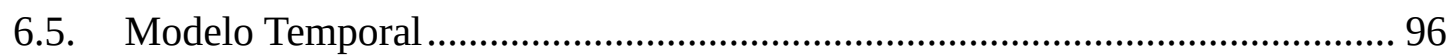

6.6. Resultados de la simulación matemática ............................................................ 98

6.6.1. Distancia de la fuente de interferencia ................................................... 98

6.6.2. Separación de canales con la fuente interferencia ................................. 100

6.6.3. Intervalo de paquetes de la fuente de interferencia .............................. 102

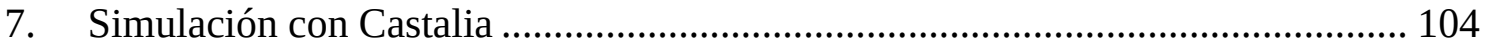

7.1. Modelo de pérdida promedio por recorrido de señal (Average Path-loss model) 104

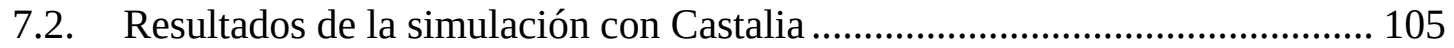

7.2.1. Distancia de la fuente de interferencia .................................................. 105

7.2.2. Separación de canales con la fuente de interferencia ............................. 107

7.2.3. Intervalo de paquetes de la fuente de interferencia .............................. 109

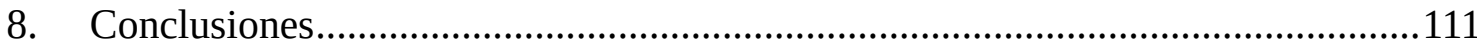

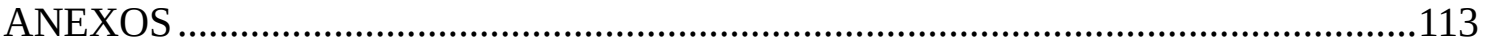

Anexo A - Script de simulación de Octave .............................................................113

A.1 - Variación de la distancia de fuente de interferencia ...................................113

A.2 - Variación de intervalo de paquetes de fuente de interferencia. .....................114

A.3 - Variación del canal de transmisión de la fuente de señal..............................115

Anexo B - Archivos de configuración de simulación Castalia ..................................117

B.1 - Omnet.ini para simulación de interferencia IEEE802.15.4 .............................117

B.2 - Archivo Radio802154.txt de configuración de parámetros de radio

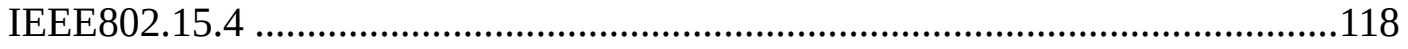

B.3 - Omnet.ini para simulación de interferencia IEEE802.11b ..........................119

B.4 - Archivo Radio80211.txt de configuración de parámetros de radio

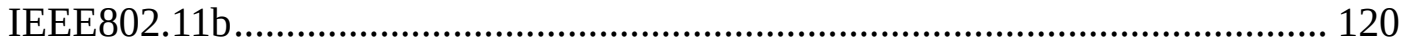

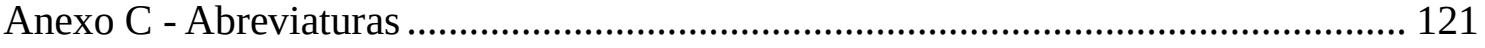

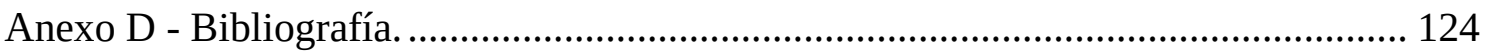

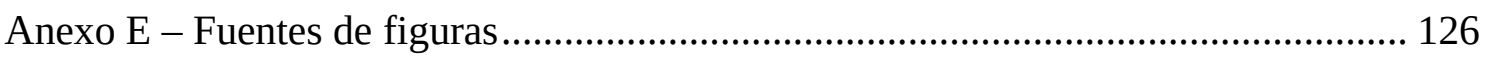




\section{Objetivos}

En el presente trabajo se analiza el impacto en el rendimiento de IEEE 802.15.6 [1] cuando es interferido por IEEE 802.15.4 [2] o IEEE 802.11[16], pretendiendo dar una medida del grado de confiabilidad del primero, que es un protocolo creado para transmisión en baja potencia de parámetros vitales de pacientes humanos, cuando comparte la banda de frecuencias ISM con otros protocolos ampliamente difundidos como son los dos últimos.

\section{Estado del arte}

Las ISM son bandas de radiofrecuencia electromagnética no licenciadas, comprendidas (entre otras) desde los 2,4 a $2,5 \mathrm{GHz}^{1}$, reservadas internacionalmente para uso no comercial en áreas industrial, científica y médica. Se ha popularizado su uso en comunicaciones WiFi (distintas versiones de IEEE 802.11), Bluethoot, IEEE 802.15.6, IEEE 802.15.4, etc; pudiendo unos comportarse como ruido electromagnético de otros, especialmente en áreas densamente pobladas.

A la fecha de redacción de la presente tesis, no se han encontrado trabajos donde se estudie el impacto en el rendimiento de IEEE 802.15.6 interferido por IEEE 802.15.4 o 802.11. Trabajos como el de R. Natarajan, P. Zand y M. Nabi [4] han realizado un estudio teórico y experimental de la degradación del rendimiento de IEEE 802.15.4 interferido por BLE (y viceversa) o por IEEE 802.11, pero no han considerado a IEEE 802.15.6. Otros como el de M.M Alam y E.B. Hamida [7] compara las estrategias de coexistencia propuestas por IEEE 802.15.6 con interferencia intra-BAN, inter-BAN y degradación del canal debido al movimiento dinámico del cuerpo, pero no considera el caso en que el protocolo comparta canales con otros estándares.

El presente trabajo analiza de forma teórica, repitiendo el escenario y método de $\mathrm{R}$. Nataraja et al, el impacto en el rendimiento de IEEE 802.15.6 cuando es interferido por IEEE 802.11 o 802.15.4.

\footnotetext{
${ }^{1}$ https://www.itu.int/net/ITU-R/terrestrial/faq/index.html\#g013 (último acceso 02/05/2018)
} 


\section{Introducción}

Una WSN (Wireless Sensor Network) es una red de sensores autónomos, distribuidos espacialmente, que monitorean condiciones físicas o ambientales, como temperatura, sonido, presión, etc. y envían esos datos de forma cooperativa a una ubicación principal. Un área de aplicación en rápido crecimiento de WSN son las BAN (Body Area Network) o WBAN (Wireless Body Area Network), que se utiliza ampliamente en aplicaciones médica y originalmente se han desarrollado a partir del estándar IEEE 802.15.4. [5] Una BAN (o WBAN) de sensores implantados en el cuerpo de un paciente podrían controlan los parámetros vitales, es por ello que la fiabilidad en la detección y transmisión de datos es un requerimiento importante para estos dispositivos.

Para un requerimiento como el mencionado, es que el IEEE aprobó en el 2012 el estándar IEEE 802.15.6 [1], siendo su principal objetivo "proporcionar una norma internacional para rango de corto alcance (es decir, sobre el rango del cuerpo humano), de baja potencia, con una comunicación inalámbrica de alta fiabilidad para su uso en las proximidades o en el interior del cuerpo humano." [1]

El estándar de IEEE802.15.6 define tres posibles medios de transmisión:

- Human Body Communication (HBC) PHY, que utiliza el cuerpo humano como medio de propagación de señal.

- Narrow Band (NB) PHY que, dependiendo de la regulación de cada país, puede operar en la banda de Medical Implant Communications Service (MICS: $402-$ 405MHz), Wireless Medical Telemetry Services (WMTS: 608-614 MHz, 1395$1400 \mathrm{MHz}$ y 1427-1432 MHz) o la Industrial, Scientific and Medica (ISM: 2,4 2,5 Ghz).

- Ultrawideband (UWB) PHY que puede trabajar en una banda de frecuencia baja (entre 3,1 y $4,8 \mathrm{GHz}$ ) o alta (entre 6 y $10,6 \mathrm{GHz}$ ). [3]

La banda de los $2,4 \mathrm{GHz}$ es muy utilizada por diversos protocolos de comunicación inalámbricos como IEEE 802.11 (en todas sus versiones), Bluethoot e IEEE 802.15.4 [2], pudiendo unos comportarse como ruido electromagnético de otros, especialmente en áreas densamente pobladas. Es por ello que en el presente trabajo se analiza el impacto en el rendimiento de IEEE 802.15.6 [1] cuando coexiste con IEEE 802.15.4 [2] o IEEE 802.11

En el cuarto capítulo de este informe se estudian los documentos de los tres protocolos mencionados, tomando con más profundidad IEEE 802.15.6 y solo analizando la capa física de los otros dos protocolos.

En el tercer capítulo se da una descripción de las herramientas informáticas que se usaron para llevar adelante el análisis.

El sexto y septimo capítulo se desarrollan los análisis matemáticos y las simulaciones, mostrando de forma cualitativa como afectan IEEE 802.15.4 e IEEE 802.11 en la performance de IEEE 802.15.6.

Finalmente, en el octavo capítulo se presentan las conclusiones de los análisis. En ellas se da una medida del grado de confiabilidad de IEEE 802.15.6 cuando comparte la banda de frecuencias ISM con otros protocolos ampliamente difundidos como son IEEE 802.15.4 e IEEE 802.11. 


\section{Protocolos estudiados}

\subsection{IEEE 802.15.6}

\subsubsection{Generalidades}

\subsubsection{Topología de red}

Un escenario típico en el que se aplica IEEE 802.15.6 se compone de nodos organizados en Redes de Área Corporal (BANs). El acceso al medio y gestión de potencia es coordinado por un nodo que actúa como concentrador (hub) como se nuestra en la figura 1.

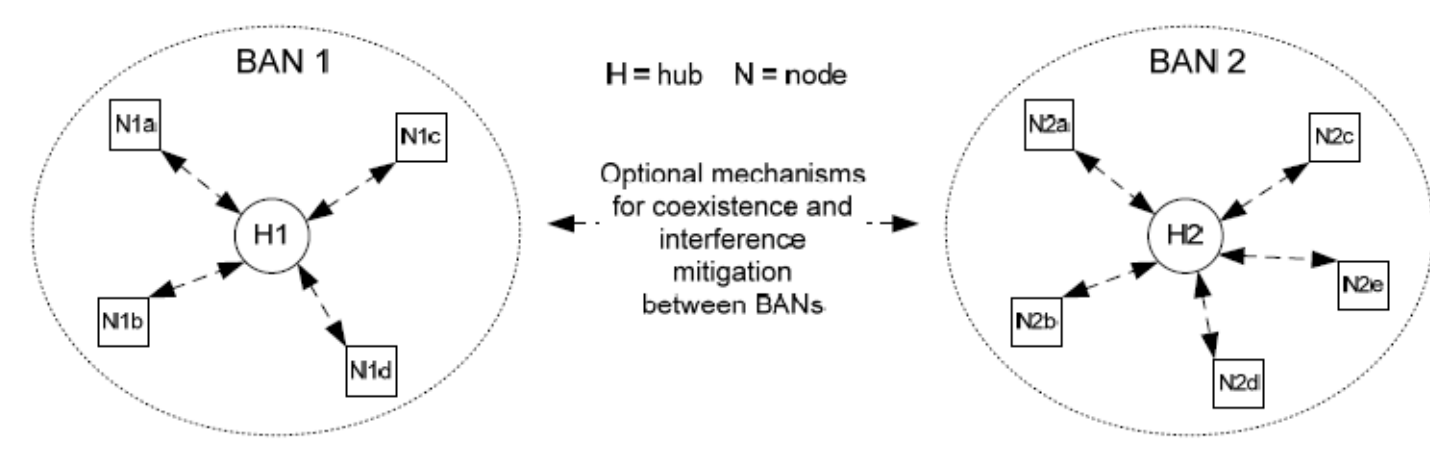

Figura 1- Topología de red. IEEE Standard for Local and metropolitan area networks - Part 15.6: Wireless Body Area Networks.

El número de nodos de una red va desde cero hasta 64 nodos. En las BAN estrella de un salto, el intercambio de tramas ocurre entre los nodos y el hub, mientras que en una de más de un salto los nodos y el hub opcionalmente pueden intercambiar tramas vía un nodo de retransmisión.

La norma IEEE802.15.6 proporciona mecanismos opcionales para la coexistencia y mitigación de interferencias entre BAN adyacentes o superpuestos, pero no especifica como se coordina el acceso en la subcapa MAC entre BAN.

\subsubsection{Modelo de referencia}

Los nodos y hubs de WBAN están internamente divididos en dos capas: Capa física (PHY) y la Capa de Acceso al Medio (MAC). Las capas PHY y MAC de un nodo o hub trabajan en un único canal de operación por vez. El servicio de seguridad de mensajes se ejecuta en la capa MAC, mientras que la generación de claves de seguridad se lleva a cabo dentro y/o fuera de la subcapa MAC. 


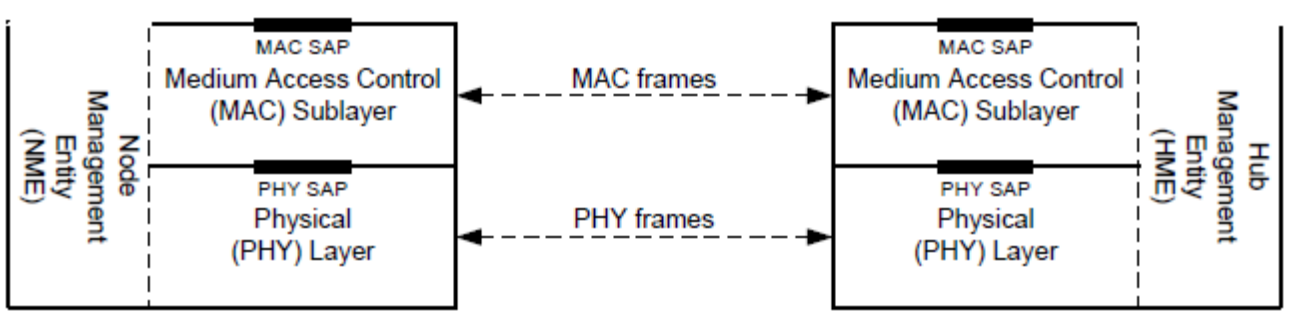

Figura 2 - Modelo de referencia. IEEE Standard for Local and metropolitan area networks - Part 15.6: Wireless Body Area Networks.

La capa MAC provee sus servicios a la capa superior a través del Servicio de Punto de Acceso (SAP) localizado inmediatamente arriba de la capa MAC, mientras que la capa PHY provee sus servicios a través de su SAP ubicado entre medio de ambas capas. En una trasmisión, el cliente MAC envía las Unidades de Datos de Servicio MAC (MSDUs) a la subcapa MAC a través del MAC SAP, y la capa MAC envía sus tramas (llamadas Unidades de Dato de Protocolo MAC o MPDUs) a la capa PHY via el PHY SAP. Por otro lado, en el receptor, la capa PHY envía las tramas a la capa MAC via PHY SAP y la capa MAC envía los MSDUs al cliente vía MAC SAP. Ambos MAC SAP y PHY SAP no están especificados en el standard IEEE802.15.6

Puede existir una entidad lógica de gestión de nodos (NME) o una entidad concentradora de gestión (HME) que intercambie información de gestión de red con las capas PHY y MAC, así como con otras capas. Sin embargo, la presencia de NME o HME no están obligado, ni se especifica el comportamiento de NME o HME en el standard.

\subsubsection{Base de tiempo}

Los nodos y hubs deben establecer una referencia temporal como se muestra en la Figura 3. Su acceso al medio debe ser programado en supertramas de igual longitud compuesta de slots de igual longitud y numeradas desde $0,1,2, \ldots, 255$.

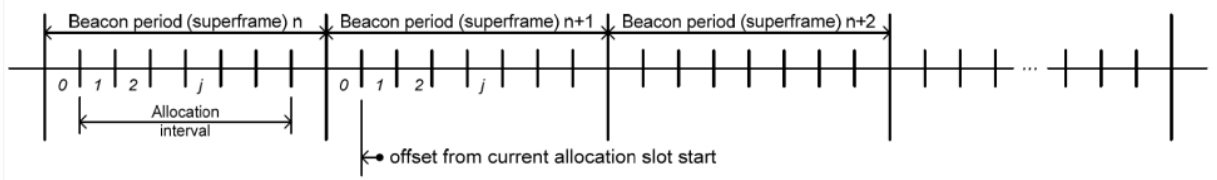

Figura 3 - Base de referencia temporal. IEEE Standard for Local and metropolitan area networks - Part 15.6: Wireless Body Area Networks.

En un modo de acceso a la WBAN sincrónico, el hub debe elegir los límites de la supertrama y sus slots de asignación. En un modo de operación coordinado, el hub necesita comuncar los límites de la supertrama transmitiendo una "baliza" al inicio o en otra locación especificada de la supertrama, y opcionalmente tramas temporizadas (TPoll) que contienen su tiempo de transmisión en relación con el tiempo de inicio del período de supertrama.

En modo de operación no programado, para la que no se transmiten balizas, pero se necesita referencia de tiempo, el concentrador debe comunicar los límites temporales mediante la transmisión de T-Poll que también contienen su tiempo de transmisión en relación con el tiempo de inicio de la supertrama actual.

Un nodo que requiera una referencia temporal en la WBAN debe derivar y recalibrar los 
límites de la supertrama y los espacios de asignación desde la recepción de balizas o tramas T-Poll.

Una transmisión de trama puede abarcar más de un slot, no necesariamente comenzando o terminando en un límite de slot.

\subsubsection{Paradigma de seguridad}

Durante la asociación de un nodo y un hub, éstos deben negociar conjuntamente el nivel de seguridad para sus tramas. Pueden elegir en uno de tres posibles niveles:

$\checkmark$ Nivel 0 - Comunicación insegura: Los mensajes son transmitidos en tramas inseguras que no proveen autenticación, integridad, confidencialidad, protección de la privacidad ni no repetición.

$\checkmark$ Nivel 1 - Autenticación sin cifrar: Los mensajes viajan en tramas autenticadas, pero no cifradas.

$\checkmark$ Nivel 2 - Autenticación y cifrado: Los mensajes viajan en tramas autenticadas y cifradas.

En una comunicación unicast segura, el nodo y el hub deben activar una "Master Key" (MK) pre compartida o establecerla vía una asociación autenticada o no autenticada y crear una "Pairwise Temporal Key" (PTK). Por otro lado, en una comunicación multicast segura, el hub debe distribuir una "Group Temporal Key" (GTK) a los miembros del grupo de forma unicast.

Los nodos y hubs deben seguir la estructura de seguridad mostrada en la figura 4 para generar las claves y proveer el servicio de seguridad. La "sesiones" indicadas en la figura refieren al tiempo en que una "Temporal Key" (TK) permanece válida, tiempo que es determinado por las políticas de seguridad que rigen las transferencias entre pares.

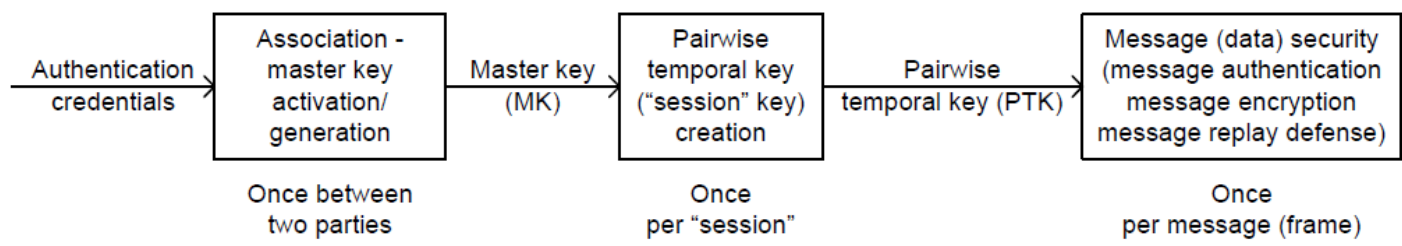

Figura 4 - Jerarquía de seguridad. IEEE Standard for Local and metropolitan area networks - Part 15.6: Wireless Body Area Networks. 
4.1.2. Capa de Acceso al Medio: Formato de trama

\subsubsection{Formato general}

La trama MAC consiste en una cabecera MAC, un cuerpo de longitud variable y un "Frame Check Sequence" (FCS) de longitud fija.

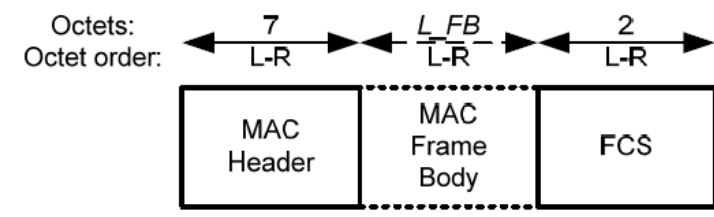

Figura 5 - Formato de trama MAC. IEEE Standard for Local and metropolitan area networks - Part 15.6: Wireless Body Area Networks.

El cuerpo de la trama tiene una longitud $L_{-} F B$ tal que $0 \leq L_{-} \mathrm{FB} \leq \mathrm{pMaxFrameBodyLength}$

\subsection{Cabecera MAC}

La cabecera está compuesta de cuatro campos: Campo de control de trama, ID de receptor, ID de transmisor e ID de BAN:

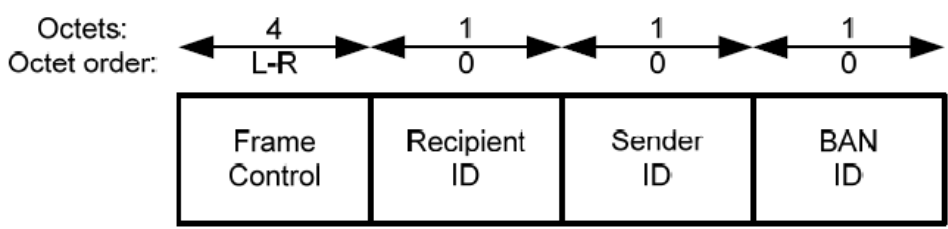

Figura 6 - Formato de cabecera MAC. IEEE Standard for Local and metropolitan area networks - Part 15.6: Wireless Body Area Networks.

\subsection{Campo de control de trama:}

Está formado por 14 subcampos:

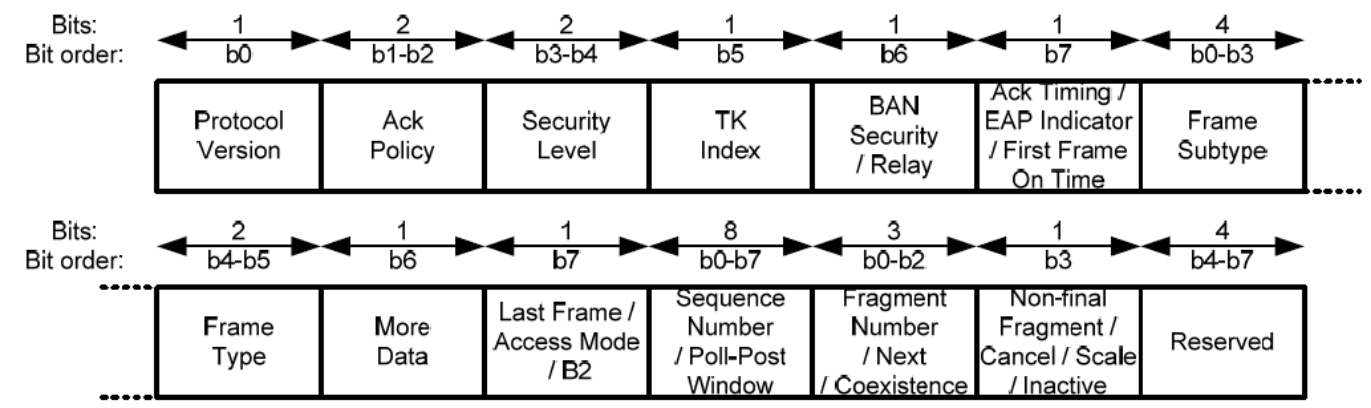

Figura 7 - Formato del Campo de Control de Trama. IEEE Standard for Local and metropolitan area networks - Part 15.6: Wireless Bodv Area Networks.

Versión del protocolo: Se establece en cero para la actual revisión del estándar. Los demás valores están reservados. 
Acknowledgment (Ack) Policy: Indica la solicitud de acknowledgment de la trama.

Security Level: Indica el nivel de seguridad de la trama.

Temporal key (TK) Index: Si la trama no está asegurada, este campo está reservado. De lo contrario, indica la PTK o GTK que está siendo usado en la trama.

BAN Security/Relay: Se usa para BAN Security en tramas beacon, Poll o T-Poll enviadas por el hub, como Relay en tramas enviadas por el nodo de reenvío en una red estrella de dos saltos o queda reservada en cualquier otro tipo de trama.

Ack Timing/EAP Indicator/First Frame On Time: Se usa como un $E A P^{2}$ indicator en tramas Beacon; como First Frame On Time en tramas de gestión o tipo de datos que no son Beacon o tramas de encuesta enviadas por un hub a un nodo; como Ack Timming en tramas I-Ack, B-Ack, I-Ack+Poll y B-Ack+Poll enviadas por un hub a un nodo; o está reservado en cualquier otro tipo de trama.

Frame subtype y Frame type: Indican el tipo y subtipo de la actual trama.

Los tipos de trama pueden ser Beacon, Asociación de seguridad, Desasociación de seguridad, PTK, GTK, Solicitud de conexión, Asignación de conexión, Desconexión, Comando, I-Ack, B-Ack, I-Ack+Poll, B-Ack+Poll, Poll, T-Poll, Wakeup, B2, Prioridad de usuario (del 0 al 6), Emergencia o mapeado según subtipo de datos.

More Data: Seteado según si la trama es de gestión o de datos enviadas por un nodo a un hub, I-Ack y B-Ack enviadas por un nodo a un hub, de gestión o de datos no-beacon enviadas por un hub a un nodo, I-Ack y B-Ack enviadas por un hub a un nodo o Poll, TPoll, I-Ack+Poll o B-Ack+Poll enviadas por un hub a un nodo.

Last Frame/Access Mode/B2: Se usa como B2 si la trama es beacon, Last Frame Field si la trama es de gestión no-beacom o de datos o como de Access Mode si la trama es IAck, B-Ack, I-Ack+Poll, B-Ack+Poll, Poll, o T-Poll enviada por un hub a un nodo.

Sequence Number/Poll-Post Window: Se usa como Sequence Number si la trama es beacon o de gestión no-beacon y como Poll-Post Window si la trama es de Poll, T-Poll, IAck+Poll o B-Ack+Poll enviada de un hub a un nodo, Wakeup, B2 o de datos.

Fragment Number/Next/Coexistence: Se usa como Fragment Number en tramas nobeacon o de datos, como Next en tramas Wakeup, Poll, T-Poll, I-Ack+Poll o B-Ack+Poll enviadas por un hub a un nodo o como Coexistence en tramas beacon o B2.

Non-final Fragment/Cancel/Scale/Inactive: Se usa como Non-final Fragment en tramas de datos o de gestión non-beacon, como Cancel en tramas I-Ack, B-Ack, Poll, TPoll, I-Ack+Poll o B-Ack+Poll enviadas desde un hub a un nodo, como Scale en tramas Wakeup o como Inactive en tramas beacon o B2.

${ }^{2}$ Exclusive Access Phase 


\subsection{Recipient ID, Sender ID y BAN ID}

El campo Sender ID, Recipient ID y BAN ID contienen la dirección abreviada (Identificador de un octeto seleccionado como dirección en intercambios de trama.) del respectivo emisor, receptor o red de la trama.

\subsubsection{MAC Frame Body}

La MAC Frame Body, cuando tiene una longitud distinta de cero, tiene un formato como el de la figura 8 y su longitud máxima (L_FB) no excede pMaxFrameBodyLength.

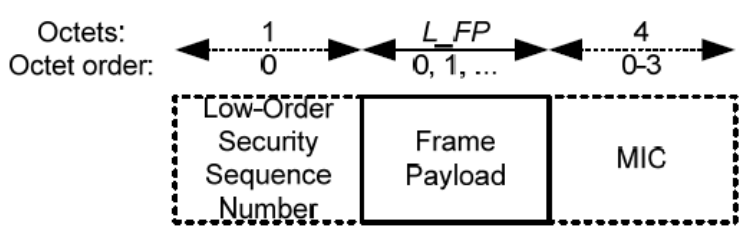

Figura 8 - Formato del MAC Frame Body. IEEE Standard for Local and metropolitan area networks - Part 15.6: Wireless Body Area Networks.

Si la trama no es segura, indicado en el campo Security Level de la cabecera MAC, los campos Low-Order Security Sequence Number y Message Integrity Code (MIC) no están presentes.

\subsection{Low-Order Security Sequence Number}

El valor del campo Low-Order Security Sequence Number se incrementa en tramas sucesivas con el mismo PTK o GTK. Su valor se incrementa indistintamente si la trama es una transmisión o una retransmisión de una trama anterior. Aunque el PTK aplique a tramas seguras enviadas en cualquier dirección, los valores de las tramas enviadas por un nodo o por el hub son independientes.

\subsection{Frame Payload}

Contiene el paquete de la capa superior y su longitud, denotada como $L_{-} F P$ en la Figura 8 , debe ser tal que el cuerpo de la trama MAC no exceda el valor pMaxFrameBodyLength.

Si la trama tiene un payload de longitud cero y ésta es segura, entonces el cuerpo de la trama MAC solo está compuesto por los campos Low-Order Security Sequence Number y $M I C$; de lo contrario la trama no tiene cuerpo. 


\subsection{Message Integrity Code (MIC)}

El campo MIC, presente en tramas seguras, contiene un código de autenticación que preservar la autenticidad e integridad de la cabecera y el cuerpo de la trama MAC.

\subsubsection{Frame Check Sequence (FCS)}

El campo FCS tiene un formato como el indicado en la figura 9, donde su orden de transmisión se define como que el $\mathrm{a}_{15}$ es el LSB y el $\mathrm{a}_{0}$ el MSB. Los bits $\mathrm{a}_{15}, \mathrm{a}_{14}, \ldots, \mathrm{a}_{0}$ son los coeficientes binarios de un polinomio de Control de Redundancia Cíclica (CRC) de grado 15 denotado como se muestra en la ecuación (1).

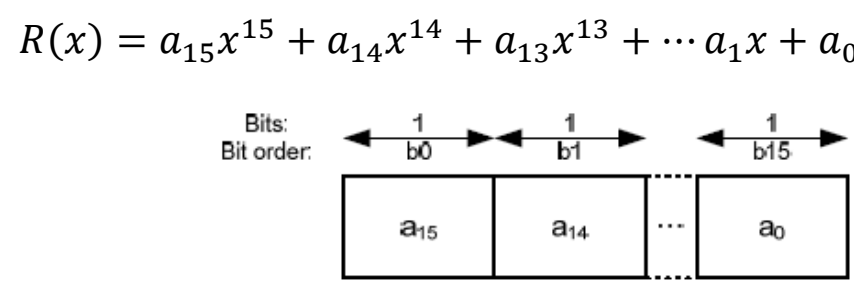

Figura 9 - FCS Format. IEEE Standard for Local and metropolitan area networks - Part 15.6: Wireless Body Area Networks.

El polinomio CRC se calcula, exceptuando el campo FCS, sobre la trama MAC utilizando el polinomio generador estándar CRC-16-CCITT de grado 16.

\subsubsection{Tipos de tramas}

El subcampo Frame Type del Campo de Control de trama indica el tipo de trama que se está transmitiendo. Existen tres tipos de tramas:

a) Tramas de gestión: Con otros 9 subtipos de tramas, gestionan el medio de comunicación, conexiones, asociaciones de seguridad y comandos.

b) Tramas de control: Con otros 8 subtipos de tramas, son las que confirman la recepción de tramas y encuestan a los nodos.

c) Trama de datos.

\subsubsection{Tramas de gestión}

Una trama de gestión contiene campos obligatorios de longitud fija y algunos componentes opcionales de longitud variable denominados elementos de información (IE). 


\subsection{Beacon}

Una baliza (Beacon) contiene una carga útil formateada como se muestra en la Figura 10. Un hub la difunde localmente en cada período de baliza (supertrama).

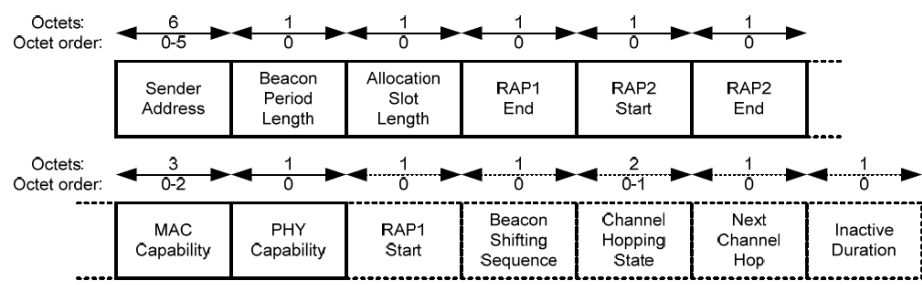

Figura 10 - Formato de payload de una baliza. IEEE Standard for Local and metropolitan area networks - Part 15.6: Wireless Body Area Networks.

Sender Address: La dirección del emisor se establece con la numeración IEEE EUI-48 del hub que envía la baliza actual.

Beacon Period Length: El campo longitud del periodo de baliza (longitud de supertrama) se indica en unidades de slots.

Allocation Slot Length: Si no está habilitado beacon shifting, los slots de una supertrama se enumeran consecutivamente, iniciando desde el valor 0 , desde el slot inicial hasta el que termina la supertrama, como se muestra en la Figura 11.

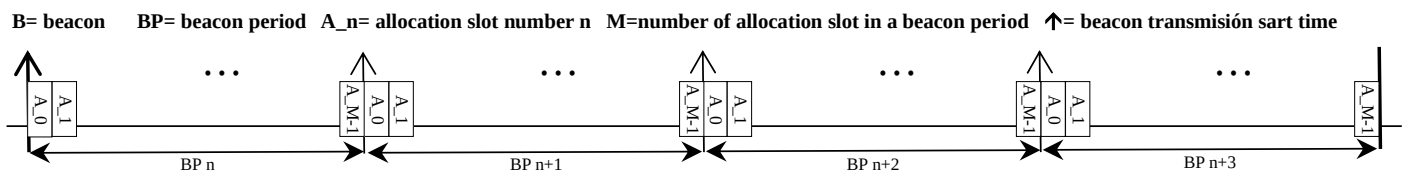

Figura 11 - Ordenación y numeración de slots de supertrama. IEEE Standard for Local and metropolitan area networks - Part 15.6: Wireless Body Area Networks.

Si el beacon shifting está habilitado, la supertrama es de $4 \mathrm{~N}$ slots, donde $\mathrm{N}$ es un número entero. Los slots están numerados $0,1, \ldots, 4 \mathrm{~N}-1 \mathrm{y}$, si el tiempo de transmisión de la baliza no está al inicio, se ajusta a los slots que inician y terminan la supertrama, como se muestra en la Figura 12. Una supertrama tiene cuatro partes que se componen de los slots 0 al $\mathrm{N}-1, \mathrm{~N}$ a $2 \mathrm{~N}-1,2 \mathrm{~N}$ a $3 \mathrm{~N}-1$ y $3 \mathrm{~N}$ a $4 \mathrm{~N}-1$, respectivamente.

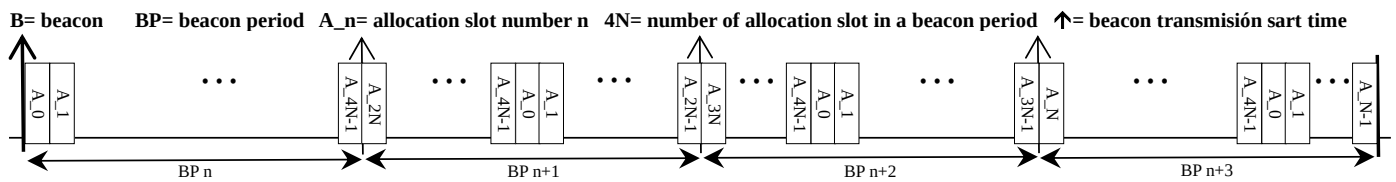

Figura 12 - Orden y numeración de slots de supertrama con un beacon shifting ejemplar. IEEE Standard for Local and metropolitan area networks - Part 15.6: Wireless Body Area Networks.

Allocation Slot Length: El campo Longitud de Slot se establece en L, de modo que la longitud de un slot sea igual a pAllocationSlotMin $+L \times p$ AllocationSlotResolution. 
RAP1 Start: El Random Access Pase 1 (RAP1) está presente solamente si el campo EAP indicator de la cabecera MAC señala que el EAP1 tiene una longitud distinta de cero e indica en que slot de la supertrama inicia el Pase de Acceso Aleatorio 1.

Tanto EAP1 como RAP1 (si son de longitud distinta de cero) se producen en la supertrama actual si él no está habilitado el Beacon Shifting o en siguiente supertrama si está habilitado.

RAP1 End: Indica el slot en el que finaliza Pase de Acceso Aleatorio 1 de la actual supertrama.

RAP2 Start: Presente solamente si el campo EAP indicator de la cabecera MAC señala que el EAP2 tiene una longitud distinta de cero e indica en que slot de la supertrama inicia el Pase de Acceso Aleatorio 2.

Tanto EAP2 como RAP2 (si son de longitud distinta de cero) se producen en la supertrama actual si él no está habilitado el Beacon Shifting o en siguiente supertrama si está habilitado.

RAP2 End: Indica el slot en el que finaliza Pase de Acceso Aleatorio 2 de la actual supertrama.

MAC Capability: Indica si el remitente soporta funciones MAC como asignaciones contenidas obtenidas mediante CSMA/CA, aloha ranurado; asignaciones encuestadas tipo I, tipo II, scheduleadas y no scheduleadas; fragmentación y reensamblado; procesamiento y funcionalidades de tramas de comandos; si el nodo está siempre en estado activo; precisión mínima del reloj del hub y si el nodo requiere provisión centralizada de un reloj; si el emisor soporta L-Ack, B-Ack y G-Ack; si el emisor soporta funciones de retransmisión en una BAN estrella extendida de dos saltos, beacon shifting, channel hopping y el cual número máximo de subtipo de tramas de datos admitidas.

PHY Capability: Indica la tasa de datos admitida, tanto para recepción como para transmisión, para la banda de trabajo (Narrow band, Ultra wideband o Human body)

Beacon Shifting Sequence: Presente solamente si el beacon shifting está habilitado, indica el tiempo de transmisión del beacon en la supertrama actual.

Channel Hopping State: Presente solamente si el Channel Hopping está habilitado, se establece en un registro de desplazamiento utilizado para generar la secuencia de salto de canal por el hub que envía esta beacon.

Next Channel Hop: Presente solo si el channel hopping está actualmente habilitado, se establece en el número de secuencia de la supertrama en el que el hub que envía la actual beacon debe saltar a otro canal de acuerdo con su secuencia.

Inactive Duration: Presente solamente si una o más supertramas inactivas inician al final de la actual, como lo indica el subcampo Non-final Fragment/Cancel/Scale/Inactive del campo de Control de Trama. Si está presente, este campo indica cuantas supertramas inactivas habrá después de cada supertrama activa. 


\subsection{Asociación de seguridad}

Una trama de Asociación de Seguridad contiene un Payload formateado como se muestra en la Figura 13. Ésta es intercambiada entre un nodo y un hub durante la ejecución del protocolo de asociación de seguridad para generar una nueva o activar una MK precompartida.

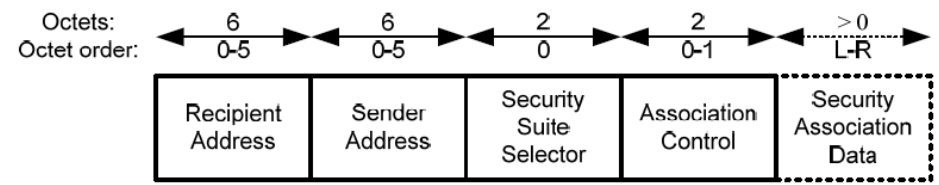

Figura 13 - Formato de payload de una trama de Asociación de Seguridad. IEEE Standard for Local and metropolitan area networks - Part 15.6: Wireless Body Area Networks.

Dirección del destinatario: Si se conoce, este campo se establece con la numeración IEEE EUI-48 del destinatario de la trama actual; de lo contrario se establece en cero.

Dirección del emisor: El campo se establece con la numeración IEEE EUI-48 del remitente de la trama actual.

Security Suite Selector: Define el protocolo de asociación de seguridad, nivel de seguridad requerido por el emisor, si se solicita autenticación y/o cifrado y la función de cifrado seleccionada por el emisor.

Association Control: Establece en el número (es decir, la posición) de la trama actual en la ejecución del protocolo de asociación de seguridad seleccionado e indica el estado de asociación de seguridad actual.

Security Association Data: Es específico del protocolo de asociación de seguridad seleccionado. Para asociación no autenticada, asociación oculta de clave pública, asociación autenticada por contraseña y asociación autenticada de visualización, el campo Datos de asociación de seguridad establece en un número estadísticamente único por remitente y por procedimiento de asociación de seguridad, la PK del remitente y una key message authentication code (KMAC) para ciertos campos de payloads.

Para la asociación con MK precompartida, el campo éste no está presente.

\subsection{Disociación de seguridad}

Una trama de disociación de seguridad contiene un payload formateada como se muestra en la Figura 14. Se transmite por un nodo asociado o hub para derogar una asociación de seguridad existente, es decir, la MK compartida.

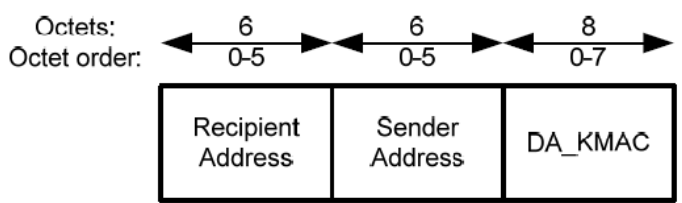

Figura 14 - Formato de payload para una trama de disociación de seguridad. IEEE Standard for Local and metropolitan area networks - Part 15.6: Wireless Body Area Networks. 
Dirección del destinatario y remitente: Los campos se establecen con la numeración IEEE EUI-48 del emisor o remitente de la trama actual.

DA_KMAC: Establece la KMAC de los campos de payload de esta trama de disociación de seguridad.

\subsubsection{4. $\quad$ Pairwise Temporal Key (PTK)}

Una trama PTK contiene un payload formateada como se muestra en la Figura 15. Se intercambia entre un nodo y el hub con el que está asociado para crear una PTK basada en una MK compartida.

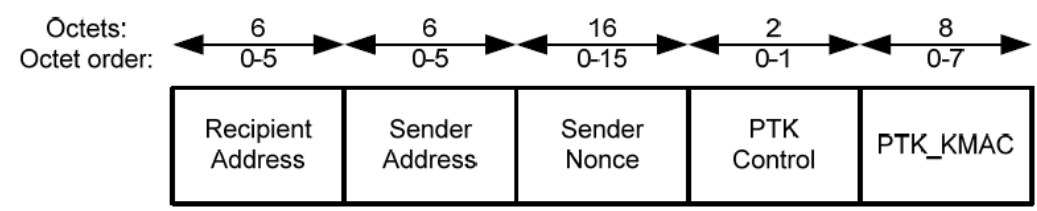

Figura 15 - Formato del payload de la trama PTK. IEEE Standard for Local and metropolitan area networks - Part 15.6: Wireless Body Area Networks

Dirección del destinatario y remitente: Los campos se establecen con la numeración IEEE EUI-48 del emisor o remitente de la trama actual.

Sender Nonce: Se establece en un número estadísticamente único por remitente y por procedimiento de creación de PTK.

PTK Control: Establece en el número (es decir, la posición) de la trama en el procedimiento de creación de PTK actual, el Índice PTK de la primera trama transmitida o retransmitida por el nodo o hub e indica del estado actual de creación de PTK.

PTK_KMAC: Establece en un KMAC para ciertos campos de los payloads en el procedimiento de creación de PTK.

\subsection{Group Temporal Key (GTK)}

Las tramas GTK contienen un payload formateado como se muestra en la Figura 16. Es transmitida por un hub para distribuir una GTK a un nodo seguro protegiendo así el tráfico multicast.

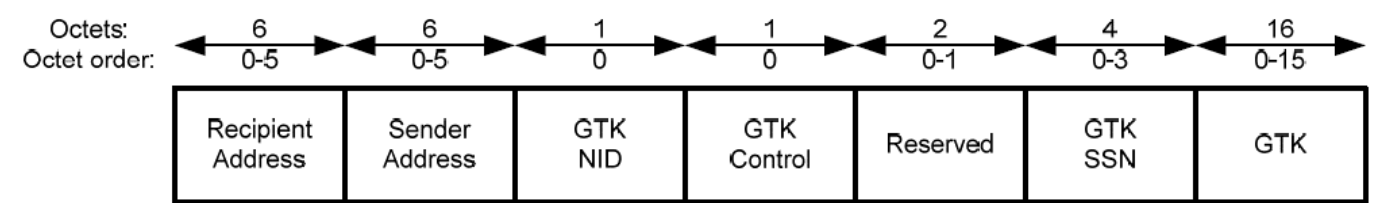

Figura 16 - Formato de payload de una trama GTK. IEEE Standard for Local and metropolitan area networks - Part 15.6: Wireless Body Area Networks 
Dirección del destinatario y remitente: Los campos se establecen con la numeración IEEE EUI-48 del emisor o remitente de la trama actual.

GTK NID: Se configura según sea la trama asegurada por GTK unicast o multicast de acuerdo al campo Recipient ID de la cabecera MAC.

GTK Control: Su valor depende si el hub previamente distribuyó o no el GTK para el GTK NID indicado en la trama actual.

GTK SSN: Establece en el número de secuencia de seguridad de la última trama asegurada con el GTK distribuido y dirigido al GTK NID indicado en la trama actual.

GTK: Establece la cadena de bits que representa el GTK distribuido en la trama actual.

\subsection{Connection Request}

Contiene payload formateada como se muestra en la Figura 17. Es transmitida por un nodo para solicitar la creación o modificación de una conexión con un hub.

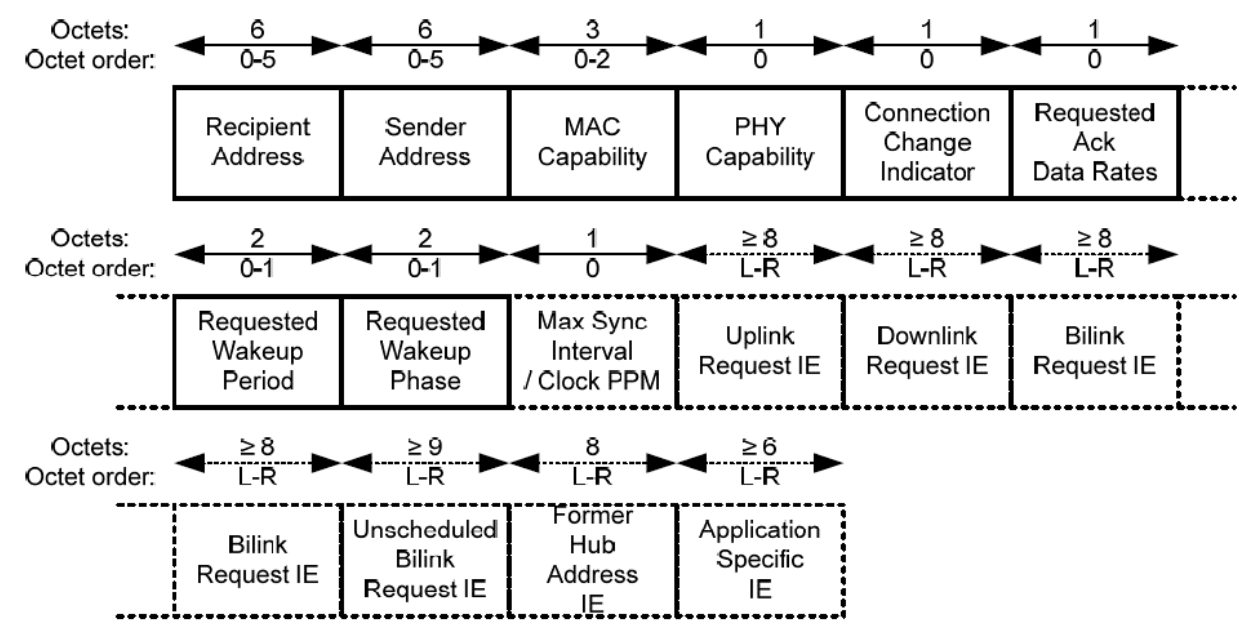

Figura 17 - Formato payload para tramas Connection Request. IEEE Standard for Local and metropolitan area networks - Part 15.6: Wireless Body Area Networks.

Dirección del destinatario: Si se conoce, este campo se establece con la numeración IEEE EUI-48 del destinatario de la trama actual; de lo contrario se establece en cero.

Dirección del emisor: El campo se establece con la numeración IEEE EUI-48 del remitente de la trama actual.

MAC Capability y PHY Capability: Se incluyen en la trama beacon y algunas otras de gestión. Un hub y un nodo generalmente tienen diferentes requisitos funcionales para la capacidad de soportar o no una función dada, especialmente en el campo Capability MAC. La indicación de ser capaz de soportar una función también implica estar dispuesto a habilitarla y realizarla.

Connection Change Indicator: Indica que ciertos campos de la trama actual se han proporcionado nuevamente o han cambiado de valor desde su último intercambio entre el sender y el recipient. 
Requested Ack Data Rate: Define las velocidades de datos solicitadas para enviar tramas I-Ack y BAck entre el remitente y el destinatario mientras intercambian tramas de tipo de datos.

Requested Wakeup Phase: Establece el número de secuencia de la siguiente supertrama en el que un nodo emisor planea despertar.

Requested Wakeup Period: Establece la longitud, en unidades de períodos de supertramas, entre el inicio de períodos de reactivación sucesivos en los que el nodo emisor planea despertar, comenzando desde el indicado en el campo Requested Wakeup Phase anterior.

Max Sync Interval/Clock PPM: El Max Sync Interval/Clock PPM solo está presente si este nodo requiere un aprovisionamiento centralizado de tiempo de guarda como se indica en el campo de capacidad MAC de la trama actual.

Uplink Request IE: Se incluye opcionalmente en las tramas de Connection Request para solicitar la creación o modificación de una o más asignaciones de uplink programados.

Downlink Request IE: Se incluye opcionalmente en tramas Connection Request para solicitar la creación o modificación de una o más asignaciones de downlink programadas.

Bilink Request IE: Se incluye opcionalmente en tramas Connection Request para solicitar la creación o modificación de una o más asignaciones de blink programadas.

Unscheduled Bilink Request IE: Presente de forma opcional para solicitar la creación o modificación de una o más asignaciones de enlaces no programadas.

Former Hub Address IE: Contenido opcionalmente en las tramas de Connection Request para transmitir el IEEE EUI-48 del último hub con el que se conectó este nodo.

Application Specific IE: Incluido en algunas tramas de gestión para transmitir información específica de la aplicación. 


\subsection{Connection Assignment}

Una trama Connection Assignment contiene un payload formateada como se muestra en la Figura 18. Es transmitida por un hub para responder a una solicitud de conexión o para iniciar o cambiar una asignación de conexión.

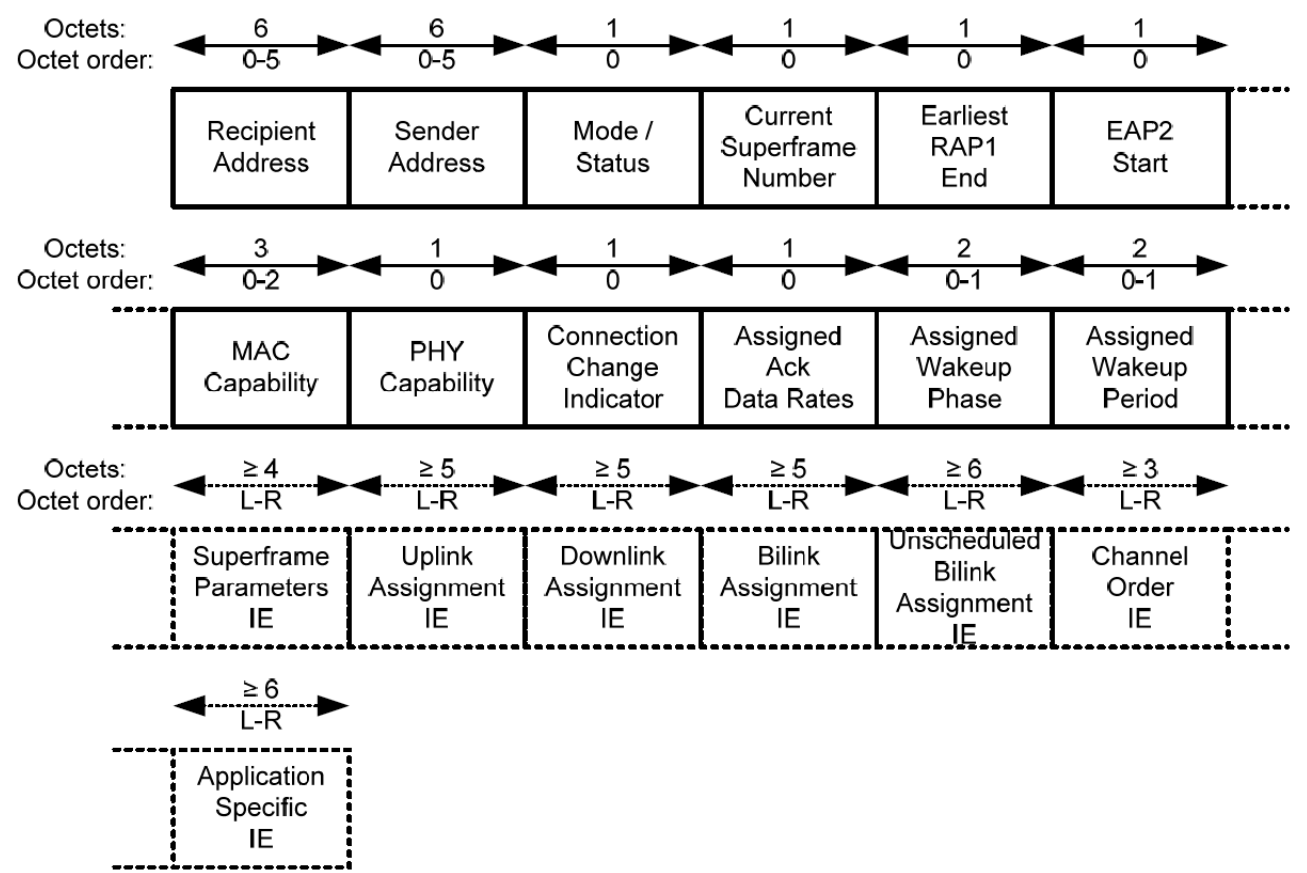

Figura 18 - Payload de la trama Connection Asignment. IEEE Standard for Local and metropolitan area networks Part 15.6: Wireless Body Area Networks.

Dirección del destinatario y remitente: Los campos se establecen con la numeración IEEE EUI-48 del emisor o remitente de la trama actual.

Mode/Status: Indica el modo de transmisión (beacon con supertrama y CSMA/CA para acceso aleatorio; beacon con supertramas y aloha ranurada para acceso aleatorio; beacon con supertramas y sin acceso aleatorio o Sin beacon sin supertramas y CSMA/CA para acceso aleatorio.) y el status de la solicitud de conexión (aceptada, rechazada, asignación de conexión modificada).

Current Superframe Number: Reservado para modo no-beacon sin supertrama, establece en el número de secuencia de la supertrama actual.

Earliest RAP1 End: Indica el número de slot mínimo donde puede finalizar el RAP1 en cualquier supertrama.

EAP2 Start: Establece el número del slot en cuyo tiempo de inicio comienza el EAP2.

Minimum CAP Length: Establece la mínima longitud de CAP en número de slots.

MAC Capability: Indica si el remitente soporta funciones MAC como asignaciones contenidas obtenidas mediante CSMA/CA, aloha ranurado; asignaciones encuestadas tipo I, tipo II, scheduleadas y no scheduleadas; fragmentación y reensamblado; procesamiento y funcionalidades de tramas de comandos; si el nodo está siempre en estado activo; precisión mínima del reloj del hub y si el nodo requiere provisión 
centralizada de un reloj; si el emisor soporta L-Ack, B-Ack y G-Ack; si el emisor soporta funciones de retransmisión en una BAN estrella extendida de dos saltos, beacon shifting, channel hopping y el cual número máximo de subtipo de tramas de datos admitidas.

PHY Capability: Indica la tasa de datos admitida, tanto para recepción como para transmisión, para la banda de trabajo (Narrow band, Ultra wideband o Human body)

Connection Change Indicator: Indica que ciertos campos de la trama actual se han proporcionado recientemente o han cambiado de valor desde su último intercambio entre el remitente y el destinatario.

Assigned Ack Data Rates: Define las velocidades de datos asignadas para enviar tramas de datos I-Ack y BAck entre el remitente y el destinatario de la trama actual mientras intercambian tramas de de datos.

Assigned Wakeup Phase: Define en el número de secuencia de la próxima supertrama en el que el nodo receptor necesita despertarse para la recepción y transmisión de trama.

Assigned Wakeup Period: Establece la longitud, en unidades de supertramas comenzando desde el Assigned Wakeup Phase precedente, del período en los que el nodo receptor necesita despertarse para la recepción y transmisión.

Superframe Parameters IE: Indica los valores de operación elegido de la supertrama.

Uplink Assignment IE: Asigna o reasigna una o más enlaces slot-base scheduleados ascendentes al nodo direccionado en modo beacon o no-beacon con supertramas.

Downlink Assignment IE: Asigna o reasigna una o más enlaces slot-base scheduleados descendentes al nodo direccionado en modo beacon o no-beacon con supertramas.

Bilink Assignment IE: Asigna o reasigna una o más enlaces Bilink slot-base scheduleados al nodo direccionado en modo beacon o no-beacon con supertramas.

Unscheduled Bilink Assignment IE: Puede ser tanto Type-I Unscheduled Bilink Assignment IE como Type-I Unscheduled Bilink Assignment IE y asigna o reasigna una o más enlaces Bilink slot-base no scheduleados al nodo direccionado en modo beacon o nobeacon con supertramas.

Channel Order IE: Puede ser tanto Nibble Encoded Channel Order IE para indicar algunos o todos los canales operativos seleccionados, incluidos en la banda de frecuencia de trabajo, y el orden en que se selecciona el canal operativo; como Channel Hopping and Ordering IE para indicar los canales incluidos en el channel hopping de la banda de frecuencia operativa o el orden en que se selecciona el canal operativo.

Application Specific IE: Indica información específica de la aplicación. 


\subsection{Disconnection}

Con un payload como se muestra en la Figura 19, es transmitida por un hub a un nodo o por un nodo a un hub para derogar una conexión.

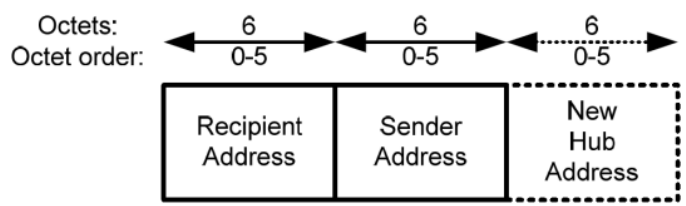

(a) Sent by a node

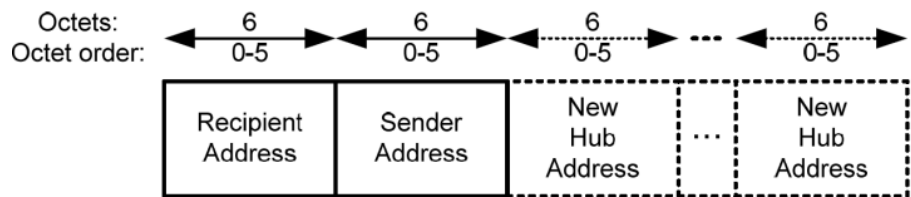

(b) Sent by a hub

Figura 19 - Formato de trama de desconexión. IEEE Standard for Local and metropolitan area networks - Part 15.6: Wireless Body Area Networks.

Dirección del destinatario y remitente: Los campos se establecen con la numeración IEEE EUI-48 del emisor o remitente de la trama actual.

New Hub Address: Si está en una trama enviada por un nodo, ésta indica la dirección del hub con el que desea desconectarse.

Si está en la trama enviada por el hub, setea en orden de prioridades los hub con los que el nodo podría conectarse.

\subsection{Command}

Con un formato como el de la Figura 20, ésta trama es opcionalmente emitida por un hub hacia un nodo.

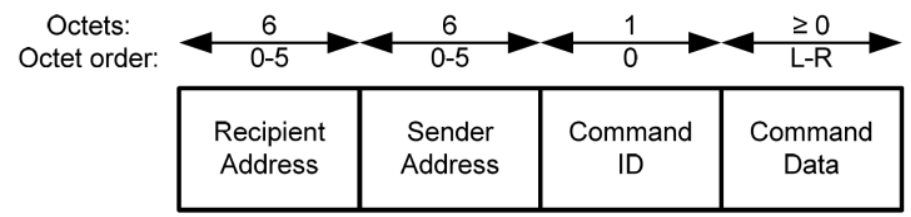

Figura 20 - Payload de una trama de comando. IEEE Standard for Local and metropolitan area networks - Part 15.6: Wireless Body Area Networks.

Dirección del destinatario y remitente: Los campos se establecen con la numeración IEEE EUI-48 del emisor o remitente de la trama actual.

Command ID: Identifica el ID del comando de emitido en la trama.

Command Data: En contenido de este campo es específico del comando transmitido. 


\subsubsection{Tramas de Control}

El payload de una trama de control puede ser de longitud fija, variable o puede ser que no lo contenga.

Existen 4 tipos de tramas de control: I-Ack, B-Ack, I-Ack+Poll y B-Ack+Poll.

\subsection{Immediate Acknowledgement (I-Ack)}

Es transmitida por un nodo o un hub para acusar recibo de la trama anterior. Opcionalmente el hub proporciona un timestamp en términos de Current Allocation Slot Number y un Current Allocation Slot Offset en el payload de la trama para la sincronización del reloj del nodo.

Una trama I-Ack transmitida de un hub a un nodo contiene payload que está formateada como se muestra en la Figura 21.

Las tramas I-Ack transmitido por un nodo a un concentrador no contiene payload.

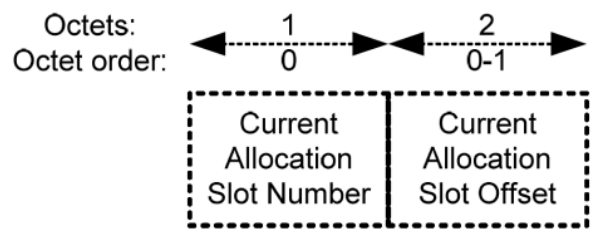

Figura 21 - Formato de payload de una trama I-Ack. IEEE Standard for Local and metropolitan area networks - Part 15.6: Wireless Body Area Networks.

Current Allocation Slot Number: Presente solamente si el campo Ack Timing del MAC header de la trama actual está configurado en uno, indica el número de slot en el que hub inicia la transmisión de la trama.

Current Allocation Slot Offset: Presente solamente si el campo Ack Timing del MAC header de la trama actual está configurado en uno, indica el offset en el slot a partir del donde el hub inicia la transmisión de la trama.

\subsection{Block Acknowledgement (B-Ack)}

Una trama B-Ack contiene selectivamente un payload que está formateada como se muestra en la Figura 22.

Una trama B-Ack es transmitida por un nodo o un hub para reconocer el estado de recepción de ciertas tramas de tipo de datos anteriores, mientras que opcionalmente proporciona un timestamp del hub en términos de un Current Allocation Slot Number y un Current Allocation Slot Offset para la sincronización del reloj del nodo. 
Los dos primeros campos que se muestran en la Figura 22 están presente solo si el campo Ack Timing del MAC header está seteado en uno y los tres campos finales están presentes solo si no se espera y permite una nueva trama.

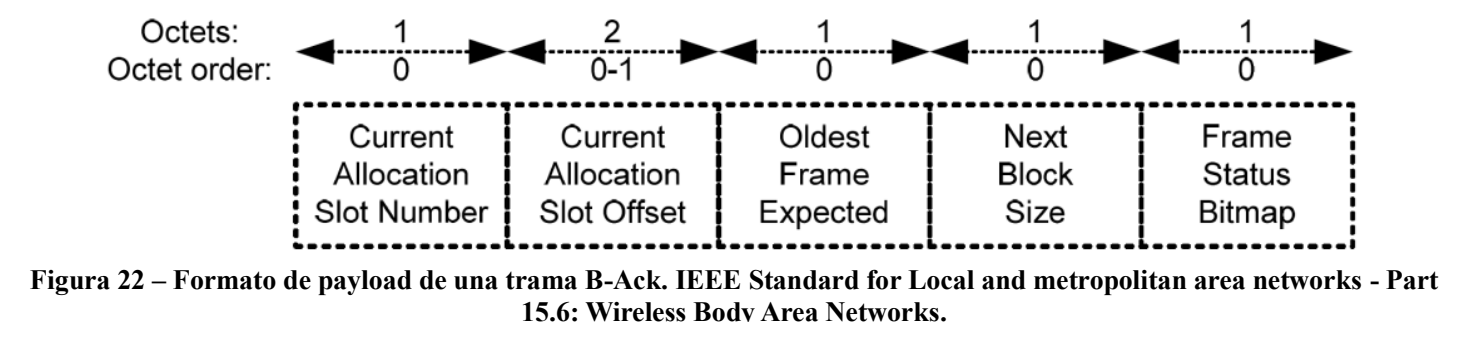

Current Allocation Slot Number: Indica el número de slot en el que hub inicia la transmisión de la trama.

Current Allocation Slot Offset: Indica el offset en el slot a partir del donde el hub inicia la transmisión de la trama.

Oldest Frame Expected: Indica el próximo número de secuencia esperado.

Next Block Size: Indica en el número máximo de tramas de datos permitidas en la siguiente transmisión de cuyo estado de recepción se proporcionará en la próxima trama B-Ack y cuyo su subtipo de trama es el mismo que el de la trama de datos que precede a esta trama B-Ack.

Frame Status Bitmap: Indica el estado de recepción de hasta $m B A c k L i m i t$ tramas que son del mismo subtipo al que precede a esta trama, y están delimitadas en secuencia entre la indicada en el campo Oldest Frame Expected y la precedente a ésta.

\subsection{Immediate Acknowledgement + Poll (I-Ack+Poll)}

Contiene un payload con un formato como el de una I-Ack y es transmitida por un hub para acusar recibo de la trama anterior y enviar un Poll al nodo direccionado, mientras que opcionalmente proporciona un timestamp en términos de un Current Allocation Slot Number y Current Allocation Slot Offset en el Payload para el reloj del nodo sincronización. Una trama I-Ack+Poll es equivalente en función a una trama I-Ack seguida de una trama Poll o T-Poll.

\subsection{Block Acknowledgement + Poll (B-Ack+Poll)}

Contiene un payload con un formato como el de una B-Acky es transmitido por un hub para reconocer el estado de recepción de ciertas tramas de datos anteriores y enviar un Poll al nodo direccionado, mientras que opcionalmente proporciona un timestamp en términos de un Current Allocation Slot Number y Current Allocation Slot Offset en el Payload para el reloj del nodo sincronización. Una trama B-Ack+Poll es equivalente en función a una trama B-Ack seguida de una trama Poll o T-Poll. 


\subsubsection{5. $\underline{\text { Poll }}$}

No contiene payload y es transmitido por un hub para otorgar al nodo direccionado una locación encuestada inmediata que inicia pSIFS después del final de la trama o para informar al nodo de una encuesta o publicación futura.

\subsection{Timed-Poll (T-Poll)}

Una trama T-Poll contiene un payload que está formateada como se muestra en la Figura 23. Excepto que se indique lo contrario, es transmitida por un hub para otorgar al/los nodo/s direccionado/s una locación encuestada inmediata que inicia $p S I F S$ después del final de la tarma o para informar al nodo de una encuesta o publicación futura, al tiempo que proporciona un timestamp por parte del hub en términos de Current Allocation Slot Number, Current Allocation Slot Offset, y selectivamente Current Allocation Slot Length o Current Superframe Number en el payload para la sincronización del reloj del nodo. Una trama T-Poll es equivalente en función a una trama Poll expandida que contiene un timestamp de transmisión y sincronización de límite de slots $\mathrm{y}$, opcionalmente, una calidad de enlace de retransmisión para la selección de retransmisión.

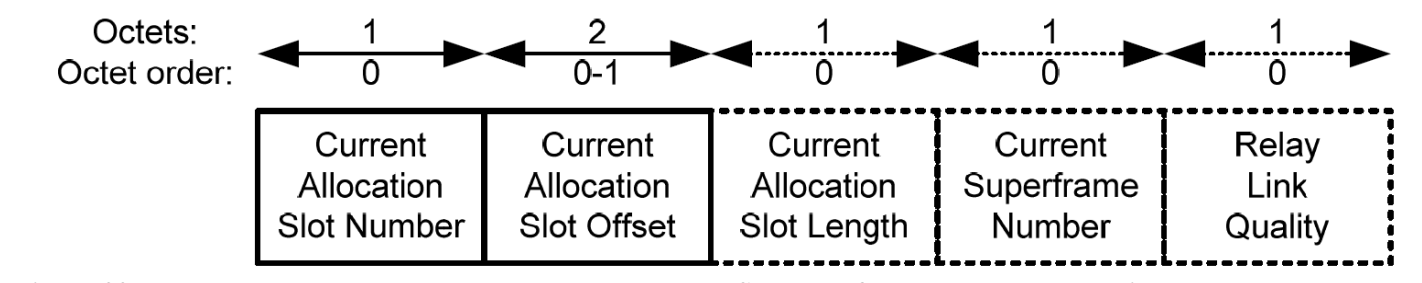

Figura 23 - Formato del payload de una trama T-Poll. IEEE Standard for Local and metropolitan area networks - Part 15.6: Wireless Body Area Networks.

Current Allocation Slot Number: Indica el slot en el que el hub empieza a enviar esta trama.

Current Allocation Slot Offset: Indica el offset en microsegundos en que el hub comienza a enviar esta trama luego del inicio del slot indicado en el campo anterior.

Current Allocation Slot Length: Presente en tramas con el campo ID del destinatario del MAC Header configuradas como Unconnected_Broadcast_NID o Broadcast_NID, establece la longitud del slot.

Current Superframe Number: Presente en tramas con el campo ID de destinatario del MAC header establecido en Broadcast_NID, indica el número de secuencia de la actual supertrama.

Relay Link Quality: Opcionalmente presente en tramas con el campo ID de destinatario del MAC header establecido en Broadcast_NID, son transmitidos por un nodo dispuesto a admitir retransmisión. 


\subsection{Wakeup}

Con un payload formateado como la Figura 24, opcionalmente es transmitido por un hub para activar un nodo que opera en la banda del Medical Implant Communications Service (MICS).

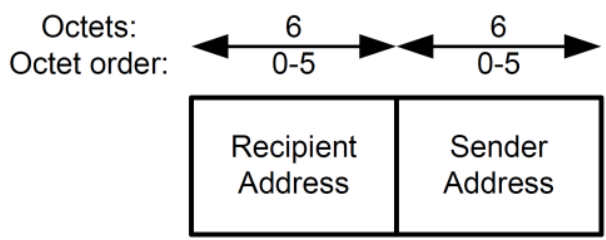

Figura 24 -Payload de una trama Wakeup. IEEE Standard for Local and metropolitan area networks - Part 15.6: Wireless Body Area Networks.

Los campos Dirección del destinatario y Dirección del remitente se establecen con la numeración IEEE EUI-48 del emisor o remitente de la trama actual.

\subsection{Tramas B2}

Con un formato de payload como el de la Figura 25, opcionalmente un hub la transmite para anunciar información de tiempo compartido asistido por B2 y/o proporcionar reconocimiento de grupo.

La información de tiempo compartido asistido por B2 consta de la duración del período de baliza, la longitud del slot, el número del slot actual, el offset de la ranura de asignación actual y los campos de finalización de CAP, y está presente solo si el campo Coexistence field del MAC header de la actual trama B2 se establece en uno.

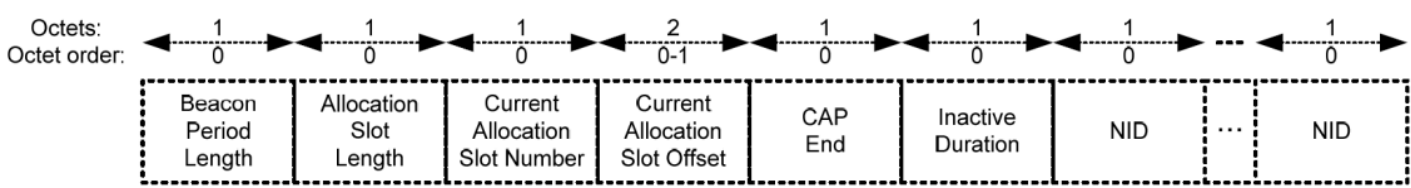

Figura 25 - Formato de payload de trama B2. IEEE Standard for Local and metropolitan area networks - Part 15.6: Wireless Body Area Networks.

Beacon Period Length: Opcionalmente presente, indica la longitud de la actual supertrama.

Allocation Slot Length: Indica la longitud del slot.

Current Allocation Slot Number: Indica el slot en el que el hub inicia la transmisión de la trama.

Current Allocation Slot Offset: Indica el offset del slot en el que el hub inicia la transmisión de la trama.

CAP End: Indica el número de slot de la presente supertrama en donde termina el contention access pase (CAP). El CAP comienza al final de la actual trama B2 y una trama B2 que no contiene este campo, define un CAP implícito que comienza al final de la trama B2 y termina con el período de supertrama. 
Inactive Duration: Cuando está presente, indica el número de supertramas inactivas luego de cada supertrama activa.

NID: Cuando está presente, establece en el NID de un nodo desde el cual el hub recibió una trama que requiere confirmación de grupo desde la última trama B2 transmitida.

\subsubsection{Data type frames}

Una trama de tipo de datos contiene una MSDU completa, fragmentada o nula.

Puede ser del subtipo de emergencia, para indicar un informe de emergencia o de un evento de implante médico, o de User Priority ( $\mathrm{UP}=0,1, \ldots$ o 6 ), para indicar que el subtipo de trama es de datos y tiene una prioridad de usuario UP.

\subsubsection{Capa de Acceso al Medio: Funciones MAC}

\subsubsection{División y clasificación de acceso}

Para proporcionar o soportar una referencia temporal en su BAN, un hub establecerá una base de tiempo en períodos de beacon (supertramas), independientemente de si se trata o no de transmitir beacon.

Un hub operará en uno de los siguientes tres modos de acceso:

$\checkmark$ Modo de baliza con períodos de beacon (supertramas)

$\checkmark$ Modo sin beacon con supertramas.

$\checkmark$ Modo sin beacon sin supertramas.

\subsection{Modo de baliza con períodos de beacon (supertramas)}

En este modo, un hub debe organizar las fases de acceso aplicables en cada supertrama activa como se ilustra en la Figura 26, donde B representa el beacon. El hub puede mantener I supertramas inactivas después de cada activa si no hay intervalos de asignación scheduleados en las supertramas inactivas. En una supertrama activa, un hub debe transmitir un beacon y proporcionar fases de acceso. En una supertrama inactiva, un hub no transmitirá ningún beacon ni proporcionará fase de acceso.

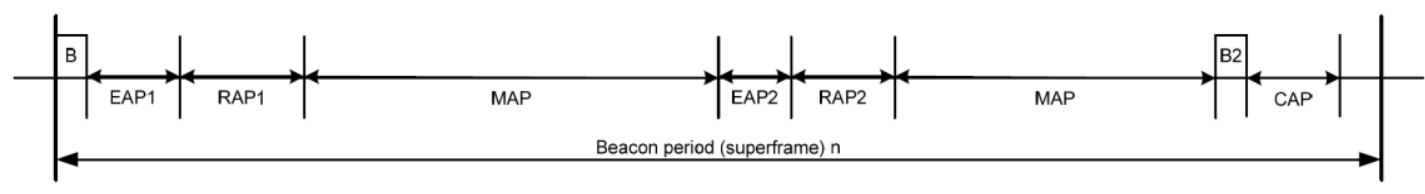

Figura 26 - Layout de fases de acceso en un período de beacon (supertrama). IEEE Standard for Local and metropolitan area networks - Part 15.6: Wireless Body Area Networks.

El hub ubicará las fases de acceso -Exclusive Access Phase 1 (EAP1), Random Access Phase 1 (RAP1), Managed Access Phase (MAP), Exclusive Access Phase 2 (EAP2), Random Access Phase 2 (RAP2), otra Managed Access Phase (MAP) y Contention Access Phase (CAP)- en el orden indicado arriba. El hub puede establecer en cero la 
longitud de cualquiera de estas fases de acceso, pero no debe finalizar RAP1 antes del menor tiempo garantizado comunicado en las tramas Connection Assignment enviadas a los nodos que todavía están conectados con él.

Un nodo puede obtener e iniciar transacciones de trama en EAP1, RAP1, EAP2, RAP2 y CAP en cualquier supertrama activa usando CSMA/CA o acceso aleatorio basado en Aloha.

Solamente en MAP, como se muestra en la Figura 27, el hub puede organizar intervalos uplink allocation, downlink allocation y bilink allocation scheduleados; proveer intervalos bilink allocation no scheduleados; improvisar type-I, intervalos polled allocation inmediatos y allocation intervals iniciados en el actual MAP.

En EAP, RAP, o CAP, o MAP, como se muestra en la Figura 26, el hub puede improvisar futuras encuestas o publicaciones que inicien o terminen en un MAP como se muestra en la Figura 27 (mediante tramas Poll, T-Poll, I-Ack+Poll y B-Ack+Poll).

Estos intervalos de asignación, junto con los métodos de acceso correspondientes mediante los cuales se obtienen, se ilustran en la Figura 27.

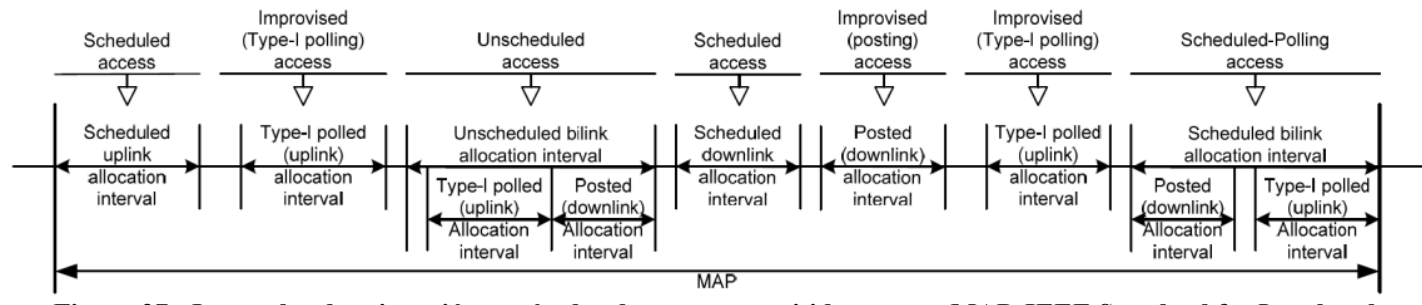

Figura 27 - Intervalos de asignación y métodos de acceso permitidos en una MAP. IEEE Standard for Local and metropolitan area networks - Part 15.6: Wireless Body Area Networks.

\subsection{Modo sin beacon con supertramas}

En este modo un hub solamente tiene Managed Access Phase (MAP) como se ilustra en la Figura 27, en una supertrama como se ilustra en la Figura 28.

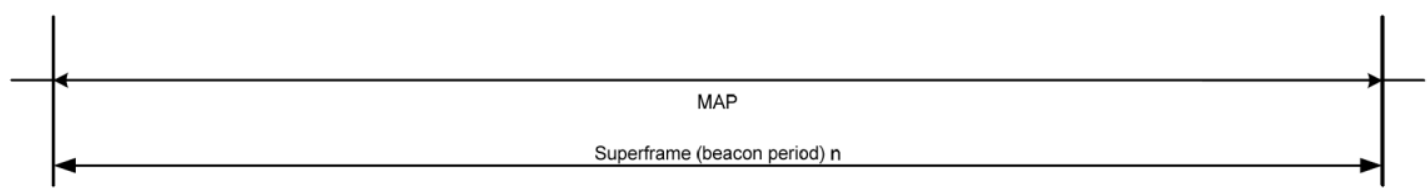

Figura 28 - Layout de fases de acceso en una supertrama para el modo sin beacon. IEEE Standard for Local and metropolitan area networks - Part 15.6: Wireless Body Area Networks. 


\subsection{Modo sin beacon sin supertramas}

En este modo un hub puede proveer intervalos bilink allocation que comprenden asignaciones encuestadas type-II y/o locaciones publicadas como se ilustra en la Figura 29. Después de determinar que el hub para el próximo intercambio de tramas está operando en modo no beacon sin supertrama, un node puede tratar cualquier intervalo de tiempo como una parte de EAP1 o RAP1 y emplear acceso aleatorio basado en CSMA/CA para obtener una asignación contenida.

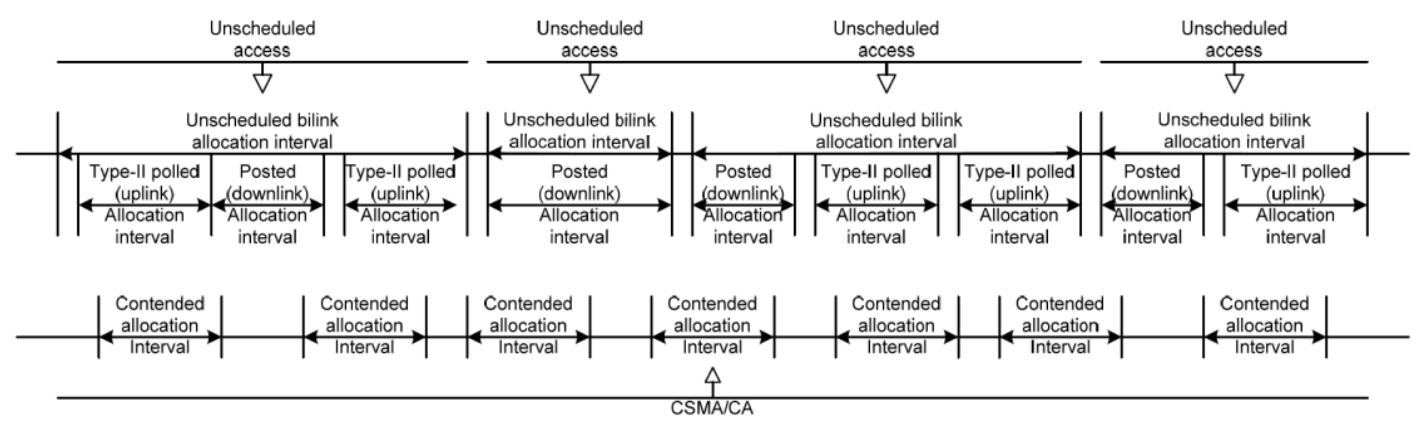

Figura 29 - Intervalos de locación y métodos de acceso permitidos en el modo sin beacon sin supertrama. IEEE Standard for Local and metropolitan area networks - Part 15.6: Wireless Body Area Networks.

\subsubsection{Creación/operación de una BAN y conección/desconección de un nodo}

\subsection{Operación/Creación de una BAN}

Un hub elegirá un canal operativo para iniciar un BAN, de acuerdo con las normas de política, las condiciones del canal, los requisitos de la aplicación, las consideraciones de coexistencia, etc.

A menos que se indique lo contrario, un nodo debe encontrar el canal operativo del concentrador con el que necesita comunicarse antes de enviar una trama al hub.

El hub deberá elegir y habilitar un modo de acceso aplicable para admitir los métodos de acceso deseados.

Si el hub seleccionó el modo no beacon sin supertramas, transmitirá tramas de poll a cada Unconnected_Broadcast_NID direccionado y proporcionará una asignación de poll TipoII para habilitar la conexión o reconexión de los nodos no conectados.

Si el hub seleccionó el modo no beacon con supertramas, transmitirá tramas T-Poll a cada Unconnected_Broadcast_NID direccionado y proporcionará una asignación de Poll TipoI para permitir la conexión o reconexión de nodos no conectados.

Si el hub seleccionó el modo beacon con supertramas, puede transmitir tramas T-Poll a cada Unconnected_Broadcast_NID direccionado y proporcionar una asignación de poll Tipo-I para facilitar los nodos la conexión o reconexión de los nodos no conectados.

Una asignación encuestada no conectada es una asignación del Tipo-I o Tipo-II otorgada por un hub a través de una trama de poll o T-Poll dirigida a Unconnected_Broadcast_NID. 


\subsection{Conexión de nodos}

Un nodo no conectado enviará una trama Connection Request a un hub y éste responderá con una trama Connection Assignment como se muestra en la Figura 30.

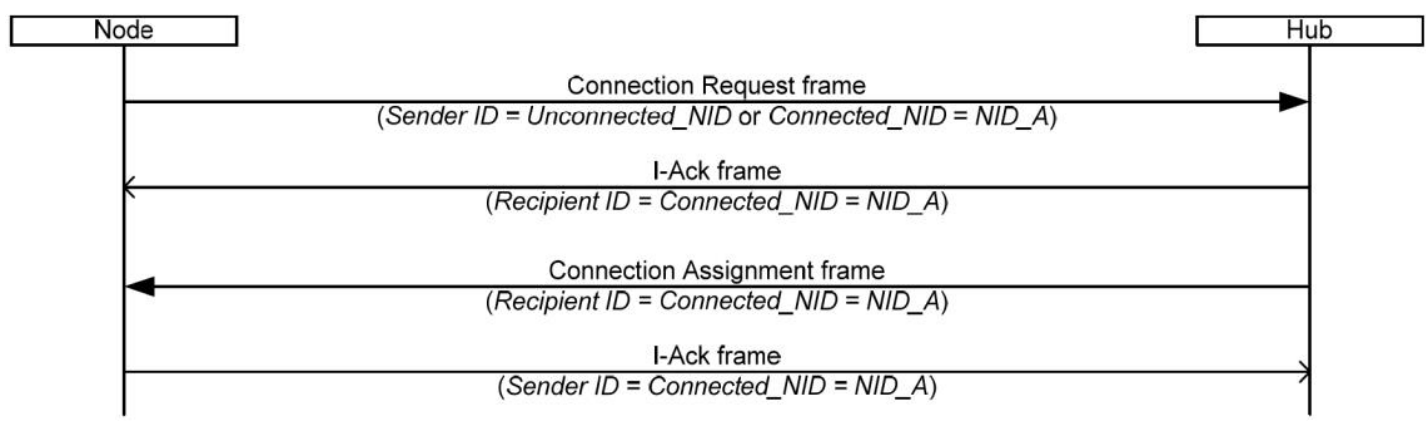

Figura 30 - Procedimiento de conexión. IEEE Standard for Local and metropolitan area networks - Part 15.6: Wireless Bodv Area Networks.

En vista del procedimiento de transición de NID del nodo, el hub puede necesitar volver a enviar su trama Connection Request antes de recibir una trama I-Ack esperada si el nodo necesita tiempo para confirmar su nuevo Connected_NID a través de una trama Connection Assignment, como en el caso en el que el nodo ha perdido su conexión (y por lo tanto su Connected_NID) o está en estado huérfano intentando iniciar una comunicación no segura con el hub.

\subsection{Desconexión del nodo}

Un nodo o un hub puede enviar una trama Disconnection como se muestra en la Figura 31 para finalizar su conexión, es decir, para anular el Connected NID del nodo, la disposición de activación y cualquier asignación programada y no programada con el concentrador.

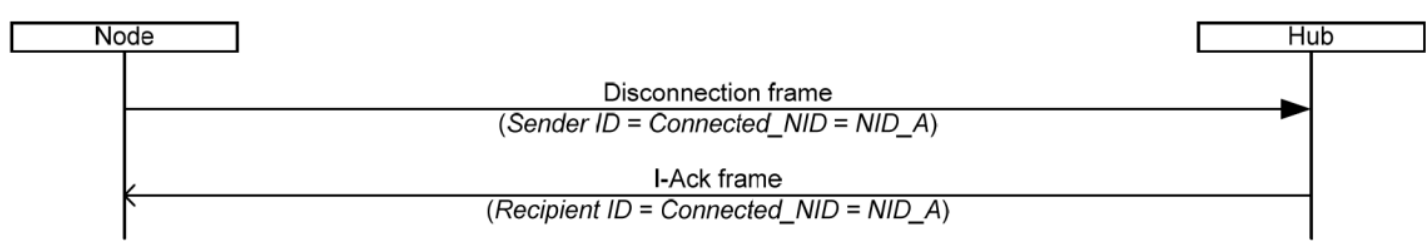

(a) Initiated by node

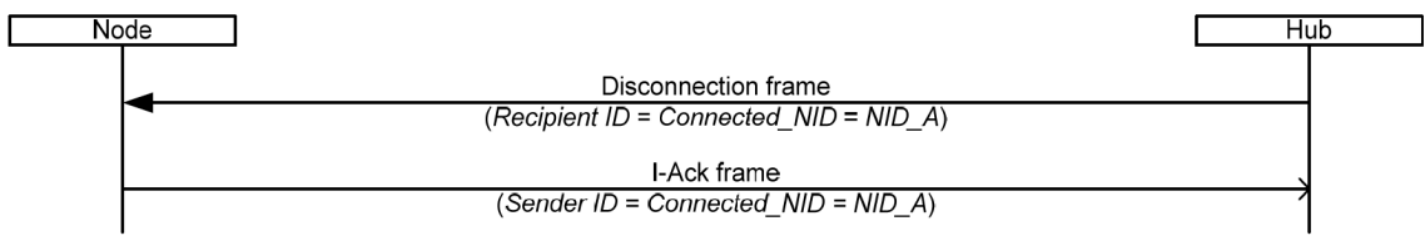

(b) Initiated by hub

Figura 31 - Procedimiento de desconexión. IEEE Standard for Local and metropolitan area networks - Part 15.6: Wireless Body Area Networks. 
El hub puede enviar una trama Disconnection al nodo después de recibir una I-Ack y con una Connection Assignment con estado de conexión que indica que la solicitud de conexión fue rechazada por alguna razón.

\subsubsection{Acceso Aleatorio}

En EAP1, RAP1, EAP2, RAP2 y CAP solo pueden ser asignaciones contenidas, que son intervalos de tiempo no recurrentes válidos por instancia de acceso. El método de acceso para obtener las asignaciones contenidas será CSMA/CA o Aloha ranurado.

Un hub o un nodo puede obtener asignaciones contenidas en EAP1 y EAP2, solo si necesita enviar tramas de tipo de datos con UP alta (es decir, que contiene información de emergencia). El hub puede obtener tal asignación $p S I F S$ después del inicio de EAP1 o EAP2 sin realizar realmente el procedimiento de acceso CSMA/CA o Aloha ranurado. Solo los nodos pueden obtener asignaciones contenidas en RAP1, RAP2 y CAP, para enviar marcos de gestión o tipo de datos.

Para obtener asignaciones contenidas en EAP1, RAP1, EAP2 o RAP2 de una supertrama con beacon, un nodo recibirá primero la beacon que especifica los tiempos de inicio y finalización de estas fases de acceso.

Para enviar tramas de tipo de datos del UP más alto basado en CSMA/CA, un hub o un nodo puede tratar los EAP y RAP como un solo EAP para permitir la invocación continua de CSMA/CA y mejorar la utilización del canal. Para enviar tramas de tipo de datos del UP más alto basado en el acceso Aloha ranurado, un hub o nodo puede tratar los RAP1 y RAP2 como otro EAP1 o EAP2, pero no como una continuación de ellos debido al atributo de intervalo de tiempo de acceso Aloha ranurado.

El acceso para el tráfico de diferentes UP se logrará a través de las relaciones predefinidas en la Tabla 1 y Tabla 2 entre los límites $C W \max$ y $C W m i n$ de la Contention Window $(C W)$ y UP para CSMA/CA, y entre los umbrales CPmax y CPmin de CP y UP para acceso Aloha ranurado.

Tabla 1 - Mapero de User Priority [1]

\begin{tabular}{|c|c|c|c|}
\hline Priority & User priority & Traffic designation & Frame type \\
\hline \multirow[t]{7}{*}{ Lowest } & 0 & Background (BK) & Data \\
\hline & 1 & Best effort (BE) & Data \\
\hline & 2 & Excellent effort (EE) & Data \\
\hline & 3 & Video (VI) & Data \\
\hline & 4 & Voice (VO) & Data \\
\hline & 5 & Medical data or network control & Data or management \\
\hline & 6 & High-priority medical data or network control & Data or management \\
\hline Highest & 7 & Emergency or medical implant event report & Data \\
\hline
\end{tabular}


Tabla 2 - Límites de Ventana de Contención para CSMA/CA y umbrales de Probabilidad de Contención para acceso Aloha ranurado [1].

\begin{tabular}{|c|c|c|c|c|}
\hline \multirow{2}{*}{ User Priority } & \multicolumn{2}{|c|}{ CSMA/CA } & \multicolumn{2}{c|}{ Slotted Aloha access } \\
\cline { 2 - 5 } & CWmin & CWmax & CPmax & CPmin \\
\hline 0 & 16 & 64 & $1 / 8$ & $1 / 16$ \\
\hline 1 & 16 & 32 & $1 / 8$ & $3 / 32$ \\
\hline 2 & 8 & 32 & $1 / 4$ & $3 / 32$ \\
\hline 3 & 8 & 16 & $1 / 4$ & $1 / 8$ \\
\hline 4 & 4 & 16 & $3 / 8$ & $1 / 8$ \\
\hline 5 & 4 & 8 & $3 / 8$ & $3 / 16$ \\
\hline 6 & 2 & 8 & $1 / 2$ & $3 / 16$ \\
\hline 7 & 1 & 4 & 1 & $1 / 4$ \\
\hline
\end{tabular}

\subsubsection{Acceso improvisado y acceso no programado}

Un hub puede emplear acceso improvisado

- Como un método de acceso independiente para enviar encuestas o publicaciones en un modo best-effort, sin previa reserva y asignación a través de tramas de Connection Request y Connection Assignment;

- Como un método de acceso suplementario para el acceso programado y no programado para enviar más encuestas y publicaciones fuera de asignaciones programadas y no programadas de bilink; $y$

- Como un método de acceso habilitante para el acceso de sondeo programado y no programado para enviar encuestas o publicaciones dentro de las asignaciones de enlaces programados y no programados.

Un hub y un nodo que lo admitan, pueden emplear acceso no programado para iniciar transacciones de trama en un enlace downlink y/o uplink en un modo best-effort, con reserva anticipada y asignación tentativa a través de tramas Connection Request y Connection Assignment. Para admitir el acceso no programado en supertramas con o sin beacon, un nodo siempre estará activo durante los intervalos de tiempo en los que se permite enviar encuestas y publicaciones.

\subsubsection{Acceso continuo, finalización y timeout}

Dependiendo de la configurar los campos More Data y Last Frame del encabezado MAC de una trama de gestión o tipo de datos a enviar, un nodo o un hub determinarán primero si puede iniciar otra transacción de trama en el intervalo de asignación actual de acuerdo con los modos de acceso vistos anteriormente.

Un intervalo de asignación uplink es un intervalo de asignación de enlace ascendente contendido, sondeado o programado. Un intervalo de asignación downlink es un intervalo de asignación de enlace descendente publicado o programado. Un intervalo de asignación de bilink comprende encuestas, intervalos de asignación encuestados (iniciados por encuestas) y / o intervalos de asignación publicados (iniciados por publicaciones). 


\subsubsection{Extensión en dos saltos de topología estrella.}

Excepto en la banda MICS, un nodo y un hub pueden usar una extensión de dos saltos para intercambiar tramas a través de otro nodo que esté conectado y sea capaz de comunicarse directamente con ambos, como se ilustra en la Figura 32, convirtiendo los nodos terminales e intermedios en nodos retransmitidos y de retransmisión, respectivamente, y el hub en el objetivo del nodo retransmitido.

El nodo retransmitido o el hub de destino pueden iniciar una extensión de dos saltos en momentos determinados por el iniciador, independientemente de si nunca han estado, o ya no están, en comunicación directa entre sí.

El nodo de retransmisión también puede intercambiar sus propias tramas con el hub directamente como en una red estelar de un salto.

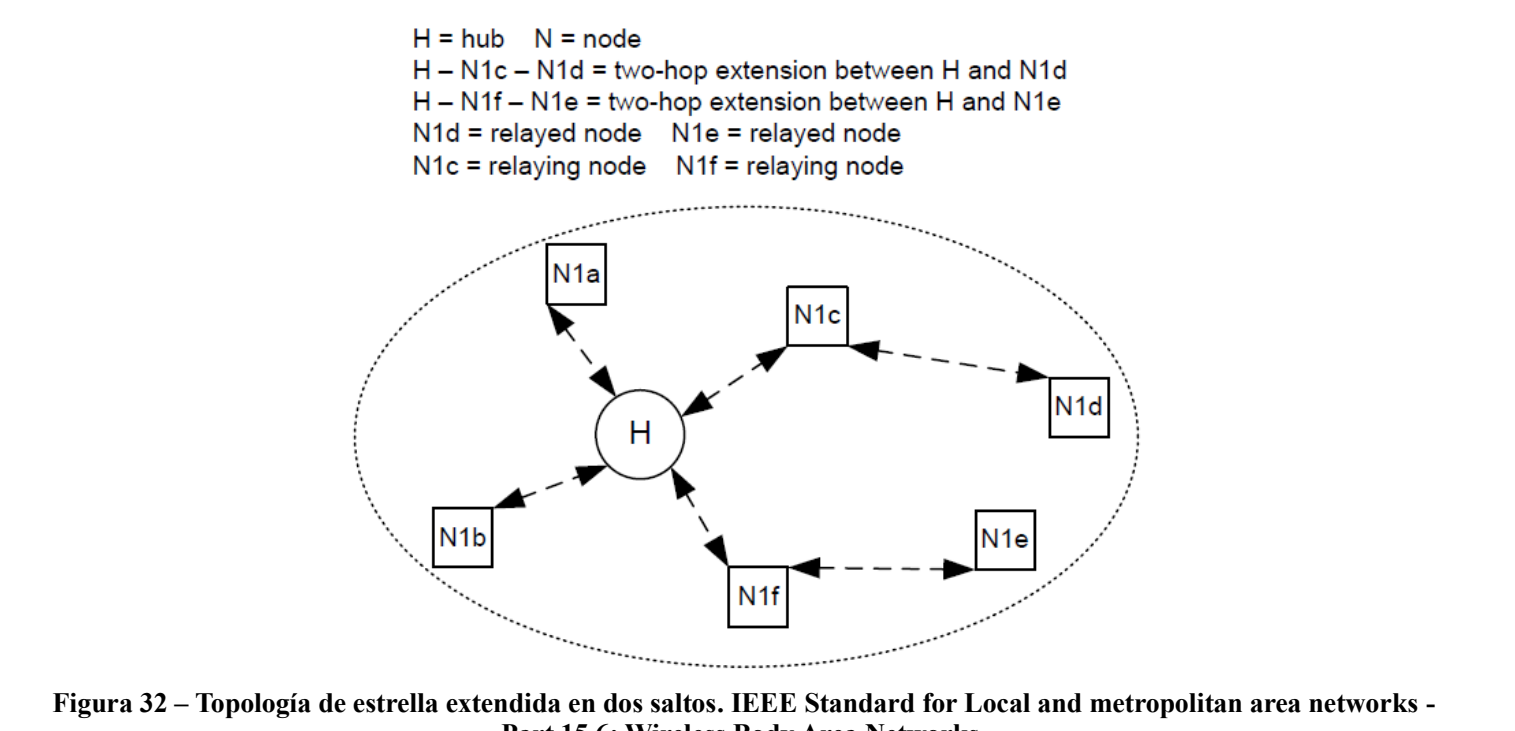
Part 15.6: Wireless Body Area Networks.

\subsubsection{Gestión de energía}

Un nodo que no indica estar siempre activo en su último campo de MAC Capability transmitido puede hibernar, es decir, estar en estado inactivo a través de sus períodos de beacon sin activación (supertrama). Puede dormir, es decir, estar en estado inactivo durante algunos intervalos de tiempo en sus períodos de beacon de activación (supertrama).

\subsubsection{Coexistencia y mitigación de interferencia.}

Un hub puede emplear uno o más de los mecanismos opcionales descritos a continuación para la coexistencia y/o la mitigación de interferencias entre su BAN y las BAN vecinas. 


\subsection{Beacon shifting}

Un hub puede transmitir sus beacons en diferentes offsets de tiempo en relación con el inicio de las supertramas incluyendo un campo de Beacon Shifting Sequence en sus beacon. Un hub debe elegir una secuencia de offset de beacon que no esté siendo utilizada por sus hubs vecinos para mitigar posibles colisiones repetidas de beacon y conflictos de asignaciones programadas entre BAN superpuestas o adyacentes que operan en el mismo canal.

\subsection{Channel hopping}

Un hub puede habilitar el channel hopping solo si trabaja en la narrow band (NB), y fuera de la banda MICS, o trabaja en la frecuencia de modulación ultra-wideband (FM-UWB). En tales casos, el hub puede cambiar periódicamente su canal operativo al incluir los campos Channel Hopping State y Next Channel Hop en sus beacon, y/o en el Superframe Parameters IE de sus tramas Connection Assignment. Un hub debe elegir una secuencia de channel hopping que no esté siendo utilizada por sus vecinos.

\subsection{Supertrama activa entrelazada}

Una BAN, denominada BAN 1, puede compartir en cualquier momento el mismo canal operativo con otra BAN, denominada BAN 2, entrelazando sus supertramas activas como se ilustra en la Figura 33. Un concentrador que admita el entrelazado de supertrama activo y que opere en modo no baliza con supertrama enviará una trama B2 en cada supertrama activa.

Independientemente de si BAN 1 está operando con una supertrama de una duración inactiva que son adecuadas para intercalar las supertramas activas entre BAN 1 y BAN 2, el hub de BAN 2 (el hub designado), puede enviar al hub de BAN 1 (el hub denotado), una trama de Command-Active Superframe Interleaving Request para solicitar la intercalación de supertrama activa entre las dos BAN, después de recibir una beacon o una trama B2 del hub 1 con el campo Superframe Interleaving del MAC header seteado en uno, indicando el soporte de la intercalación de supertramas activas. 


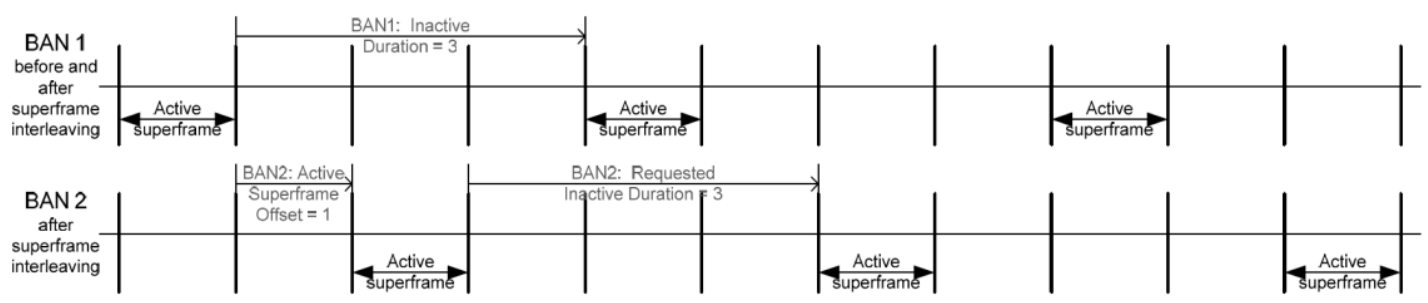

(a) Without active superframe adjustment

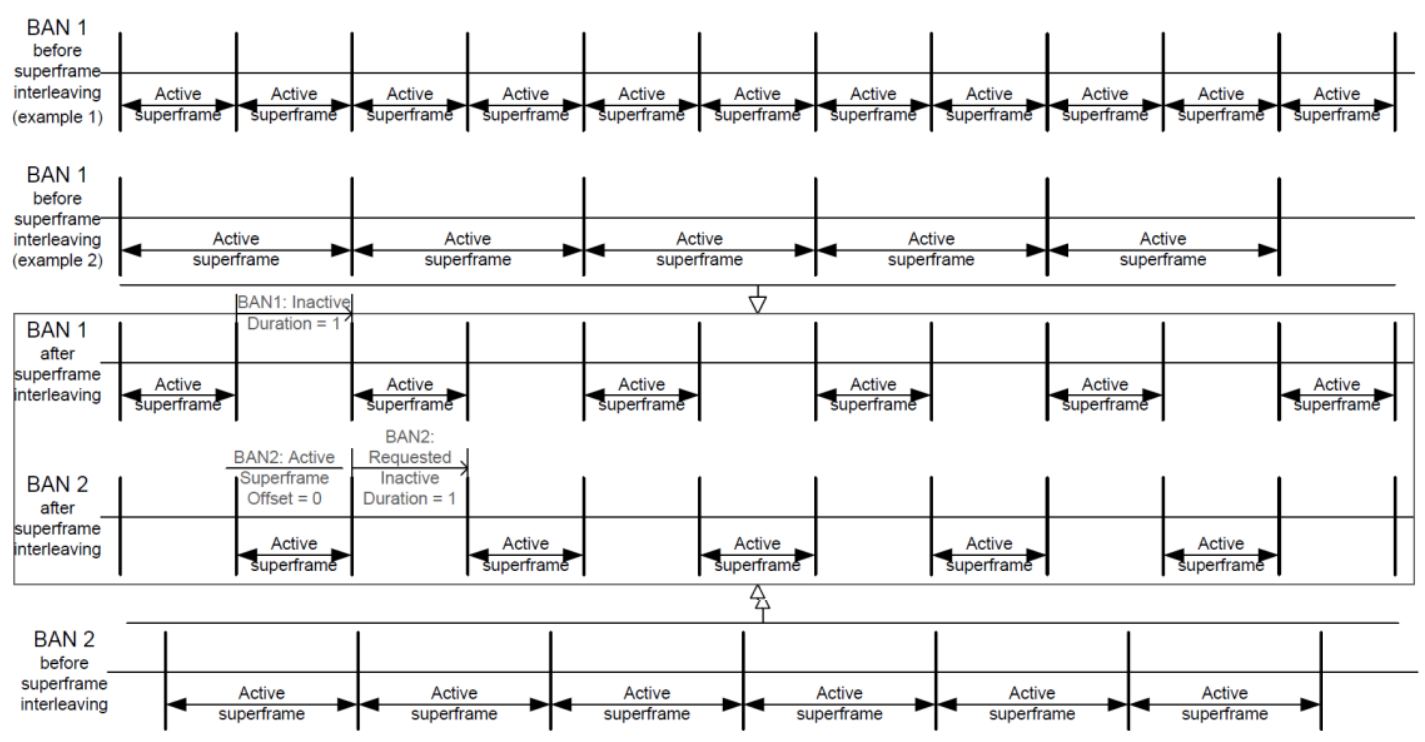

(b) With active superframe adjustment

Figura 33 - Ilustración de supertramas activas entrelazadas. IEEE Standard for Local and metropolitan area networks - Part 15.6: Wireless Body Area Networks.

\subsubsection{Manejo/interacción de capacidades MAC/PHY y uso de Application Specific} IE

\subsection{Soporte de capacidades MAC/PHY opcionales}

Un nodo o un hub debe estar listo para llevar a cabo una función que ha indicado que es capaz de soportar en su último campo MAC Capability o PHY Capability transmitido. Un nodo o un hub no iniciará ni ejecutará una función que su interlocutor ha indicado que es incapaz de soportar a través del último campo MAC Capability o PHY Capability enviado.

Para transmitir beacon, tramas Poll y T-Poll dirigidas a Unconnected_Broadcast_NID, Local_Broadcast_NID o Broadcast_NID según corresponda, un hüb utilizará una velocidad de datos obligatoria de la banda de frecuencia operativa para el PHY subyacente.

\subsection{Interacción MAC/PHY para ARQ híbridas}

Un nodo y un hub pueden emplear una type-II hybrid automatic repeat request (HARQ) en la transmisión y recepción de una trama para UWB PHY si su pHybridARQ se 
establece en TRUE.

El remitente enviará la trama con el campo Ack Policy del MAC header establecido en IAck. A menos que el emisor reciba una trama I-Ack esperada o anule la retransmisión de trama actual en el PHY, transmitirá alternativamente los bits de paridad de la trama MAC construida en la PHY según el esquema HARQ, o la trama MAC misma, un tiempo $p$ SIFS después del final estimado de la trama I-Ack esperada.

Cuando un remitente invoca una operación type-II HARQ para la transmisión de trama, las tramas que contiene una MAC o los bits de paridad de la misma, las tramas I-Ack esperadas y un tiempo de guarda apropiado, se ajustarán dentro de un intervalo de asignación que ha obtenido.

\subsection{Uso de Application Specific IE}

Un hub puede incluir uno o más Application Specific IE's al final de su beacon.

Un nodo puede incluir uno o más Application Specific's IE al final de su trama de Connection Request. Un hub también puede incluir uno o más Application Specific IE's al final de su trama de Connection Assignment.

Un destinatario ignorará los Application Specific IE's no reconocidos.

\subsubsection{Parámetros de la subcapa MAC}

La Tabla 3 proporciona los valores para los parámetros de la subcapa MAC.

Tabla 3 - Parámetros de la subcapa MAC [1].

\begin{tabular}{|l|l|}
\hline \multicolumn{1}{|c|}{ Parameter } & Value \\
\hline mBAckLimit & 8 \\
\hline mCSMATxLimit & 2 for UP $\leq 5$ or 4 for UP $\geq 6$ \\
\hline mHubClockPPMLimit & $40 \mathrm{ppm}$ \\
\hline mClockResolution & $4 \mu \mathrm{s}$ \\
\hline mG-AckDataSubtype & 1111 (binary) \\
\hline mMaxFragmentCount & 8 \\
\hline mMaxBANSize & 64 \\
\hline mNominalSynchInterval & $8 \times$ Beacon Period (Superframe) Length \\
\hline mScheduledAllocationAborted & 32 \\
\hline mTimeOut & $30 \mu \mathrm{s}$ \\
\hline mUnscheduledAllocationAborted & 32 \\
\hline mUnscheduledNoResponseLimit & 3 \\
\hline
\end{tabular}

Las Tablas 4, 5 y 6 proporcionan los valores de los parámetros dependientes de PHY utilizados por la subcapa MAC. 
Tabla 4 - Parámetros de subcapa MAC dependientes de PHY pertenecientes a NB PHY [1].

\begin{tabular}{|c|c|}
\hline Parameter & Value \\
\hline pAllocationSlotMin & $500 \mu \mathrm{s}$ \\
\hline pAllocationSlotResolution & $500 \mu \mathrm{s}$ \\
\hline pCCATime & 63 / Symbol Rate (see Table 29 to Table 35 for Symbol Rate) \\
\hline pChannelSeparation & 2 \\
\hline pChannelsTotal & See Table 45 \\
\hline pChannelSwitchTime & $100 \mu \mathrm{s}$ \\
\hline pCSMAMACPHYTime & $40 \mu \mathrm{s}$ \\
\hline pCSMASlotLength & pCCATime + pCSMAMACPHYTime \\
\hline pExtraIFs & $10 \mu \mathrm{s}$ \\
\hline pHybridARQ & FALSE \\
\hline pMaxFrameBodyLength & 255 octets \\
\hline pMICSChannelsTotal & 10 \\
\hline pMICSChannelSwitchTime & $100 \mu \mathrm{s}$ \\
\hline pMICSHubMaxRetries & 10 \\
\hline pMICSMcastPollRxTime & pMICSPollTxTime + pMIFS + pMICSPreambleTxTime $=1567 \mu \mathrm{s}$ \\
\hline pMICSMcastPolls & $\begin{array}{l}\lceil\text { pMICSChannelsTotal } \times(\text { pMICSMcastPollRxTime }+ \\
\text { pMICSChannelSwitchTime }) /(\text { pMICSPollTxTime }+ \text { pMIFS })\rceil=16\end{array}$ \\
\hline pMICSNodeEmergencyRetries & 2 \\
\hline pMICSPollRxTime & pMICSPollTxTime + pMICSPollSpace + pMICSPreambleTxTime $=2157 \mu \mathrm{s}$ \\
\hline pMICSPollSpace & $2 \times$ pSIFS + pMICSPreambleTxTime + mTimeOut $=610 \mu \mathrm{s}$ \\
\hline pMICSPollTxTime & $\begin{array}{l}\text { pMICSPreambleTxTime }+ \text { pMICSPLCPHeaderTxTime }+\{(7+2) \times 8+12 \times \\
\lceil(7+2) \times 8 / 51\rceil\} / 187.5 \mathrm{~ms}=1323 \mu \mathrm{s}\end{array}$ \\
\hline pMICSPreambleTxTime & $90 / 187.5 \mathrm{~ms}=480 \mu \mathrm{s}$ \\
\hline pMICSPLCPHeaderTxTime & $2 \times 31 / 187.5 \mathrm{~ms}=331 \mu \mathrm{s}$ \\
\hline pMICSUnconnectedPollPeriod & $\begin{array}{l}>(\text { pMICSUnconnectedPollTxTime }+ \text { pMICSPollSpace }) \times \\
\text { pMICSUnconnectedPolls }=25130 \mu \mathrm{s}\end{array}$ \\
\hline pMICSUnconnectedPollRxTime & $\begin{array}{l}\text { pMICSUnconnectedPollTxTime }+ \text { pMICSPollSpace }+ \\
\text { pMICSPreambleTxTime }=2275 \mu \mathrm{s}\end{array}$ \\
\hline pMICSUnconnectedPolls & $\begin{array}{l}\lceil\text { pMICSChannels Total } \times(\text { pMICSUnconnectedPollRxTime }+ \\
\text { pMICSChannelSwitchTime }) /(\text { pMICSUnconnectedPollTxTime }+ \\
\text { pMICSPollSpace })\rceil=14\end{array}$ \\
\hline pMICSUnconnectedPollTxTime & $\begin{array}{l}\text { pMICSPreambleTxTime + pMICSPLCPHeaderTxTime }+\{(7+4+2) \times \\
8+12 \times\lceil(7+4+2) \times 8 / 51\rceil\} / 187.5 \mathrm{~ms}=1558 \mu \mathrm{s}\end{array}$ \\
\hline pMIFs & $20 \mu \mathrm{s}$ \\
\hline pRandomAccess & $\mathrm{CSMA} / \mathrm{CA}$ \\
\hline pSIFS & $75 \mu \mathrm{s}$ \\
\hline pUnconnectedPolledAllocationMin & $\begin{array}{l}\geq \text { transmission time of two PHY packets containing a MAC frame of } 7+104+2 \\
\text { and } 7+2 \text { octets, respectively, both transmitted at the highest mandatory data rate } \\
\text { of the operating frequency band specified in Clause } 8 \text {. }\end{array}$ \\
\hline
\end{tabular}


Tabla 5 - Parámetros de la subcapa MAC dependientes de PHY pertenecientes a UWB PHY [1]

\begin{tabular}{|l|l|}
\hline \multicolumn{1}{|c|}{ Parameter } & \multicolumn{1}{c|}{ Value } \\
\hline pAllocationSlotMin & $16 \mu \mathrm{s}$ \\
\hline pAllocationSlotResolution & $16 \mu \mathrm{s}$ \\
\hline pAlohaSlotLength & pUnconnectedPolledAllocationMin \\
\hline pCCATime & $252 \mu \mathrm{s}$ \\
\hline pCSMAMACPHYTime & $40 \mu \mathrm{s}$ \\
\hline pCSMASlotLength & pCCATime + pCSMAMACPHYTime \\
\hline pExtraIFS & $10 \mu \mathrm{s}$ \\
\hline pHybridARQ & TRUE \\
\hline pMaxFrameBodyLength & 255 octets \\
\hline pMIFS & $20 \mu \mathrm{s}$ \\
\hline pRandomAccess & CSMA/CA or Slotted Aloha \\
\hline pSIFS & $75 \mu \mathrm{s}$ \\
\hline pUnconnectedPolledAllocationMin & $\begin{array}{l}\geq \text { transmission time of two PHY packets containing a MAC frame of } \\
\text { data rate of the operating frequency band specified in Clause 9. }\end{array}$ \\
\hline
\end{tabular}

Tabla 6 - Parámetros de la subcapa MAC dependientes de PHY pertenecientes a HBC PHY [1].

\begin{tabular}{|l|l|}
\hline \multicolumn{1}{|c|}{ Parameter } & \multicolumn{1}{c|}{ Value } \\
\hline pAllocationSlotMin & $500 \mu \mathrm{s}$ \\
\hline pAllocationSlotResolution & $500 \mu \mathrm{s}$ \\
\hline pAlohaSlotLength & pUnconnectedPolledAllocationMin \\
\hline pExtraIFS & $10 \mu \mathrm{s}$ \\
\hline pHybridARQ & FALSE \\
\hline pMaxFrameBodyLength & 255 octets \\
\hline pMIFS & $20 \mu \mathrm{s}$ \\
\hline pRandomAccess & Slotted Aloha \\
\hline pSIFS & $75 \mu$ s \\
\hline & $\begin{array}{l}\geq \text { transmission time of two PHY packets containing a MAC frame of } \\
7+104+2 \text { and } 7+2 \text { octets, respectively, both transmitted at the highest } \\
\text { pUnconnectedPolledAllocationMin data rate of the operating frequency band specified in } \\
\text { Clause 10. }\end{array}$ \\
\hline
\end{tabular}

\subsubsection{Seguridad del mensaje}

La seguridad comienza con una negociación de la suite de seguridad deseado entre las dos partes que se comunican: un nodo y un hub. La selección de seguridad, a su vez, desencadena una asociación de seguridad entre las dos partes para activar una Master Key (MK) precompartida o nueva, y termina con una disociación de seguridad para derogar legítimamente la MK compartida entre las dos partes.

La autenticación y cifrado de mensajes a nivel MAC está basada en la función de cifrado de Advanced Encryption Standard (AES) para claves de 128 bits que funcionan en modo contador y modo Cipher Block Chaining (CBC), respectivamente. Como parte de la seguridad del mensaje, también se proporciona protección de reproducción. 


\subsubsection{Capa Física}

El estándar define distintas capas físicas (PHY):

Human Body Communication (HBC) PHY, que utiliza el cuerpo humano como medio de propagación de señal. Usualmente trabaja en el rango de frecuencias que va desde los 5 a los $50 \mathrm{MHz}$.

Narrow Band (NB) PHY que, dependiendo de la regulación de cada país, puede operar en la banda de Medical Implant Communications Service (MICS: 402 - 405MHz), Wireless Medical Telemetry Services (WMTS: 608-614 MHz, 1395-1400 MHz y 1427-1432 MHz) o la Industrial, Scientific and Medica (ISM: 2,4 2,5 Ghz).

Ultrawideband (UWB) PHY que puede trabajar en una banda de frecuencia baja (entre 3,1 y $4,8 \mathrm{GHz}$ ) o alta (entre 6 y $10,6 \mathrm{GHz}$ ). [3]

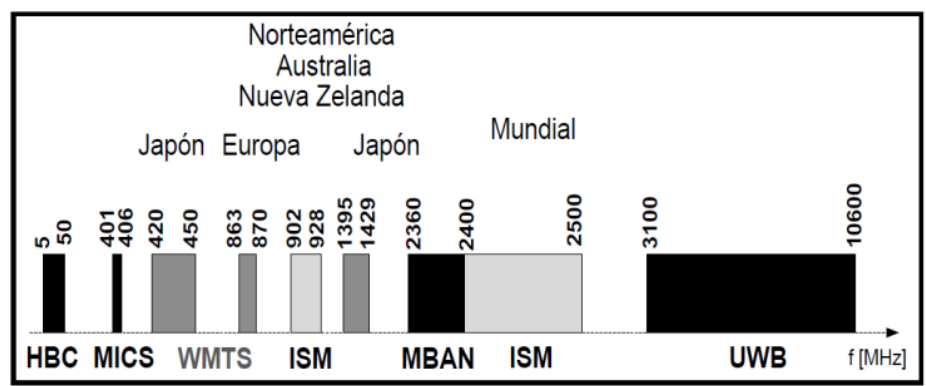

Figura 34 - Denominación de bandas de frecuencia para IEEE 802.15.6. Redes de Area Corporal Inalámbricos: Requisitos, Desafíos e Interferencias.

Las ISM son bandas de radiofrecuencia electromagnética no licenciadas, comprendidas (entre otras) desde los 2,4 a $2,5 \mathrm{GHz}^{3}$, reservadas internacionalmente para uso no comercial en áreas industrial, científica y médica. Se ha popularizado su uso en comunicaciones WiFi (distintas versiones de IEEE 802.11), Bluethoot, IEEE 802.15.6, IEEE 802.15.4 [2], etc; pudiendo unos comportarse como ruido electromagnético de otros, especialmente en áreas densamente pobladas.

\subsubsection{Especificaciones bajo la Narrow Band PHY}

La capa física es responsable de:

$\checkmark$ Activación y desactivación del transceptor de radio.

$\checkmark$ Clear channel assessment (CCA) dentro del canal actual.

$\checkmark$ Transmisión y recepción de datos.

También proporciona un método para transformar una Physical-layer Service Data Unit (PSDU) en una Physical-layer Protocol Data Unit (PPDU). Durante la transmisión, la PSDU se adjuntará previamente con un preámbulo de capa física y un encabezado de capa

\footnotetext{
${ }^{3}$ https://www.itu.int/net/ITU-R/terrestrial/faq/index.html\#g013 (último acceso 02/05/2018)
} 
física para crear la PPDU. En el receptor, el preámbulo y el encabezado sirven como ayudas en la demodulación, decodificación y entrega de la PSDU.

La Figura 35 muestra el formato de la PPDU, que se compone de tres componentes principales: el Physical-Layer Convergence Protocol (PLCP), el encabezado PLCPU y la PSDU.

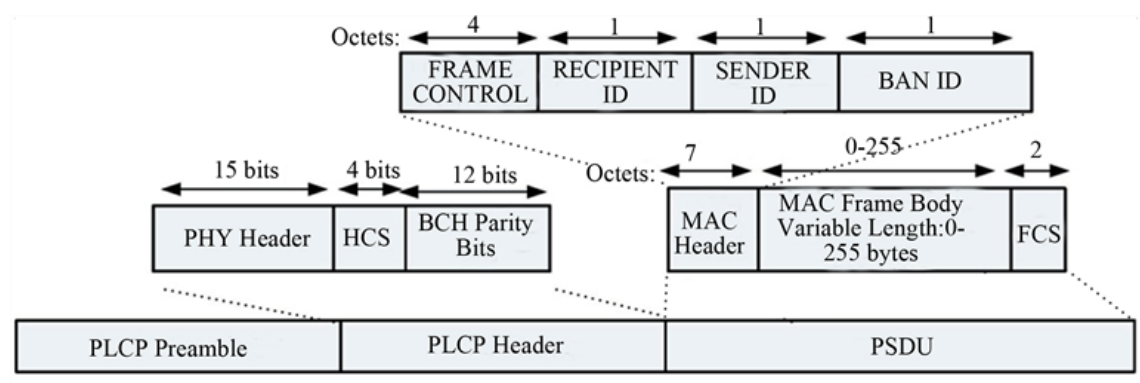

Figura 35 - Estructura de la PPDU. An overview of IEEE 802.15.6 standard.

El preámbulo PLCP es el primer componente de la PPDU. El propósito de éste es ayudar al receptor durante la sincronización de tiempo y la recuperación de desplazamiento de portadora.

El PLCP header es el segundo componente principal de la PPDU. Su propósito es transmitir la información necesaria sobre los parámetros PHY para ayudar en la decodificación de la PSDU en el receptor.

La PSDU es el último componente de la PPDU. Este componente se forma concatenando el MAC header con el cuerpo de trama MAC y Frame Check Sequence (FCS). La PSDU se puede codificar y extender/intercalar antes de ser codificada. La PSDU se transmitirá utilizando una de las velocidades de datos disponibles en la banda de frecuencia de funcionamiento.

\subsubsection{Parámetros dependientes de la velocidad de datos}

Para cada una de las posibles bandas de trabajo, el standard define distintos parámetros dependientes de la velocidad de datos. En el presente estudio solo nos concentraremos en la banda ISM.

Tabla 7 - Parámetros de modulación para PLCP header y PSDU [1].

\begin{tabular}{|c|c|c|c|c|c|c|c|}
\hline $\begin{array}{c}\text { Packet } \\
\text { component }\end{array}$ & $\begin{array}{l}\text { Modulation } \\
\qquad(M)\end{array}$ & $\begin{array}{c}\text { Symbol rate } \\
=1 / T_{s} \\
\text { (ksps) }\end{array}$ & $\begin{array}{c}\text { Code rate } \\
(k / n)\end{array}$ & $\begin{array}{c}\text { Spreading } \\
\text { factor } \\
(S) \\
\end{array}$ & Pulse shape & $\begin{array}{c}\text { Information } \\
\text { data rate } \\
\text { (kbps) }\end{array}$ & Support \\
\hline PLCP header & $\begin{array}{c}\pi / 2 \text {-DBPSK } \\
(M=2)\end{array}$ & 600 & $19 / 31^{\mathrm{a}}$ & 4 & $\mathrm{SRRC}$ & 91.9 & Mandatory \\
\hline PSDU & $\begin{array}{c}\pi / 2 \text {-DBPSK } \\
(M=2)\end{array}$ & 600 & $51 / 63$ & 4 & SRRC & 121.4 & Mandatory \\
\hline PSDU & $\begin{array}{c}\pi / 2 \text {-DBPSK } \\
(M=2)\end{array}$ & 600 & $51 / 63$ & 2 & SRRC & 242.9 & Mandatory \\
\hline PSDU & $\begin{array}{c}\pi / 2 \text {-DBPSK } \\
(M=2)\end{array}$ & 600 & $51 / 63$ & 1 & SRRC & 485.7 & Mandatory \\
\hline PSDU & $\begin{array}{c}\pi / 4 \text {-DQPSK } \\
(M=4)\end{array}$ & 600 & $51 / 63$ & 1 & SRRC & 971.4 & Mandatory \\
\hline
\end{tabular}

${ }^{\mathrm{a}} \mathrm{BCH}(31,19)$ code is a shortened code derived from a $\mathrm{BCH}(63,51)$ code. 


\subsubsection{Preámbulo PLCP}

Se agrega un preámbulo antes del encabezado PLCP para ayudar al receptor en la detección de paquetes, sincronización de tiempo y recuperación de desplazamiento de portadora. Es estándar define dos preámbulos, con longitud (Npreamble) de 90 bits, para mitigar falsas alarmas debido a redes que operan en canales adyacentes.

Los preámbulos se transmitirán a la velocidad de símbolos para la banda de operación deseada y se codificarán utilizando los mismos parámetros de modulación definidos para el PLCP header.

\subsubsection{PLCP Header}

Se agregará un PLCP header después del preámbulo para transmitir información sobre los parámetros PHY que se necesitan en el receptor para decodificar la PSDU. La longitud del encabezado PLCP, Nheader, es de 31 bits, y se construirá para la transmisión como se muestra en la Figura 36:

a) El PHY header se formará en base a la información proporcionada la capa MAC.

b) Se calcula el valor del HCS de 4 bits sobre el encabezado PHY utilizando el polinomio CRC-4 ITU: $1+\mathrm{x}+\mathrm{x}^{4}$.

c) Como se muestra en la Figura 37, un código $\mathrm{BCH}(31,19)$, que es una abreviación derivada del $\mathrm{BCH}(63,51)$, se aplica a la concatenación del encabezado PHY (15 bits) y HCS (4 bits)

d) Los bits codificados se distribuyen utilizando un código de repetición, donde Ntotal $=31$, y luego se entrelazan utilizando un intercalador de bits con factor de dispersión determinado por la banda de frecuencia de operación.

e) El flujo de bits resultante se aleatoriza, donde la semilla del aleatorizador se determina por el número de canal.

f) Finalmente, el flujo de bits codificado resultante se asigna a la constelación apropiada, que se determina por la banda de frecuencia de operación.

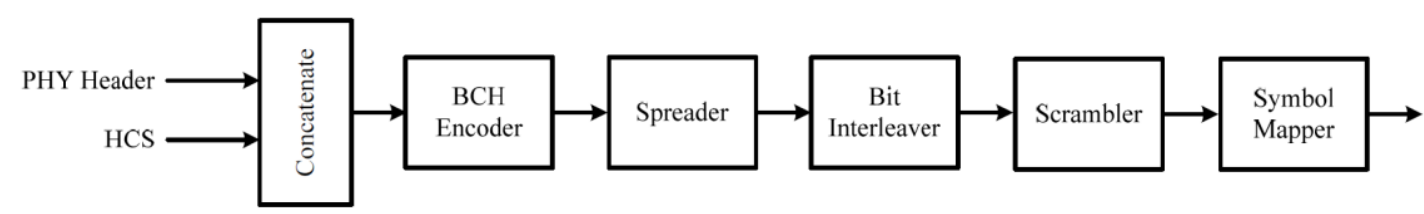

Figuta 36 - Diagrama de bloques de construcción del PLCP header para la transmisión. IEEE Standard for Local and metropolitan area networks - Part 15.6: Wireless Body Area Networks. 


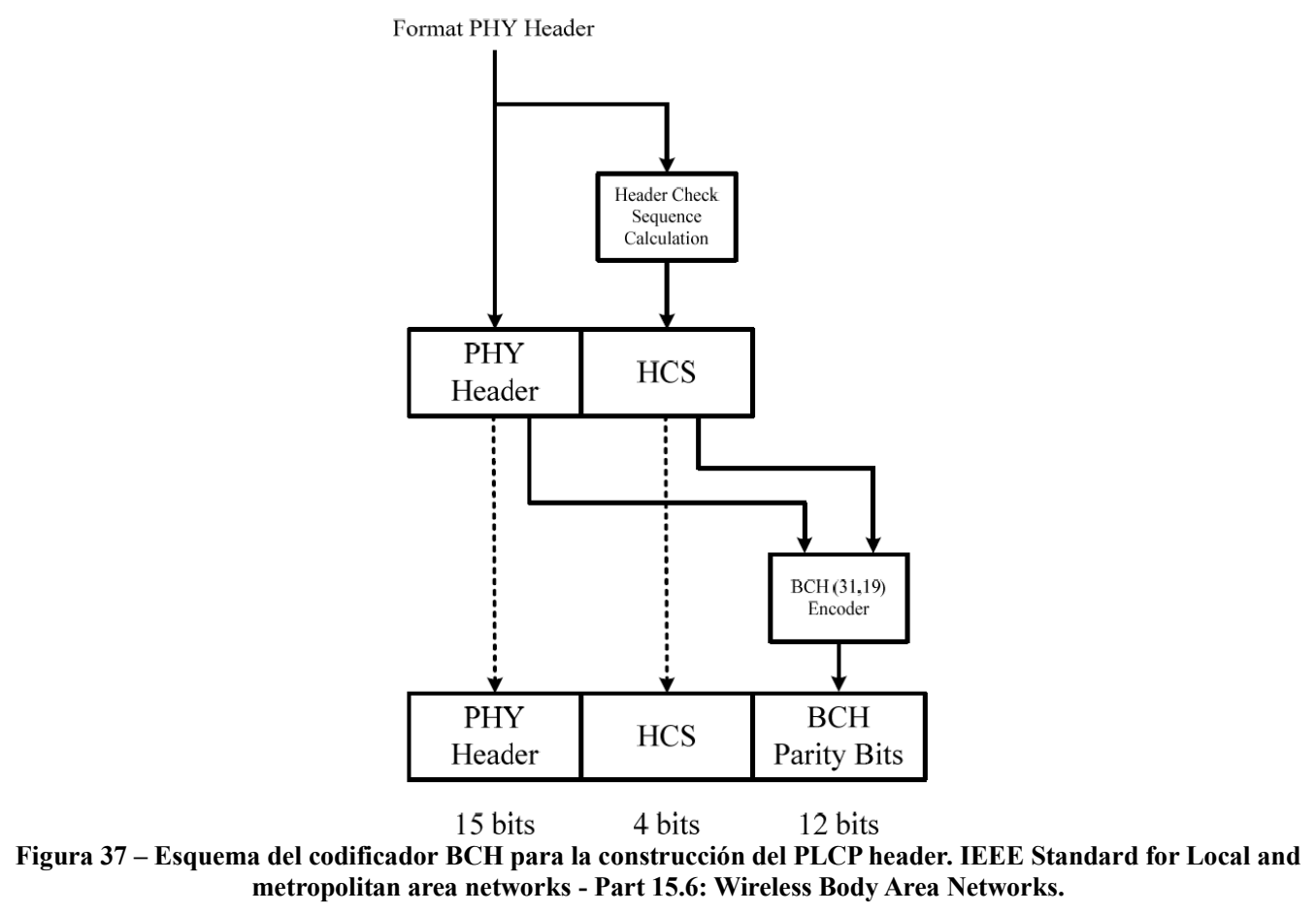

\subsection{PHY header}

El PHY header contiene información sobre la data rate, la longitud del cuerpo de la trama MAC (que no incluye el MAC header o el FCS) e información sobre el próximo paquete.

El campo de PHY header está compuesto de 15 bits, numerados del 0 al 14 como se ilustra en la Figura 38: Los bits 0-2 codificarán el campo RATE, que transmite información sobre el tipo de modulación, la data rate de información, la pulse shaping, la tasa de codificación y el spreading factor utilizado para transmitir la PSDU; los bits 4-11 codificarán el campo LONGITUD, transmitiéndose primero el LSB y el bit 13 codificará si el paquete se está transmitiendo o no en burst (streaming) mode; el bit 14 codificará la scrambler seed.

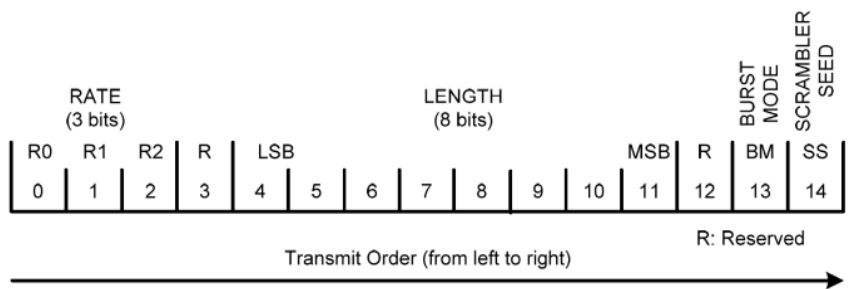

Figura 38 - Asignación de bits de la PHY Header. IEEE Standard for Local and metropolitan area networks - Part 15.6: Wireless Body Area Networks. 


\subsection{Header Check Sequence}

El PHY header estará protegido con una Header Check Sequence (HCS) de 4 bits (CRC4 ITU). El HCS será el complemento del resto generado por la división del módulo 2 del PHY header por el polinomio: $1+x+x^{4}$. Los bits HCS se procesarán en el orden de transmisión. En la Figura 39 se muestra un esquema del orden de procesamiento. Los registros se inicializarán todos en uno.

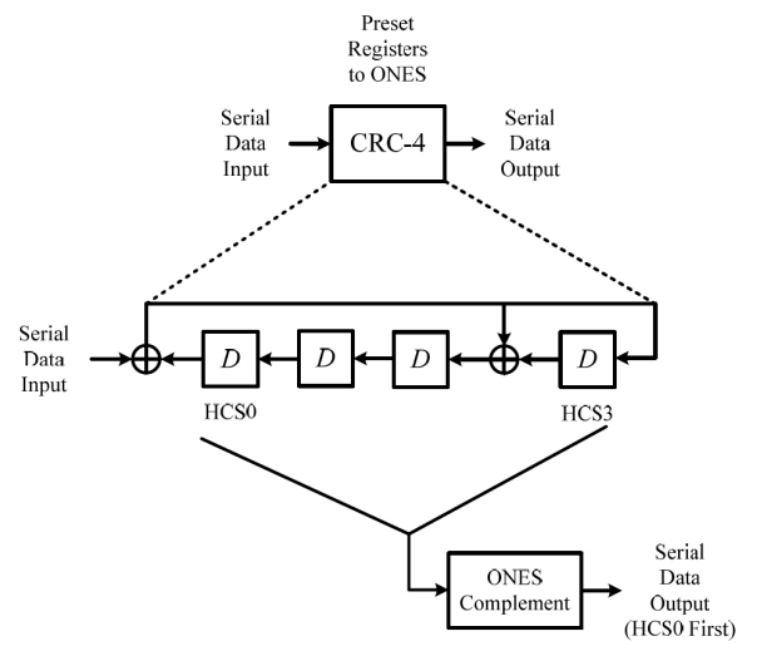

Figura 39 - Diagrama de bloques de una implementación CRC-4. IEEE Standard for Local and metropolitan area networks - Part 15.6: Wireless Body Area Networks.

\subsection{Codificador BCH del PLCP header}

El PLCP header utiliza un código $B C H(31,19, t=2)$, que es un código recortado derivado del $B C H(63,51, t=2)$, agregando 32 bits ceros a los 19 bits de información, para mejorar la robustez del PLCP header.

\subsubsection{PSDU}

La PSDU es el último componente principal de la PPDU y se construye como se muestra en la Figura 40.

a) El PSDU se forma anteponiendo el MAC header de 7 octetos al cuerpo de la trama MAC y agregue un FCS de 2 octetos al resultado.

b) Si la tasa de código $(k / n)<1$, la PSDU es:

a. Dividido en bloques de mensajes que inician con el LSB del octeto menos significativo y continúan hacia el MSB del octeto más significativo;

b. Los bits de acortamiento se pueden agregar a los mensajes que luego se codifican con $\mathrm{BCH}(63,51)$ para lograr la velocidad de código deseada;

c. Finalmente, los bits acortados se eliminan de cada una de las palabras de código.

c) Los bits de relleno se agregan para alinearse en un límite de símbolo.

d) Si el spreading factor es de 2 o 4 , los bits codificados o no codificados resultantes se distribuyen utilizando un código de repetición y luego se intercalan. 
e) El flujo de bits resultante se codifica.

f) Finalmente, el flujo de bits codificado resultante se asigna a la constelación apropiada que está determinada por la velocidad de datos y la banda de frecuencia de operación.

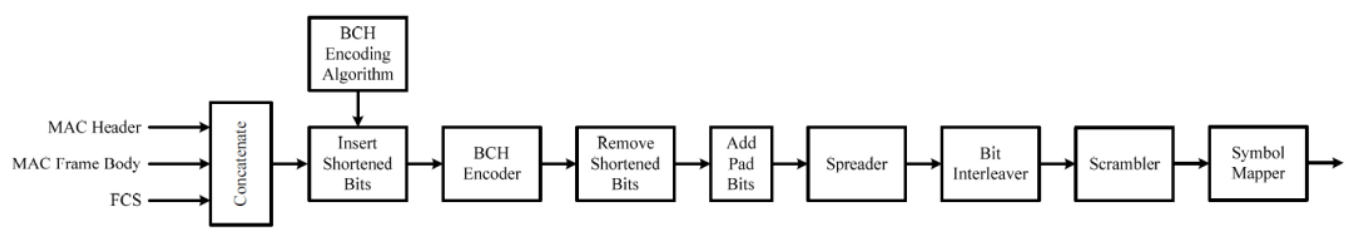

Figura 40 - Diagrama de bloques de la construcción del PSDU para su transmisión. IEEE Standard for Local and metropolitan area networks - Part 15.6: Wireless Body Area Networks.

\subsection{Codificador BCH para el PSDU}

\subsection{Proceso de codificación $\mathrm{BCH}$}

Un codificador $\mathrm{BCH}$ sistemático admitirá una tasa de código de 51/63. Los bits de información se codificarán utilizando el proceso de codificación $\mathrm{BCH}$ que se ilustra en la Figura 41:

$$
\begin{gathered}
\text { BCH Encoding } \\
\text { (concatenate parity bits) }
\end{gathered}
$$

\begin{tabular}{|c|c|c|c|c|c|c|c|}
\hline $\begin{array}{c}\text { Message } \\
\text { Bits }\end{array}$ & $\begin{array}{c}\text { Message } \\
\text { Bits }\end{array}$ & $\begin{array}{c}\text { Shortened } \\
\text { Bits }\end{array}$ & $\begin{array}{c}\text { Message } \\
\text { Bits }\end{array}$ & $\begin{array}{c}\text { Shortened } \\
\text { Bits }\end{array}$ & $\begin{array}{c}\text { Parity } \\
\text { Bits }\end{array}$ & $\begin{array}{c}\text { Message } \\
\text { Bits }\end{array}$ & $\begin{array}{c}\text { Parity } \\
\text { Bits }\end{array}$ \\
\hline
\end{tabular}

Figura 41 - Proceso de codificación para una única palabra de código. IEEE Standard for Local and metropolitan area networks - Part 15.6: Wireless Body Area Networks.

a) Se calcula el número de bits NPSDU como se muestra en la ecuación (1):

$$
\mathrm{N}_{\text {PSDU }}=\left(\mathrm{N}_{\text {MACheader }}+\mathrm{N}_{\text {MACFrameBody }}+\mathrm{N}_{\mathrm{FCS}}\right) \times 8
$$

donde $\mathrm{N}_{\text {MACheader }}$ es el número de octetos del MAC Header, NMACFrameBody es el número de octetos del cuerpo de la trama $\mathrm{MAC}$ y $\mathrm{N}_{\mathrm{FCS}}$ es el número de octetos en el FCS.

b) Se calcula el número de palabras de código $\mathrm{BCH} \mathrm{N}_{\mathrm{CW}}$ como se muestra en la ecuación (2):

$$
N_{C W}=\left\lceil\frac{N_{P S D U}}{k}\right\rceil
$$

donde $\mathrm{k}$ es el número de bits de mensaje para el código $\mathrm{BCH}$ seleccionado.

c) Se calcula el número de bits de acortamiento, $\mathrm{N}_{\text {shorten, }}$ con que se rellenarán con los bits de datos de $\mathrm{N}_{\mathrm{PSDU}}$ antes de codificar como se muestra en la Ecuación (3):

$$
N_{\text {shorten }}=N_{C W} \times k-N_{P S D U}
$$


d) Los bits de acortamiento se distribuyen equitativamente entre todas las palabras de código $\mathrm{N}_{\mathrm{CW}}$ con las primeras palabras de código rem $\left(N_{\text {shorten, }} N_{C W}\right)$ acortadas un bit más que las palabras de código restantes, como se muestra en la ecuación (4):

$$
N_{S P C W}=\left\lfloor\frac{N_{\text {shorten }}}{N_{C W}}\right\rfloor
$$

donde $\lfloor f\rfloor$ es el entero más grande no mayor que $f$.

e) Luego de la codificación, los bits acortados se descartarán antes de la transmisión, es decir, los bits acortados nunca se transmiten.

\subsection{Codificador $\mathrm{BCH}(63,51)$}

La definición para el codificador $\mathrm{BCH}$ sistemático $(63,51, \mathrm{t}=2)$, donde $t$ es el número de errores de bit que se pueden corregir, viene dado por la ecuación (5):

$$
g(x)=1+x^{3}+x^{4}+x^{5}+x^{8}+x^{10}+x^{12}
$$

Los bits de paridad se determinan calculando el resto del polinomio $r(x)$ como se muestra en la ecuación (6):

$$
r(x)=\sum_{i=0}^{11} r_{i} x^{i}=x^{12} m(x) \bmod g(x)
$$

donde $m(x)$ es el polinomio del mensaje que se muestra en la ecuación (7):

$$
m(x)=\sum_{i=0}^{50} m_{i} x^{i}
$$

y $r_{i}, i=0, \ldots, 11$ y $m_{i}, i=0, \ldots, 50$ son elementos de $\mathrm{GF}(2)^{4}$.

El polinomio del mensaje $m(x)$ se crea de la siguiente manera: $m_{50}$ y $m_{0}$ es, respectivamente, el primer y el último bit del mensaje transmitido, que puede ser un bit acortado. El orden de los bits de paridad es $\mathrm{r}_{11}, \mathrm{r}_{10}$ y $\mathrm{r}_{0}$ es, respectivamente, el primer, segundo y último bit de paridad transmitido.

\subsection{Bits de relleno}

Los bits de relleno se agregarán después del codificador BCH para alinear el flujo de bits en un límite de símbolo. El número de bits de relleno, $\mathrm{N}_{\text {pad, }}$ que se inserta es una función del número de bits de PSDU $\mathrm{N}_{\mathrm{PSDU}}$, el número de palabras de código $\mathrm{N}_{\mathrm{CW}}$, el número de bits de paridad ( $\mathrm{n}-\mathrm{k}$ ) y el tamaño de constelación de modulación $\mathrm{M}$, consulte la ecuación (8):

\footnotetext{
${ }^{4}$ Galois Field de grado 2: $G F(2)=X^{2}+X+1$
} 


$$
N_{\text {pad }}=\log _{2}(M) \times\left\lceil\frac{N_{P S D U}+N_{C W} \times(n-k)}{\log _{2}(M)}\right\rceil-\left[N_{P S D U}+N_{C W} \times(n-k)\right]
$$

Los bits de relleno se agregarán a la PSDU (codificado o no) y todos los bits de relleno añadidos se pondrán a cero. En el caso de transmisión no codificada, $\mathrm{N}_{\mathrm{CW}}$ se establece en cero.

\subsection{Expansión}

Para un factor de dispersión de 2, cada bit de entrada se repite dos veces [ver Figura 42 (a)]. Para un factor de dispersión de 4, cada bit de entrada se repite cuatro veces [ver Figura $42(\mathrm{~b})]$.

(a)

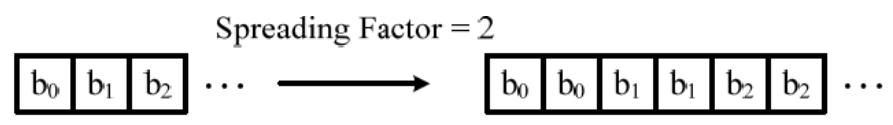

Spreading Factor $=4$

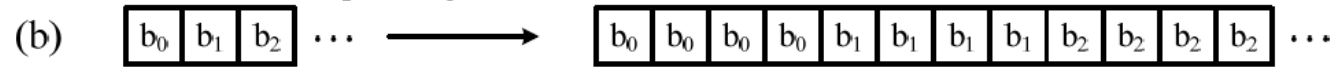

Figura 42 - Esquema de expansión. IEEE Standard for Local and metropolitan area networks - Part 15.6: Wireless Body Area Networks.

\subsection{Entrelazador de bits}

En el caso de que el factor de dispersión sea igual a 2 o 4, la salida del separador se intercalará antes de la modulación para proporcionar robustez contra la propagación de errores. La estructura exacta del entrelazador de bits depende del número de bits sin codificar o codificados que se transmitirán, que viene dada por la ecuación (9):

$$
N_{\text {total }}=N_{P S D U}+N_{C W} \times(n-k)+N_{\text {pad }}
$$

donde $\mathrm{N}_{\mathrm{CW}}$ se establece en cero en el caso de transmisión no codificada.

Si $\operatorname{rem}\left(N_{\text {total }}, 2\right)=0$, la operación de entrelazado de bits se realiza primero agrupando los bits extendidos en bloques de $2 \mathrm{~S}$ bits, donde $\mathrm{S}$ es el factor de expansión, y luego usando un entrelazador de bloques de tamaño $S \times 2$ para permutar los bits . Dejando que las secuencias $a(i)$ y $b(i)$, donde $\mathrm{i}=0,1, \ldots, 2 \mathrm{~S}-1$, representan los bits de entrada y salida del entrelazador de bits $S \times 2$, respectivamente. La salida del intercalador $S \times 2$ bit viene dada por la relación en la ecuación (10):

$$
b(i)=a\left[S \times \operatorname{rem}(i, 2)+\left\lfloor\frac{i}{2}\right\rfloor\right] \quad i=0,1,2, \ldots, 2 S-1
$$

Si $\operatorname{rem}\left(N_{\text {total }}, 2\right)=1$, la operación de entrelazado de bits se realiza agrupando los primeros bits extendidos $3 \mathrm{~S}$ en un solo bloque y luego usando un entrelazador de bloques de tamaño $\mathrm{S} \times 3$ para permutar los bits dentro de ese bloque único. Dejando que las secuencias $a(i) \mathrm{y}$ $b(i)$, donde $\mathrm{i}=0,1, \ldots, 3 \mathrm{~S}-1$, representan los bits de entrada y salida del entrelazador de bits $S \times 3$, respectivamente. La salida del intercalador $S \times 3$ bit viene dada por la relación en la ecuación (11): 


$$
b(i)=a\left[S \times \operatorname{rem}(i, 3)+\left\lfloor\frac{i}{3}\right\rfloor\right] \quad i=0,1,2, \ldots, 3 S-1
$$

Los bits extendidos restantes se agrupan en bloques de bits $2 \mathrm{~S}$ y se intercalan utilizando el intercalador de bloques de tamaño $\mathrm{S} \times 2$ que se muestra en la Ecuación (10).

\subsection{Codificador de datos}

Se utiliza un aleatorizador de flujo lateral con polinomio $\mathrm{G}(\mathrm{x})=1+\mathrm{x}^{2}+\mathrm{x}^{12}+\mathrm{x}^{13}+\mathrm{x}^{14}$ para blanquear la PSDU. La Figura 43 muestra una implementación típica del aleatorizador de flujo lateral. La salida del codificador se genera como se muestra en la ecuación (12):

$$
x[n]=x[n-2] \oplus x[n-12] \oplus x[n-13] \oplus x[n-14]
$$

donde $\bigoplus$ denota la adición del módulo 2 .

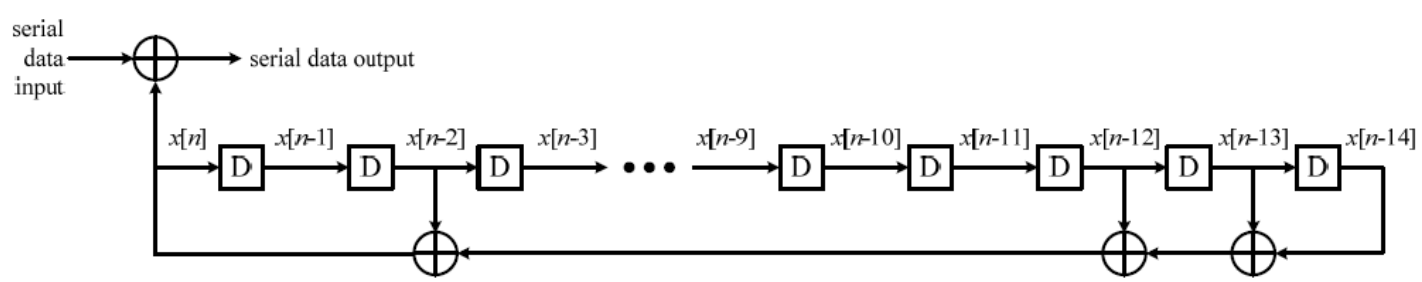

Figura 43 - Diagrama de bloques de un codificador de flujo lateral. IEEE Standard for Local and metropolitan area networks - Part 15.6: Wireless Bodv Area Networks.

La Tabla 8 define el vector de inicialización, $x_{\text {init, }}$ para el aleatorizador de flujo lateral en función del valor de inicialización del aleatorizador.

Tabla 8 - Selección de semillas del aleatorizador [1].

\begin{tabular}{|c|c|}
\hline Scrambler seed (SS) & $\begin{array}{c}\text { Initialization vector } \\
x_{\text {init }}=x[-\mathbf{1}] \boldsymbol{x}[-\mathbf{2}] \ldots \boldsymbol{x}[-\mathbf{1 4}]\end{array}$ \\
\hline 0 & 00101111001101 \\
\hline 1 & 00000001001111 \\
\hline
\end{tabular}

La MAC establece la inicialización del aleatorizador en 0 cuando se inicialice el PHY y la inicialización del aleatorizador se incrementará, utilizando un contador de rollover de 1 bit, en cada trama enviada por el PHY.

En el receptor, el descodificador de flujo lateral se inicializará con el mismo vector de inicialización, xinit, utilizado por el transmisor. El vector de inicialización se determina a partir del valor SS en el encabezado PHY de la trama recibida.

\subsubsection{Mapeo de constelación}

El mapeador de constelaciones opera en el flujo de bits que es la concatenación del preámbulo PLCP, el PLCP header y la PSDU. 


\subsection{Gaussian minimum shift keying (GMSK)}

Para GMSK, $\mathrm{b}(\mathrm{n}), \mathrm{n}=0,1, \ldots, \mathrm{N}-1$ se correlacionan con una desviación de frecuencia correspondiente $\Delta \mathrm{f}$, que será el producto de la velocidad de símbolos y un índice de modulación de 0,5 dividido por 2 . La relación entre el flujo de bits $b(n)$ y la desviación de frecuencia se da en la Tabla 9.

Tabla 9 - Mapeo de símbolos GMSK [1].

\begin{tabular}{|c|c|}
\hline$b(n)$ & Frequency deviation \\
\hline 0 & $-\Delta f$ \\
\hline 1 & $+\Delta f$ \\
\hline
\end{tabular}

\subsection{Differential phase-shift keying (D-PSK)}

Para D-PSK, $\mathrm{b}(\mathrm{n}), \mathrm{n}=0,1, \ldots, \mathrm{N}-1$ se correlacionará con una de las tres constelaciones codificadas diferencialmente y rotadas: $\pi / 2$-DBPSK, $\pi / 4$-DQPSK $0 \pi / 8$-D8PSK. La información codificada se transporta en las transiciones de fase entre símbolos.

El flujo de bits binario $b(n), n=0,1, \ldots, N-1$ se correlacionará con una secuencia de valores complejos correspondiente $\mathrm{S}(\mathrm{k}), \mathrm{k}=0,1, \ldots,(\mathrm{N} / \log 2(\mathrm{M}))-1$ como se muestra en la ecuación (13):

$$
S(k)=S(k-1) e^{j \varphi_{k}} \quad k=0,1, \ldots,\left(\frac{N}{\log _{2}(M)}\right)-1
$$

donde $S(-1)=e^{j \frac{\pi}{2}}$ es la referencia al primer símbolo del preámbulo y la relación entre el flujo de bits $b(n)$ y el cambio de fase $\varphi_{\mathrm{k}}$ está dada por las Tablas 10,11 y 12 para $\pi / 2$ DBPSK, $\pi / 4$-DQPSK, o $\pi / 8$-D8PSK, respectivamente. 
Tabla 10 - Mapeo $\pi / 2$-DBPSK [1].

\begin{tabular}{|c|c|}
\hline$b(\boldsymbol{n})$ & $\varphi_{k}$ \\
\hline 0 & $\pi / 2$ \\
\hline 1 & $3 \pi / 2$ \\
\hline
\end{tabular}

Tabla 11 - Mapeo $\pi / 4$-DBPSK [1].

\begin{tabular}{|c|c|c|}
\hline$b(\mathbf{2 n})$ & $b(\mathbf{2 n + 1})$ & $\boldsymbol{\varphi}_{k}$ \\
\hline 0 & 0 & $\pi / 4$ \\
\hline 0 & 1 & $3 \pi / 4$ \\
\hline 1 & 0 & $7 \pi / 4$ \\
\hline 1 & 1 & $5 \pi / 4$ \\
\hline
\end{tabular}

Tabla 12 - Mapeo $\pi / 8$-DBPSK [1].

\begin{tabular}{|c|c|c|c|}
\hline $\boldsymbol{b}(\mathbf{3} \boldsymbol{n})$ & $\boldsymbol{b}(\mathbf{3} \boldsymbol{n}+\mathbf{1})$ & $\boldsymbol{b}(\mathbf{3} \boldsymbol{n}+\mathbf{2})$ & $\boldsymbol{\varphi}_{\boldsymbol{k}}$ \\
\hline 0 & 0 & 0 & $\pi / 8$ \\
\hline 0 & 0 & 1 & $3 \pi / 8$ \\
\hline 0 & 1 & 0 & $7 \pi / 8$ \\
\hline 0 & 1 & 1 & $5 \pi / 8$ \\
\hline 1 & 0 & 0 & $15 \pi / 8$ \\
\hline 1 & 0 & 1 & $13 \pi / 8$ \\
\hline 1 & 1 & 0 & $9 \pi / 8$ \\
\hline 1 & 1 & 1 & $11 \pi / 8$ \\
\hline
\end{tabular}

En las constelaciones D-PSK se utiliza la forma de pulso square-root raised cosine (SRRC) con factor de caída $\beta$ y período de símbolo $\mathrm{T}_{\mathrm{s}}$, descrito en la Ecuación (14), para filtrar los símbolos y dar forma al espectro.

$$
p(t)=\left\{\begin{array}{lr}
1-\beta+4 \frac{\beta}{\pi} & t=0 \\
\frac{\beta}{\sqrt{2}}\left[\left(1+\frac{2}{\pi}\right) \sin \left(\frac{\pi}{4 \beta}\right)+\left(1-\frac{2}{\pi} \cos \left(\frac{\pi}{4 \beta}\right)\right)\right] & t= \pm \frac{T_{S}}{4 \beta} \\
\frac{\sin \left[\pi \frac{t}{T_{S}}(1-\beta)\right]+4 \beta \frac{t}{T_{S}} \cos \left[\pi \frac{t}{T_{S}}(1+\beta)\right]}{\pi \frac{t}{T_{S}}\left[1-\left(4 \beta \frac{t}{T_{S}}\right)^{2}\right]} & \text { Cualquier otro caso }
\end{array}\right.
$$

El valor exacto para el factor de caída $\beta$ y la duración de la forma del pulso SRRC depende de la implementación.

\subsubsection{Requerimientos generales}

\subsection{Bandas de frecuencia de operación}

Un dispositivo compatible soporta transmisiones y recepción en una o más de las siguientes bandas de frecuencia:
a) $402 \mathrm{MHz}$ a $405 \mathrm{MHz}$
b) $420 \mathrm{MHz}$ a $450 \mathrm{MHz}$
c) $863 \mathrm{MHz}$ a $870 \mathrm{MHz}$
d) $902 \mathrm{MHz}$ a $928 \mathrm{MHz}$
e) $950 \mathrm{MHz}$ a $958 \mathrm{MHz}$ 
f) $2360 \mathrm{MHz}$ a $2400 \mathrm{MHz}$

g) $2400 \mathrm{MHz}$ a $2483.5 \mathrm{MHz}$

\subsection{Numeración de canales}

La relación entre la frecuencia central, $\mathrm{f}_{\mathrm{c}}$, y el número de canal, $\mathrm{n}_{\mathrm{c}}$, se muestra en la Tabla 13.

Tabla 13 - Relación entre la frecuencia central y el número del canal [1].

\begin{tabular}{|c|c|c|}
\hline Frequency band (MHz) & Relationship between $f_{c}$ and $\boldsymbol{n}_{c}$ & Number of channels $\left(\boldsymbol{N}_{c h}\right)$ \\
\hline 402 to 405 & $f_{c}=402.15+0.30 \times n_{c}(\mathrm{MHz}), n_{c}=0, \ldots, 9$ & 10 \\
\hline 420 to 450 & $f_{c}=420.30+0.50 \times g_{1}\left(n_{c}\right)(\mathrm{MHz}), n_{c}=0, \ldots, 11$ & 12 \\
\hline 863 to 870 & $f_{c}=863.20+0.40 \times g_{2}\left(n_{c}\right)(\mathrm{MHz}), n_{c}=0, \ldots, 13$ & 14 \\
\hline 902 to 928 & $f_{c}=903.20+0.40 \times n_{c}(\mathrm{MHz}), n_{c}=0, \ldots, 59$ & 16 \\
\hline 950 to 958 & $f_{c}=951.10+0.40 \times n_{c}(\mathrm{MHz}), n_{c}=0, \ldots, 15$ & 39 \\
\hline 2360 to 2400 & $f_{c}=2361.00+1.00 \times n_{c}(\mathrm{MHz}), n_{c}=0, \ldots, 38$ & 79 \\
\hline 2400 to 2483.5 & $f_{c}=2402.00+1.00 \times n_{c}(\mathrm{MHz}), n_{c}=0, \ldots, 78$ & 78 \\
\hline
\end{tabular}

Las funciones de mapeo $\mathrm{g}_{1}(\mathrm{nc})$ y $\mathrm{g}_{2}(\mathrm{nc})$ utilizadas en las bandas de frecuencia de $420 \mathrm{MHz}$ a $450 \mathrm{MHz}$ y $863 \mathrm{MHz}$ a $870 \mathrm{MHz}$, respectivamente, se definen como se muestra en las ecuaciones (15) y (16):

$$
g_{1}\left(n_{c}\right)=\left\{\begin{array}{lr}
n_{c} & 0 \leq n_{c} \leq 1 \\
n_{c}+6.875 & 2 \leq n_{c} \leq 4 \\
n_{c}+13.4 & n_{c}=5 \\
n_{c}+35.025 & 6 \leq n_{c} \leq 7 \\
n_{c}+40.925 & 8 \leq n_{c} \leq 9 \\
n_{c}+47.25 & 10 \leq n_{c} \leq 11
\end{array}\right.
$$

y

$$
g_{2}\left(n_{c}\right)=\left\{\begin{array}{lr}
n_{c} & 0 \leq n_{c} \leq 7 \\
n_{c}+0.5 & n_{c}=8 \\
n_{c}+1 & 9 \leq n_{c} \leq 12 \\
n_{c}+1.5 & n_{c}=13
\end{array}\right.
$$

\subsection{Asignación de secuencia del preámbulo}

La relación entre el número de canal, $\mathrm{n}_{\mathfrak{c}}$, y la secuencia de preámbulo utilizada en el preámbulo de PLCP se muestra en la Tabla 14.

Tabla 14 - Relación entre el número del canal y el preámbulo [1].

\begin{tabular}{|c|c|}
\hline $\begin{array}{c}\text { Relationship between } \\
\text { preamble sequence and } \boldsymbol{n}_{c}\end{array}$ & Preamble sequence \\
\hline $\operatorname{rem}\left(n_{c}, 2\right)=0$ & 1 \\
\hline $\operatorname{rem}\left(n_{c}, 2\right)=1$ & 2 \\
\hline
\end{tabular}




\subsubsection{Sincronización de la capa PHY}

Los valores de los parámetros de temporización de la capa PHY se definen en la Tabla 15.

Tabla 15 - Parámetros de sincronización de la capa física [1].

\begin{tabular}{|c|c|}
\hline PHY parameter & Value \\
\hline pSIFS & $75 \mu \mathrm{s}$ \\
\hline pMIFS & $20 \mu \mathrm{s}$ \\
\hline pExtraIFS & $10 \mu \mathrm{s}$ \\
\hline pEDTime & 8 preamble symbols \\
\hline pCCATime & 63 preamble symbols \\
\hline pChannelSwitchTime & $100 \mu \mathrm{s}$ \\
\hline
\end{tabular}

\subsection{Duración del paquete}

La ecuación (17) proporciona la duración total (en el tiempo) de un paquete, que comprende los símbolos para el preámbulo PLCP, el PLCP header y la PSDU:

$$
t_{\text {packet }}=T_{S} \times\left[N_{\text {Preambulo }}+N_{\text {Header }} \times S_{\text {Header }}+\frac{N_{\text {Total }}}{\log _{2}(M)} \times S_{P S D U}\right]
$$

donde $T_{\mathrm{s}}, \mathrm{S}_{\text {header, }}, \mathrm{S}_{\text {PSDU y }} \mathrm{M}$ se definen en la Tabla 7 , donde $\mathrm{N}_{\text {Preambulo }}$ se definió en el capítulo 4.1.7.3, $\mathrm{N}_{\text {Header }}$ en el capítulo 4.1.7.4 y $\mathrm{N}_{\text {Total }}$ en el capítulo 4.1.7.5. S $\mathrm{S}_{\text {header }} \mathrm{Se}$ refiere al valor de S para el encabezado PLCP y SPSDU se refiere al valor de S para la velocidad de datos de la PSDU.

\subsection{Tiempo entre transmisiones sucesivas}

Para transmisiones en modo burst, el espacio entre tramas de transmisiones sucesivas ininterrumpidas por un dispositivo debe estar entre pMIFS y pMIFS + pExtraIFS. El espaciado entre tramas se define como el tiempo transcurrido desde el final de una trama en la interfaz aérea local, hasta el inicio de una trama en la interfaz aérea local. 


\subsubsection{Especificaciones del transmisor}

4.1.7.9.1. Máscara de densidad espectral de potencia (PSD)

La máscara de PSD transmitida debe ser inferior $\mathrm{a}-\mathrm{X} \mathrm{dB_{ \textrm {r } }}(\mathrm{dB}$ en relación con la densidad espectral máxima de la señal) para $f-f_{c} \geq f_{\mathrm{BW}} / 2$, donde $f_{c}$ es la frecuencia central del canal y $f_{\mathrm{BW}}$ es el ancho de banda del canal que es función de la frecuencia de trabajo como se define en la Tabla 16 y se ilustra en la Figura 44.

Tabla 16 - Ancho de banda en función de la frecuencia de trabajo [1].

\begin{tabular}{|c|c|c|}
\hline Frequency $(\mathbf{M H z})$ & $-\boldsymbol{X ~ d B r}$ & $f_{B W}$ \\
\hline 402 to 405 & -20 & $300 \mathrm{kHz}$ \\
\hline 420 to 450 & -20 & $320 \mathrm{kHz}$ \\
\hline 863 to 870 & -20 & $400 \mathrm{kHz}$ \\
\hline 902 to 928 & -20 & $400 \mathrm{kHz}$ \\
\hline 950 to 958 & -20 & $400 \mathrm{kHz}$ \\
\hline 2360 to 2400 & -20 & $1 \mathrm{MHz}$ \\
\hline 2400 to 2483.5 & -20 & $1 \mathrm{MHz}$ \\
\hline
\end{tabular}

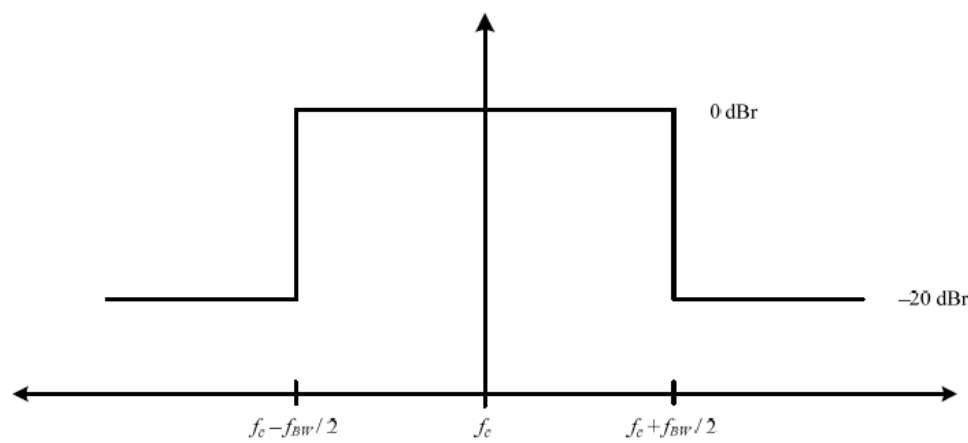

Figura 44 - Mascara espectral de transmisión para todas las bandas de frecuencia. IEEE Standard for Local and metropolitan area networks - Part 15.6: Wireless Body Area Networks.

La densidad espectral transmitida también debe cumplir con todas las regulaciones definidas por los organismos reguladores locales.

\subsection{Potencia de transmisión}

Cuando se opera en un modo low power/low duty cycle (LP/LDC) en una frecuencia central de $403.65 \mathrm{MHz}$, un transmisor debe ser capaz de transmitir a lo sumo $-40 \mathrm{dBm}$ de EIRP; cuando se opera en un modo no LP/LDC en la banda de frecuencia de $402 \mathrm{MHz}$ a $405 \mathrm{MHz}$, debe ser capaz de transmitir como máximo - $16 \mathrm{dBm}$ EIRP; en todas las demás bandas, debe ser capaz de transmitir al menos -10 dBm EIRP.

Los dispositivos deben transmitir a la potencia más baja cuando sea posible para reducir la interferencia a otros dispositivos y sistemas y proteger la seguridad del cuerpo humano. La potencia máxima de transmisión está limitada por los organismos reguladores locales. 


\subsection{Relación de potencia de canal adyacente (ACPR)}

La ACPR se define como la relación entre la potencia total en el canal adyacente y la potencia total en el canal deseado, donde el ancho de banda de medición en ambos casos es igual al ancho de banda del canal como se indica en la Tabla 15.

Un dispositivo compatible debe tener un ACPR que no sea mayor que los valores dados en la Tabla 17.

Tabla 17 - ACPR como función de la banda de operación [1].

\begin{tabular}{|c|c|c|}
\hline Frequency (MHz) & ACPR node (dB) & ACPR hub (dB) \\
\hline 402 to 405 & -26 & -32 \\
\hline 420 to 450 & -26 & -26 \\
\hline 863 to 870 & -26 & -26 \\
\hline 902 to 928 & -26 & -26 \\
\hline 950 to 958 & -26 & -26 \\
\hline 2360 to 2400 & -26 & -26 \\
\hline 2400 to 2483.5 & -26 & -26 \\
\hline
\end{tabular}

\subsubsection{Especificaciones del receptor}

\subsection{Sensibilidad del receptor}

Para una PER menor o igual al 10\% con una PSDU de 255 octetos en AWGN, un dispositivo receptor compatible deberá alcanzar las sensibilidades iguales o mejores a las enumeradas en la Tabla 18. Los niveles mínimos de entrada se miden en el conector de la antena, donde se ha asumido una figura de ruido de $13 \mathrm{~dB}$ y una pérdida de implementación de $6 \mathrm{~dB}$.

Tabla 18 - Sensibilidad del receptor [1].

\begin{tabular}{|c|c|c|}
\hline Frequency band (MHz) & Information data rate (kbps) & Maximum input level at sensitivity (dBm) \\
\hline \multirow{3}{*}{402 to 405} & 75.9 & -95 \\
\cline { 2 - 3 } & 151.8 & -92 \\
\cline { 2 - 3 } & 303.6 & -89 \\
\cline { 2 - 3 } & 455.4 & -83 \\
\hline \multirow{3}{*}{420 to 450} & 75.9 & -90 \\
\cline { 2 - 3 } & 151.8 & -87 \\
\hline \multirow{3}{*}{863 to 870} & 187.5 & -84 \\
\hline 902 to 928 & 101.2 & -94 \\
\hline 950 to 958 & 202.4 & -91 \\
\cline { 2 - 3 } & 404.8 & -87 \\
\cline { 2 - 3 } & 607.1 & -82 \\
\hline \multirow{3}{*}{2360 to 2400} & 121.4 & -92 \\
\cline { 2 - 3 } 2400 to 2483.5 & 242.9 & -90 \\
\cline { 2 - 3 } & 485.7 & -87 \\
\cline { 2 - 3 } & 971.4 & -83 \\
\hline
\end{tabular}




\subsection{Rechazo de canales adyacentes (ACR)}

El ACR se define como la relación entre la potencia de la señal interferente en el canal adyacente y la potencia de la señal deseada, cuando la intensidad de la señal de interés se establece $3 \mathrm{~dB}$ por encima de la sensibilidad dependiente de la frecuencia, y la potencia de la señal interferente se ha elevado hasta que se alcanza un 10\% de PER para una longitud de PSDU de 255 octetos. Un dispositivo compatible debe tener un ACR que no sea menor que los valores dados en la Tabla 19.

Tabla 19 - ACR en función de la banda de trabajo [1].

\begin{tabular}{|c|c|c|}
\hline Frequency band (MHz) & Information data rate (kbps) & ACR (dB) \\
\hline \multirow{4}{*}{402 to 405} & 75.9 & 17 \\
\cline { 2 - 3 } & 151.8 & 14 \\
\cline { 2 - 3 } & 303.6 & 10 \\
\cline { 2 - 3 } & 455.4 & 5 \\
\hline \multirow{3}{*}{420 to 450} & 75.9 & 12 \\
\cline { 2 - 3 } & 151.8 & 9 \\
\cline { 2 - 3 } 863 to 870 & 187.5 & 6 \\
\hline 902 to 928 & 101.2 & 17 \\
\cline { 2 - 3 } 950 to 958 & 202.4 & 14 \\
\cline { 2 - 3 } & 404.8 & 10 \\
\cline { 2 - 3 } 2360 to 2400 & 607.1 & 5 \\
\hline 2400 to 2483.5 & 121.4 & 17 \\
\cline { 2 - 3 } & 242.9 & 15 \\
\cline { 2 - 3 } & 485.7 & 13 \\
\hline & 971.4 & 9 \\
\hline
\end{tabular}




\subsection{IEEE 802.15.4}

Debido a que la intención de este trabajo es analizar los efectos del protocolo IEEE 802.15.4 sobre el IEEE802.15.6, no se profundizará en el estudio del primero. Solamente se prestó atención al tiempo que requiere el envío de cada trama, la distancia temporal que puede llegar a haber entre cada una, la potencia con la que se transmite, bandas de trabajo y anchos de banda, es lo que se abordará en este capítulo.

4.2.1. Capa de acceso al medio: Formato de trama.

\subsubsection{Descripción funcional de MAC}

\subsection{Acceso al canal}

\subsection{Estructura de supertrama}

Una supertrama está limitada por la transmisión de una trama Beacon y puede tener una porción activa y una porción inactiva.

La parte activa de cada supertrama se divide en aNumSuperframeSlots ranuras equiespaciadas de duración 2macSuperframeOrder $\times$ aBaseSlotDuration, y se compone de una beacon, un CAP y un CFP. La beacon se transmite, sin el uso de CSMA, al comienzo de la ranura 0 , y el CAP comienza inmediatamente después de la beacon. El inicio del slot 0 se define como el punto en el que se transmite el primer símbolo de la PPDU del beacon. El CFP, si está presente, sigue inmediatamente después del CAP y se extiende hasta el final de la porción activa de la supertrama. Cualquier GTS asignado se ubicará dentro de la PPC.

Un ejemplo de una estructura de supertrama se muestra en la Figura 45.

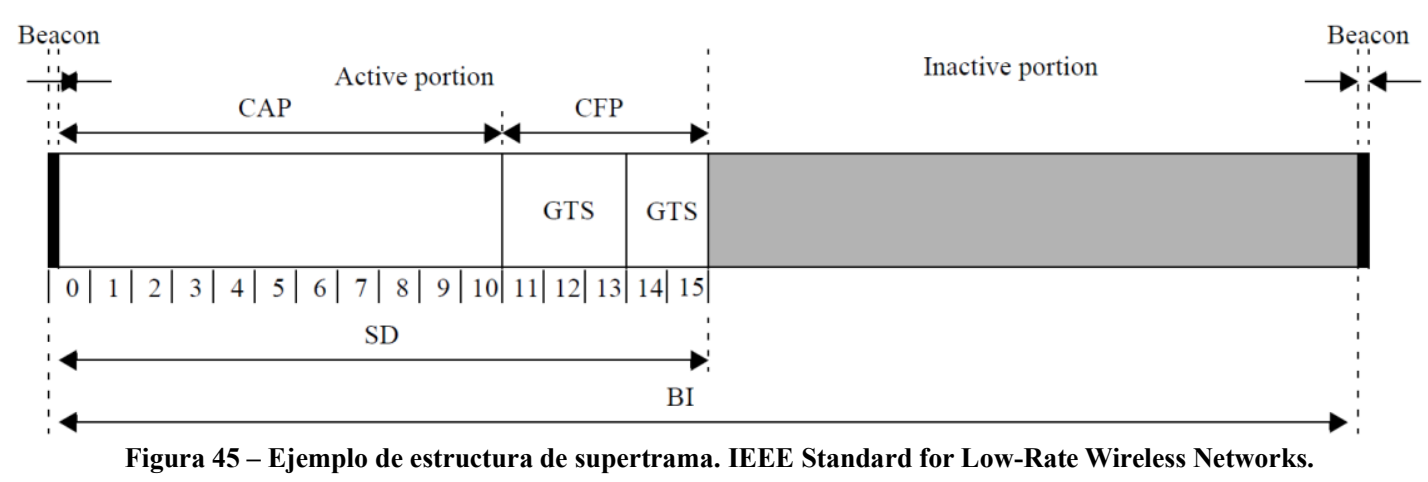




\subsection{Interfame Space (IFS)}

La subcapa MAC necesita un tiempo finito para procesar los datos recibidos por la capa PHY. Para permitir esto, dos tramas sucesivas transmitidas desde un dispositivo deben estar separadas por al menos un período IFS; si la primera transmisión requiere un acuse de recibo, la separación entre la trama Ack y la segunda transmisión será al menos el Acknowledgment Interframe Spacing (AIFS). La duración del período IFS depende del tamaño de la trama que se acaba de transmitir. Los MPDU de hasta aMaxSifsFrameSize irán seguidos de un período Short Interfame Space (SIFS) de una duración de al menos max(macSifsPeriod, aTurnaroundTime). Los MPDU con longitudes mayores que aMaxSifsFrameSize irán seguidos por el máximo de espacio Long Interframe Spacing (LIFS) de una duración de al menos max(macLifsPeriod, aTurnaroundTime). Estos conceptos se ilustran en la Figura 46.

Acknowledged transmission

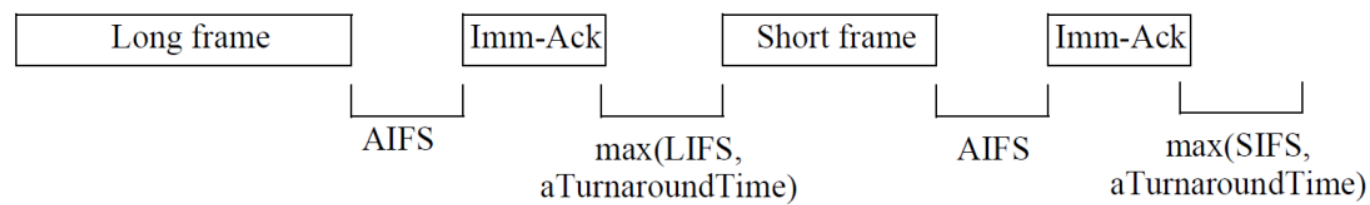

Unacknowledged transmission

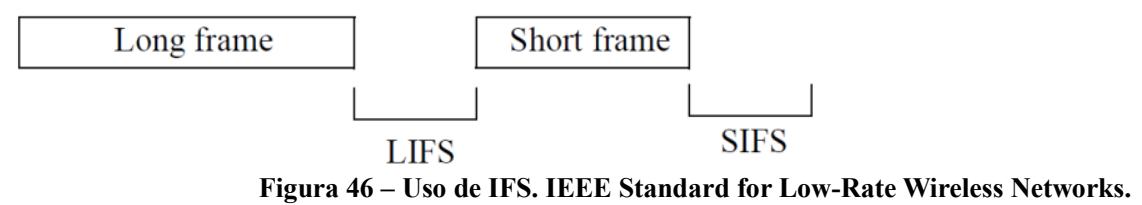

Para garantizar que haya suficiente tiempo para que el la capa PHY haga la transición de TX a RX o RX a TX, se debe cumplir la siguiente relación:

AIFS $\leq$ SIFS $<$ LIFS

aTurnaroundTime: Es el tiempo de transición de RX a TX o TX a RX (en períodos de símbolo).

Para los SUN, TVWS y LECIM FSK PHYs, el valor es $1 \mathrm{~ms}$ expresado en períodos de símbolos, redondeado al siguiente número entero de períodos de símbolos utilizando la función de techo().

Para el LECIM DSSS PHY, el valor es $1 \mathrm{~ms}$ expresado en períodos de símbolo de modulación, redondeado al siguiente número entero de períodos de símbolo utilizando la función techo().

El valor es 12 para todos los demás PHY.

AIFS: El valor de AIFS es de $1 \mathrm{~ms}$ para los PHY SUN, PHY LECIM o TVWS PHYs, y es igual a macSifsPeriod para todos los demás PHY.

Periodos mínimos LIFS y SIFS: Para todos los PHY que no sean HRP UWB PHY y RCC PHY, el período mínimo LIFS y el período SIFS son los siguientes:

macLifsPeriod: 40 símbolos

macSifsPeriod: 12 símbolos 
Para el RCC PHY, el período mínimo LIFS y el período SIFS son los siguientes: macLifsPeriod: 5 símbolos macSifsPeriod: 5 símbolos

\subsubsection{Formato general de trama $M A C$}

La trama MAC tiene un formato general como el que se ilustra en la figura 47.

\begin{tabular}{|c|c|c|c|c|c|c|c|c|c|c|}
\hline $\begin{array}{c}\text { Octets: } \\
1 / 2\end{array}$ & $0 / 1$ & $0 / 2$ & $0 / 2 / 8$ & $0 / 2$ & $0 / 2 / 8$ & variable & \multicolumn{2}{|c|}{ variable } & variable & $2 / 4$ \\
\hline \multirow{2}{*}{ 影 } & \multirow{2}{*}{ 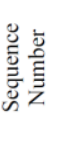 } & 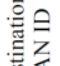 & 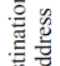 & : & 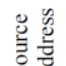 & \multirow{2}{*}{ 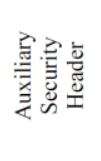 } & \multicolumn{2}{|c|}{ IE } & \multirow{2}{*}{ 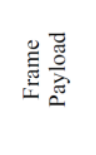 } & \multirow{2}{*}{ U. } \\
\hline & & & Addre & ing fie & & & Header IEs & Payload IEs & & \\
\hline \multicolumn{8}{|c|}{ MHR } & \multicolumn{2}{|c|}{ MAC Payload } & MFR \\
\hline
\end{tabular}

Figura 47 - Formato general de trama MAC. IEEE Standard for Low-Rate Wireless Networks.

Los campos del MHR aparecen en un orden fijo; sin embargo, dependiendo del tipo de trama, algunos puede que no estén incluidos en todas las tramas.

\subsubsection{Formato individual del tipo de trama}

\subsection{Formato de trama Beacon}

Según la versión de la trama, el beacon puede ser simple (como lo representa la figura 48) o mejorado (como se representa en la figura 49).

\begin{tabular}{|c|c|c|c|c|c|c|c|c|}
\hline Octets: $\mathbf{2}$ & $\mathbf{1}$ & $\mathbf{4 / 1 0}$ & variable & $\mathbf{2}$ & variable & variable & variable & $\mathbf{2 / 4}$ \\
\hline $\begin{array}{c}\text { Frame } \\
\text { Control }\end{array}$ & $\begin{array}{c}\text { Sequence } \\
\text { Number }\end{array}$ & $\begin{array}{c}\text { Addressing } \\
\text { fields }\end{array}$ & $\begin{array}{c}\text { Auxiliary } \\
\text { Security } \\
\text { Header }\end{array}$ & $\begin{array}{c}\text { Superframe } \\
\text { Specification }\end{array}$ & $\begin{array}{c}\text { GTS } \\
\text { Info }\end{array}$ & $\begin{array}{c}\text { Pending } \\
\text { address }\end{array}$ & $\begin{array}{c}\text { Beacon } \\
\text { Payload }\end{array}$ & FCS \\
\hline \multicolumn{7}{|c|}{ MHR } & \multicolumn{5}{c|}{ MAC Payload } & MFR \\
\hline
\end{tabular}

Figura 48 - Formato de trama Beacom [2]

\begin{tabular}{|c|c|c|c|c|c|c|c|}
\hline Octets: 2 & $0 / 1$ & variable & variable & \multicolumn{2}{|c|}{ variable } & variable & $2 / 4$ \\
\hline \multirow{2}{*}{$\begin{array}{l}\text { Frame } \\
\text { Control }\end{array}$} & \multirow{2}{*}{$\begin{array}{l}\text { Sequence } \\
\text { Number }\end{array}$} & \multirow{2}{*}{$\begin{array}{l}\text { Addressing } \\
\text { fields }\end{array}$} & \multirow{2}{*}{$\begin{array}{c}\text { Auxiliary } \\
\text { Security } \\
\text { Header }\end{array}$} & \multicolumn{2}{|c|}{ IEs } & \multirow{2}{*}{$\begin{array}{l}\text { Beacon } \\
\text { Payload }\end{array}$} & \multirow{2}{*}{$\mathrm{FCS}$} \\
\hline & & & & Header IEs & Payload IEs & & \\
\hline \multicolumn{5}{|c|}{ MHR } & \multicolumn{2}{|c|}{ MAC Payload } & MFR \\
\hline
\end{tabular}

Figura 49 - Formato de trama Enaced Beacom. IEEE Standard for Low-Rate Wireless Networks. 


\subsection{Formato de trama de datos}

La trama de datos debe tener un formato como el de la figura 50.

\begin{tabular}{|c|c|c|c|c|c|c|c|}
\hline Octets: 2 & $0 / 1$ & variable & variable & \multicolumn{2}{|c|}{ variable } & variable & $2 / 4$ \\
\hline \multirow{2}{*}{$\begin{array}{l}\text { Frame } \\
\text { Control }\end{array}$} & \multirow{2}{*}{$\begin{array}{l}\text { Sequence } \\
\text { Number }\end{array}$} & \multirow{2}{*}{$\begin{array}{l}\text { Addressing } \\
\text { fields }\end{array}$} & \multirow{2}{*}{$\begin{array}{c}\text { Auxiliary } \\
\text { Security } \\
\text { Header }\end{array}$} & \multicolumn{2}{|c|}{ IEs } & \multirow{2}{*}{ Data Payload } & \multirow{2}{*}{$\mathrm{FCS}$} \\
\hline & & & & Header IEs & Payload IEs & & \\
\hline \multicolumn{5}{|c|}{ MHR } & \multicolumn{2}{|c|}{ MAC Payload } & MFR \\
\hline
\end{tabular}

Figura 50 - Formato de trama de datos. IEEE Standard for Low-Rate Wireless Networks.

\subsection{Campo MHR de la trama de datos}

El campo Frame Type debe contener el valor que indica una trama de datos. El campo Security Enabled se establecerá en uno si la seguridad está habilitada y el campo Frame Version es distinto de cero. Todos los demás campos del Frame Control se establecerán adecuadamente de acuerdo con el uso previsto de la trama de datos.

El campo Número de secuencia, si está presente, contendrá el valor actual de macDsn. Si la versión de trama es $0 \mathrm{~b} 10$, el número de secuencia se puede suprimir configurando el campo Sequence Number Suppression en el campo Frame Control.

Los campos de direccionamiento comprenden la dirección de destino y/o de origen, según la configuración en el campo Frame Control.

El campo de Auxiliary Security Header, si está presente, contendrá la información requerida para el procesamiento de seguridad de la trama de datos.

\subsection{Formato de trama ACK}

El formato de trama Ack se usa tanto para un marco Imm-Ack como para un marco EnhAck. El tipo de trama Ack está determinado por el valor del campo Versión de la trama.

Una trama Imm-Ack tendrá un formato como el de la figura 51.

\begin{tabular}{|c|c|c|}
\hline Octets: 2 & $\mathbf{1}$ & $\mathbf{2} / \mathbf{4}$ \\
\hline Frame Control & Sequence Number & FCS \\
\hline \multicolumn{2}{|c|}{ MHR } & MFR \\
\hline
\end{tabular}

Figura 51 - Formato de trama Imm-Ack. IEEE Standard for Low-Rate Wireless Networks. 
Una trama Enh-Ack tendrá un formato como el de la figura 52.

\begin{tabular}{|c|c|c|c|c|c|c|c|c|c|c|}
\hline Octets:2 & $0 / 1$ & $0 / 2$ & $0 / 2 / 8$ & $0 / 2$ & $0 / 2 / 8$ & variable & \multicolumn{2}{|c|}{ variable } & variable & $2 / 4$ \\
\hline \multirow{2}{*}{ 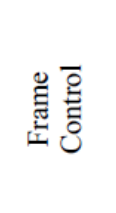 } & \multirow{2}{*}{ 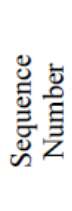 } & 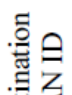 & 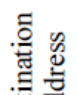 & 异目 & 总 & \multirow{2}{*}{ 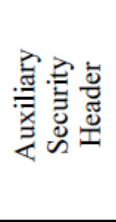 } & \multicolumn{2}{|c|}{ IE } & \multirow{2}{*}{ 茎䒿 } & \multirow{2}{*}{ D્ટ } \\
\hline & & \multicolumn{4}{|c|}{ Addressing fields } & & Header IEs & Payload IEs & & \\
\hline \multicolumn{8}{|c|}{ MHR } & \multicolumn{2}{|c|}{ MAC Payload } & MFR \\
\hline
\end{tabular}

Figura 52 - Formato de trama Enh-Ack. IEEE Standard for Low-Rate Wireless Networks.

\subsection{Formato de trama de comando MAC}

El formato de trama de comando MAC está representado en la figura 53.

\begin{tabular}{|c|c|c|c|c|c|c|c|c|}
\hline Octets: 2 & $0 / 1$ & variable & variable & \multicolumn{2}{|c|}{ variable } & 1 & variable & $2 / 4$ \\
\hline \multirow{2}{*}{$\begin{array}{l}\text { Frame } \\
\text { Control }\end{array}$} & \multirow{2}{*}{$\begin{array}{l}\text { Sequence } \\
\text { Number }\end{array}$} & \multirow{2}{*}{$\begin{array}{c}\text { Addressing } \\
\text { fields }\end{array}$} & \multirow{2}{*}{$\begin{array}{c}\text { Auxiliary } \\
\text { Security } \\
\text { Header }\end{array}$} & \multicolumn{2}{|c|}{ IE } & \multirow{2}{*}{$\begin{array}{l}\text { Command } \\
\text { ID }\end{array}$} & \multirow{2}{*}{ Content } & \multirow{2}{*}{ FCS } \\
\hline & & & & Header IEs & Payload IEs & & & \\
\hline \multicolumn{5}{|c|}{ MHR } & \multicolumn{3}{|c|}{ MAC Payload } & MFR \\
\hline
\end{tabular}

Figura 53 - Formato de trama de comando MAC [2].

\subsection{Campo MHR}

El campo Sequence Number, si está presente, contendrá el valor actual de macDsn. Si la versión de la trama es $0 \mathrm{~b} 10$, el Sequence Number se puede suprimir configurando el Sequence Number Suppression de la secuencia en el campo Frame Control.

Los campos de direccionamiento comprenderán los campos de dirección de destino y/o los campos de dirección de origen, según la configuración en el campo Frame Control.

El campo Auxiliary Security Header, si está presente, contendrá la información requerida para el procesamiento de seguridad del comando MAC.

\subsection{Formato de trama multipropósito}

El tipo de trama multipropósito tiene un formato flexible que puede usarse para una variedad de propósitos. El formato admite una forma corta y larga del campo Frame Control, y permite que todos los campos en el MHR estén presentes u omitidos según lo especificado por el servicio generador. 
La trama multipropósito tendrá un formato como el de la figura 54.

\begin{tabular}{|c|c|c|c|c|c|c|c|c|c|}
\hline $\begin{array}{c}\text { Octets: } \\
1 / 2\end{array}$ & $0 / 1$ & $0 / 2$ & $0 / 2 / 8$ & $0 / 2 / 8$ & variable & \multicolumn{2}{|c|}{ variable } & variable & $2 / 4$ \\
\hline \multirow{2}{*}{ 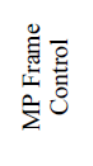 } & \multirow{2}{*}{ 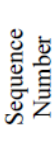 } & 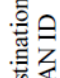 & 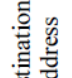 & 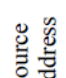 & \multirow{2}{*}{ 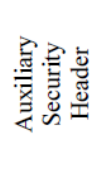 } & \multicolumn{2}{|c|}{ IE } & \multirow{2}{*}{ 氶 } & \multirow{2}{*}{ z } \\
\hline & & \multicolumn{3}{|c|}{ Addressing fields } & & Header IEs & Payload IEs & & \\
\hline \multicolumn{7}{|c|}{ MHR } & \multicolumn{2}{|c|}{ MAC Payload } & MFR \\
\hline
\end{tabular}

Figura 54 - Formato de trama multipropósito. IEEE Standard for Low-Rate Wireless Networks.

\subsection{Formato de trama extendido}

La trama extendida tiene un formato como el de la figura 55.

\begin{tabular}{|c|c|c|}
\hline Bits: $\mathbf{0 - 2}$ & $\mathbf{3 - 5}$ & variable \\
\hline Frame Type & Extended Frame Type & Extended Frame Payload \\
\hline
\end{tabular}

Figura 55 - Formato de trama extendida. IEEE Standard for Low-Rate Wireless Networks.

El campo Extended Frame Type se usa para especificar tipos de trama adicionales agregando bits adicionales al campo Frame Type.

\subsubsection{IE}

\subsection{Header IE}

El Header IE debe tener un formato como el de la figura 56:

\begin{tabular}{|c|c|c|c|}
\hline Bits: 0-6 & $\mathbf{7 - 1 4}$ & $\mathbf{1 5}$ & Octets: 0-127 \\
\hline Length & Element ID & Type $=0$ & Content \\
\hline
\end{tabular}

Figura 56 - Formato del Header IEs. IEEE Standard for Low-Rate Wireless Networks.

El campo Lengh especifica el número de octetos en el campo Content.

El campo Element ID se definen se define para cada Header IE. Dependiendo del tipo de trama, este campo puede ser usado o no. 


\subsubsection{Payload IE}

El formato general del Payload IE es como el que se muestra en la figura 57:

\begin{tabular}{|c|c|c|c|}
\hline Bits: 0-10 & 11-14 & $\mathbf{1 5}$ & Octets: 0-2047 \\
\hline Length & Group ID & Type $=1$ & Content \\
\hline
\end{tabular}

El campo Lengh especifica el número de octetos en el campo Content.

Los valores de Group ID se definen para cada uno de los Payloads IEs. Dependiendo del tipo de trama, este campo puede ser usado o no.

\subsubsection{Capa física: Requerimientos generales.}

\subsubsection{Requisitos generales y definiciones.}

A menos que se especifique lo contrario, todos los PHY usan un FCS de 2 octetos.

IEEE802.15.4 usara un esquema de modulación según la banda de trabajo. Para el caso de interés del presente trabajo, la norma define:

O-QPSK PHY: Direct Sequence Spread Spectrum (DSSS) PHY que emplea Offset Quadrature Phaseshift Keying (O-QPSK), operando en las bandas de $780 \mathrm{MHz}, 868 \mathrm{MHz}$, $915 \mathrm{MHz}, 2380 \mathrm{MHz}$ y $2450 \mathrm{MHz}$.

CSS PHY: Chirp Spread Spectrum (CSS) que emplea Differential Quadrature PhaseShift Keying (DQPSK) en la banda de $2450 \mathrm{MHz}$.

MSK PHY: Minimum Shift Keying (MSK) PHY.

SUN FSK PHY: Operando con modulación FSK a múltiples velocidades de transmisión de datos para aplicaciones SUN.

LECIM DSSS PHY: Funcionando con modulación DSS con características que permiten el soporte de aplicaciones LECIM.

\subsubsection{Rango de frecuencia de funcionamiento}

Un dispositivo compatible debe operar por lo menos en una o varias bandas de frecuencia indicadas en las tablas 20, 21 y 22 .

Para dispositivos que no sean LECIM, TVWS y RCC PHY, las bandas de frecuencia se enumeran en la Tabla 20. 
Tabla 20 - Designación de bandas y frecuencias [2].

\begin{tabular}{|c|c|}
\hline Band designation & Frequency band (MHz) \\
\hline $169 \mathrm{MHz}$ & $169.400-169.475$ \\
\hline $433 \mathrm{MHz}$ & $433.05-434.79$ \\
\hline $450 \mathrm{MHz}$ & $450-470$ \\
\hline $470 \mathrm{MHz}$ & $470-510$ \\
\hline $780 \mathrm{MHz}$ & $779-787$ \\
\hline $863 \mathrm{MHz}$ & $863-870$ \\
\hline $868 \mathrm{MHz}$ & $868-868.6$ \\
\hline $896 \mathrm{MHz}$ & $896-901$ \\
\hline $901 \mathrm{MHz}$ & $901-902$ \\
\hline $915 \mathrm{MHz}$ & $902-928$ \\
\hline $917 \mathrm{MHz}$ & $917-923.5$ \\
\hline $920 \mathrm{MHz}$ & $920-928$ \\
\hline $928 \mathrm{MHz}$ & $928-960^{\mathrm{a}}$ \\
\hline $1427 \mathrm{MHz}$ & $1427-1518^{\mathrm{a}}$ \\
\hline $2380 \mathrm{MHz}$ & $2360-2400$ \\
\hline $2450 \mathrm{MHz}$ & $2400-2483.5$ \\
\hline HRP UWB sub-gigahertz & $250-750$ \\
\hline HRP UWB low band & $3244-4742$ \\
\hline HRP UWB high band & $5944-10234$ \\
\hline LRP UWB & $6289.6-9185.6$ \\
\hline
\end{tabular}

Noncontiguous

Las bandas de frecuencia para dispositivos compatibles con LECIM DSSS PHY se muestran en la Tabla 21. 
Tabla 21 - Rangos de frecuencia de funcionamiento de LECIM DSSS PHY (Continuación) [2].

\begin{tabular}{|c|c|c|c|}
\hline \multirow{10}{*}{$917 \mathrm{MHz}$} & \multirow{2}{*}{200} & BPSK & 200 \\
\hline & & O-QPSK & 400 \\
\hline & \multirow{2}{*}{400} & BPSK & 400 \\
\hline & & O-QPSK & 800 \\
\hline & \multirow{2}{*}{600} & BPSK & 600 \\
\hline & & O-QPSK & 1200 \\
\hline & \multirow{2}{*}{800} & BPSK & 800 \\
\hline & & O-QPSK & 1600 \\
\hline & \multirow{2}{*}{1000} & BPSK & 1000 \\
\hline & & O-QPSK & 2000 \\
\hline \multirow{10}{*}{$920 \mathrm{MHz}$} & \multirow{2}{*}{200} & BPSK & 200 \\
\hline & & O-QPSK & 400 \\
\hline & \multirow{2}{*}{400} & BPSK & 400 \\
\hline & & O-QPSK & 800 \\
\hline & \multirow{2}{*}{600} & BPSK & 600 \\
\hline & & O-QPSK & 1200 \\
\hline & \multirow{2}{*}{800} & BPSK & 800 \\
\hline & & O-QPSK & 1600 \\
\hline & \multirow{2}{*}{1000} & BPSK & 1000 \\
\hline & & O-QPSK & 2000 \\
\hline \multirow{10}{*}{$921 \mathrm{MHz}$} & \multirow{2}{*}{200} & BPSK & 200 \\
\hline & & O-QPSK & 400 \\
\hline & \multirow{2}{*}{400} & BPSK & 400 \\
\hline & & O-QPSK & 800 \\
\hline & \multirow{2}{*}{600} & BPSK & 600 \\
\hline & & O-QPSK & 1200 \\
\hline & \multirow{2}{*}{800} & BPSK & 800 \\
\hline & & O-QPSK & 1600 \\
\hline & \multirow{2}{*}{1000} & BPSK & 1000 \\
\hline & & O-QPSK & 2000 \\
\hline \multirow{2}{*}{$2450 \mathrm{MHz}$} & \multirow{2}{*}{1000} & BPSK & 1000 \\
\hline & & O-QPSK & 2000 \\
\hline
\end{tabular}

Las bandas de frecuencia para dispositivos que admiten los RCC PHY se muestran en la Tabla 23. 


\begin{tabular}{|c|c|c|}
\hline Band designation & Frequency range $(\mathrm{MHz})$ & Modulation and bit rate \\
\hline $161 \mathrm{MHz}$ & $160.170-161.580$ & \multirow{4}{*}{$\begin{array}{l}\text { LMR GMSK: } 9.6 / 19.2 \mathrm{~kb} / \mathrm{s} \\
\text { LMR 4-FS } 9.6 / 19.2 / 38.4 \mathrm{~kb} / \mathrm{s} \\
\text { LMR QPSK: } 16 / 32 \mathrm{~kb} / \mathrm{s} \\
\text { LMR } \pi / 4 \text { DQPSK: } 16 / 32 / 36 \mathrm{~kb} / \mathrm{s}\end{array}$} \\
\hline $216 \mathrm{MHz}$ & $216-217$ & \\
\hline $217 \mathrm{MHz}$ & $217-220$ & \\
\hline $220 \mathrm{MHz}$ & $220-222$ & \\
\hline $450 \mathrm{MHz}$ & $450-470$ & $\begin{array}{l}\text { LMR GMSK: } 9.6 / 19.2 \mathrm{~kb} / \mathrm{s} \\
\text { LMR 4-FSK: } 9.6 / 19.2 / 38.4 \mathrm{~kb} / \mathrm{s} \\
\text { LMR QPSK: } 16 / 32 \mathrm{~kb} / \mathrm{s} \\
\text { LMR } \pi / 4 \text { DQPSK: } 1132 / 36 \mathrm{~kb} / \mathrm{s}\end{array}$ \\
\hline $770 \mathrm{MHz}$ & $769-775$ & \multirow{3}{*}{$\begin{array}{l}\text { LMR GMSK: } 9.6 / 19.2 \mathrm{~kb} / \mathrm{s} \\
\text { LMR 4-FSK : } 9.6 / 19.2 / 38.4 \mathrm{~kb} / \mathrm{s} \\
\text { LMR QPSK } 16 / 32 \mathrm{~kb} / \mathrm{s} \\
\text { LMR } \pi / 4 \text { DQPSK: } 16 / 32 / 36 \mathrm{~kb} / \mathrm{s}\end{array}$} \\
\hline $800 \mathrm{MHz}$ & 799-805 & \\
\hline $806 \mathrm{MHz}$ & $\begin{array}{l}806-821 \\
851-866\end{array}$ & \\
\hline $896 \mathrm{MHz}$ & $\begin{array}{l}896-901 \\
935-940\end{array}$ & $\begin{array}{l}\text { LMR GMSK: } 9.6 / 19.2 \mathrm{~kb} / \mathrm{s} \\
\text { LMR 4-FSK: } 9.6 / 19.2 / 38.4 \mathrm{~kb} / \mathrm{s} \\
\text { LMR QPSK: } 16 / 32 \mathrm{~kb} / \mathrm{s} \\
\text { LMR } \pi / 4 \text { DQPSK: } 16 / 32 / 36 \mathrm{~kb} / \mathrm{s}\end{array}$ \\
\hline $915 \mathrm{MHz}$ & $902-928$ & $\begin{array}{l}\text { LMR GMSK: } 9.6 / 19.2 \mathrm{~kb} / \mathrm{s} \\
\text { LMR 4-FSK: } 9.6 / 19.2 / 38.4 \mathrm{~kb} / \mathrm{s} \\
\text { LMR QPSK: } 16 / 32 \mathrm{~kb} / \mathrm{s} \\
\text { LMR } \pi / 4 \text { DQPSK: } 16 / 32 / 36 \mathrm{~kb} / \mathrm{s} \\
\text { LMR DSSS DPSK } \\
\text { LMR DSSS BPSK }\end{array}$ \\
\hline $928 \mathrm{MHz}$ & $928-960$ & $\begin{array}{l}\text { LMR GMSK: } 9.6 / 19.2 \mathrm{~kb} / \mathrm{s} \\
\text { LMR 4-FSK: } 9.6 / 19.2 / 38.4 \mathrm{~kb} / \mathrm{s} \\
\text { LMR QPSK: } 16 / 32 \mathrm{~kb} / \mathrm{s} \\
\text { LMR } \pi / 4 \text { DQPSK: } 16 / 32 / 36 \mathrm{~kb} / \mathrm{s}\end{array}$ \\
\hline $2450 \mathrm{MHz}$ & $2400-2483.5$ & LMR DSSS BPSK \\
\hline $4965 \mathrm{MHz}$ & $4940-4990$ & $\begin{array}{l}\text { LMR DSSS DPSK } \\
\text { LMR DSSS BPSK }\end{array}$ \\
\hline $5800 \mathrm{MHz}$ & $5725-5850$ & $\begin{array}{l}\text { LMR DSSS DPSK } \\
\text { LMR DSSS BPSK }\end{array}$ \\
\hline
\end{tabular}

\subsubsection{Asignación de canales}

Las asignaciones de canales se definen mediante una combinación del número de canales y páginas de canales.

Para cada PHY admitido, un dispositivo compatible deberá admitir todos los canales permitidos por las regulaciones para la región en la que opera el dispositivo.

\section{Numeración de canales para bandas de 868 MHz, 915 MHz y 2450 MHz.}

Esta subcláusula no se aplica a las especificaciones SUN PHY o LECIM PHY. Para obtener explicaciones sobre la numeración de canales para los PHY SUN y los PHY LECIM.

Para la página cero del canal, hay 16 canales disponibles en la banda de $2450 \mathrm{MHz}, 10$ en la banda de $915 \mathrm{MHz}$ y 1 en la banda de $868 \mathrm{MHz}$. Esta página de canales admite los canales definidos en la edición 2003 de este estándar IEEE802.15.4. La frecuencia central de estos canales se define de la siguiente manera: 
$F_{c}=868,3[\mathrm{MHz}]$, para $\mathrm{k}=0$

$F_{c}=906+2(k-1)[\mathrm{MHz}]$, para $\mathrm{k}=1,2, \ldots, 10$

$F_{c}=2405+5(k-11)[M H z]$, para $\mathrm{k}=11,12, \ldots, 26$

Donde $k$ es el número de canal.

\section{Numeración de canales para CSS PHY}

El CSS PHY los números de canal definidos en la ecuación (20). Diferentes subconjuntos de estos canales de frecuencia están disponibles en diferentes regiones del mundo.

$F_{c}=2412+5 k[M H z]$, para $\mathrm{k}=0,1,2, \ldots, 13$

\section{Numeración de canales para MSK en la banda 2450 MHz}

Para MSK en la banda de $2450 \mathrm{MHz}$, se utiliza la página de canal 7 con los números de canal definidos en la ecuación (21). Un total de 42 canales numerados del 15 al 56 están disponibles en la banda de $2400 \mathrm{MHz}$ a 2483.5 MHz. Diferentes subconjuntos de estos canales de frecuencia están disponibles en diferentes regiones del mundo. Los receptores compatibles deberán implementar todos estos canales.

$$
F_{c}=\left\{\begin{array}{lr}
2401,75+2(k-15)[M H z] & \text { para } k=15,16, \ldots, 25 \\
2422,50[\mathrm{MHz}] & \text { para } k=26 \\
2423,25[\mathrm{MHz}] & \text { para } k=27 \\
2425,75+2(k-28)[\mathrm{MHz}] & \text { para } k=28,29, \ldots, 35 \\
2442,00[\mathrm{MHz}] & \text { para } k=36 \\
2443,75+2(k-37)[\mathrm{MHz}] & \text { para } k=37,38, \ldots, 45 \\
2462,00[\mathrm{MHz}] & \text { para } k=46 \\
2463,75+2(k-47)[\mathrm{MHz}] & \text { para } k=47,47, \ldots, 56
\end{array}\right.
$$

\section{Numeración de canales para SUN y TVWS}

La frecuencia central del canal ChanCenterFreq para todos los SUN y TVWS, excepto el S-O-QPSK que opera en la banda de $868-870 \mathrm{MHz}$, se derivará de la siguiente manera:

ChanCenterFreq $=$ ChanCenterFreq0 + NumChan $\times$ ChanSpacing

dónde 
ChanCenterFreq0 es la frecuencia central del primer canal.

ChanSpacing es la separación entre canales adyacentes.

NumChan es el número de canal de 0 a TotalNumChan-1

TotalNumChan es el número total de canales para la banda de frecuencia disponible.

Los parámetros ChanSpacing, TotalNumChan y ChanCenterFreq0 para diferentes bandas de frecuencia y esquemas de modulación se especifican en la Tabla 23.

Tabla 23 - Numeración decanales para SUN [2].

\begin{tabular}{|c|c|c|c|c|}
\hline $\begin{array}{l}\text { Frequency band } \\
\quad(\mathrm{MHz})\end{array}$ & Modulation & $\begin{array}{l}\text { Chanspacing } \\
\text { (MHz) }\end{array}$ & TotalNumChan & $\begin{array}{c}\text { ChanCenterFreq, } \\
(\mathrm{MHz})\end{array}$ \\
\hline \multirow[t]{7}{*}{$917-923.5$} & OFDM Option4 & 0.2 & 32 & 917.1 \\
\hline & OFDM Option 3 & 0.4 & 16 & 917.3 \\
\hline & OFDM Option2 & 0.8 & 8 & 917.5 \\
\hline & OFDM Optionl & 1.2 & 5 & 917.9 \\
\hline & SUN FSK operating mode \#1 & 0.2 & 32 & 917.1 \\
\hline & $\begin{array}{l}\text { SUN FSK operating mode } \# 2 \& \\
\# 3\end{array}$ & 0.4 & 16 & 917.3 \\
\hline & O-QPSK & 2 & 3 & 918.1 \\
\hline \multirow[t]{8}{*}{$920-928$} & SUN FSK operating mode \#1 & 0.2 & 38 & 920.6 \\
\hline & SUN FSK operating mode $\# 2$ & 0.4 & 18 & 920.9 \\
\hline & $\begin{array}{l}\text { SUN FSK operating mode \#3 \& } \\
\# 4\end{array}$ & 0.6 & 12 & 920.8 \\
\hline & OFDM Option 4 & 0.2 & 39 & 920.2 \\
\hline & OFDM Option3 & 0.4 & 19 & 920.4 \\
\hline & OFDM Option2 & 0.8 & 9 & 920.8 \\
\hline & OFDM Optionl & 1.2 & 6 & 921.2 \\
\hline & O-QPSK & 0.2 & 38 & 920.6 \\
\hline \multirow[t]{3}{*}{ 928-960 } & SUN FSK operating mode $\#^{2}$ & 0.0125 & 2559 & 928.0125 \\
\hline & SUN FSK operating mode $\# 2^{b}$ & 0.0125 & 2557 & 928.025 \\
\hline & SUN FSK operating mode $\# 3^{c}$ & 0.0125 & 2553 & 928.05 \\
\hline \multirow[t]{3}{*}{$1427-1518$} & SUN FSK operating mode $\# 1^{2}$ & 0.0125 & 7279 & 1427.0125 \\
\hline & SUN FSK operating mode $\# 2^{b}$ & 0.0125 & 7277 & 1427.025 \\
\hline & SUN FSK operating mode $\# 3^{c}$ & 0.0125 & 7273 & 1427.05 \\
\hline \multirow[t]{7}{*}{$2400-2483.5$} & SUN FSK operating mode \#1 & 0.2 & 416 & 2400.2 \\
\hline & $\begin{array}{l}\text { SUN FSK operating mode } \# 2 \& \\
\# 3\end{array}$ & 0.4 & 207 & 2400.4 \\
\hline & OFDM Option4 & 0.2 & 416 & 2400.2 \\
\hline & OFDM Option3 & 0.4 & 207 & 2400.4 \\
\hline & OFDM Option2 & 0.8 & 97 & 2400.8 \\
\hline & OFDM Optionl & 1.2 & 64 & 2401.2 \\
\hline & O-QPSK & 5 & 16 & 2405 \\
\hline
\end{tabular}

Two adjacent ChanSpacing(s) are aggregated to form an overlapping channel with bandwidth of $25 \mathrm{kHz}$.

'Eight adjacent Chan Spacing(s) are aggregated to form an overlapping chamnel with bandwidth of $100 \mathrm{kHz}$

Nota: El documento del standard IEEE802.15.4 tiene una tabla más completa. 


\section{Numeración de canales para LECIM DSSS}

La frecuencia central del canal, ChanCenterFreq, para todas las bandas de frecuencia LECIM DSSS se derivará de la siguiente manera:

$$
\begin{gathered}
\text { ChanCenterFreq }=\text { FreqBandEdge }+ \text { FreqOffset }+ \\
(\text { phyCurrentChannel }-1) \times \text { ChanSpacing }
\end{gathered}
$$

dónde

ChanCenterFreq

FreqBandEdge

(phyLecimCurrentBand)

FreqOffset

phyCurrentChannel es el número de identificador de canal designado de 1 a $N$

ChanSpacing es la separación entre canales adyacentes (phyChannelSpacing)

Los parámetros FreqBandEdge, FreqOffset, ChanSpacing y el rango de números de canal

Tabla 24 - Banda de frecuencia, desplazamiento de banda de frecuencia y espacio entre canales para LECIM DSSS PHY [2].

\begin{tabular}{|c|c|c|c|c|}
\hline \multirow{2}{*}{$\begin{array}{c}\text { Band } \\
\text { designation }\end{array}$} & $\begin{array}{c}\text { FreqBandEdge } \\
(\mathbf{M H z})\end{array}$ & $\begin{array}{c}\text { FreqOffset } \\
(\mathbf{M H z})\end{array}$ & $\begin{array}{c}\text { ChanSpacing } \\
(\mathbf{M H z})\end{array}$ & $\begin{array}{c}\text { phy CurrentChannel } \\
\text { range }\end{array}$ \\
\hline \multirow{2}{*}{$433 \mathrm{MHz}$} & 433 & 0.17 & 0.1 & $1-16$ \\
\hline & 433 & 0.22 & 0.2 & $1-8$ \\
\hline $470 \mathrm{MHz}$ & 470 & 0.2 & 0.2 & $1-199$ \\
\hline $780 \mathrm{MHz}$ & 779 & 0.2 & 0.2 & $1-39$ \\
\hline $863 \mathrm{MHz}$ & 863 & 0.075 & 0.1 & $1-69$ \\
\hline & 863 & 0.125 & 0.2 & $1-34$ \\
\hline $915 \mathrm{MHz}$ & 902 & 0.2 & 0.2 & $1-129$ \\
\hline $917 \mathrm{MHz}$ & 917 & 0.1 & 0.2 & $1-32$ \\
\hline $920 \mathrm{MHz}$ & 920 & 0.6 & 0.2 & $1-36$ \\
\hline $921 \mathrm{MHz}$ & 921 & 0.2 & 0.2 & $1-34$ \\
\hline $922 \mathrm{MHz}$ & 915 & 0.2 & 0.2 & $1-64$ \\
\hline $2450 \mathrm{MHz}$ & 2400 & 0.2 & 0.2 & $1-416$ \\
\hline
\end{tabular}

phyCurrentChannel válidos para cada banda de frecuencia se enumeran en la Tabla 24.

\section{Numeración de canales para RCC PHY}

Las regulaciones aplicables se utilizan para definir la numeración de canales donde se indica en la Tabla 26. Para todas las demás bandas, la frecuencia central del canal, ChanCenterFreq, para un RCC se derivará de la siguiente manera:

$$
\text { ChanCenterFreq }=\text { ChanCenterFreq0 }+ \text { NumChan } \times \text { ChanSpacing }
$$

dónde 
ChanCenterFreq0

ChanSpacing

NumChan

TotalNumChan disponible.

es la frecuencia central del primer canal.

es la separación entre canales adyacentes.

es el número de canal de 0 a TotalNumChan - 1

es el número total de canales para la banda de frecuencia

Los parámetros ChanSpacing, TotalNumChan y ChanCenterFreq0 para cada banda de frecuencia se especifican en la Tabla 26, que se aplica a todos los esquemas de modulación RCC.

Table 25 - Información de numeración del canal RCC PHY [2].

\begin{tabular}{|c|c|c|c|}
\hline Band designation & $\begin{array}{c}\text { ChanSpacing } \\
\text { (MHz) }\end{array}$ & TotalNumChan & $\begin{array}{c}\text { ChanCenterFreq } \\
\text { (MHz) }\end{array}$ \\
\hline $161 \mathrm{MHz}$ & 0.0075 & 187 & 160.1775 \\
\hline $216 \mathrm{MHz}$ & 0.00625 & 159 & 216.00625 \\
\hline $217 \mathrm{MHz}$ & 0.00625 & 479 & 217.00625 \\
\hline $220 \mathrm{MHz}$ & 0.005 & 400 & 220.0025 \\
\hline $450 \mathrm{MHz}$ & 0.00625 & 3199 & 450.00625 \\
\hline $770 \mathrm{MHz}$ & 0.00625 & 960 & 769.003125 \\
\hline $800 \mathrm{MHz}$ & 0.00625 & 960 & 799.003125 \\
\hline $806 \mathrm{MHz}$ & As defined in 47 CFR, Part 90, Subpart S, Section 90.613 \\
\hline $896 \mathrm{MHz}$ & As defined in 47 CFR, Part 90, Subpart S, Section 90.613 \\
\hline $915 \mathrm{MHz}$ & 0.500 & 51 & 902.500 \\
\hline $928 \mathrm{MHz}$ & 0.00625 & 5119 & 928.0125 \\
\hline $2450 \mathrm{MHz}$ & \multicolumn{4}{|c|}{0.2} & 416 & 2400.2 \\
\hline $4965 \mathrm{MHz}$ & As defined in 47 CFR, Part 90, Subpart Y, Section 90.1213 \\
\hline $5800 \mathrm{MHz}$ & \multicolumn{4}{|c|}{0.5} & 249 & 5725.5 \\
\hline
\end{tabular}

\section{Common signaling mode (CSM) para SUN}

El CSM es un modo común especificado para facilitar el esquema de gestión multi-PHY (MPM). Un dispositivo SUN que actúe como coordinador y con un ciclo de trabajo superior al 1\%, admitirá CSM. La especificación de CSM se da en la Tabla 27.

Tabla 26 - Especificación PHY del esquema CSM para MPM [2].

\begin{tabular}{|c|c|c|c|c|}
\hline Band designation & Modulation & Modulation index & Channel spacing & Data rate \\
\hline $470 \mathrm{MHz}$ & & & & \\
$780 \mathrm{MHz}$ & & & & \\
$863 \mathrm{MHz}$ & $2-\mathrm{FSK}$ & 1 & $200 \mathrm{kHz}$ & $50 \mathrm{kB} / \mathrm{s}$ \\
$915 \mathrm{MHz}$ & & & & \\
$917 \mathrm{MHz}$ & & & & \\
$920 \mathrm{MHz}$ & & & & \\
$2450 \mathrm{MHz}$ & & & & \\
\hline
\end{tabular}




\subsubsection{Capa física: Modulación O-QPSK}

\subsubsection{Formato PPDU}

El PPDU tiene un formato como el representado en las Figuras 58, 59, 60 y 61.

$$
\begin{array}{|l|l|l|l|}
\hline \text { SHR } & \text { PHR } & \text { PHY payload } \\
\hline
\end{array}
$$

Figura 58 - Formato PPDU. IEEE Standard for Low-Rate Wireless Networks.

$$
\begin{array}{|l|l|}
\text { Preamble } & \text { SFD } \\
\hline
\end{array}
$$

Figura 59 - Formato SHR. IEEE Standard for Low-Rate Wireless Networks.

\begin{tabular}{|c|c|c|c|c|c|c|c|}
\hline Bits: 0 & $\mathbf{1}$ & $\mathbf{2}$ & $\mathbf{3}$ & $\mathbf{4}$ & $\mathbf{5}$ & $\mathbf{6}$ & $\mathbf{7}$ \\
\hline 1 & 1 & 1 & 0 & 0 & 1 & 0 & 1 \\
\hline
\end{tabular}

Figura 60 - Formato del campo SFD. IEEE Standard for Low-Rate Wireless Networks.

\begin{tabular}{|c|c|}
\hline Bits: 0-6 & 7 \\
\hline Frame Length & Reserved \\
\hline
\end{tabular}

Figura 61 - Formato de PHR. IEEE Standard for Low-Rate Wireless Networks.

La longitud del preámbulo para los PHY de O-QPSK es de 8 símbolos (es decir, 4 octetos), y sus bits serán todos ceros binarios.

El campo PHY payload carga el PSDU.

\subsubsection{Modulación y dispersión}

O-QPSK emplea una técnica de modulación cuasi-ortogonal de 16-arios. Durante cada período de símbolo, se utilizan cuatro bits de información para seleccionar 1 de 16 secuencias de pseudo-random noise (PN) casi ortogonales a transmitir. Las secuencias PN para símbolos de datos sucesivos se concatenan, y la secuencia de chip agregado se modula en el portador utilizando la codificación de offset quadrature phase-shift keying (O-QPSK).

El diagrama de bloques funcional en la Figura 62 es una referencia para especificar las funciones de dispersión y modulación O-QPSK.

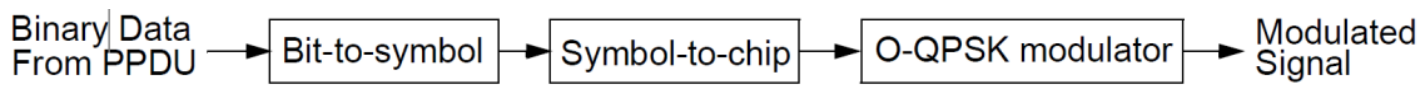

Figura 62 - Diagrama de modulación y dispersión para O-QPSK. IEEE Standard for Low-Rate Wireless Networks.

La velocidad de datos cuando se modula con O-QPSK es de $250 \mathrm{~kb} / \mathrm{s}$ cuando opere en las bandas de $2450 \mathrm{MHz}, 915 \mathrm{MHz}, 780 \mathrm{MHz}$ o $2380 \mathrm{MHz}$ y de $100 \mathrm{~kb} / \mathrm{s}$ cuando opere en la banda de $868 \mathrm{MHz}$. 
Mapeo Bit-to-Symbol: Los 4 LSB (b0, b1, b2, b3) y los 4 MSB (b4, b5, b6, b7) de cada octeto se mapearán en el símbolo de datos sucesivos. Cada octeto de la PPDU se procesa mediante las funciones de modulación y difusión, como se ilustra en la Figura 62, secuencialmente, comenzando con el campo Preámbulo y terminando con el último octeto de la PSDU. Dentro de cada octeto, el símbolo menos significativo (b0, b1, b2, b3) se procesa primero y el símbolo más significativo $(\mathrm{b} 4, \mathrm{~b} 5, \mathrm{~b} 6, \mathrm{~b} 7)$ se procesa en segundo lugar.

Mapeo Symbol-to-chip: En las bandas de $2450 \mathrm{MHz}$ y $2380 \mathrm{MHz}$, cada símbolo de datos se mapea en una secuencia PN de 32 chips (secuencia de 32 bits). Las secuencias PN están relacionadas entre sí a través de desplazamientos cíclicos y/o conjugación (es decir, inversión de valores de chips indexados de manera impar).

Modulador O-QPSK: Las secuencias de chips que representan cada símbolo de datos se modulan en el portador utilizando O-QPSK con forma de half-sine pulse. Los chips indexados pares se modulan en el portador en fase (I), y los chips indexados impares se modulan en el portador de fase en cuadratura (Q). En las bandas de $2450 \mathrm{MHz}$ y 2380 $\mathrm{MHz}$, cada símbolo de datos está representado por una secuencia de 32 chips, por lo que la velocidad de los chips es 32 veces la velocidad de los símbolos. En las bandas de 915 $\mathrm{MHz}, 868 \mathrm{MHz}$ y $780 \mathrm{MHz}$, cada símbolo de datos está representado por una secuencia de 16 chips, por lo que la velocidad de los chips es 16 veces la velocidad de los símbolos. Para formar el desplazamiento entre la modulación de chip de fase I y de fase Q, los chips de fase Q se retrasarán por $T c$ con respecto a los chips de fase I, como se ilustra en la Figura 63, donde $T c$ es el inverso del chip rate.

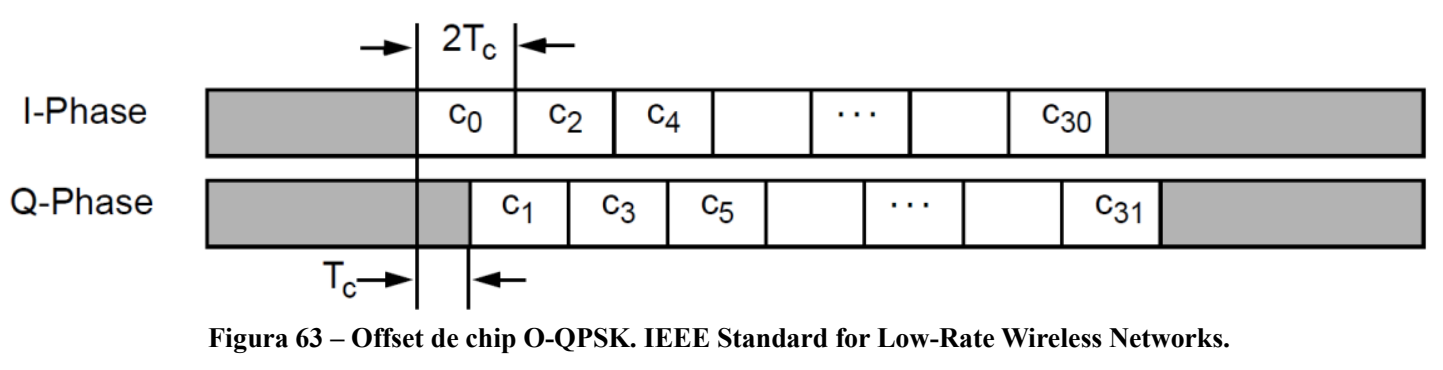

4.2.4.3.O-QPSK PHY Requisitos de RF

Rango de frecuencia de operación: Con O-QPSK opera en las siguientes bandas:

- $\quad 779-787 \mathrm{MHz}$

- $868.0-868.6 \mathrm{MHz}$

- $902-928 \mathrm{MHz}$

- $2360-2400 \mathrm{MHz}$

- $\quad 2400.0-2483.5 \mathrm{MHz}$

Mascara de Power Spectral Density (PSD) transmitida: Cuando un dispositivo IEEE802.15.4 opera en la banda de $2380 \mathrm{MHz}$ o $2450 \mathrm{MHz}$, los límites de PSD deben ser inferiores a: 
Frecuencia: $\left|f-f_{c}\right|>3,5 \mathrm{MHz}$

Límite relativo: $-20 \mathrm{~dB}$

Límite absoluto: -30dBm

\section{Energía de bit y densidad espectral de potencia:}

La energía de bit está dada por

$S_{B}(f)=4 E_{b} \log _{2} M \operatorname{sinc}^{2}\left(2 T_{b} \log _{2} M f\right)[\mathrm{W} / \mathrm{Hz}](25)$

Que luego de modular a la frecuencia la señal, se obtiene una la densidad espectral de potencia de la señal transmitida dada por

$$
\begin{gathered}
S_{B}^{\prime}(f)=\frac{1}{2}\left[S_{b}\left(f+f_{c}\right)+S_{B}\left(f-f_{c}\right)\right] \\
=2 E_{b} \log _{2} M\left[\operatorname{sinc}^{2}\left(2 T_{b} \log _{2} M\left(f+f_{c}\right)\right)+\operatorname{sinc}^{2}\left(2 T_{b} \log _{2} M\left(f-f_{c}\right)\right)\right][\mathrm{W} / \mathrm{Hz}]
\end{gathered}
$$

Tasa de símbolos: La tasa de símbolos en O-QPSK PHY debe ser de $25 \mathrm{ksymbol} / \mathrm{s}$ cuando se opera en la banda de $868 \mathrm{MHz}$ y $62,5 \mathrm{ksymbol} / \mathrm{s}$ en la banda de $780 \mathrm{MHz}$, $915 \mathrm{MHz}, 2380 \mathrm{MHz}$ o $2450 \mathrm{MHz}$ con una precisión de $\pm 40 \times 10^{-6}$.

\subsubsection{Capa física: Modulación: Chirp spread spectrum (CSS)}

\subsubsection{Formato PPDU}

El PPDU tiene un formato como el representado en las Figuras 64, 65 y 66.

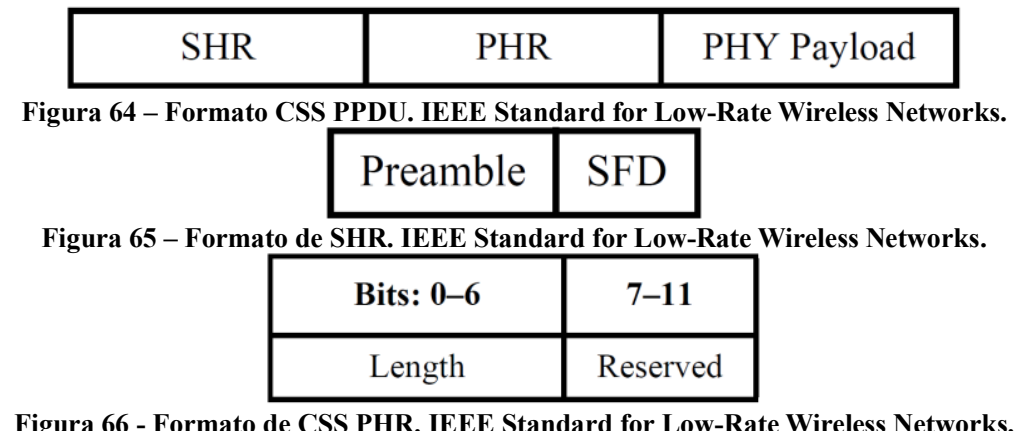

El preámbulo para $1 \mathrm{Mb} / \mathrm{s}$ consta de 8 símbolos chirp y para (opcional) $250 \mathrm{~kb} / \mathrm{s}$ consta de 20 símbolos chirp.

El campo SFD consta de 16 bits y se definen diferentes secuencias para $1 \mathrm{Mb} / \mathrm{s}$ y $250 \mathrm{~kb} / \mathrm{s}$

El campo PHY Payload carga la PSDU. 


\subsubsection{Modulación y expansión}

El CSS PHY utiliza técnicas CSS en combinación con Differential Quadrature PhaseShift Keying (DQPSK) y codificación bi-ortogonal de 8 o 64 -arios para una velocidad de datos de $1 \mathrm{Mb} / \mathrm{s}$ o $250 \mathrm{~kb} / \mathrm{s}$. Mediante el uso de intervalos de tiempo alternos junto con secuencias de señales de chirp (subchirps) en diferentes subbandas de frecuencia con diferentes direcciones de chirp, este CSS PHY proporciona división de secuencia de subchirp y división de frecuencia.

La velocidad de datos del CSS (2450 MHz) PHY será de $1 \mathrm{Mb} / \mathrm{s}$ y, opcionalmente, 250 $\mathrm{kb} / \mathrm{s}$.

Los datos binarios contenidos en el campo PHR y el PHY Payload se codificarán utilizando la modulación que se muestra en el diagrama de bloques funcional del modulador de referencia en la Figura 67.

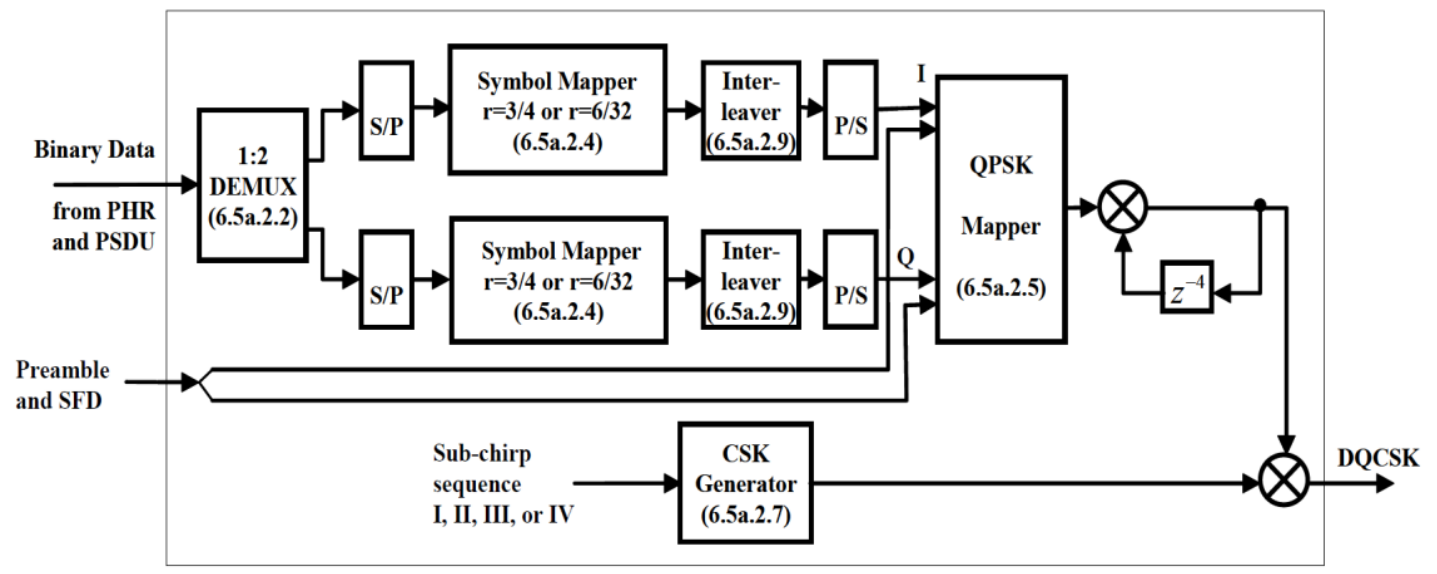

Figura 67 - Modulador diferencial bi-ortogonal cuaternario-chirp-shift-keying y difusión (r=3/4 para 8 arios $1 \mathrm{Mb} / \mathrm{s}, \mathrm{r}=3 / 16$ para 64 arios $250 \mathrm{~kb} / \mathrm{s}$ ). IEEE Standard for Low-Rate Wireless Networks.

El primer bloque DEMUX que se muestra en la Figura 67 divide de forma alternada los bits en las rutas I (en fase) y Q (en cuadratura).

Mediante el uso de dos conversores de serie a paralelo (S/P), los streams secundarias se dividen independientemente en conjuntos de bits para formar símbolos. Para la velocidad de datos de $1 \mathrm{Mb} / \mathrm{s}$, un símbolo constará de tres bits y para la opcional de $250 \mathrm{~kb} / \mathrm{s}$, un símbolo de datos consistirá en 6 bits.

En el bloque Symbol Mapper, para la velocidad de $1 \mathrm{Mb} / \mathrm{s}$, se asignará a una palabra de código bi-rtogonal de 4 chips (c0, c1, c2, c3) a cada símbolo de datos de 3 bits y para la velocidad opcional de $250 \mathrm{~kb} / \mathrm{s}$ se asignará a una palabra de código bi-ortogonal de 32 chips $(\mathrm{c} 0, \mathrm{c} 1, \mathrm{c} 2, \ldots, \mathrm{c} 31)$ a cada símbolo de datos de 6 bits.

Luego, cada palabra de código bi-ortogonal se convertirá en una secuencia de chip en serie en el conversor Paralelo/Serie (bloque P/S) para luego asignarlo a un símbolo QPSK. La secuencia de símbolos QPSK se codificará diferencialmente utilizando un codificador con una memoria de retroalimentación de símbolo QPSK de longitud 4. (En otras palabras, las diferencias de fase entre el símbolo QPSK 1 y 5,2 y 6,3 y 7, 4 y 8, y así sucesivamente).

Finalmente, la secuencia de símbolos DQPSK se modulará en la secuencia de subchirps 
generada por el Chirp-Shift Keying (CSK) generator. El efecto de la Differential Quadrature Chirp-Shift Keying (DQCSK) será que cada subchirp se multiplique con un valor DQPSK que tenga una unidad de magnitud y una fase constante durante la duración del subchirp.

El generador CSK creará periódicamente una de cuatro secuencias de subchirp definidas (símbolos chirp). Dado que cada símbolo chirp consta de cuatro subchirps, la tasa de subchirp es cuatro veces mayor que la tasa del símbolo chirp.

Cuatro señales de chirp individuales, aquí llamadas subchirps, se concatenarán para formar un símbolo de chirp completo (secuencia de subchirp) que ocupa dos subbandas de frecuencia adyacentes. Se definen cuatro secuencias de subchirp diferentes. Cada subchirp se pondera con una ventana de coseno elevada en el dominio del tiempo.

\subsubsection{Requerimientos de RF de CSK}

Además de cumplir con los requisitos reglamentarios regionales, los dispositivos CSS que funcionan en la banda de $2450 \mathrm{MHz}$ también deben cumplir con los requisitos de esta subcláusula.

La densidad de potencia espectral transmitida de una señal CSS $s(t)$ está dentro de los límites relativos especificados en la plantilla que se muestra en la Figura 68. Específicamente, el espectro de frecuencia normalizado al valor pico en el ancho de banda de la señal $\left|f-f_{c}\right| \leq 7 \mathrm{MHz}$ es menor o igual a $-30 \mathrm{~dB}$ en la banda de detención $11 \mathrm{MHz} \leq\left|f-f_{c}\right| \leq 22 \mathrm{MHz}$ menor o igual a $-50 \mathrm{~dB}$ y en la banda de detención $\left|f-f_{c}\right| \leq 22 M H z$.

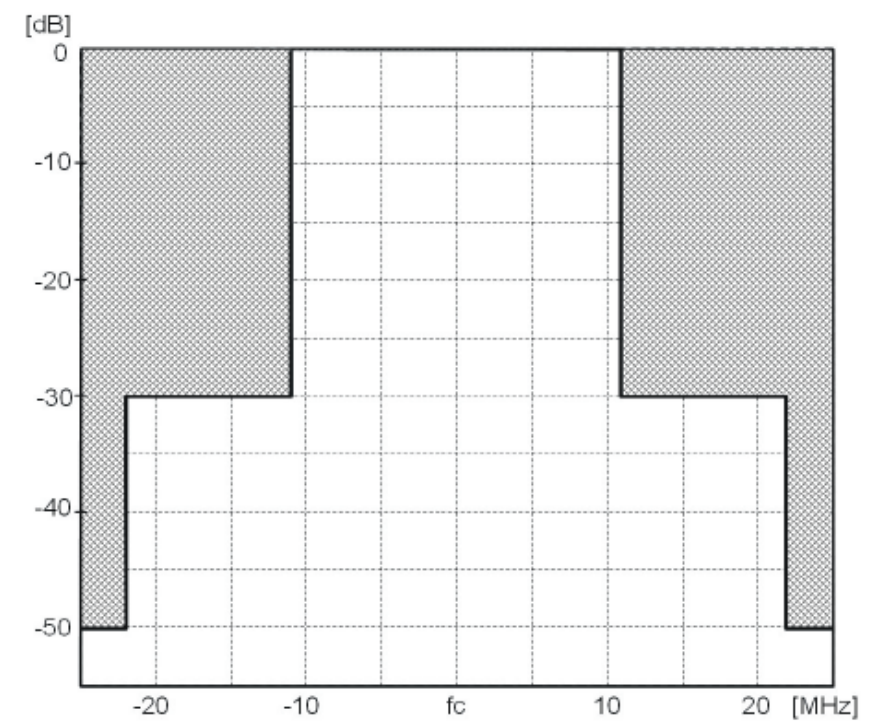

Figura 68 - Máscara PSD transmitida. IEEE Standard for Low-Rate Wireless Networks.

La velocidad del símbolo PHY DQCSK en la banda de $2450 \mathrm{MHz}$ es $166.667 \mathrm{ksymbol} / \mathrm{s}$ $(1 / 6 \mathrm{Msymbol} / \mathrm{s}) \pm 40 \times 10-6$.

En CSS, un dispositivo compatible con la norma es capaz de transmitir a un nivel de potencia de al menos $-3 \mathrm{dBm}$. 


\subsubsection{Capa física: Minimum Shift Keying (MSK)}

\subsubsection{Formato PPDU y tasa de datos}

En MSK PHY se usa el mismo formato de PPDU que con O-QPSK salvo que el preámbulo es de 32 simbolos (4 octectos).

\subsubsection{Modulación MSK}

El diagrama de bloques funcional de la Figura 69 representa el proceso de modulación MSK PHY. Cabe señalar que el preámbulo no está incluido en el esquema de whitening.

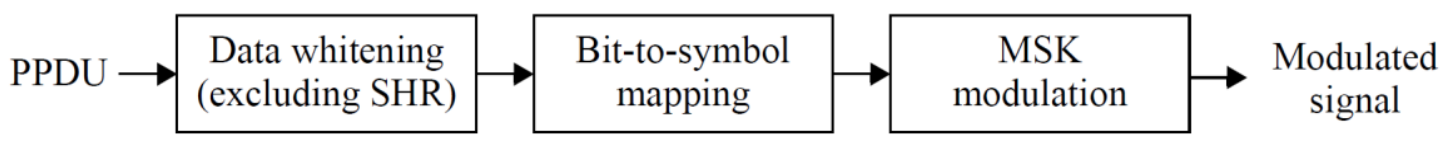

Figura 69 - Diagrama de bloques funcional de MSK. IEEE Standard for Low-Rate Wireless Networks.

Para la banda de $2450 \mathrm{GHz}$, PSK PHY transmite a $250 \mathrm{~kb} / \mathrm{s}$. La tasa de bits y la velocidad de símbolos son iguales.

El mapeo de bits a frecuencia será como se describe la ecuación 27:

$$
f= \begin{cases}f_{c}-\Delta f & \text { parabit }=0 \\ f c+\Delta f & \text { parabit }=1\end{cases}
$$

Donde:

fc es la frecuencia de portadora.

$\Delta f=\frac{1}{4 \times T_{S}} \quad$ donde $T_{\mathrm{S}}$ es la tasa de símbolos.

MSK usa FSK con índice de modulación $\mathrm{h}=0.5$. Este índice de modulación corresponde al espaciado de frecuencia mínimo que permite que dos señales FSK sean coherentemente ortogonales.

MSK tiene dos frecuencias posibles en cualquier intervalo de símbolos. Éstas difieren en frecuencia a la mitad de la velocidad de bits según 27 :

$$
f_{1}-f_{2}=\frac{1}{2} T_{b}(27)
$$

Esta es la diferencia de frecuencia es la mínima permitida para que dos señales sean ortogonales.

\subsubsection{Requerimientos MSK PHY}

Con MSK, IEEE802.15.4 puede trabajar en las bandas de frecuencia de operación de: 
$-433,05 \mathrm{MHz}$ a $434,79 \mathrm{MHz}$

$-2400 \mathrm{MHz}$ a $2483 \mathrm{MHz}$

La PSD para MSK se muestra en la Tabla 27. Los productos espectrales transmitidos deberán ser inferiores a los límites allí especificados.

En la banda de $2450 \mathrm{MHz}$, MSK transmite a una potencia de por lo menos $-13 \mathrm{dBm}$.

Tabla 27 - Limite de PSD para MSK PHY [2].

\begin{tabular}{|c|c|c|c|c|}
\hline $\begin{array}{c}\text { Frequency } \\
\text { band }\end{array}$ & Data rate & Frequency & Relative limit & Absolute limit \\
\hline $433 \mathrm{MHz}$ & $31.25 \mathrm{ksymbol} / \mathrm{s}$ & $\left|f-f_{c}\right|>200 \mathrm{kHz}$ & $-20 \mathrm{~dB}$ & $-20 \mathrm{dBm}$ \\
\cline { 2 - 5 } & $100 \mathrm{ksymbo1} / \mathrm{s}$ & $\left|f-f_{c}\right|>600 \mathrm{kHz}$ & $-20 \mathrm{~dB}$ & $-20 \mathrm{dBm}$ \\
\cline { 2 - 5 } & $250 \mathrm{ksymbol} / \mathrm{s}$ & $\left|f-f_{c}\right|>1.2 \mathrm{MHz}$ & $-20 \mathrm{~dB}$ & $-20 \mathrm{dBm}$ \\
\hline $2450 \mathrm{MHz}$ & $250 \mathrm{ksymbol} / \mathrm{s}$ & $\left|f-f_{c}\right|>1.2 \mathrm{MHz}$ & $-20 \mathrm{~dB}$ & $-20 \mathrm{dBm}$ \\
\hline
\end{tabular}

4.2.7. Capa física: Smart Utility Network (SUN) Frequency Shift Keying (FSK)

\subsubsection{Formato de PPDU}

La PPDU se esquematiza en la Figura 70:

\begin{tabular}{|c|c|c|}
\hline SHR & PHR & PHY payload \\
\hline
\end{tabular}

Figura 70 - Formato PPDU de SUN FSK. IEEE Standard for Low-Rate Wireless Networks.

El SHR está compuesto de una concatenación del preámbulo y el campo SFD.

Dependiendo si se modula en 2-FSK o 4-FSK, el campo SHR puede tener 24bits o 48bits.

El campo PHR (en modo switch o no) tiene 16bits. 


\subsubsection{Modulación y codificación para SUN FSK}

La Tabla 28 muestra los parámetros de modulación y canal para los modos operativos en las bandas de $1427 \mathrm{MHz}$ y $2450 \mathrm{MHz}$. Existen tres modos operativos especificados en la misma tabla.

Tabla 28 - Modulación SUN FSK y parámetros de canal [2].

\begin{tabular}{|c|c|c|c|c|}
\hline $\begin{array}{c}\text { Frequency band } \\
(\mathrm{MHz})\end{array}$ & Parameter & $\begin{array}{c}\text { Operating mode } \\
\# 1\end{array}$ & $\underset{\# 2}{\text { Operating mode }}$ & $\underset{\# 3}{\text { Operating mode }}$ \\
\hline \multirow{4}{*}{$1427-1518^{b}$} & Data rate $(\mathrm{kb} / \mathrm{s})$ & 10 & 20 & 40 \\
\hline & Modulation & 2-FSK & 2-FSK & 2-FSK \\
\hline & Modulation index & 0.5 & 0.5 & 0.5 \\
\hline & Channel spacing $(\mathrm{kHz})$ & 25 & 25 & 25 \\
\hline \multirow{4}{*}{$2400-2483.5$} & Data rate $(\mathrm{kb} / \mathrm{s})$ & 50 & 150 & 200 \\
\hline & Modulation & 2-FSK & 2-FSK & 2-FSK \\
\hline & Modulation index & 1.0 & 0.5 & 0.5 \\
\hline & Channel spacing $(\mathrm{kHz})$ & 200 & 400 & 400 \\
\hline
\end{tabular}

${ }^{\mathrm{a}} \mathrm{Data}$ rates shown are over-the-air data rates (the data rate transmitted over the air regardless of whether the FEC is enabled).

boncontiguous.

La Figura 71 proporciona el diagrama de bloques funcional del modulador para flujo de datos SUN FSK PHY.

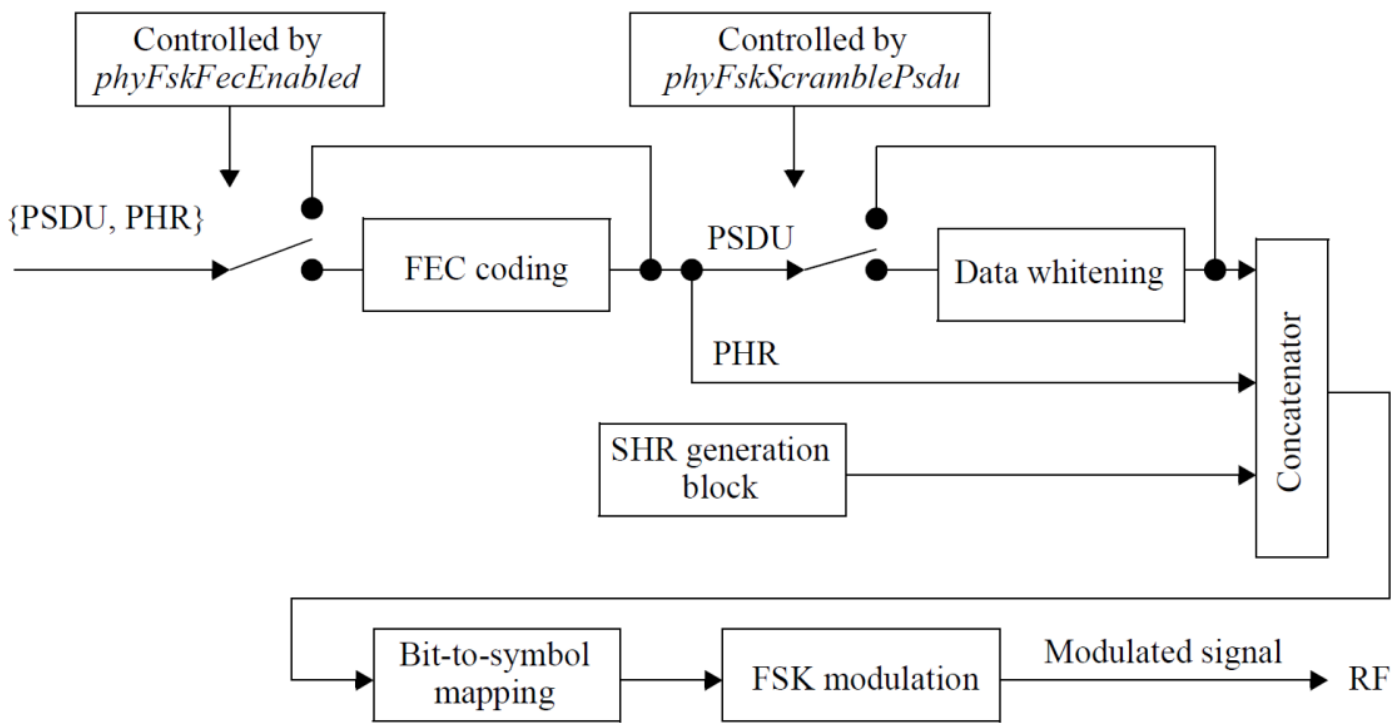

Figura 71 - Modulador SUN FSK. IEEE Standard for Low-Rate Wireless Networks. 


\subsection{Mapeo bit-to-symbol}

La desviación de frecuencia nominal es dada por 28 :

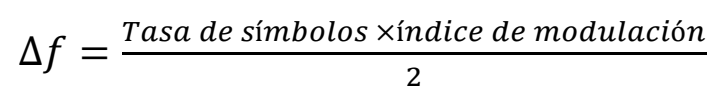

El símbolo que codifica para 2-FSK y 4-FSK se muestran en las Tablas 29 y 30 respectivamente, donde la desviación de frecuencia, $\mathrm{f}_{\mathrm{dev}}$, es igual a $\Delta f$ para 2 -FSK e igual a $3 \times \Delta f$ para 4-FSK. Para la modulación 4-FSK, se asignan dos bits a cuatro niveles de desviación de frecuencia para el campo de carga útil PHR y PHY. El SHR se codifica en las desviaciones de frecuencia más bajas $\left(-f_{\text {dev }}\right)$ y más altas $\left(+f_{\text {dev }}\right)$. La velocidad de símbolo es la misma para toda la PPDU.

Tabla 29 - Codificación de símbolos SUN 2-FSK [2].

\begin{tabular}{|c|c|}
\hline Symbol (binary) & Frequency deviation \\
\hline 0 & $-f_{\text {dev }}$ \\
\hline 1 & $+f_{\text {dev }}$ \\
\hline
\end{tabular}

Tabla 30 - Codificación de símbolos SUN 4-FSK [2].

\begin{tabular}{|c|c|}
\hline Symbol (binary) & Frequency deviation \\
\hline 01 & $-f_{\text {dev }}$ \\
\hline 00 & $-f_{\text {dev }} / 3$ \\
\hline 10 & $+f_{\text {dev }} / 3$ \\
\hline 11 & $+f_{\text {dev }}$ \\
\hline
\end{tabular}

\subsubsection{Requisitos de RF en SUN FSK}

El contenido espectral de transmisión es la relación entre la potencia total transmitida fuera del canal y la potencia total transmitida dentro del canal en un ancho de banda de integración dado.

El ancho de banda de integración es igual a 1,5xR, donde $\mathrm{R}$ es la velocidad de símbolos expresada en $\mathrm{Hz}$.

La potencia fuera del canal es medida a dos frecuencias de desplazamiento con respecto a la frecuencia portadora. Las frecuencias de desplazamiento $\mathrm{M}_{1} \mathrm{y}_{2}$ se definen según 29 y 30 :

$$
\begin{aligned}
& M_{1}=1,5 \times R \times(1+h) \\
& M_{2}=3 \times R \times(1+h)
\end{aligned}
$$

donde $h$ es el índice para la modulación de 2 niveles y tres veces el índice de modulación para la modulación de 4 niveles. 
El contenido espectral de transmisión en $\mathrm{M}_{1}$ y $\mathrm{M}_{2}$ son inferior a $-25 \mathrm{~dB}$ y $-35 \mathrm{~dB}$ respectivamente.

La señal modulada utiliza un patrón de datos PN de 511 bits o más.

Un dispositivo compatible transmite una potencia de por lo menos $-3 \mathrm{dBm}$, pero no muy superior a ese valor para reducir la interferencia a otros dispositivos y sistemas.

La potencia máxima de transmisión es limitada por los organismos reguladores locales.

\subsubsection{Capa física: Low Energy Critical Infrastructure Monitoring (LECIM)} Direct Sequence Spread Spectrum (DSSS)

\subsubsection{Formato de PPDU}

El campo PSDU transporta los datos de la PPDU. El tamaño del campo se establece mediante el valor de phyLecimDsssPsduSize. La PPDU se formateará como se ilustra en la Figura 72.

\begin{tabular}{|c|c|c|}
\hline Octets: $0 / 2 / 4$ & $0 / 1$ & $16 / 24 / 32$ \\
\hline Preamble & SFD & PSDU \\
\hline \multicolumn{2}{|l|}{ SHR } & PHY payload \\
\hline
\end{tabular}

La longitud del preámbulo es seleccionada a través de phyLecimDsssPreambleSize.

El campo SFD, si está presente, indica el comienzo de la trama. Se utiliza un SFD cuando la longitud del preámbulo es de 2 octetos y un segundo SFD cuando es de 4 octetos.

\subsubsection{Modulación y expansión}

La velocidad de datos de información depende de la banda en uso, el factor de expansión, la velocidad de modulación y la modulación que se utiliza, y se calcula en $\mathrm{kb} / \mathrm{s}$ según (31):

$$
\text { DataRate }=0,5 \times \frac{\text { phyLecimDSSPPDUModulationRate } \times \text { ChipPerSimbol }}{\text { phyLECIMDSSPSDUSpreadingFactor }}(31)
$$

donde

ChipPerSymbol $=1$ cuando se usa la modulación BPSK y 2 cuando se usa la modulación O-QPSK.

El término 0,5 representa la codificación FEC 1/2.

La Figura 73 representa el diagrama de bloques de modulación LECIM DSSS. Todos los datos binarios contenidos en el SHR y la PSDU se codifican según este diagrama. 


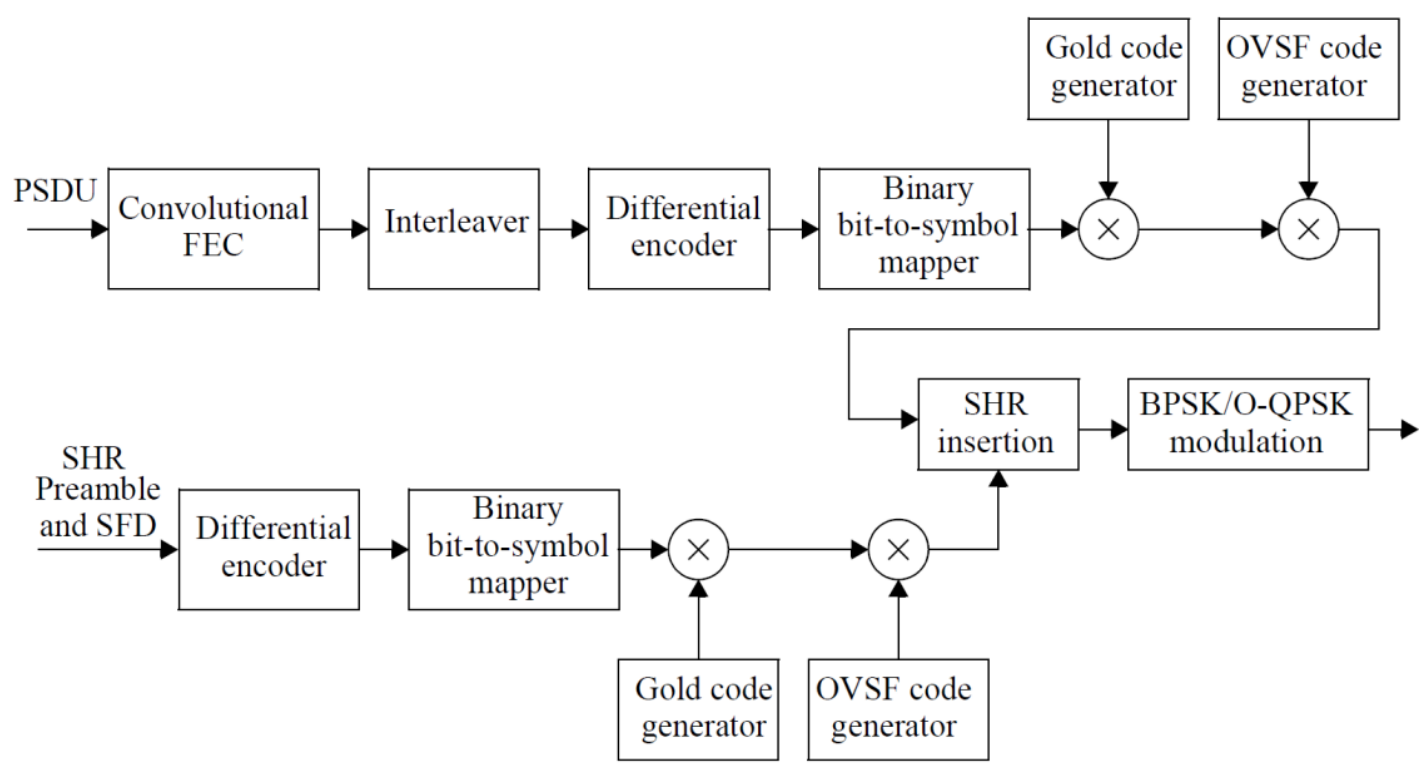

Figura 73 - Diagrama de referencia de modulación LCIM DSS. IEEE Standard for Low-Rate Wireless Networks.

En modulación BPSK, un valor de chip de uno corresponde a un pulso positivo y un valor de chip de cero corresponde a un pulso negativo. Durante cada período de símbolo se transmite desde el chip $\mathrm{C} 0$ hasta el $\mathrm{C}_{\mathrm{SF}-1}$.

En modulación O-QPSK, los chips indexados pares se modulan en fase con la portadora (I), y los chips indexados impares se modulan en cuadratura con la portadora (Q). Para formar el desplazamiento entre la modulación de chips, los chips de $\mathrm{Q}$ se retrasarán $\mathrm{T}_{\mathrm{c}}$ con respecto a los chips de fase I (como se ilustra en la Figura 74), donde $\mathrm{T}_{\mathrm{c}}$ es el inverso del chip rate y SF es phyLecimDsssPsduSpreadingFactor.

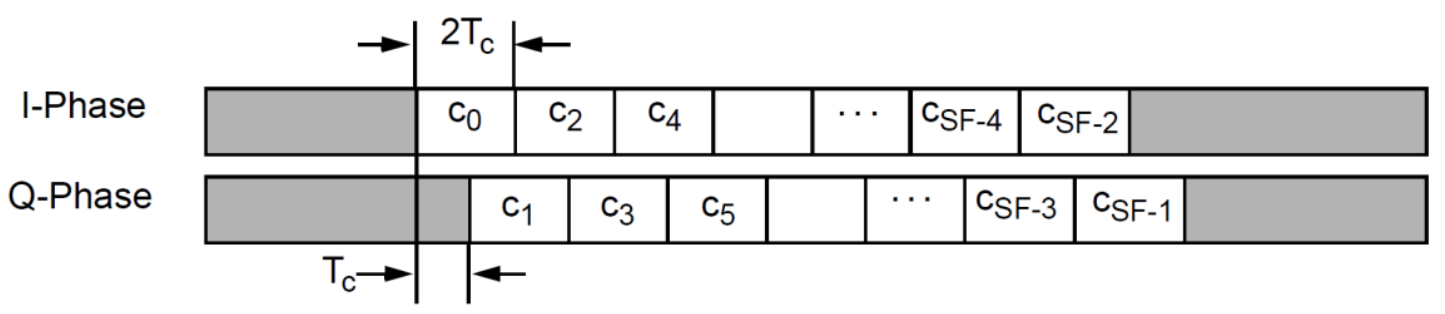

Figura 74 - Modulación de chips en O-QPSK. IEEE Standard for Low-Rate Wireless Networks.

\subsubsection{Requisitos de RF en en LCIM DSSS}

El tiempo de switch de canal, definido como el tiempo transcurrido entre el borde posterior del último símbolo de una PPDU y el borde delantero del primer símbolo de una PPDU consecutiva enviada en un canal diferente, es menor o igual a $500 \mu \mathrm{s}$.

Un transmisor compatible es capaz de transmitir $-3 \mathrm{dBm}$ o más, limitada solamente por los organismos reguladores locales. 


\subsection{IEEE802.11b}

Al igual que con IEEE 802.15.4, la intención de este trabajo no es analizar el protocolo IEEE802.11b sino ver cómo afecta éste a IEEE802.15.6. Es por ello que solo se estudia el tiempo que requiere el envío de cada trama, la distancia temporal que puede llegar a haber entre cada una, la potencia con la que se transmite, bandas de trabajo y anchos de banda.

\subsubsection{Formato de PSDU de datos}

Cada trama consta de los siguientes componentes básicos:

a) Un encabezado MAC, que comprende información de control de trama, duración, dirección y control de secuencia;

b) Un frame body de longitud variable, que contiene información específica del tipo de trama;

c) Una frame check sequence (FCS), que contiene un cyclic redundancy code (CRC) IEEE de 32 bits.

La figura 75 esquematiza el formato de una PSDU de datos, ésta contiene el cuerpo de la trama que se desea transmitir:

\begin{tabular}{|c|c|c|c|c|c|c|c|c|} 
Octets: 2 & \multicolumn{2}{c}{6} & $0-2312$ & 4 \\
\hline $\begin{array}{c}\text { Frame } \\
\text { Control }\end{array}$ & $\begin{array}{c}\text { Duration / } \\
\text { ID }\end{array}$ & Address 1 & Address 2 & Address 3 & $\begin{array}{c}\text { Sequence } \\
\text { Control }\end{array}$ & Address 4 & Frame Body & FCS \\
\hline
\end{tabular}

Figura 75 - Formato de una PSDU de datos. IEEE Standard for Low-Rate Wireless Networks. 
4.3.2. Descripción funcional de la subcapa MAC

\subsubsection{Arqutiectura MAC}

La arquitectura MAC se describe en la figura 76 como la que proporciona la Point Coordination Funcion (PCF) a través de los servicios de la Distributed Coordination Function (DCF).

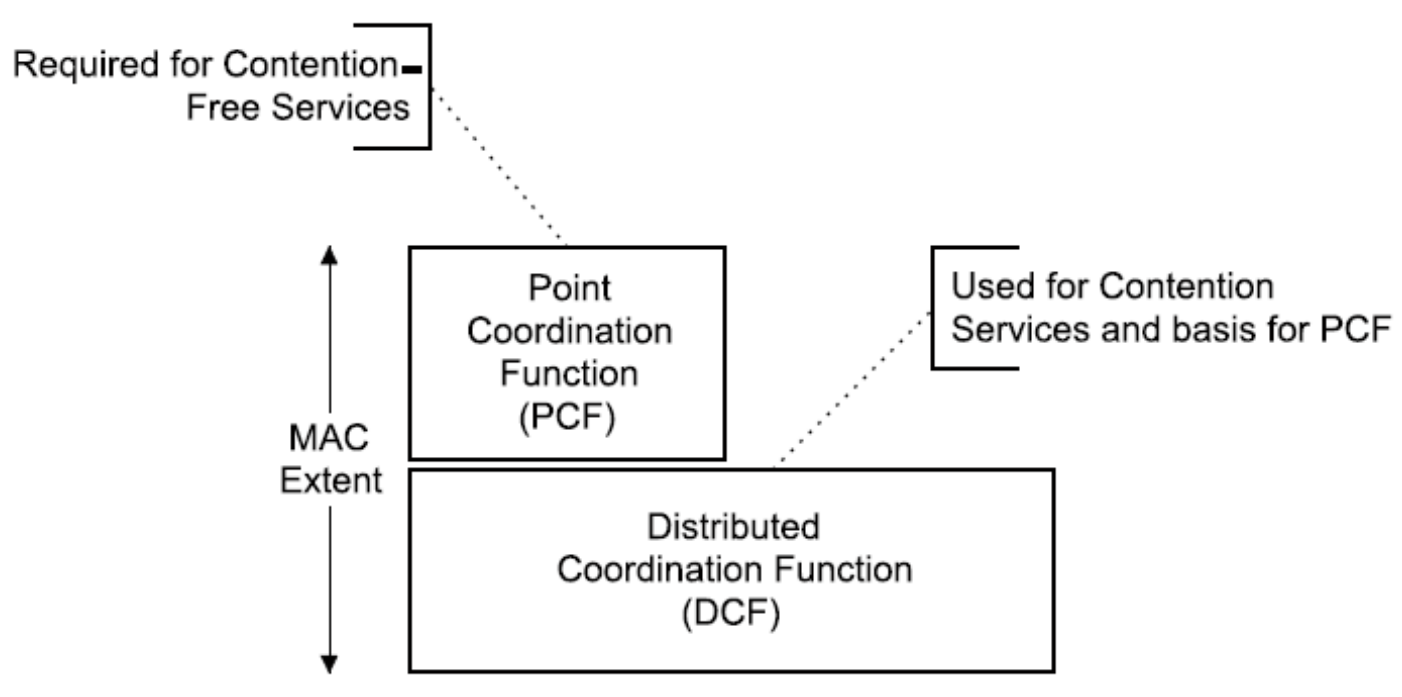

Figura 76 - Arquitectura MAC. Part 11: Wireless LAN Medium Access Control (MAC) and Physical Layer (PHY) specifications: Higher-Speed Physical Layer Extension in the 2.4GHz Band.

\subsection{Distributed Coordination Function (DCF)}

El método de acceso fundamental de IEEE 802.11 es un DCF conocido como carrier sense multiple access with collision avoidance (CSMA/CA). El DCF se implementa en todas las STA.

\subsection{Point Coordination Funcion (PCF)}

IEEE 802.11 incorpora un método de acceso opcional llamado PCF, que solo se puede usarse en configuraciones de red de infraestructura. Este método de acceso utiliza un point coordinator (PC) que opera en el Access Point del BSS para determinar qué STA tiene el derecho de transmitir. La operación es esencialmente la de sondeo, con la PC desempeñando el papel del maestro de sondeo.

El PCF utiliza un mecanismo virtual de detección de portadora ayudado por uno de prioridad de acceso. La PCF distribuirá información dentro de las tramas de gestión de beacon para obtener el control del medio estableciendo el network allocation vector (NAV) en las STA. Además, todas las transmisiones bajo la PCF pueden usar un interframe

space (IFS) que es más pequeño que el de las tramas transmitidas a través de DCF. 


\subsection{Coexistencia de DCF y PCF}

El DCF y el PCF coexistirán de una manera que permita que ambos operen simultáneamente dentro del mismo BSS. Cuando un PC está operando en un BSS, los dos métodos de acceso se alternan, con un contention-free period (CFP) seguido de un contention period $(\mathrm{CP})$.

\subsubsection{Distributed Coordination Function (DCF)}

El protocolo de acceso al medio es DCF que permite compartir el medio entre PHY compatibles mediante el uso de CSMA/CA y un tiempo de retroceso aleatorio luego de una condición. Además, todo el tráfico utiliza acuse de recibo positivo inmediato (trama $\mathrm{ACK}$ ) donde el remitente programa la retransmisión si no se recibe éste ACK.

El censado del portador se realizará a través de mecanismos físicos (Capa PHY) o virtuales (Capa MAC).

El mecanismo virtual de detección de portador se logra mediante la distribución de información de reserva que anuncia el uso inminente del medio. El intercambio de tramas Request To Send (RTS) y Clear To Send (CTS) antes de la trama de datos es un medio de distribución de información de reserva. Las tramas RTS y CTS contienen un campo Duración/ID que define el período de tiempo que el medio debe reservarse para transmitir la trama de datos y la trama ACK de respuesta. Todas las STA dentro del rango de recepción de la STA de origen (que transmite el RTS) o la STA de destino (que transmite el CTS) son conscientes de la reserva de medios.

Otro medio de distribuir la información de reserva del medio es el campo Duración/ID en tramas transmitidas. Este campo proporciona el tiempo que el medio está reservado, ya sea al final del ACK inmediatamente siguiente, o en el caso de una secuencia de fragmentos, al final del ACK que sigue al siguiente fragmento.

\subsection{Interframe space (IFS)}

El intervalo de tiempo entre tramas se llama IFS. Se definen cuatro IFS diferentes para proporcionar niveles de prioridad de acceso al medio. La Figura 77 muestra estas el uso de éstas IFS.
a) SIFS: Short Interframe Space
b) PIFS: PCF Interframe Space
c) DIFS: DCF Interframe Space
d) EIFS: Extended Interframe Space 
Los diferentes IFS son independientes de la velocidad de bits de STA y se definen como intervalos de tiempo en el medio, fijados para cada PHY (incluso en PHY con capacidad multirate). Los valores IFS se determinan a partir de los atributos especificados por el PHY.

Immediate access when medium is free >= DIFS

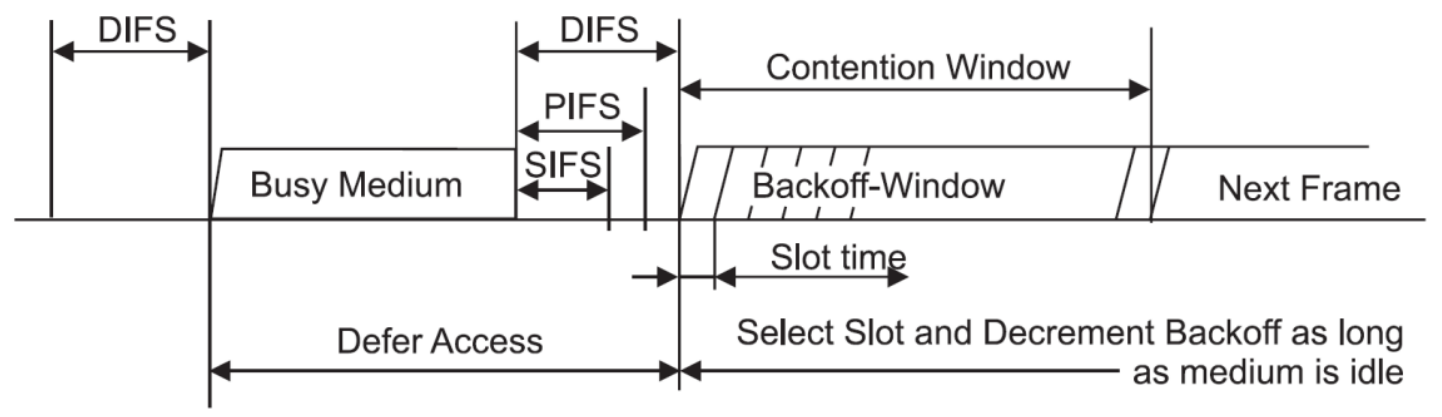

Figura 77 - Relación de algunas IFS. Part 11: Wireless LAN Medium Access Control (MAC) and Physical Layer (PHY) specifications: Higher-Speed Physical Laver Extension in the $2.4 \mathrm{GHz}$ Band.

SIFS: El más corto de los IFS, es el tiempo desde el último símbolo de la trama anterior hasta el comienzo del primer símbolo del preámbulo de la siguiente. El SIFS se utilizará para una trama ACK, una CTS, la segunda o posterior MPDU de una ráfaga de fragmentos y por una STA que responda a cualquier encuesta realizada por la PCF.

PIFS: El segundo más corto de los IFS, es utilizado solo por las STA que operan bajo la PCF para obtener acceso prioritario al medio. A una STA que use la PCF se le permitirá transmitir tráfico sin contención después de que su mecanismo de detección determine que el medio está inactivo en el límite de la ranura TxPIFS.

DIFS: El tercero en longitud, DIFS es utilizado por las STA que operan bajo el DCF para transmitir tramas de datos (MPDU) y/o tramas de gestión (MMPDU).

EIFS: Se utiliza siempre que el PHY haya indicado a la MAC que se inició una transmisión de trama que no dio como resultado la recepción con un valor FCS correcto.

\subsection{Tiempo aleatorio de backoff}

Una STA que desee iniciar la transferencia de MPDU y/o MMPDU, invoca el mecanismo de detección de portadora para determinar el estado ocupado/inactivo del medio. Si el medio está ocupado, el STA espera hasta que se determine que el medio esté inactivo sin interrupción durante un período de tiempo de DIFS o después de que se determine esté inactivo sin interrupción por un período de tiempo de EIFS. Luego de esta espera la STA generará un período de backoff aleatorio por un tiempo de aplazamiento adicional antes de transmitir.

$$
\text { Backoff Time }=\text { Random }(\quad) \times \text { aSlotTme }
$$

Donde:

Random ()$=$ Entero pseudoaleatorio extraído de una distribución uniforme en el intervalo $[0, \mathrm{CW}]$, donde $\mathrm{CW}$ es un entero dentro del rango de valores de $\mathrm{PHY}$ aCWmin $\leq \mathrm{CW} \leq \mathrm{aCWmax}$. 
aSlotTime $=$ Valor de la característica PHY nombrada.

El parámetro Contention Window $(\mathrm{CW})$ toma un valor inicial de aCWmin. Cada STA mantiene un STA short retry count (SSRC) así como un STA long retry count (SLRC), los cuales toman un valor inicial de cero. El SSRC se incrementa siempre que se incremente cualquier recuento de reintentos cortos asociado con cualquier MSDU mientras que el SLRC se incrementará siempre que se incremente cualquier recuento de reintentos largos asociado con cualquier MSDU. En cada intento fallido de transmisión, el CW toma el siguiente valor de la serie hasta que el CW alcance el valor de aCWmax. Una vez que alcanza aCWmax, la $\mathrm{CW}$ permanecerá en el valor de aCWmax hasta que se restablezca. Ver Figura 78.

El CW se restablecerá a aCWmin después de cada intento exitoso, cuando SLRC alcance

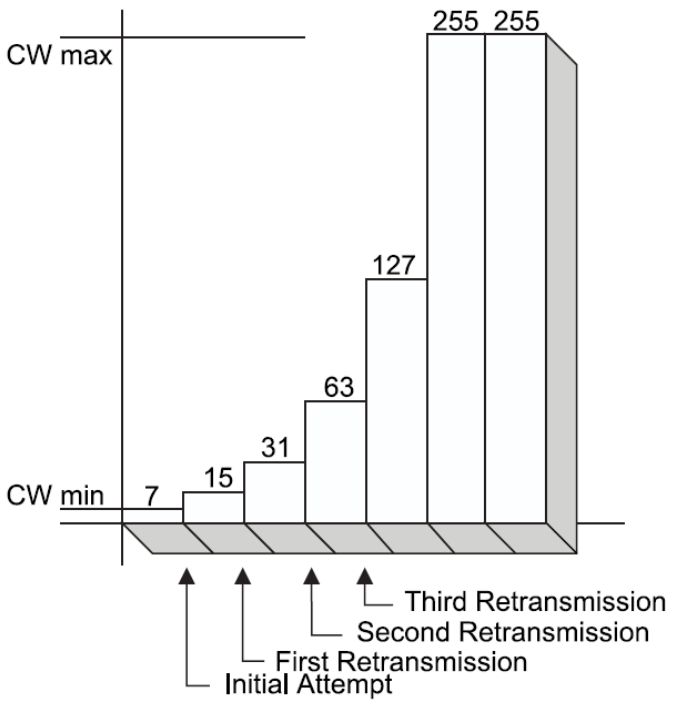

Figura 78 - Ejemplo decrecimiento exponencial de CW. Part 11: Wireless LAN Medium Access Control (MAC) and Physical Layer (PHY) specifications: Higher-Speed Physical Layer Extension in the 2.4GHz Band.

aLongRetryLimit, o cuando SSRC llegue a dot11ShortRetryLimit. El SSRC se restablecerá a 0 cada vez que se reciba una trama CTS en respuesta a una trama RTS, cada vez que se reciba una trama ACK en respuesta a una transmisión MPDU o MMPDU, o cuando se transmita una trama con una dirección de grupo en el campo Dirección1. El SLRC se restablecerá a 0 siempre que se reciba una trama ACK en respuesta a la transmisión de una MPDU o MMPDU de longitud mayor que el umbral dot11RTST, o cuando se transmita una trama con una dirección de grupo en el campo Dirección1.

\subsection{Procedimiento de acceso DCF}

CSMA/CA es la base de DCF. Las reglas operativas varían ligeramente entre el DCF y el PCF.

\section{Acceso básico}

El acceso básico se refiere al mecanismo central que usa una STA para determinar si puede transmitir. 
Una STA operando en DCF puede transmitir una MPDU cuando determina que el medio está inactivo por más de un período DIFS o un período EIFS si el evento anterior fue una trama que no se recibió correctamente.

Se requiere que las STA que tienen una FH PHY completen la transmisión de toda la MPDU y el reconocimiento asociado antes de que termine el tiempo de permanencia. Si, al transmitir o retransmitir una MPDU, no queda tiempo suficiente para permitir la transmisión de la MPDU más el acuse de recibo, la STA diferirá la transmisión seleccionando un random backoff time del presente $\mathrm{CW}$. El contador de reintentos cortos y el contador de reintentos largos para la MSDU no se ven afectados.

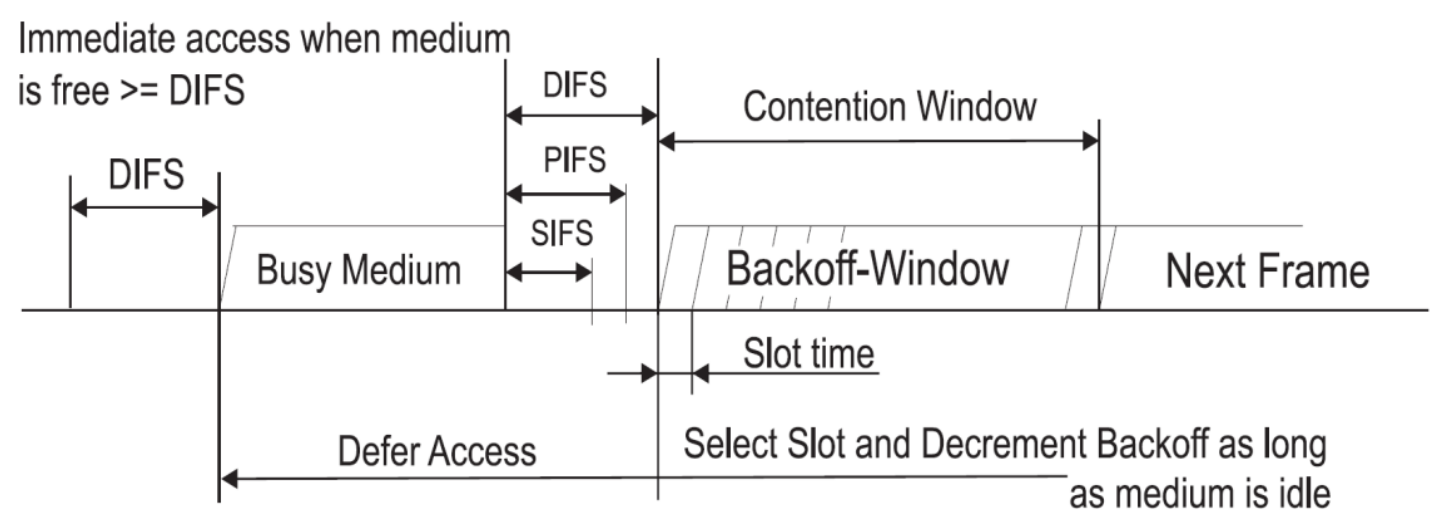

Figura 79 - Método de acceso básico. Part 11: Wireless LAN Medium Access Control (MAC) and Physical Layer (PHY) specifications: Higher-Speed Physical Layer Extension in the 2.4GHz Band.

\section{Procedimiento de backoff}

Se invocará el procedimiento de backoff cuando la STA encuentre el medio ocupado o cuando ésta infiere una transmisión fallida.

También se realizará un procedimiento de backoff inmediatamente después del final de cada MPDU con el bit More Fragments en 0. En el caso de transmisiones exitosas, este procedimiento comenzará al final de la trama ACK recibida, y en el caso de transmisiones fallidas que requieren acuse de recibo, comenzará al final del intervalo de tiempo de espera ACK. Si la transmisión es exitosa, el valor $\mathrm{CW}$ vuelve a $a C W m i n$ antes de que se elija el intervalo de backuoff aleatorio, y el recuento de reintentos cortos y/o largos se actualizan asegurando esto que las tramas siempre estén separadas por al menos un intervalo backoff.

El efecto de este procedimiento es que cuando varias STA están diferiendo y entran en backoff aleatorio, la que seleccione el menor tiempo ganará la contienda.

\section{Relación de tiempos de DCF}

Las relaciones entre los IFS se definen como brechas de tiempo en el medio. Los atributos asociados son proporcionados por el PHY específico. (Ver Figura 80.) 
Todos los tiempos a los que se hace referencia desde el final de una transmisión, se referencian desde el final del último símbolo de una trama en el medio; mientras que el

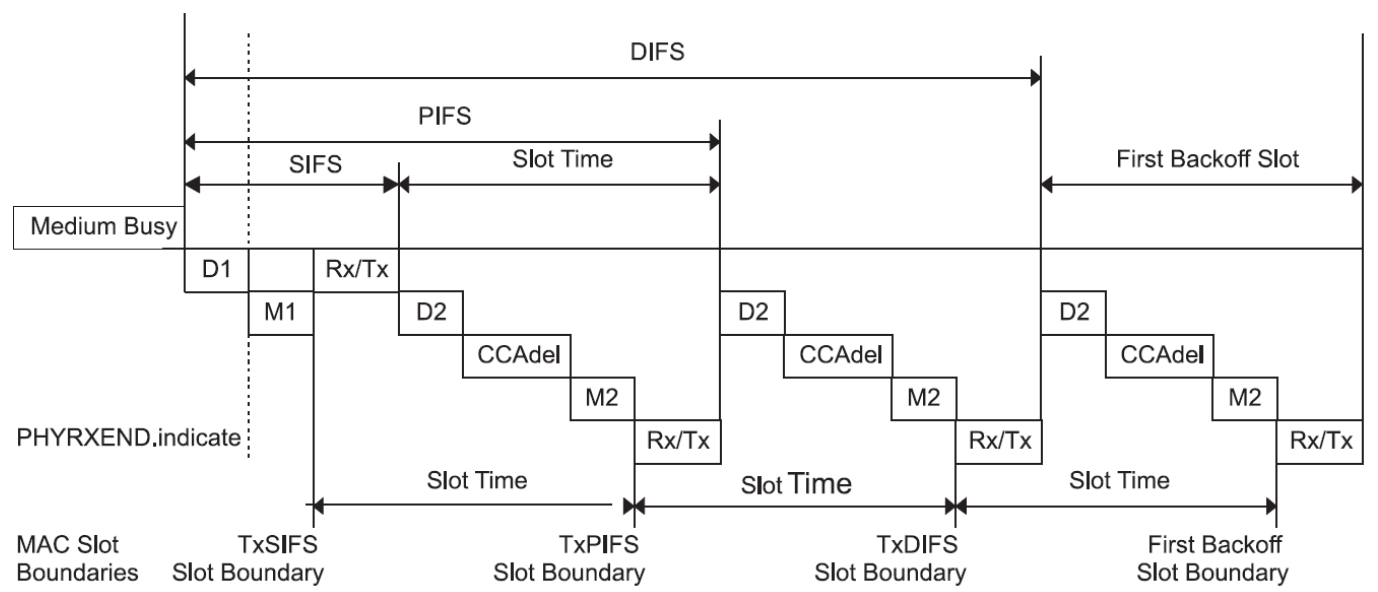

$\mathrm{D} 1=\mathrm{aRxRFDelay}+\mathrm{aRxPLCPDelay}$ (referenced from the end of the last symbol of a frame on the medium)

D2 = D1 + Air Propagation Time

$\mathrm{Rx} / \mathrm{Tx}=\mathrm{aRXTXTurnaroundTime}$ (begins with a PHYTXSTART.request)

$\mathrm{M} 1=\mathrm{M} 2=$ aMACPrcDelay

CCAdel $=$ aCCA Time - D1

Figura 80 - Relación de tiempos de DCF. Part 11: Wireless LAN Medium Access Control (MAC) and Physical Layer (PHY) specifications: Higher-Speed Physical Layer Extension in the 2.4GHz Band.

inicio de la transmisión, se refiere al primer símbolo de la siguiente trama en el medio.

aSIFSTime y aSlotTime se fijan por la PHY.

$$
\begin{aligned}
& \text { aSIFSTime }=a R x R F \text { Delay }+ \text { aRxPLCPDelay }+ \text { aMACProcessingDelay }+ \\
& \text { aRxTxTurnaroundTime }
\end{aligned}
$$

$$
\begin{gathered}
\text { aSlotTime }=\text { aCCATime }+ \text { aRxTxTurnaroundTime }+ \text { aAirPropagationTime }+ \\
\text { aMACProcessingDelay }
\end{gathered}
$$

Los PIFS y DIFS se derivan de las siguientes ecuaciones, como se ilustra en la Figura 80.

$$
\begin{aligned}
& \text { PIFS }=\text { aSIFSTime }+ \text { aSlottime } \\
& \text { DIFS }=\text { aSIFSTime }+2 \times \text { aSlotTime }
\end{aligned}
$$

EIFS se deriva de SIFS y DIFS y el tiempo que lleva transmitir una trama de control ACK a $1 \mathrm{Mbit} / \mathrm{s}$ mediante la siguiente ecuación:

$$
\begin{aligned}
E I F S= & \text { aSIFSTime }+(8 \times \text { ACKSize })+\text { aPreambleLength }+ \\
& \text { aPLCPHeaderLength }+ \text { DIFS }
\end{aligned}
$$

Donde

ACKSize es la longitud en bytes de una trama ACK

$(8 \times$ ACKSize $)+$ aPreambleLength + aPLCPHaderLength se expresa en los microsegundos requeridos para transmitir a la menor tasa permitida por PHY. 
La Figura 80 ilustra la relación entre SIFS, PIFS y DIFS medidos en el medio y los diferentes límites de MAC slots TxSIFS, TxPIFS y TxDIFS. Estos límites de intervalo definen cuándo MAC activará el transmisor para cumplir con los diferentes tiempos de IFS en el medio.

Las siguientes ecuaciones definen los límites de las MAC slots, utilizando los atributos proporcionados por el PHY que compensan las variaciones de tiempo de implementación. La referencia inicial de estos límites de ranura es el final del último símbolo de la trama anterior en el medio.

$$
\begin{aligned}
& \text { TxSIFS }=\text { SIFS }- \text { aRxTxTurnaroundTime } \\
& \text { TxPIFS }=\text { TxSIFS }+ \text { aSlotTime } \\
& \text { TxDIFS }=\text { TxSIFS }+2 \times \text { aSlotTime }
\end{aligned}
$$

\subsubsection{Capa Física: Formato de PPDU}

IEEE 802.11b tiene dos posibles preámbulos y encabezados: el preámbulo largo obligatorio con su encabezado que es interoperable con la especificación DSSS de 1 $\mathrm{Mbit} / \mathrm{s}$ y $2 \mathrm{Mbit} / \mathrm{s}$ y opcionalmente un preámbulo corto y encabezado.

\subsubsection{Formato largo de PLC PPDU}

La Figura 81 esquematiza la PPDU interoperable (larga), incluyendo el preámbulo High Rate PLCP, el encabezado High Rate PLCP y la PSDU. El preámbulo de PLCP contiene los campos sincronización (Sync) y delimitador de trama de inicio (SFD). El encabezado PLCP contiene los campos de señalización (SIGNAL), servicio (SERVICE), longitud

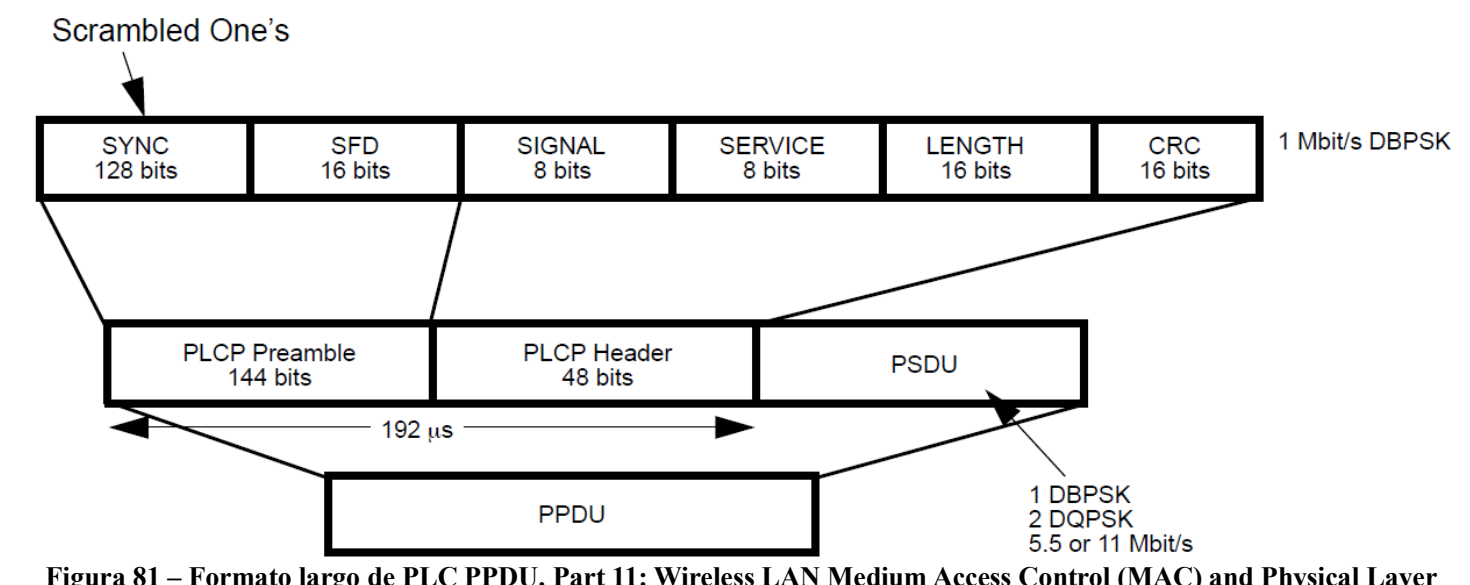

Figura 81 - Formato largo de PLC PPDU. Part 11: Wireless LAN Medium Access Control (MAC) and Physical Layer (PHY) specifications: Higher-Speed Physical Layer Extension in the 2.4GHz Band.

(LENGTH) y CCITT CRC-16. 


\subsubsection{Formato corto de PLC PPDU (Opcional)}

Opcionalmente existe un preámbulo y encabezado PLCP corto (HR/DSSS/short). Éste se usa para minimizar la sobrecarga y, por lo tanto, maximizar el rendimiento. El formato de la PPDU, con HR/DSSS/short, se muestra en la Figura 82.

El preámbulo de PLCP abreviado utiliza el código Barker de $1 \mathrm{Mbit} / \mathrm{s}$ que se extiende con modulación DBPSK. El encabezado corto PLCP utiliza el código Barker de $2 \mathrm{Mbit} / \mathrm{s}$ que se extiende con la modulación DQPSK, y el PSDU se transmite a 2Mbit/s, $5.5 \mathrm{Mbit} / \mathrm{s}$ o $11 \mathrm{Mbit} / \mathrm{s}$.

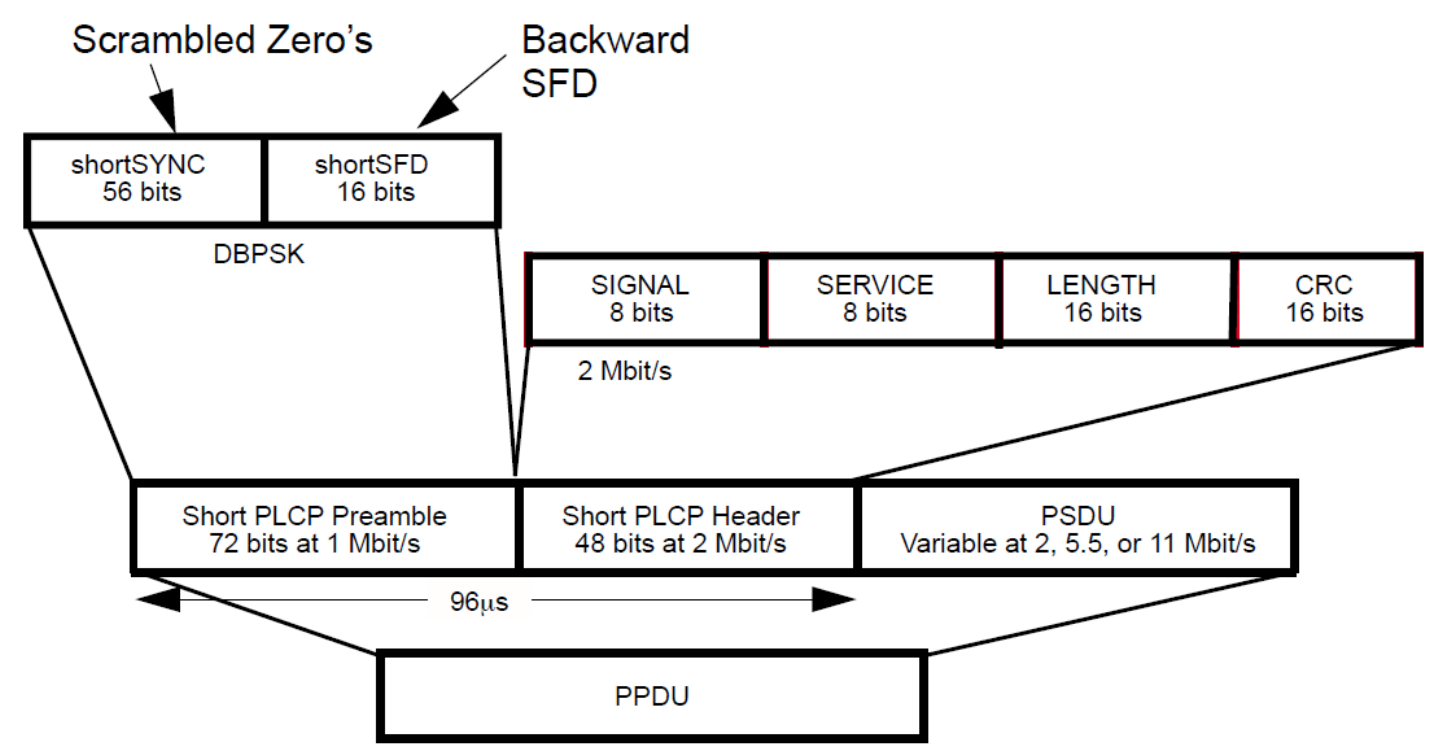

Figura 82 - Formato corto de PLCP PPDU. Part 11: Wireless LAN Medium Access Control (MAC) and Physical Layer (PHY) specifications: Higher-Speed Physical Layer Extension in the 2.4GHz Band.

\subsubsection{Subcapa de High Rate PMD}

La subcapa High Rate PMD acepta primitivas de servicio de subcapa PLCP y proporciona

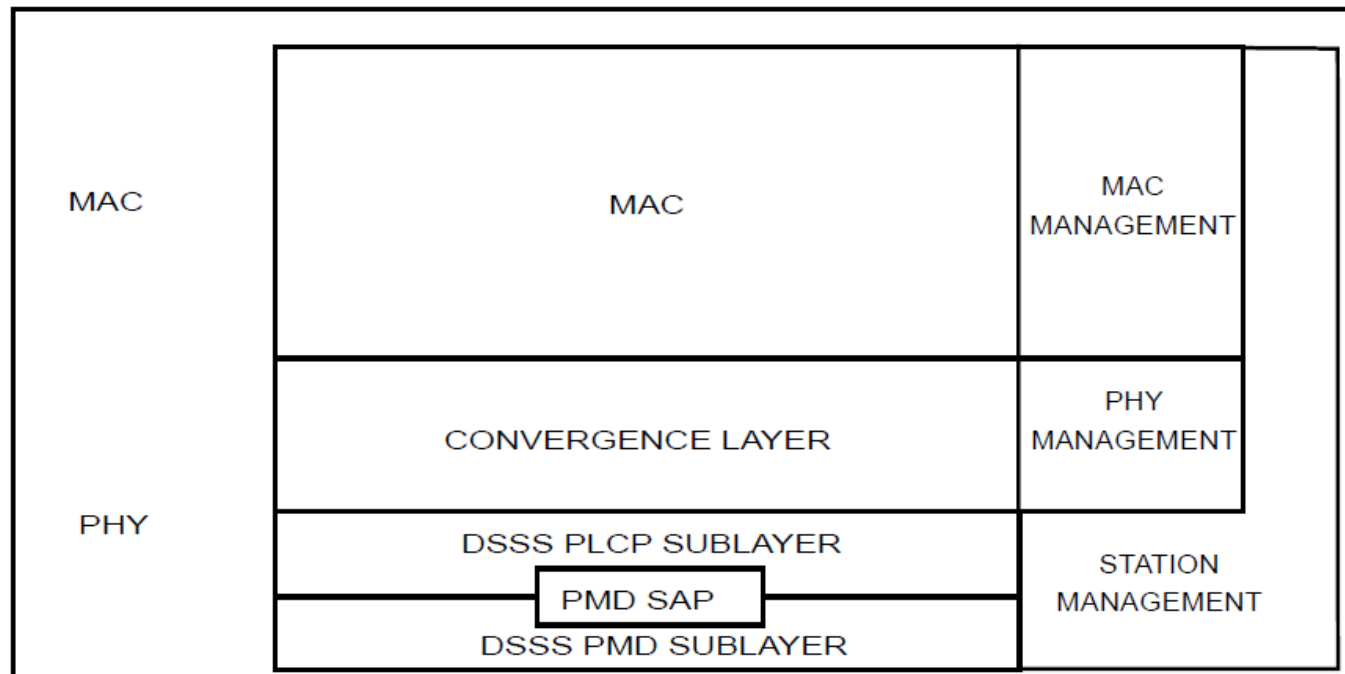

Figura 83 - Modelo de referencia de capas. Part 11: Wireless LAN Medium Access Control (MAC) and Physical Layer (PHY) specifications: Higher-Speed Physical Layer Extension in the 2.4GHz Band. 
los medios reales por los cuales se transmiten o reciben datos. Las funciones combinadas de las primitivas y parámetros de la subcapa High Rate PMD para la función de recepción dan como resultado un flujo de datos, información de temporización y parámetros de señal recibida asociados que se entregan a la subcapa PLCP.

\subsubsection{Numero de canales de operación}

IEEE $802.11 \mathrm{~b}$ trabaja en las frecuencias centrales de los canales de transmisión dadas por:

$$
F c=2407+5 n c[M H z](n c=1,2,3, \ldots, 14)
$$

Cada canal tiene un ancho de banda de $22 \mathrm{MHz}$

En la tabla 32 se muestra las frecuencias centrales del canal y los números CHNL ID. La FCC (EE. UU.), IC (Canadá) y ETSI (Europa) especifican la operación desde 2,4 hasta 2,4835 GHz. Para Japón, la operación se especifica como 2,471-2,497 GHz. Francia permite la operación desde 2,4465-2,4835 GHz, y España permite la operación desde $2,445-2,475 \mathrm{GHz}$.

La tabla 31 especifica con una "X" los canales admitidos en cada dominio de regulación.

Tabla 31 - Canales de frecuencia de High Rate PMD [16].

\begin{tabular}{|c|c|c|c|c|c|c|c|}
\hline \multirow[b]{2}{*}{ CHNL_ID } & \multirow[b]{2}{*}{$\begin{array}{l}\text { Frequency } \\
\text { (MHz) }\end{array}$} & \multicolumn{6}{|c|}{ Regulatory domains } \\
\hline & & $\begin{array}{l}X^{\prime} 10^{\prime} \\
\text { FCC }\end{array}$ & $\begin{array}{c}\mathrm{X}^{\prime} \mathbf{2 0} \\
\mathrm{IC}\end{array}$ & $\begin{array}{l}X^{\prime} 30^{\prime} \\
\text { ETSI }\end{array}$ & $\begin{array}{l}X^{\prime} 31^{\prime} \\
\text { Spain }\end{array}$ & $\begin{array}{c}\mathrm{X}^{\prime} 32^{\prime} \\
\text { France }\end{array}$ & $\begin{array}{l}X^{\prime} 40^{\prime} \\
\text { MKK }\end{array}$ \\
\hline 1 & 2412 & $\mathrm{X}$ & $\mathrm{X}$ & $\mathrm{X}$ & - & - & - \\
\hline 2 & 2417 & $\mathrm{X}$ & $\mathrm{X}$ & $\mathrm{X}$ & - & - & - \\
\hline 3 & 2422 & $\mathrm{X}$ & $\mathrm{X}$ & $\mathrm{X}$ & - & - & - \\
\hline 4 & 2427 & $\mathrm{X}$ & $\mathrm{X}$ & $\mathrm{X}$ & - & - & - \\
\hline 5 & 2432 & $\mathrm{X}$ & $\mathrm{X}$ & $\mathrm{X}$ & - & - & - \\
\hline 6 & 2437 & $\mathrm{X}$ & $\mathrm{X}$ & $\mathrm{X}$ & - & - & - \\
\hline 7 & 2442 & $\mathrm{X}$ & $\mathrm{X}$ & $\mathrm{X}$ & - & - & - \\
\hline 8 & 2447 & $\mathrm{X}$ & $\mathrm{X}$ & $\mathrm{X}$ & - & - & - \\
\hline 9 & 2452 & $\mathrm{X}$ & $\mathrm{X}$ & $\mathrm{X}$ & - & - & - \\
\hline 10 & 2457 & $\mathrm{X}$ & $\mathrm{X}$ & $\mathrm{X}$ & $\mathrm{X}$ & $\mathrm{X}$ & - \\
\hline 11 & 2462 & $\mathrm{X}$ & $\mathrm{X}$ & $\mathrm{X}$ & $\mathrm{X}$ & $\mathrm{X}$ & - \\
\hline 12 & 2467 & - & - & $\mathrm{X}$ & - & $\mathrm{X}$ & - \\
\hline 13 & 2472 & - & - & $\mathrm{X}$ & - & $\mathrm{X}$ & - \\
\hline 14 & 2484 & - & - & - & - & - & $\mathrm{X}$ \\
\hline
\end{tabular}




\subsubsection{Modulación y tasa de datos del canal.}

El protocolo admite cuatro formatos de modulación y tasa de datos para el PHY de alta velocidad: La velocidad de acceso básica que se basa en modulación DBPSK de $1 \mathrm{Mbit} / \mathrm{s}$, la velocidad de acceso mejorada basada en 2 Mbit/s DQPSK y la especificación de DSSS que define dos velocidades de datos basados en el esquema de modulación CCK para 5,5 Mbit/s y $11 \mathrm{Mbit} / \mathrm{s}$.

\subsubsection{Expansión de secuencias y modulación CCK en 5,5 Mbit/s y $11 \mathrm{Mbit} / \mathrm{s}$}

Para modulación CCK, la longitud del código de expansión es 8 y se basa en códigos complementarios. La velocidad de corte es de $11 \mathrm{Mchip} / \mathrm{s}$ y la duración del símbolo será exactamente de 8 chips complejos.

La fórmula 42 se utilizará para derivar las palabras de código CCK que se utilizarán para difundir tanto 5,5 Mbit/s y $11 \mathrm{Mbit} / \mathrm{s}$ :

$$
\left\{e^{j\left(\varphi_{1}+\varphi_{2}+\varphi_{3}+\varphi_{4}\right)}, e^{j\left(\varphi_{1}+\varphi_{3}+\varphi_{4}\right)}, e^{j\left(\varphi_{1}+\varphi_{2}+\varphi_{4}\right)},-e^{j\left(\varphi_{1}+\varphi_{4}\right)}, e^{j\left(\varphi_{1}+\varphi_{2}+\varphi_{3}\right)}, e^{j\left(\varphi_{1}+\varphi_{3}\right)},-e^{j\left(\varphi_{1}+\varphi_{2}\right)}, e^{j \varphi_{1}}\right\}
$$

Donde $\mathrm{C}$ es la palabra código $\mathrm{C}=\left\{\mathrm{C}_{0}\right.$ a $\left.\mathrm{C}_{7}\right\}$

La fórmula 41 crea 8 chips complejos $\left(\mathrm{C}_{0}\right.$ a $\left.\mathrm{C}_{7}\right)$, donde $\mathrm{C}_{0}$ se transmite primero en el tiempo.

El término $\varphi_{1}$ modifica la fase de todos los chips de código de la secuencia y se codifica en DQPSK para 5,5 Mbit/s y $11 \mathrm{Mbit} / \mathrm{s}$ tomando la forma de rotar todo el símbolo en la cantidad apropiada en relación con la fase del símbolo anterior.

A 5,5 Mbit/s, se transmiten 4 bits ( $\mathrm{d}_{0} \mathrm{a} \mathrm{d}_{3}$; $\mathrm{d}_{0}$ primero en el tiempo) por símbolo. Los bits de datos $\mathrm{d}_{0} \mathrm{y} \mathrm{d}_{1}$ codifican $\varphi_{1}$ según DQPSK y $\mathrm{d}_{2} \mathrm{y} \mathrm{d}_{3} \mathrm{CCK}$ codifican el símbolo $\mathrm{C}_{\mathrm{x}}$.

A $11 \mathrm{Mbit} / \mathrm{s}$, se transmiten 8 bits ( $\mathrm{d}_{0}$ a $\mathrm{d}_{7} ; \mathrm{d}_{0}$ primero en el tiempo) por símbolo. El primer dibit $\left(\mathrm{d}_{0}, \mathrm{~d}_{1}\right)$ codifica $\varphi_{1}$ basado en DQPSK y los siguientes dibits $\left(\mathrm{d}_{2}, \mathrm{~d}_{3}\right),\left(\mathrm{d}_{4}, \mathrm{~d}_{5}\right)$ y $\left(\mathrm{d}_{6}\right.$, $\mathrm{d}_{7}$ ) codifican $\varphi_{2}, \varphi_{3}$ y $\varphi_{4}$ respectivamente, según QPSK.

\subsubsection{Especificaciones de transmisión de PMD}

IEEE802.11b modula CCK que transmite a 11Mchips/seg con QPSK. Cada chip está compuesto de 8 bits (11Mbs) o 4 bits $(5,5 \mathrm{Mbps})$ cuya densidad espectral de potencia está dada por

$$
S_{B}(f)=2 E_{b} \log _{2} M \operatorname{sinc}^{2}\left(2 T_{b} \log _{2} M f\right)[\mathrm{W} / \mathrm{Hz}]
$$

Que luego de ser modulada, la densidad espectral de potencia de la señal transmitida está dada por 


$$
S_{B}^{\prime}(f)=\frac{1}{2}\left[S_{B}\left(f+f_{c}\right)+S_{B}\left(f-f_{c}\right)\right]
$$

$=E_{b} \log _{2} M\left[\operatorname{sinc}^{2}\left(2 T_{b} \log _{2} M(f+f c)\right)+\operatorname{sinc}^{2}\left(2 T_{b} \log _{2} M(f-f c)\right)\right][\mathrm{W} / \mathrm{Hz}]$

La tabla 33 especifica la potencia máxima de salida permitida. En los EE. UU., Las emisiones radiadas también deben cumplir con los estándares de emisión de radiación no controlada ANSI (IEEE Std C95.1-1999)

Tabla 33 - Niveles de potencia de transmisión [16].

\begin{tabular}{|l|l|l|}
\hline \multicolumn{1}{|c|}{$\begin{array}{c}\text { Maximum output } \\
\text { power }\end{array}$} & Geographic location & Compliance document \\
\hline $1000 \mathrm{~mW}$ & USA & FCC 15.247 \\
\hline $100 \mathrm{~mW}(\mathrm{EIRP})$ & Europe & ETS 300-328 \\
\hline $10 \mathrm{~mW} / \mathrm{MHz}$ & Japan & $\begin{array}{l}\text { MPT ordinance for Reg- } \\
\text { ulating Radio Equip- } \\
\text { ment, Article 49-20 }\end{array}$ \\
\hline
\end{tabular}

Los el espectro de potencia transmitido es inferior a $-30 \mathrm{dBr}(\mathrm{dB}$ en relación con el pico de $\operatorname{Sinc}(\mathrm{x}))$ para

$$
\begin{aligned}
& \mathrm{f}_{\mathrm{c}}-22 \mathrm{MHz}<\mathrm{f}<\mathrm{f}_{\mathrm{c}}-11 \mathrm{MHz} ; \mathrm{y} \\
& \mathrm{f}_{\mathrm{c}}+11 \mathrm{MHz}<\mathrm{f}<\mathrm{f}_{\mathrm{c}}+22 \mathrm{MHz}
\end{aligned}
$$

y debe ser menor a $50 \mathrm{dBr}$ para

$$
\begin{aligned}
& \mathrm{f}<\mathrm{f}_{\mathrm{c}}-22 \mathrm{MHz} \text {; y para } \\
& \mathrm{f}>\mathrm{f}_{\mathrm{c}}+22 \mathrm{MHz} .
\end{aligned}
$$

donde $f_{c}$ es la frecuencia central del canal.

La figura 84 esquematiza la densidad espectral de potencia de transmisión.

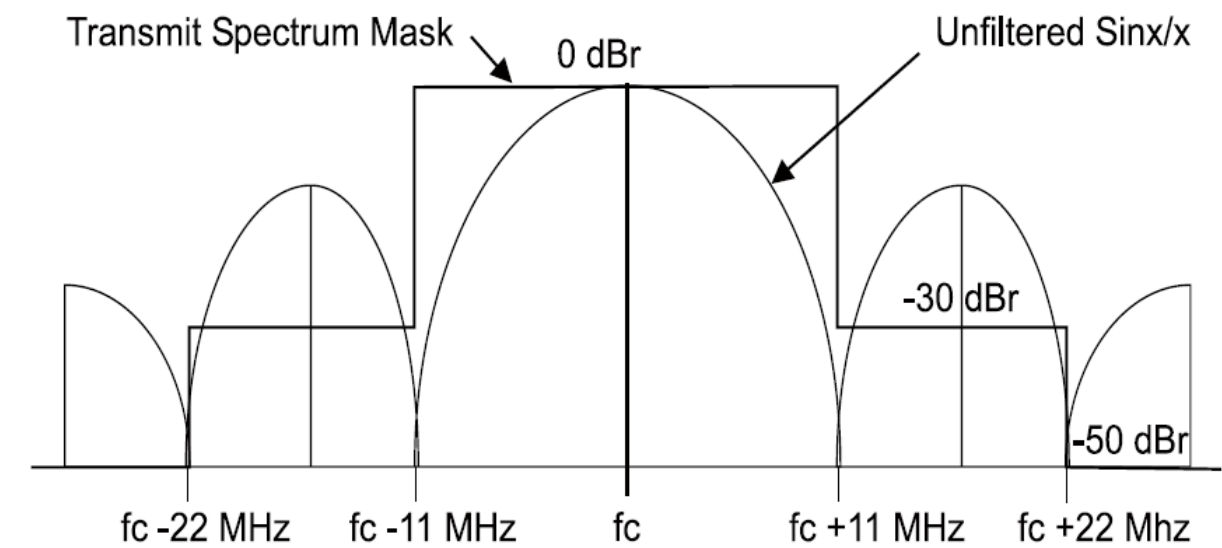

Figura 84 - Densidad espectral de potencia de transmisión. Part 11: Wireless LAN Medium Access Control (MAC) and Physical Layer (PHY) specifications: Higher-Speed Physical Layer Extension in the 2.4GHz Band.

La portadora de RF es reducida a una potencia menor de e15dB por debajo del pico del especto de potencia $\operatorname{Sinc}(x)$ 


\section{Herramientas informáticas utilizadas}

A la fecha de escritura del presente trabajo, se comercializan muy pocos dispositivos que implementen IEEE 802.15.6. Trabajos como [8] han realizado estudios sobre una implementación propia.

Castalia es un simulador de WSN, BAN y redes de dispositivos de baja potencia en general. Desarrollado a partir de OMNET++ y presentado en el 2007 por NICTA ${ }^{5}$. Su versión más reciente (3.3) se caracteriza por tener modelos de canal y radios avanzados basados en valores medidos empíricamente. Contempla en el modelado variaciones temporales y pérdidas de trayecto. [9]

Debido a la poca disponibilidad de dispositivos comerciales, a la complejidad que agregaría una implementación y a que existe un simulador como Castalia desarrollado a partir de valores empíricos, es que se optó por trabajar en un escenario simulado en el desarrollo de la presente tesis.

El escenario de simulación fue armado en Castalia y contenía 4 nodos estáticos: Por un lado, el nodo receptor (sobre el que se tomaron las mediciones de PER) y el transmisor IEEE802.15.6; y por el otro los nodos transmisores IEEE802.15.4 o IEEE802.11b.

Los nodos se dispusieron en el simulador de la forma que se describe en la figura 85 $\mathrm{y}$, según la variable en estudio se fue variando la distancia, canal de transferencia y e intervalo de paquetes de señal de la fuente no IEEE802.15.6 mientras se medía el PER en el nodo receptor.

\subsection{GNU Octave ${ }^{6}$}

GNU Octave es un software libre multiplataforma bajo Licencia Pública General de GNU (GPL) de la Free Software Foundation. Fue concebido originalmente en 1988 por James B. Rawlings, de la Universidad de Wisconsin-Madison, y John G. Ekerdt, de la Universidad de Texas, para ser un software complementario para un libro de texto de nivel universitario sobre diseño de reactores químicos que, después de ver las limitaciones de ese enfoque, los desarrolladores optaron por intentar construir una herramienta mucho más flexible.

GNU Octave también es un lenguaje de alto nivel, destinado principalmente a cálculos numéricos. Proporciona una interfaz de línea de comandos conveniente para resolver problemas lineales y no lineales numéricamente, y para realizar otros experimentos numéricos utilizando un lenguaje principalmente compatible con Matlab.

Cuenta con amplias herramientas para resolver problemas comunes de álgebra lineal numérica, encontrar las raíces de ecuaciones no lineales, integrar funciones ordinarias, manipular polinomios e integrar ecuaciones diferenciales y algebraicas diferenciales

\footnotetext{
${ }^{5}$ National Information and Communications Technology Australia Ltd

${ }^{6}$ https://www.gnu.org/software/octave/about.html (Último acceso 29/07/2020)
} 
ordinarias. Es fácilmente extensible y personalizable a través de funciones definidas por el usuario escritas en el propio lenguaje de Octave, o utilizando módulos cargados dinámicamente escritos en $\mathrm{C}++, \mathrm{C}$, Fortran u otros idiomas.

\subsubsection{Detalles técnicos ${ }^{7}$}

- Octave está escrito en C++ usando la biblioteca STL.

- Tiene un intérprete de su propio lenguaje (de sintaxis casi idéntica a Matlab), y permite una ejecución interactiva o por lotes.

- Su lenguaje puede ser extendido con funciones y procedimientos, por medio de módulos dinámicos.

- Utiliza otros programas GNU para ofrecer al usuario la posibilidad de crear gráficos para luego imprimirlos o guardarlos (Grace).

- Dentro del lenguaje también se comporta como una consola de órdenes (shell). Esto permite listar contenidos de directorios, por ejemplo.

- Además de correr en plataformas Unix también lo hace en Windows.

- Puede cargar archivos con funciones de Matlab (reconocibles por la extensión .m).

- Tiene ayuda en español.

\subsubsection{El lenguaje Octave ${ }^{7}$}

- La sintaxis es casi idéntica a la utilizada en MATLAB.

- Es un lenguaje interpretado.

- No permite pasar argumentos por referencia. Siempre son pasados por valor.

- No permite punteros.

- Se pueden generar scripts.

- Soporta gran parte de las funciones de la biblioteca estándar de C.

- Puede ser extendido para ofrecer compatibilidad con las llamadas al sistema UNIX.

- El lenguaje está pensado para trabajar con matrices, y provee mucha funcionalidad para trabajar con estas.

- Soporta estructuras similares a los "struct"s de C.

- Dispone de un entorno de desarrollo integrado y se han desarrollado otros para enseñar a programar, como ToolboX.

\subsection{OMNeT $++^{8}$}

OMNeT++ es un framework de simulación de red de eventos discretos modulares orientado a objetos. Tiene una arquitectura genérica, por lo que puede usarse (y ha sido) utilizada en varios dominios de problemas:

- Modelado de redes de comunicación cableadas e inalámbricas.

- Modelado de protocolo.

- Modelado de redes de colas.

\footnotetext{
${ }^{7}$ https://es.wikipedia.org/wiki/GNU_Octave (Último acceso 29/07/2020)

${ }^{8}$ https://doc.omnetpp.org/omnetpp/manual/\#tcha:introduction (último acceso 01/08/2020)
} 
- Modelado de multiprocesadores y otros sistemas de hardware distribuido.

- Validación de arquitecturas de hardware.

- Evaluar aspectos de rendimiento de sistemas de software complejos.

- Modelado y simulación general de cualquier sistema en el que el enfoque de eventos discretos sea adecuado y pueda asignarse convenientemente a entidades que se comunican mediante el intercambio de mensajes.

OMNeT++ en sí mismo no es un simulador de nada concreto, sino que proporciona infraestructura y herramientas para escribir simulaciones. Uno de los ingredientes fundamentales de esta infraestructura es una arquitectura de componentes para modelos de simulación. Los modelos se ensamblan a partir de componentes reutilizables denominados módulos. Los módulos bien escritos son realmente reutilizables y se pueden combinar de varias maneras, como los bloques LEGO.

Los módulos se pueden conectar entre sí a través de gates y combinarlos para formar módulos compuestos, sin una limitación en la profundidad de anidamiento. Los módulos se comunican a través del paso de mensajes, con estructuras de datos arbitrarias, a lo largo de rutas predefinidas a través de puertas y conexiones o directamente a su destino (este último, por ejemplo, es útil para simulaciones inalámbricas).

Los módulos pueden tener parámetros que pueden usarse para personalizar el su comportamiento y/o parametrizar la topología del modelo. En el nivel más bajo de la jerarquía, los módulos se denominan módulos simples y encapsulan el comportamiento del modelo. Éstos se programan en $\mathrm{C}++$ y utilizan la biblioteca de simulación.

Las simulaciones de OMNeT++ se pueden ejecutar en varias interfaces de usuario. Las que son gráficas y animadas son muy útiles para fines de demostración y depuración, y las de línea de comandos son las mejores para la ejecución por lotes.

El simulador, así como las interfaces y herramientas de usuario, son altamente portátiles. Se prueban en los sistemas operativos más comunes (Linux, MacOS/X, Windows), y se pueden compilar de fábrica o después de modificaciones triviales en la mayoría de los sistemas operativos tipo Unix.

OMNeT++ también admite simulación distribuida paralela; puede usar varios mecanismos para la comunicación entre particiones de una simulación distribuida paralela, por ejemplo, MPI o canalizaciones con nombre. El algoritmo de simulación en paralelo se puede ampliar fácilmente o conectar con otros nuevos; los modelos no necesitan ninguna instrumentación especial para ejecutarse en paralelo, es solo una cuestión de configuración. OMNeT++ incluso se puede utilizar para la presentación en el aula de algoritmos de simulación paralelos, porque las simulaciones se pueden ejecutar en paralelo incluso bajo la GUI que proporciona información detallada sobre lo que está sucediendo.

OMNeT ++ es gratis solo para uso académico y sin fines de lucro; para fines comerciales existe OMNEST de Simulcraft Inc, versión comercial compatible de OMNeT++. 


\subsubsection{Castalia ${ }^{9}$}

Castalia es un framework de modelos de OMNeT++ para simular Wireless Sensor Networks (WSN), Body Area Networks (BAN) y, en general, redes de dispositivos integrados de baja potencia, desarrollado por Thanassis Boulis en el tema de Sistemas en red en NICTA desde 2007.

Castalia es utilizada por investigadores y desarrolladores para probar sus algoritmos y/o protocolos distribuidos en modelos de radio y canales inalámbricos realistas, con un comportamiento de nodo realista especialmente relacionado con el acceso a la radio.

Las características más destacadas de Castalia incluyen: modelo para la variación temporal de la pérdida de trayectoria, interferencia de grano fino y cálculo de RSSI, modelado de procesos físicos, deriva de reloj de nodo y varios protocolos MAC populares implementados.

Castalia es altamente paramétrica, proporciona herramientas para ayudar a ejecutar grandes estudios de simulación paramétrica, procesar y visualizar los resultados.

\footnotetext{
${ }^{9}$ https://omnetpp.org/download-items/Castalia.html (último acceso 01/08/2020)
} 


\section{Análisis matemático}

En nuestro análisis matemático de coexistencia, adoptamos la metodología desarrollada en [12] para estimar el PER causado por la interferencia de IEEE802.15.4 e IEE802.11b sobre IEEE802.15.6. El PER puede ser usada para estimar otras métricas de performance, como por ejemplo la latencia o el throughput.

En el análisis matemático, solo consideramos el efecto de la capa física de las tecnologías inalámbricas estudiadas. Los efectos de la capa MAC, serán considerados en el capítulo 7.

\subsection{Metodología}

Se adoptó la metodología desarrollada en [12], donde toma el modelo geométrico de la Affected Wireless Network (AWN) y la Interfering Wireless Network (IWN) como punto de partida. Luego utiliza un modelo de path-loss para calcular la Signa-Interference Ratio (SIR) promedio en el receptor AWN, que refleja la potencia de transmisión de la señal y la interferencia y la geometría de las redes. A continuación, se usa un modelo de capa física para calcular la Symbol Error Rate (SER) en función del SIR en el receptor AWN, suponiendo una interferencia continua.

Finalmente, un modelo temporal toma en cuenta la naturaleza dinámica de la interferencia al modelarla como un generador de impulsos con propiedades estadísticas conocidas, y calcula el PER del AWN en función de SER.

\subsection{Modelo Geométrico}

El modelo geométrico describe la ubicación de los nodos de la AWN y IWN. Consideramos la configuración simple propuesta en [12] que se muestra en la Figura 85, donde cada red consta de solo dos nodos. Además, se supone que solo el nodo de IWN más cercano a la AWN causa interferencia sobre ésta última. 
Para estudiar la interferencia del caso más desfavorable durante la transferencia unidireccional, suponemos que el nodo en $(0 ; 0)$ es el receptor, el nodo en $(0 ; \mathrm{D})$ es el transmisor y el nodo en $(\mathrm{d} ; 0)$ es el interferente.

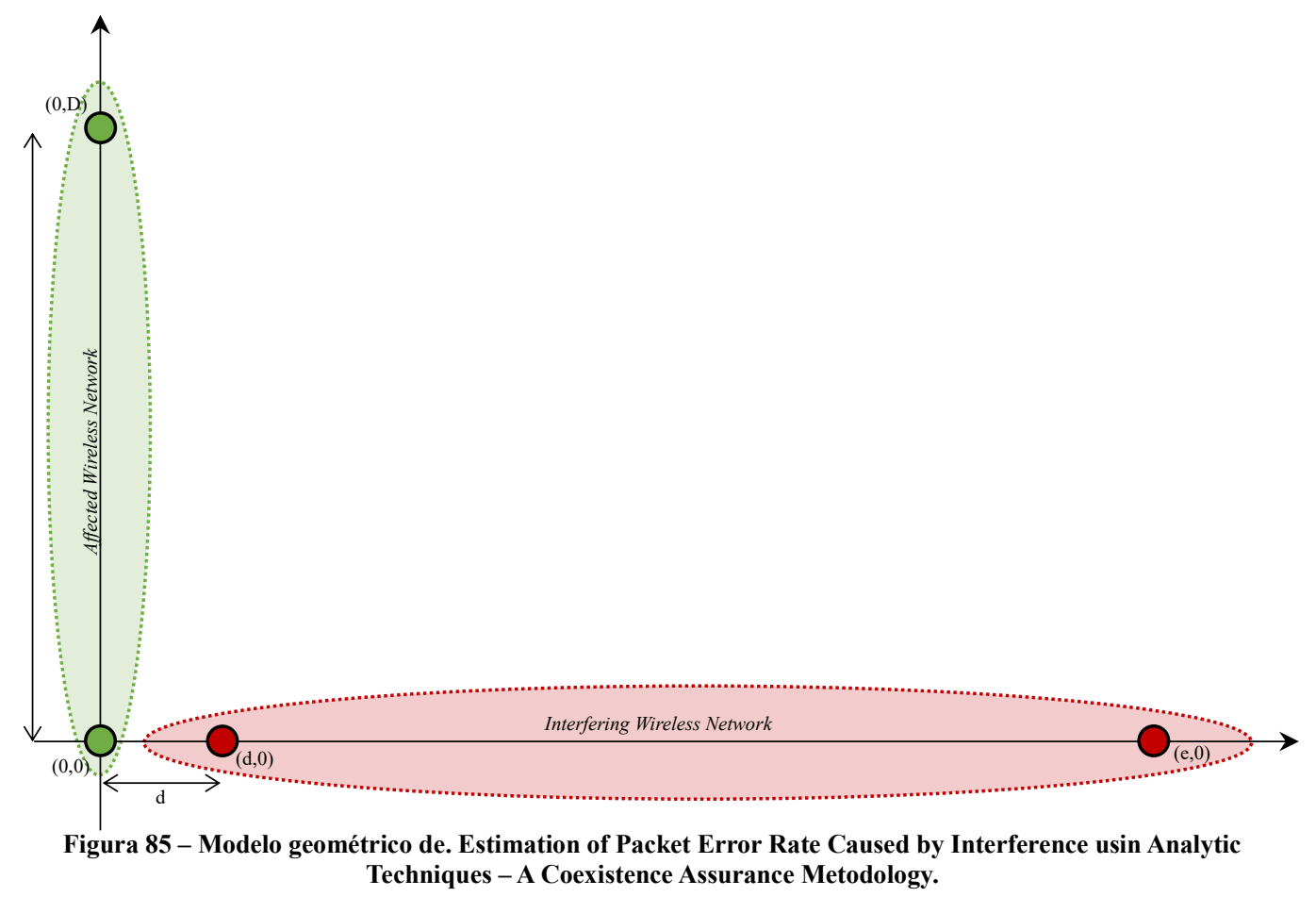

\subsection{Modelo de pérdida por recorrido de señal (Path-loss model)}

Las distancias del modelo geométrico se traducen en atenuación de señal utilizando. El modelo de pérdida por ruta se elige según la banda de frecuencia utilizada y el entorno en el que operan las redes. En nuestro caso de estudio, usaremos el modelo recomendado en [19] para entornos interiores en la banda de 2,4GHz. Este un modelo lineal por partes, descrito por la ecuación (45), que representa la pérdida de trayectoria en el espacio libre hasta $8 \mathrm{~m}$ y un entorno más desordenado más allá de $8 \mathrm{~m}$.

$$
P(d)_{d B}^{r}=\left\{\begin{array}{lr}
40,2+20 \log _{10}(d) & 0,5 m<d \leq 8 m \\
58,5+33 \log _{10}(d) & d>8 m
\end{array}\right.
$$

A distancias menores a los 0,5 metros, no es posible usar la fórmula anterior debido a problemas de campo cercano y de diseño del dispositivo [12]. Es por ello que no se estudiaron los efectos de la interferencia antes de $10 \mathrm{~s} 50 \mathrm{~cm}$.

La señal de interferencia recibida atraviesa un filtro de entrada, por lo que la potencia recibida luego éste está dado por (46):

$$
P_{I}^{r}= \begin{cases}P_{I}^{r} & B_{I} \leq B_{f} \\ P_{I}^{r} \frac{B_{f}}{B_{I}} & B_{I}>B_{f}\end{cases}
$$


Donde $\mathrm{B}_{\mathrm{I}}$ es el ancho de banda de la señal de interferencia y $\mathrm{B}_{\mathrm{f}}$ es el ancho de banda del filtro de entrada.

Con las potencias de señal y de interferencia recibidas en el receptor, la SIR (en dB) se obtiene con la ecuación (47):

$$
S I R_{d B}=P_{s, d B}^{r}-P_{I, d B}^{r}
$$

Donde $P_{s, d B}^{r}$ es la potencia recibida de la señal (en decibelios) y $P_{I, d B}^{r}$ es la potencia recibida de interferencia (en decibelios) después del filtro de entrada.

\subsection{Modelo de capa físico (Physical layer model)}

El modelo de capa física se usa para calcular el SER del AWN en función del SIR en el receptor. Hemos adoptado el modelo de capa PHY básico de [12] y lo hemos modificado para IEEE 802.15.6. La señal es un paquete de LS símbolos, cada uno de los cuales tienen una duración $\mathrm{T}$, y la interferencia es continua. Se supone que todos los símbolos se transmiten a través de un esquema de modulación y una tasa de código comunes.

El modelo comienza con la expresión BER para BPSK y DQPSK en presencia de Additive White Gaussian Noise (AWGN). A continuación, se obtiene la relación entre $\mathrm{E}_{\mathrm{S}} / \mathrm{N}_{0}$ y la Signal-to-Noise Ratio (SNR) en el receptor.

\section{Cálculo de la Probabilidad de Error}

La Tasa de Error de Bit se calcula [7]:

$$
B E R=\left\{\begin{array}{lc}
0,5 e^{-\frac{E b}{N o}} & B P S K \\
Q\left(\sqrt{\frac{4 E S}{N o}} \sin \frac{\pi}{4 \sqrt{2}}\right) & D Q P S K
\end{array}\right.
$$

Donde $E b$ es la energía de bit.

La probabilidad de que se produzca un evento erróneo [11]

$$
\begin{aligned}
& P e \cong \operatorname{erfc}\left(\sqrt{\frac{2 E S}{N o}} \sin \frac{\pi}{2 M}\right) \quad M \geq 410 \\
& P e=B E R=0,5 e^{-\frac{E b}{N o}} \quad M=2
\end{aligned}
$$

Un evento erróneo en el receptor consiste en un símbolo mal decodificado por el receptor, por lo que la probabilidad de que produzca un evento de error $(\mathrm{Pe})$ es igual a la Tasa de Error de Símbolo (SER) [12].

\footnotetext{
${ }^{10}$ Para grandes valores de $\frac{E s}{N o}$
} 


\section{Cálculo de $E s / N o$}

Si llamamos a:

Es: Energía de símbolo

Eb: Energía de bit

$\mathrm{N}_{0}$ : Densidad espectral de potencia de ruido

La relación entre Es y Eb es

$$
E s=\log _{2}(M) E b
$$

donde $\mathrm{M}$ es la cantidad de símbolos de la constelación. Por lo que la relación entre Es/No y Eb/No es

$$
\frac{E s}{N o}=\log _{2}(M) \frac{E b}{N o}(51)
$$

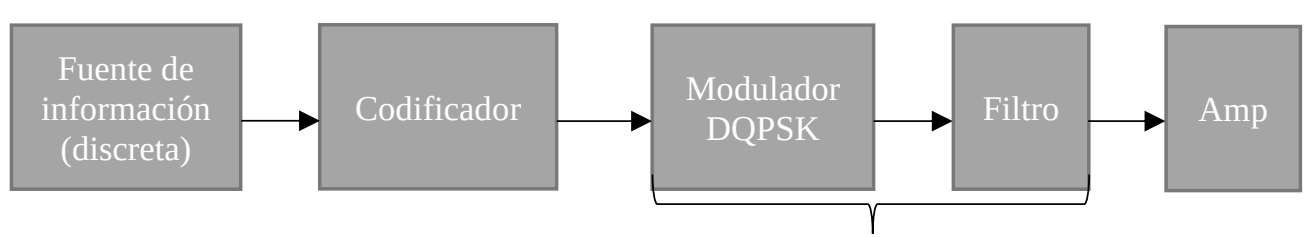

SRRC

Figura 86 - Modelo en bloques del emisor.

El codificador agrega bits redundantes para que el receptor pueda corregir errores [11]

$$
R b_{i}=R c R b_{t}(52)
$$

Donde $R b_{t}$ es la tasa del bit transmitido, $R b_{i}$ es la tasa del bit de información y $R c$ es la tasa de codificación. Tener en cuenta que, como el codificador agrega bits, la tasa de bits transmitidos es mayor que la tasa de bits de información.

$$
E b_{t}=S T b_{t}=\frac{S}{R b_{t}}=\left(\frac{R_{c}}{R b_{i}}\right) S
$$

Donde $S$ es la potencia de la señal y $T b_{t}$ es el tiempo que dura el bit transmitido.

Si divido ambos términos por la densidad espectral de potencia de ruido (No):

$$
\frac{E b_{t}}{N o}=\frac{\left(\frac{S}{N o}\right) R c}{R b_{i}}=\left(\frac{R c}{R b_{i}}\right) S N R
$$

Combinando (53) con (54) 


$$
\frac{E b_{t}}{N o}=\frac{R c}{R b_{i}} S N R
$$

\subsection{Modelo Temporal}

Se consideró el modelo temporal de [12] y éste convierte la Tasa de Error de Símbolos (SER) en Tasa de Error de Paquetes (PER), tomando los aspectos temporales de la señal y la interferencia.

El principio básico de este modelo es considerar la probabilidad de colisión entre los paquetes de señal e interferencia.

Si $X$ denota el número de símbolos colisionados, entonces $X$ es una variable aleatoria con función masa de probabilidad $f_{x}(x)$, donde $x=0,1,2, \ldots, L s$, y donde $L s$ es la longitud del paquete señal. El PER está dado por la ecuación (56):

$$
P E R=\sum_{x=0}^{L S}\left(1-(1-\rho)^{x}\right) f_{x}(x)
$$

Donde $\rho$ es el SER.

$f_{x}(x)$ depende de la longitud del paquete $L s$, de la longitud del paquete de interferencia $L i$ y el intervalo de paquetes de interferencia $L i_{p e r}$.

Se consideraron los paquetes de señal e interferencia de longitud fija y el $L i_{p e r}$ de una longitud de forma de acomodar los paquetes de señal e interferencia.

Dependiendo de la posición aleatoria del paquete de señal relativa al paquete de interferencia, como se ve en la figura 87, surgen tres posibles escenarios: colisión total, parcial y no colisión [12].
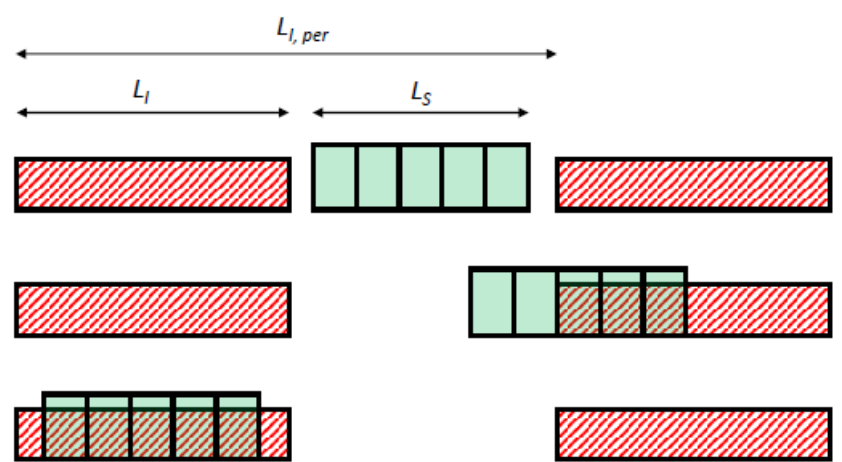

$\square$ Signal packet

EOA Interference packet

Figura 87: Modelo temporal de [4]. Analysis of coexistence between IEEE 802.15.4, BLE and IEEE 802.11 in the 2.4 GHz ISM band.

Para valores fijos de $L s$ y $L i$, la función masa de probabilidad, $f_{x}(x)$, toma la forma genérica (57) [12] 


$$
f_{x}(x)= \begin{cases}c_{1} & x=0 \\ c_{2} & x=1,2, \ldots, K-1 \\ c_{3} & x=K \\ 0 & x=K+1, K+2, \ldots, \max (L s, L i)\end{cases}
$$

Donde $c_{1}, c_{2}$ y $c_{3}$ son constantes y $\mathrm{K}$ es el máximo número de símbolos colisionados dados por $\min (L s, L i)$.

Combinando las ecuaciones (56) y (57) y simplificando, se obtiene el PER como función del SER, $\rho$ :

$$
P E R=\frac{c_{2}\left(K \rho-1+(1-\rho)^{K}\right.}{\rho}+c_{3}\left(1-(1-\rho)^{K}\right)
$$

Las constantes $c_{1}, c_{2}$ y $c_{3}$ dependen de $L s, L i$ y $L i_{p e r}$.

Si se considera a la trama de información igualmente probable de iniciar en cualquier parte de $L i_{p e r}$, la probabilidad de inicio es:

$$
\frac{1}{L i_{p e r}}
$$

Para que $L i$ colisione totalmente con $L s$, es necesario que la primera inicie entre el primer símbolo de $L s$ y el símbolo $L s-L i$; por lo que, considerando (59):

$$
C_{3}=\frac{L s-L i}{L i_{\text {per }}}
$$

Para que existan colisiones parciales, es necesario que $L i$ inicie entre el símbolo $L s-L i$ y el último símbolo de $L s$ o que $L s$ inicie en el espacio que ocupa $L i$. Por lo que, considerando esto y (59):

$$
\frac{2(L i-1)}{L i_{\text {per }}}(61)
$$

La ecuación (61) es la probabilidad que exista un choque parcial, pero como interesa la probabilidad que Li choque con 1 símbolo, 2 símbolos, 3 símbolos, etc; y considerando esto igualmente probables para todos los casos, entonces:

$$
c_{2}=\frac{2(L i-1)}{L i_{p e r}} \frac{1}{(L i-1)}=\frac{2}{L i_{p e r}}(62)
$$

Por último, existe una única forma que no se produzca una colisión de tramas y es que $L s$ inicie entre $L s+L i$ y $L i_{p e r}$. Por lo que:

$$
c_{1} \frac{L i_{\text {per }}-(L s-1)-(L i-1)}{L i_{\text {per }}}=\frac{L i_{\text {per }}-L s-L i+2}{L i_{\text {per }}}
$$




\subsection{Resultados de la simulación matemática}

\subsubsection{Distancia de la fuente de interferencia}

Condiciones de la simulación:

\begin{tabular}{|c|c|c|c|}
\hline & IEEE 802.15.6 & IEEE802.15.4 & IEEE $802.11 \mathrm{~b}$ \\
\hline Potencia de transmisión & $-40 \mathrm{~dB}$ & $-30 \mathrm{~dB}$ & $-10 \mathrm{~dB}$ \\
\hline Ancho de banda & $1 \mathrm{MHz}$ & $2 \mathrm{MHz}$ & $22 \mathrm{MHz}$ \\
\hline Frecuencia de trabajo & $2240 \mathrm{MHZ}$ y $2442 \mathrm{MHz}$ & $2440 \mathrm{MHz}$ & $2442 \mathrm{MHz}$ \\
\hline $\begin{array}{l}\text { Distancia de la fuente de } \\
\text { interferencia al receptor }\end{array}$ & & \multicolumn{2}{|c|}{$\begin{array}{l}\text { de } 0,5 \text { a } 20^{11} \text { metros haciendo } \\
\text { mediciones cada } 0,1 \text { metros. }\end{array}$} \\
\hline $\begin{array}{l}\text { Distancia entre emisor y } \\
\text { receptor }\end{array}$ & $0,5 \mathrm{~m}$ & & \\
\hline Tasa de transmisión & $\begin{array}{l}121,4 \mathrm{Kbps}-600000 \\
\text { baudios }\end{array}$ & $250 \mathrm{Kbps}$ & $11 \mathrm{Mbps}$ \\
\hline Tiempo de símbolo de señal & $\mathrm{T}=1 / 600000 \mathrm{baud}=1,66 \mu \mathrm{seg}$ & & \\
\hline Longitud de paquete & $11222 \mathrm{~T}$ & $5254 \mathrm{~T}$ & $563 \mathrm{~T}$ \\
\hline Intervalo de paquetes & & $18000 \mathrm{~T}$ & $12000 \mathrm{~T}$ \\
\hline
\end{tabular}

${ }^{11}$ En el paper original [4], la fuente de interferencia se alejaba hasta los 100 metros. En éste trabajo se redujo a 20 metros porque el valor de PER para cada caso llegaba a 0 mucho antes. 


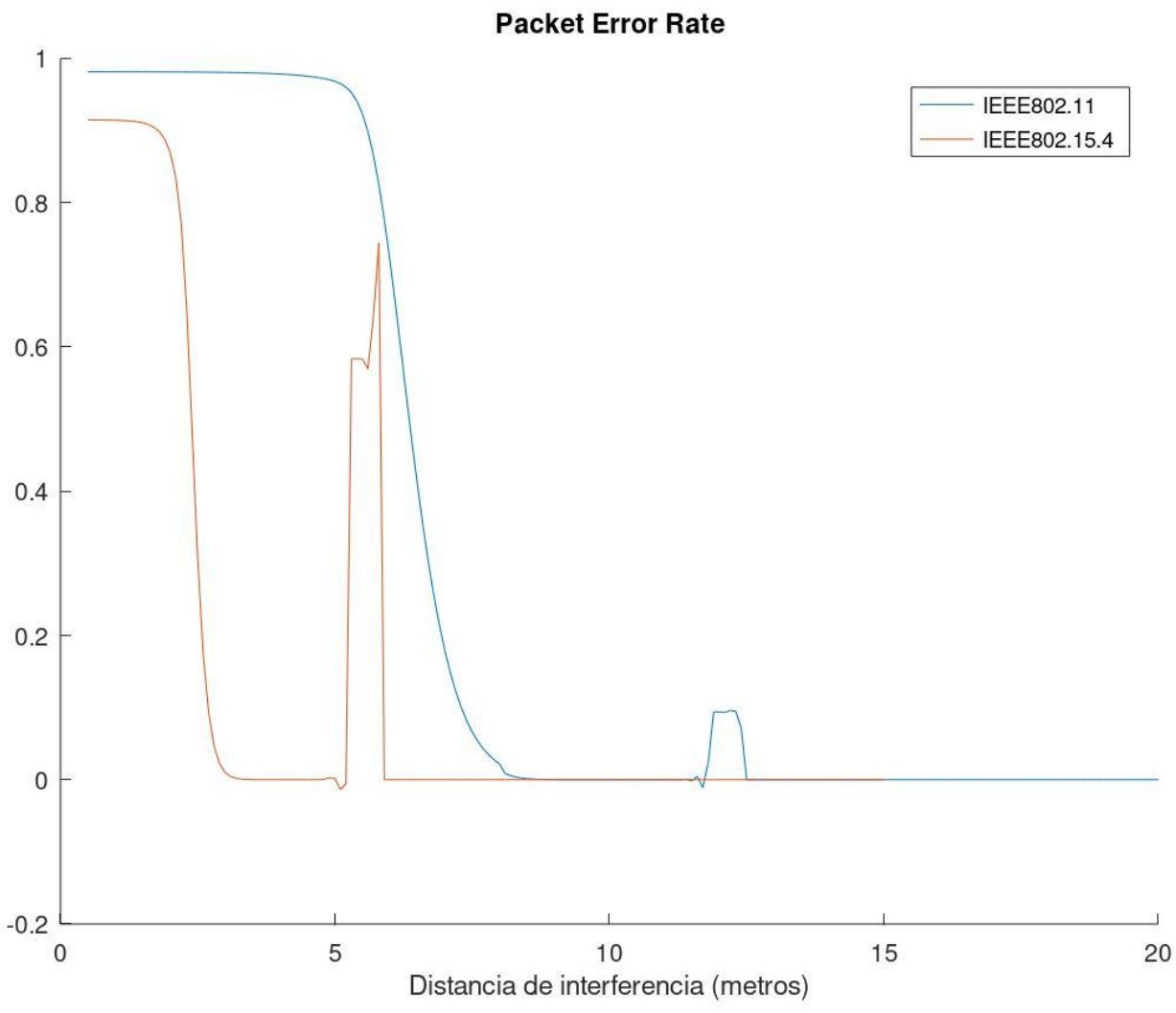

Figura 88 - PER en función de la distancia

Resultados:

PER de IEEE802.15.6 cae por debajo del $10 \%$ a $\mathbf{3 , 2 m}$ en IEEE802.15.4 y a $\mathbf{8 , 2} \mathbf{m}$ en IEEE802.11b. 
6.6.2. Separación de canales con la fuente interferencia

Condiciones de la simulación:

\begin{tabular}{|l|l|l|l|}
\hline & IEEE 802.15.6 & IEEE802.15.4 & IEEE 802.11b \\
\hline Potencia de transmisión & $-40 \mathrm{~dB}$ & $-30 \mathrm{~dB}$ & $-10 \mathrm{~dB}$ \\
\hline Ancho de banda & $1 \mathrm{MHz}$ & $2 \mathrm{MHz}$ & $22 \mathrm{MHz}$ \\
\hline Frecuencia de trabajo & $\begin{array}{l}\text { Desde } 2424 \mathrm{MHz} \text { hasta } \\
2458 \mathrm{MHz}\end{array}$ & $2440 \mathrm{MHz}$ & $2442 \mathrm{MHz}$ \\
\hline $\begin{array}{l}\text { Distancia de la fuente de } \\
\text { interferencia al receptor }\end{array}$ & & $1 \mathrm{~m}$ & $2 \mathrm{~m}$ \\
\hline $\begin{array}{l}\text { Distancia entre emisor y } \\
\text { receptor }\end{array}$ & $0,5 \mathrm{~m}$ & $250 \mathrm{Kbps}$ & $11 \mathrm{Mbps}$ \\
\hline Tasa de transmisión & $121,4 \mathrm{Kbps}-600000$ & & \\
\hline Tiempo de símbolo de señal & $\mathrm{T}=1 / 600000 \mathrm{baud}=1,66 \mu \mathrm{seg}$ & & $563 \mathrm{~T}$ \\
\hline Longitud de paquete & $11222 \mathrm{~T}$ & $5254 \mathrm{~T}$ & $18000 \mathrm{~T}$ \\
\hline Intervalo de paquetes & & & $12000 \mathrm{~T}$ \\
\hline
\end{tabular}




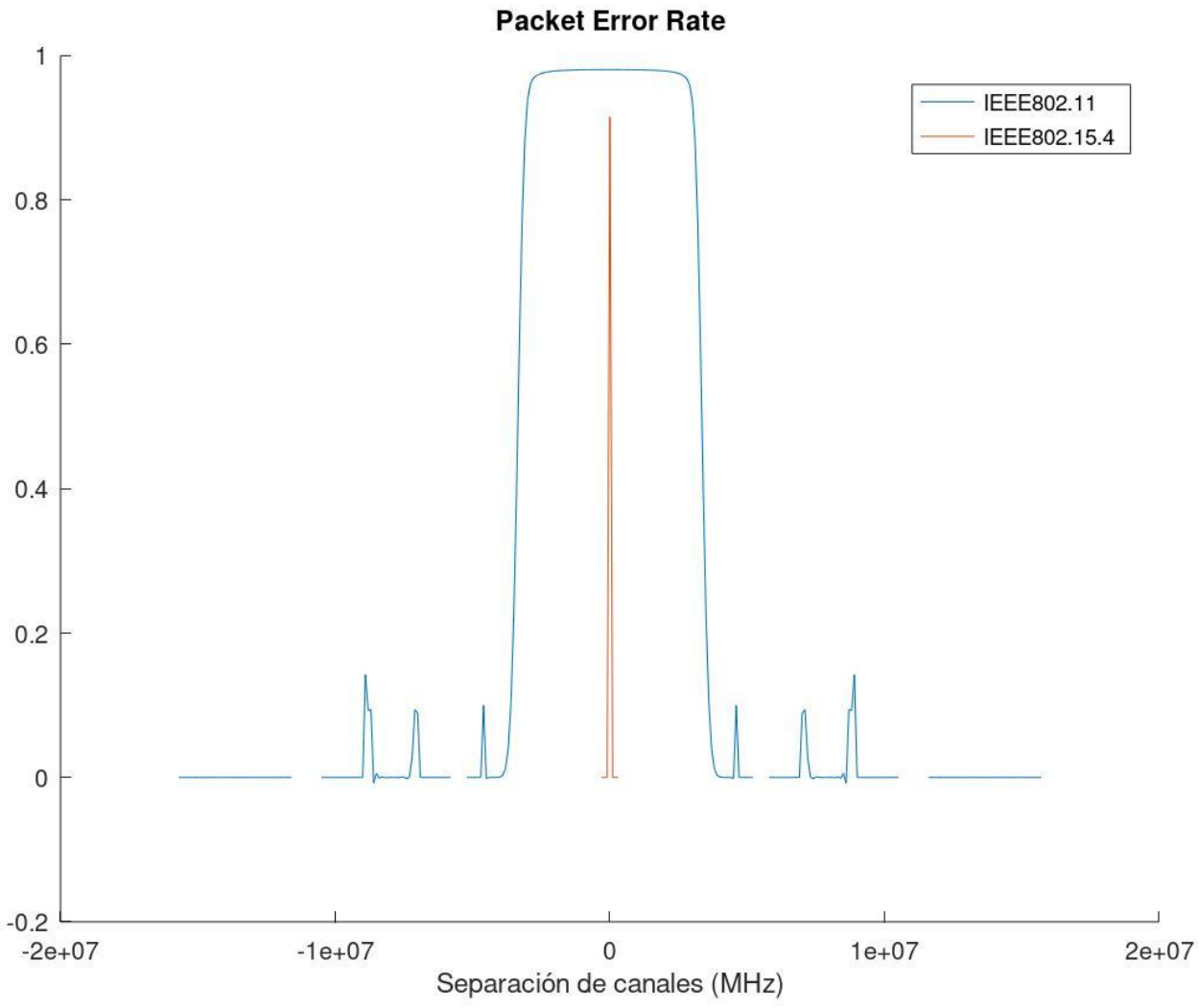

Figura 89 - PER en función de la separación de canales.

Resultados:

PER de IEEE802.15.6 cae por debajo del 10\% a cuando la diferencia de la frecuencia del canal es de $\mathbf{\pm 4 , 2} \mathbf{M H z}$ en IEEE802.11b. Para el caso que IEEE802.15.6 es interferido por IEEE802.15.4, éste segundo afecta al primero solamente cuando coinciden en el canal de transmisión. 
6.6.3. Intervalo de paquetes de la fuente de interferencia

El mínimo intervalo entre paquetes es de 1mseg (valor de AFS) para IEEE 802.11.4 [2] y $1 \mu \mathrm{seg}$ (valor de SIFS) para IEEE 802.11b [16]. Considerando esto, es que se eligieron los valores mínimos de $\mathrm{Li}_{\text {per }}$ para la simulación.

Condiciones de la simulación:

\begin{tabular}{|c|c|c|c|}
\hline & IEEE 802.15.6 & IEEE802.15.4 & IEEE $802.11 \mathrm{~b}$ \\
\hline Potencia de transmisión & $-40 \mathrm{~dB}$ & $-30 \mathrm{~dB}$ & $-10 \mathrm{~dB}$ \\
\hline Ancho de banda & $1 \mathrm{MHz}$ & $2 \mathrm{MHz}$ & $22 \mathrm{MHz}$ \\
\hline Frecuencia de trabajo & $2440 \mathrm{MHz}$ y $2442 \mathrm{MHz}$ & $2440 \mathrm{MHz}$ & $2442 \mathrm{MHz}$ \\
\hline $\begin{array}{l}\text { Distancia de la fuente de } \\
\text { interferencia al receptor }\end{array}$ & & $1 \mathrm{~m}$ & $2 \mathrm{~m}$ \\
\hline $\begin{array}{l}\text { Distancia entre emisor y } \\
\text { receptor }\end{array}$ & $0,5 \mathrm{~m}$ & & \\
\hline Tasa de transmisión & $\begin{array}{l}121,4 \mathrm{Kbps}-600000 \\
\text { baudios }\end{array}$ & $250 \mathrm{Kbps}$ & $11 \mathrm{Mbps}$ \\
\hline Tiempo de símbolo de señal & $\mathrm{T}=1 / 600000 \mathrm{baud}=1,66 \mu \mathrm{seg}$ & & \\
\hline Longitud de paquete & $11222 \mathrm{~T}$ & $5254 \mathrm{~T}$ & $563 \mathrm{~T}$ \\
\hline Intervalo de paquetes & & \multicolumn{2}{|c|}{$\begin{array}{l}\text { Desde } 16200 \mathrm{~T} \text { a } 600000 \mathrm{~T} \text { con } \\
\text { intervalos de } 600 \mathrm{~T}\end{array}$} \\
\hline
\end{tabular}




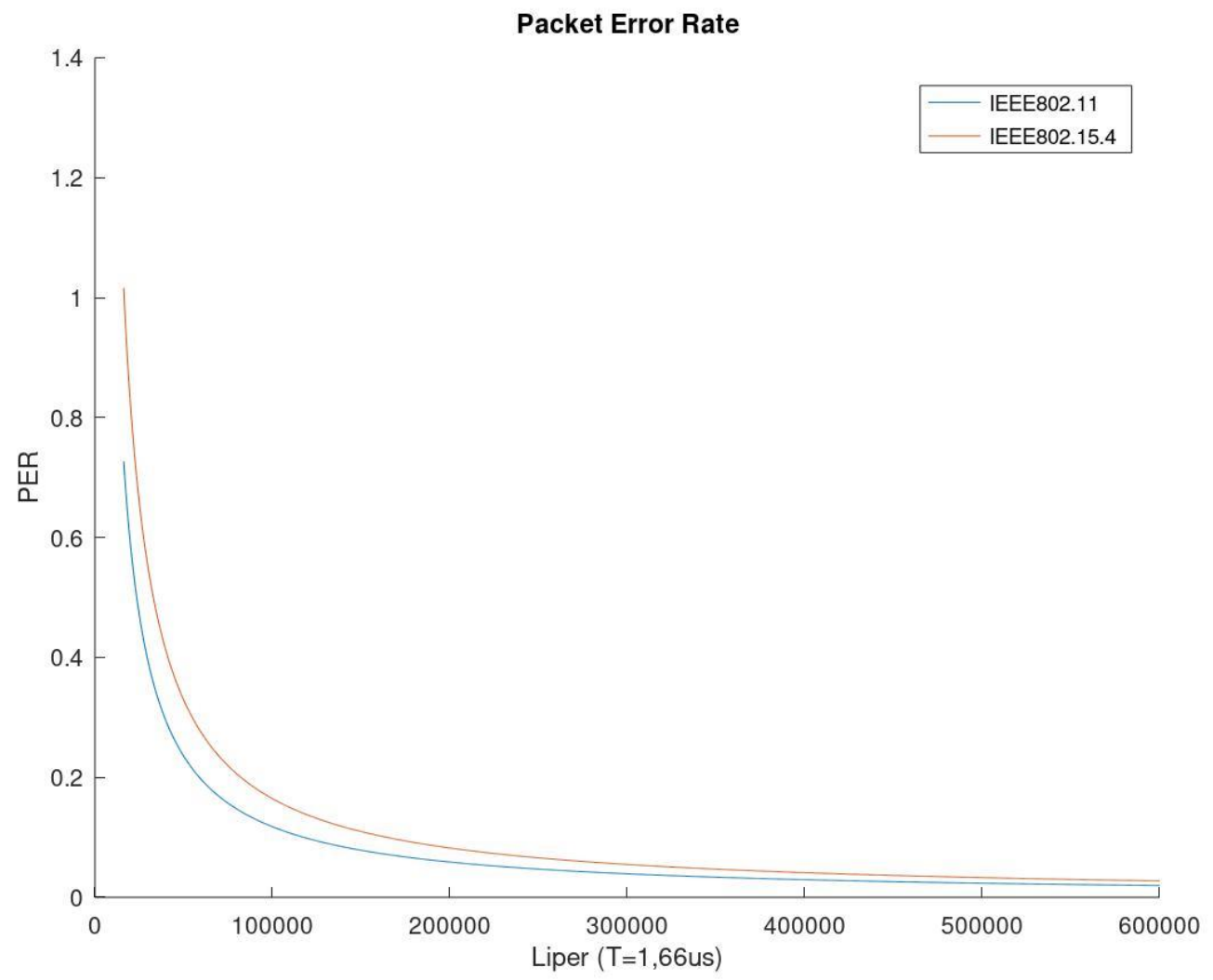

Figura 90 - PER en función de la separación de paquetes de interferencia

Resultados:

PER de IEEE802.15.6 cae por debajo del 10\% a partir de los 27,39mseg (16500T) para IEEE802.15.4 y 19,62mseg (11820T) para IEEE802.11b. 


\section{Simulación con Castalia}

7.1. Modelo de pérdida promedio por recorrido de señal (Average Pathloss model)

Para WSN, donde la separación de los nodos va desde unos metros a cientos de metros, se ha demostrado que el modelo de sombreado lognormal [13] proporciona estimaciones precisas para la pérdida de trayectoria promedio. Esta es la fórmula que usa Castalia para estimar la pérdida en $\mathrm{dB}$ en función de la distancia:

$$
P_{L}(d)=P_{L}\left(d_{0}\right)+10 \eta \log \left(\frac{d}{d_{0}}\right)+X_{\sigma}
$$

Donde:

$\mathrm{P}_{\mathrm{d}}\left(\mathrm{d}_{0}\right)$ es la pérdida a una distancia conocida $\left(\mathrm{d}_{0}\right)$

$\eta$ es el path los exponent

$\mathrm{X}_{\sigma}$ es una variable aleatoria gaussiana de media cero con estándar de desviación $\sigma$

Castalia por defecto usa los valores:

\begin{tabular}{|l|l|}
\hline$d_{0}$ & $1 \mathrm{~m}$ \\
\hline $\mathrm{P}_{\mathrm{d}}\left(\mathrm{d}_{0}\right)$ & $55 \mathrm{~dB}$ \\
\hline$\eta$ & $2,4 \mathrm{~dB}$ \\
\hline$\sigma$ & 4 \\
\hline
\end{tabular}

Considerando que la documentación de Castalia indica que éste puede ser utilizado por investigadores y desarrolladores que desean probar sus algoritmos y/o protocolos distribuidos en canales inalámbricos realistas y modelos de radio, con un comportamiento de nodo realista especialmente relacionado con el acceso a la radio [14], es que se eligió usar los parámetros por defecto. 


\subsection{Resultados de la simulación con Castalia}

\subsubsection{Distancia de la fuente de interferencia}

Condiciones de la simulación:

\begin{tabular}{|c|c|c|c|}
\hline & IEEE 802.15.6 & IEEE802.15.4 & IEEE $802.11 b$ \\
\hline Potencia de transmisión & $-40 \mathrm{~dB}$ & $-30 \mathrm{~dB}$ & $-10 \mathrm{~dB}$ \\
\hline Ancho de banda & $1 \mathrm{MHz}$ & $2 \mathrm{MHz}$ & $22 \mathrm{MHz}$ \\
\hline Frecuencia de trabajo & $2240 \mathrm{MHZ}$ y $2442 \mathrm{MHz}$ & $2440 \mathrm{MHz}$ & $2442 \mathrm{MHz}$ \\
\hline $\begin{array}{l}\text { Distancia de la fuente de } \\
\text { interferencia al receptor }\end{array}$ & & \multicolumn{2}{|c|}{$\begin{array}{l}\text { de } 0,5 \text { a } 16,5^{12} \text { metros haciendo } \\
\text { mediciones cada } 1 \text { metro. }\end{array}$} \\
\hline $\begin{array}{l}\text { Distancia entre emisor y } \\
\text { receptor }\end{array}$ & $0,5 \mathrm{~m}$ & & \\
\hline Tasa de transmisión & $\begin{array}{l}121,4 \mathrm{Kbps}-600000 \\
\text { baudios }\end{array}$ & $250 \mathrm{Kbps}$ & $11 \mathrm{Mbps}$ \\
\hline Tiempo de símbolo de señal & $\mathrm{T}=1 / 600000 \mathrm{baud}=1,66 \mu \mathrm{seg}$ & & \\
\hline Longitud de paquete & $11222 \mathrm{~T}$ & $5254 \mathrm{~T}$ & $563 \mathrm{~T}$ \\
\hline Intervalo de paquetes & & $18000 \mathrm{~T}$ & $12000 \mathrm{~T}$ \\
\hline
\end{tabular}

${ }^{12}$ En el paper original [4], la fuente de interferencia se alejaba hasta los 100 metros. En este trabajo se redujo a 20 metros porque el valor de PER para cada caso llegaba a 0 mucho antes. 


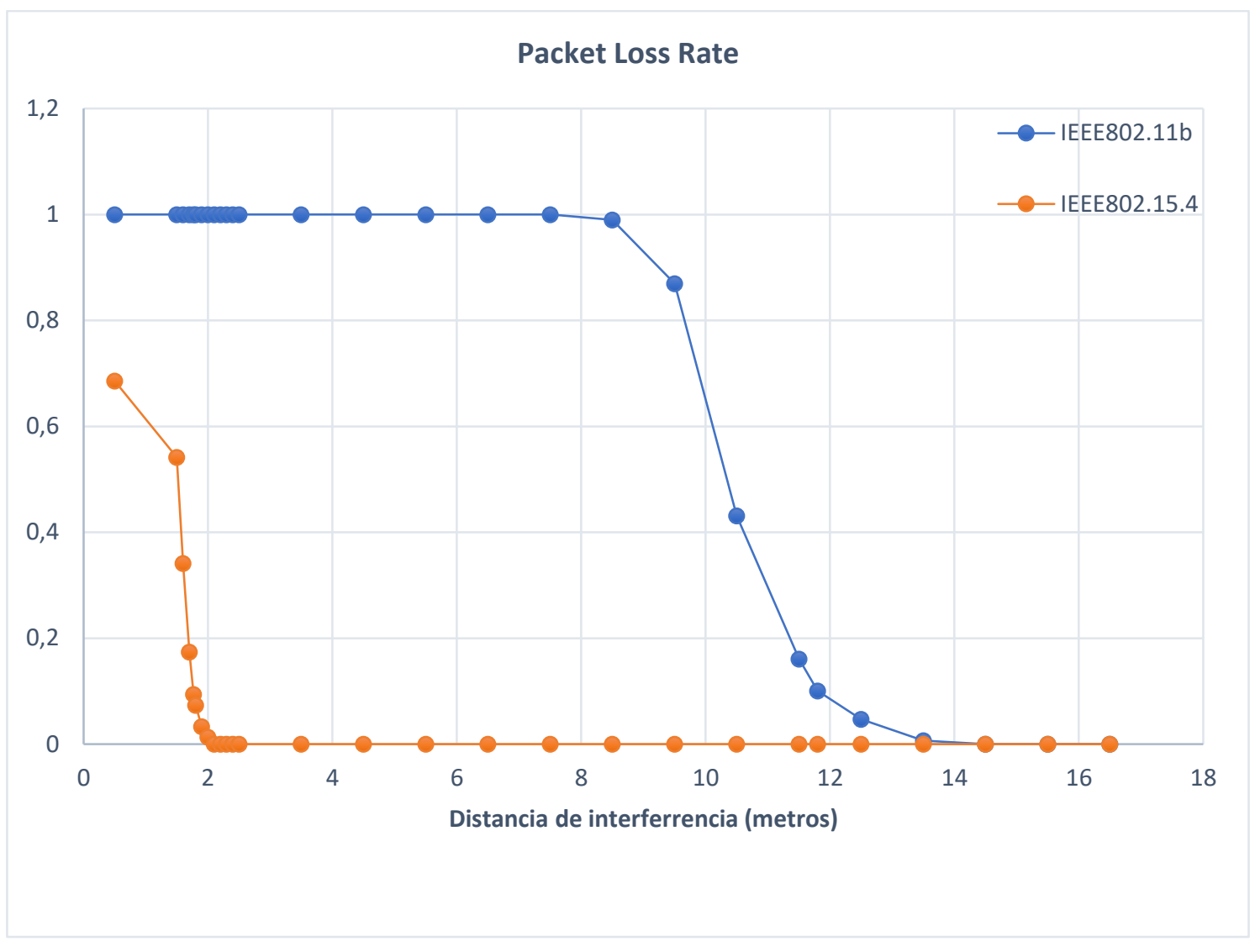

Figura 91 - PLR en función de la distancia de interferencia

$\underline{\text { Resultados: }}$

PLR de IEEE802.15.6 cae por debajo del 10\% a $\mathbf{1 , 7 7 m}$ en IEEE802.15.4 y a $\mathbf{1 1 , 8 m}$ en IEEE802.11b. 
7.2.2. Separación de canales con la fuente de interferencia

Condiciones de la simulación:

\begin{tabular}{|l|l|l|l|}
\hline & IEEE 802.15.6 & IEEE802.15.4 & IEEE 802.11b \\
\hline Potencia de transmisión & $-40 \mathrm{~dB}$ & $-30 \mathrm{~dB}$ & $-10 \mathrm{~dB}$ \\
\hline Ancho de banda & $1 \mathrm{MHz}$ & $2 \mathrm{MHz}$ & $22 \mathrm{MHz}$ \\
\hline Frecuencia de trabajo & $\begin{array}{l}\text { Desde } 2424 \mathrm{MHz} \text { hasta } \\
2458 \mathrm{MHz} \text { cada } 1 \mathrm{MHz}\end{array}$ & $2440 \mathrm{MHz}$ & $2442 \mathrm{MHz}$ \\
\hline $\begin{array}{l}\text { Distancia de la fuente de } \\
\text { interferencia al receptor }\end{array}$ & & $1 \mathrm{~m}$ & $2 \mathrm{~m}$ \\
\hline $\begin{array}{l}\text { Distancia entre emisor y } \\
\text { receptor }\end{array}$ & $0,5 \mathrm{~m}$ & $250 \mathrm{Kbps}$ & $11 \mathrm{Mbps}$ \\
\hline Tasa de transmisión & $121,4 \mathrm{Kbps}-600000$ & & \\
\hline Tiempo de símbolo de señal & $\mathrm{T}=1 / 600000 \mathrm{baud}=1,66 \mu \mathrm{seg}$ & & $563 \mathrm{~T}$ \\
\hline Longitud de paquete & $11222 \mathrm{~T}$ & $5254 \mathrm{~T}$ & $18000 \mathrm{~T}$ \\
\hline Intervalo de paquetes & & & \\
\hline
\end{tabular}




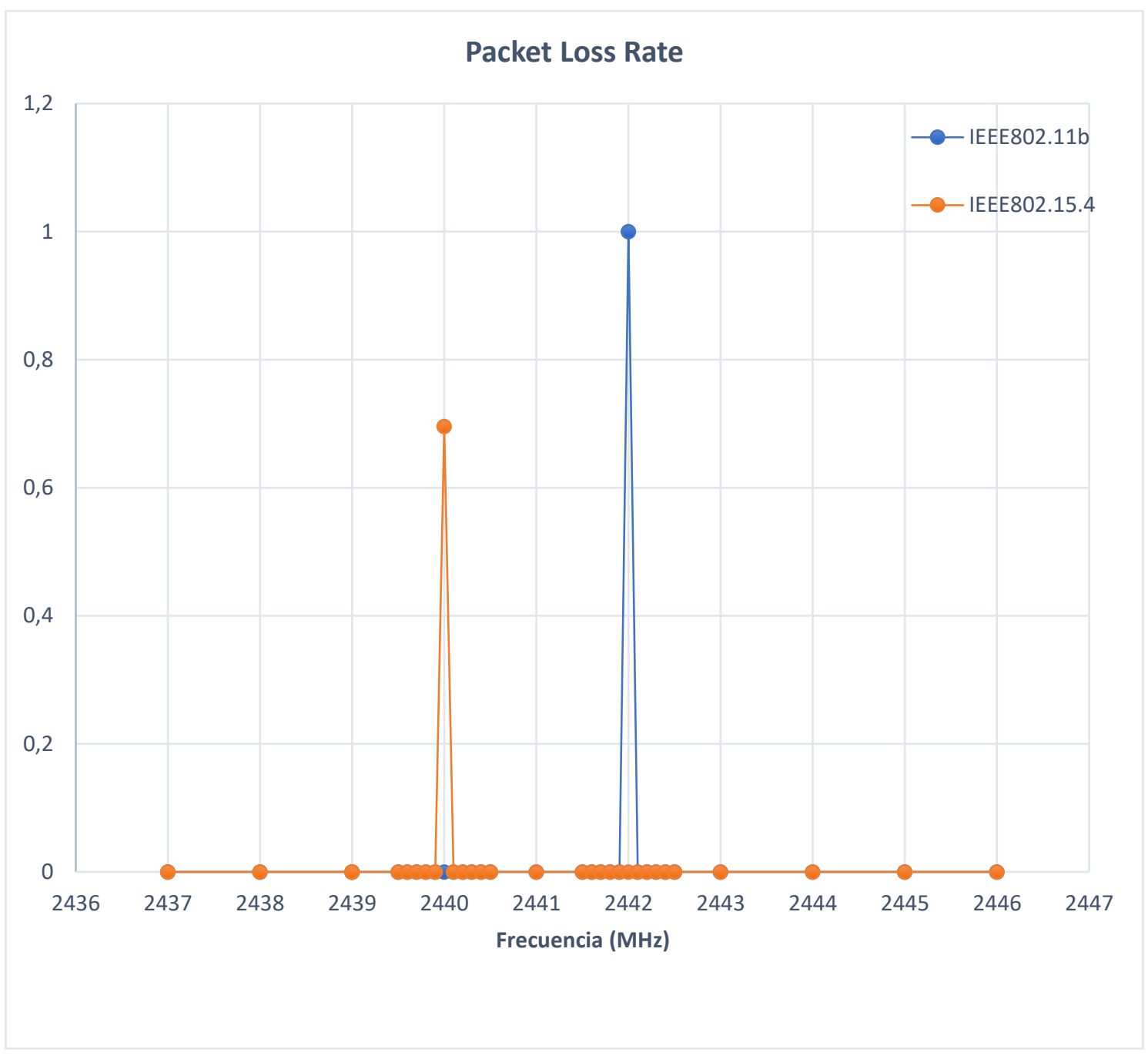

Figura 92 - PLR en función de la separación de canales

\section{$\underline{\text { Resultados: }}$}

Tanto para IEEE802.15.4 como para IEEE802.11b, IEEE802.15.6 es afectado solamente cuando coinciden en el canal de transmisión. 
7.2.3. Intervalo de paquetes de la fuente de interferencia

Condiciones de la simulación:

\begin{tabular}{|l|l|l|l|}
\hline & IEEE 802.15.6 & IEEE802.15.4 & IEEE 802.11b \\
\hline Potencia de transmisión & $-40 \mathrm{~dB}$ & $-30 \mathrm{~dB}$ & $-10 \mathrm{~dB}$ \\
\hline Ancho de banda & $1 \mathrm{MHz}$ & $2 \mathrm{MHz}$ & $22 \mathrm{MHz}$ \\
\hline Frecuencia de trabajo & $2440 \mathrm{MHz}$ y $2442 \mathrm{MHz}$ & $2440 \mathrm{MHz}$ & $2442 \mathrm{MHz}$ \\
\hline $\begin{array}{l}\text { Distancia de la fuente de } \\
\text { interferencia al receptor }\end{array}$ & & $1 \mathrm{~m}$ & $2 \mathrm{~m}$ \\
\hline $\begin{array}{l}\text { Distancia entre emisor y } \\
\text { receptor }\end{array}$ & $0,5 \mathrm{~m}$ & $250 \mathrm{Kbps}$ & $11 \mathrm{Mbps}$ \\
\hline $\begin{array}{l}\text { Tasa de transmisión } \\
\text { baudios }\end{array}$ & $269 \mathrm{Bytes}$ & $128 \mathrm{Bytes}$ & \\
\hline Payload & & & $936,72 \mu \mathrm{seg}$ \\
\hline $\begin{array}{l}\text { Longitud de paquete de } \\
\text { interferencia }\end{array}$ & 1 pps & Desde 1,33 hasta $25 \mathrm{pps}$ \\
\hline Intervalo de paquetes & & & \\
\hline
\end{tabular}

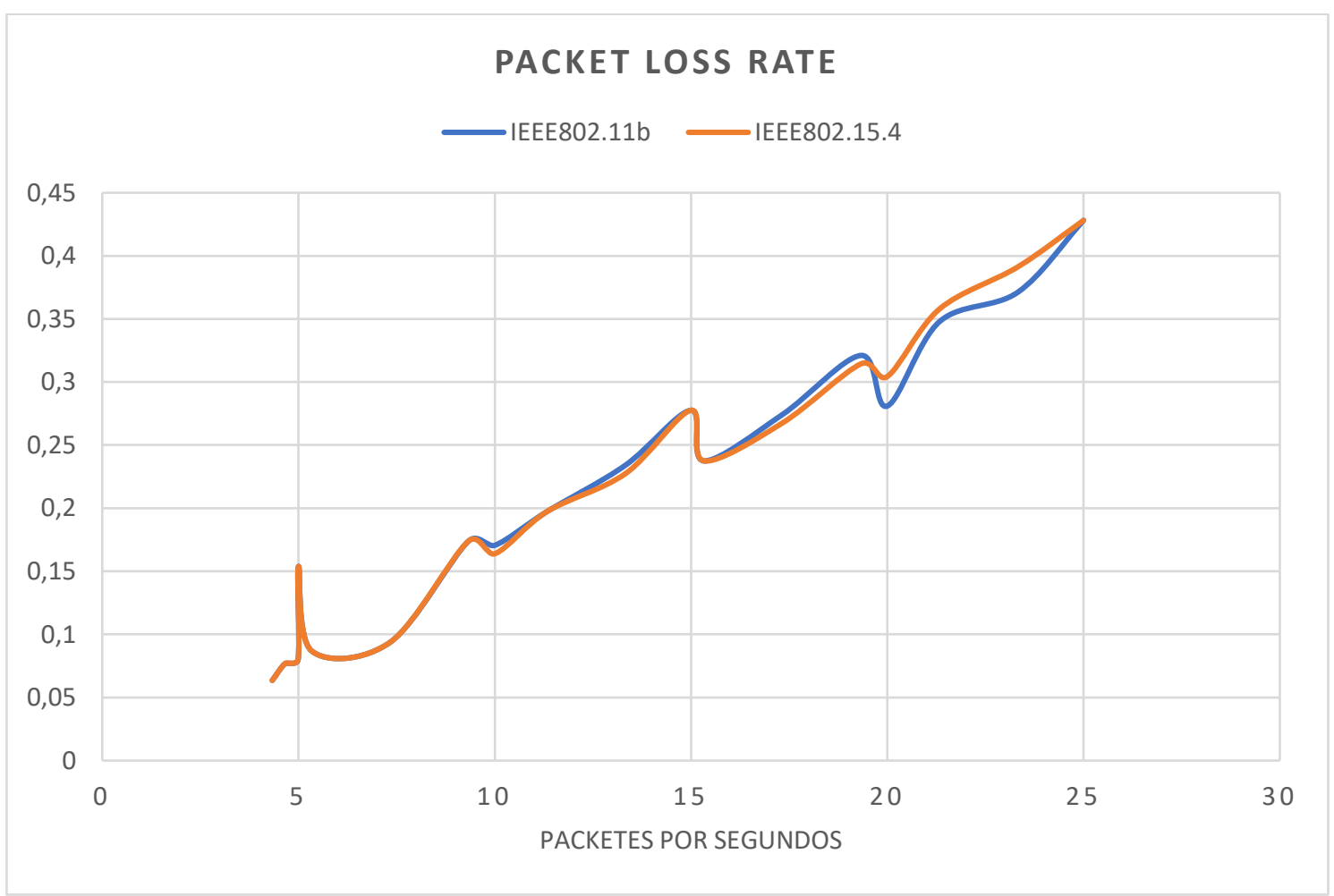

Figura 93 - PLR en función de la separación de paquetes de interferencia 
Resultados:

Ambas fuentes de interferencia generan el mismo PLR desde 1,33pps hasta 10pps (slots de 100ms).

El PLR presentó un pico de más de 15\% a los 5pps (slots de 200ms); luego sigue disminuyendo hasta caer por debajo del 10\% a partir de los 7,33pps (slots de 136,42 ms). 


\section{Conclusiones}

En este trabajo se han usado dos valores de medición de calidad: Packet Loss Rate (PLR) que mide la tasa de paquetes de señal perdidos, y el Packet Error Rate (PER), que mide la tasa error por colisiones (total o parcial) antes que éste sea sometido a un proceso de corrección de errores. Considerando un paquete perdido como un caso particular de paquete con error, el PLR siempre será menor que el PER.

Mientras que en la simulación matemática se midió el PER, el simulador de Castalia brinda PLR. Si bien, por su naturaleza, no se puede comparar de forma cuantitativa ambos resultados, es posible analizarlos de forma cualitativa.

Ordenados de mayor a menor, los parámetros que más afectaron a IEEE802.15.6 son: la Distancia, la Tasa de Transferencia y la Frecuencia.

En el análisis, tanto matemático como en las simulaciones, no se consideró los efectos que pueden causar las conexiones y desconexiones de los dispositivos IEEE802.15.6, sino que se estudiaron los efectos de los otros protocolos sobre conexiones ya establecidas.

Considerando solamente la distancia, en el mejor de los casos, la fuente de IEEE802.15.4 debe estar a más de 3,2m e IEEE802.11b a más de 8,2 metros para no influir de forma significativa a la fuente de señal de interés.

Teniendo en cuenta solamente la tasa de transferencia, se puede ver en ambos estudios que altas tasas, tanto de IEEE802.15.4 como IEEE802.11b, afectan de igual forma a IEEE802.15.6. A partir de los 7,33 paquetes por segundos $(136,42 \mathrm{mseg}$ de intervalo entre paquetes) ambas fuentes de interferencia generan un PLR de más del 10\%.

La diferencia se ven en las bajas tasas de transferencia, donde se necesitan más de 36,5pps en IEEE802.15.4 y 50,96pps en IEEE802.11b para que el PER supere el 10\%.

Con respecto a la frecuencia de trabajo, del resultado del estudio de los protocolos se observa que IEEE802.15.6 no coinciden en el canal de trabajo de IEEE802.15.4 e IEEE802.11b, pero, a diferencia del primero, el segundo sigue afectándolo aún en canales cercanos.

Si bien el protocolo cuenta con un mecanismo, FEC y HCS, que solo detectan errores, no los corrigen. En un escenario con alta tasas de paquetes erróneos o perdidos, los dispositivos se verían obligados a realizar muchas retransmisiones perjudicando, en el mejor de los casos, la tasa de transferencia de información.

IEEE802.15.6 tiene procesos para mitigar efectos de coexistencias, pero éstos solo consideran las que provienen solamente de dispositivos que transmiten bajo el mismo protocolo.

En el año 2017, la ISO e IEC publicaron una actualización del protocolo IEEE 802.15.6 [21]. Sin embargo, ésta no presenta cambios significativos en la banda de los $2,4 \mathrm{GHz}$, por lo que el problema de fiabilidad del protocolo estudiado persiste cuando convive con IEEE802.15.4 o IEEE802.11b.

A diferencia de IEEE802.15.4, IEEE802.11b es un estándar presente en muchos lugares 
de la vida cotidiana: Es posible tener WiFi en el hogar, bares, hoteles y hasta hospitales. Teniendo en cuenta que IEEE802.15.6 es un protocolo para transmisión de datos biomédicos, de los análisis realizados en el presente trabajo se puede concluir que este tendrá serios problemas para cumplir con su objetivo de alta fiabilidad trabajando en la banda de $2,4 \mathrm{GHz}$.

Al momento de desplegar una red IEEE 802.15.6 en un sitio donde también existen redes IEEE 802.15.4 o, sobre todo, IEEE 802.11b, para garantizar comunicaciones fiables, es de extrema importancia prestar atención a los canales de comunicación, evitando que se superpongan las bandas de trabajo del primer protocolo con la de los otros dos. 


\section{ANEXOS}

\section{Anexo A - Script de simulación de Octave}

A.1 - Variación de la distancia de fuente de interferencia clear ;

\# ======Lista de variables======

\# Tamaño de paquetes e intervalos

Liper154=18000; \# Condiciones propuestas por el paper original

Liper11=12000; \#Condiciones propuestas por el paper original

Ls=11222

Li154=K154=5254;

Li11=K11=563;

\# Potencias en DB

Pt154=-30;

Pt11=-10

$\mathrm{Pt}=-40$;

\# Anchos de banda en $\mathrm{Hz}$

$\mathrm{Bw}=1 \mathrm{e} 6$;

Bw154=2e6

Bw11=22e6

\# Distancias

$\mathrm{Di}=[0.5: 0.01: 20]$; \# Originalmente era hasta $100 \mathrm{~m}$, pero lo reduje a $20 \mathrm{~m}$ porque los PERS's llegan a cero antes

Ds $=0.5$;

\# Codificación

$\mathrm{Rc}=51 / 63$

\#Tasa de codificación

$\mathrm{Rb}=121400$; \#Tasa de bits de información

Rs=600000; \#Tasa de símbolos transmitidos

\# ====== Cálculo de potencia recibida IEEE802.15.6 ======

$\mathrm{Pr}=\mathrm{Pt}-40.2-20 * \log 10$ (Ds);

\#====== Cálculo de efectos de IEEE802.15.4 ======

\#Cálculo de C2 y C3

C2154=2/Liper154;

C3154=(Ls-Li154)/Liper154;

\#Cálculo de potencia recibida IEEE802.15.4

$\operatorname{tmp}(1: 751)=$ Pt154-40.2-20.* $\log 10(\operatorname{Di}(1: 751)) ; \quad$ \#Potencia recibida en DB

$\operatorname{tmp}(752: 1951)=\operatorname{Pt} 154-58.5-33 .{ }^{*} \log 10(\operatorname{Di}(752: 1951) . / 8)$;

Pr154=tmp $+10 * \log 10($ Bw/Bw154)；

\#Potencia (en DB) recibida después del filtro

\# Cálculo de relaciones de potencias recibidas

SIR154=Pr-Pr154;

tmp $=$ SIR154+10* $\log 10(B w / R s)$;

EbNo154=10.^(tmp. /10);

p154=(0.5). ${ }^{*} \exp (-E b N o 154)$;

\#Cálculo de PER

PER154=(C2154./p154) . * (K154 * *p154-1+(1-p154).^K154)+C3154 ** (1- (1-p154).^K154)；

\#====== Cálculo de efectos de IEEE802.11 ======

\#Cálculo de C2 y C3

C211=2/Liper11;

C311=(Ls-Li11)/Liper11

\#Cálculo de potencia recibida IEEE802.15.4

$\operatorname{tmp}(1: 751)=\operatorname{Pt} 11-40.2-20 .{ }^{*} \log 10(\operatorname{Di}(1: 751))$;

$\operatorname{tmp}(751: 1951)=P t 11-58.5-33 .{ }^{*} \log 10(\operatorname{Di}(77: 1951) . / 8) ;$

$\operatorname{Pr} 11=\operatorname{tmp}+10 * \log 10(B w / B w 11)$;

\#Potencia recibida en DB

del filtro

\# Cálculo de relaciones de potencias recibidas

SIR11 $=\operatorname{Pr}-\operatorname{Pr} 11$;

tmp $=$ SIR $11+10 * \log 10(\mathrm{Bw} / \mathrm{Rs})$;

EbNo11=10.^( $\mathrm{tmp} . / 10)$;

$\mathrm{p} 11=(0.5) \cdot{ }^{*} \exp (-\mathrm{EbNo11})$

\#Calculo de PER

PER11 $=(\mathrm{C} 211 . / \mathrm{p} 11) \cdot{ }^{*}\left(\mathrm{~K} 11 .{ }^{*} \mathrm{p} 11-1+(1-\mathrm{p} 11) \cdot{ }^{\wedge K} 11\right)+\mathrm{C} 311 . *\left(1-(1-\mathrm{p} 11) \cdot{ }^{\wedge} \mathrm{K} 11\right)$;

\#====== Ploteo de losgráficos $======$

hold on

plot(Di, PER11);

plot (Di, PER154)

xlabel('Distancia de interferencia (metros)');

legend(' IEEE802.11' ' ' IEEE802.15.4');

title('Packet Error Rate');

hold off : 
A.2 - Variación de intervalo de paquetes de fuente de interferencia.

clear;

\# =====-Lista de variables======

\# Tamaño de paquetes e intervalos

Liper $=[16200: 600: 600000]$;

Ls $=11222$;

Li154=K154=5254;

Li11=K11=563;

\# Distancias

Di154=1; \# Originalmente eran $5 \mathrm{~m}$, pero lo reduje a $1 \mathrm{~m}$ porque a los $5 \mathrm{~m}$ las PER's son

Di11=2;

Ds=0.5;

\# Potencias

Pt154=-30;

Pt11=-10;

$\mathrm{Pt}=-40$;

\# Anchos de banda

$\mathrm{Bw}=1 \mathrm{e} 6$;

Bw154=2e6 ;

Bw11=22e6;

\# Codificación

$\mathrm{Rc}=51 / 63$; \#Tasa de codificación

$\mathrm{Rb}=121400$; \#Tasa de bits de información

Rs=600000; \#Tasa de símbolos transmitidos

\#====== Cálculo de potencia recibida IEEE802.15.6 ======

$\mathrm{Pr}=\mathrm{Pt}-40.2-20 * \log 10(\mathrm{Ds})$;

\#====== Cáclulo de efectos de IEEE802.15.4 ======

\# Cálculo de C2 y C3

C2154=2./Liper ;

C3154=(Ls-Li154). / Liper :

\# Cálculo de potencia recibida IEEE802.15.4 tmp $=$ Pt 154-40.2-20* $\log 10($ Di154);

Pr154=tmp $+10 * \log 10($ Bw/Bw154)

\#Potencia recibida en DB

filtro

\# Cálculo de relaciones de potencias recibidas

SIR154=Pr-Pr154

tmp $=$ SIR154+10* $\log 10($ Bw/Rs $)$;

$\mathrm{EbNo154}=10^{\wedge}(\mathrm{tmp} / 10)$

p154=0.5*exp (-EbNo154);

\# Calculo de PER

PER154=C2154 . * ( K154*p154-1+(1-p154)^K154)/p154)+C3154 . * (1-(1-p154)^K154)；

\#====== Cáclulo de efectos de IEEE802.11 ======

\# Cálculo de C2 y C3

C211=2./Liper:

C311=(Ls-Li11). /Liper ;

\# Cálculo de potencia recibida IEEE802.11

tmp=Pt11-40.2-20* $\log 10($ Di11)；

$\operatorname{Pr} 11=\mathrm{tmp}+10 * \log 10(\mathrm{Bw} / \mathrm{Bw} 11)$;

\#Potencia recibida en DB

filtro

\# Cálculo de relaciones de potencias recibidas

SIR11 $=$ Pr $-\operatorname{Pr} 11$

tmp $=$ SIR $11+10 * \log 10($ Bw/Rs $)$;

EbNo11 $=10^{\wedge}(\mathrm{tmp} / 10)$;

p11=0.5* $\exp (-E b N o 11)$;

\# Calculo de PER

PER11 $=\mathrm{C} 211 .{ }^{*}\left(\mathrm{~K} 1{ }^{*} \mathrm{p} 11-1+(1-\mathrm{p} 11)^{\wedge} \mathrm{K} 11\right) / \mathrm{p} 11+\mathrm{C} 311 .{ }^{*}\left(1-(1-\mathrm{p} 11)^{\wedge} \mathrm{K} 11\right)$ ；

\# ====== Ploteo de los gráficos ======

hold on

plot (Liper, PER11);

plot (Liper,PER154);

xlabel('Liper $(T=1,66$ us $)$ ');

ylabel('PER'):

legend( ' IEEE802.11' , ' IEEE802.15.4' ');

title('Packet Error Rate')

hold off: 
A.3 - Variación del canal de transmisión de la fuente de señal clear ;

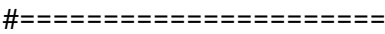

\# ======Lista de variables======

\# Tamaño de paquetes e intervalos

Liper154=18000; \# Condiciones propuestas por el paper original

Liper11=12000; \# Condiciones propuestas por el paper original

Ls=11222;

Li154=K154=5254;

$\mathrm{Li} 11=\mathrm{K} 11=563$;

\# Potencias en DB

Pt11=-10;

$\mathrm{Pt}=-40$;

Pt 154=-30:

\# Anchos de banda

$\mathrm{Bw}=1 \mathrm{e} 6$;

Bw154=2e6;

Bw11=22e6;

\# Velocidad de transmisión en Bits/seg

bps11=11e6;

bps154=250e3;

\# Cantidad de símbolos

$M 11=4$;

M154=16;

\# Separación de canales

$f=[-16 e 6: 100 e 3: 16 e 6]$;

y barremos canal por canal

\# Trabajamos con IEEE802.15.6 en el canal $39(2440 \mathrm{MHz})$

\# Distancias

Di154=1; \# Originalmente eran 5m, pero lo reduje a $1 \mathrm{~m}$ porque a los $5 \mathrm{~m}$ las PER's son

Di11=2;

Ds $=0.5$

$\mathrm{Rc}=51 / 63$

$\mathrm{Rb}=121400$

\#Tasa de codificación

$\mathrm{Rs}=600000$;

\#Tasa de bits de información

\#Tasa de símbolos transmitidos

\# ====== Cálculo de potencia recibida IEEE802.15.6 ======

$\mathrm{Pr}=\mathrm{Pt}-40.2-20 * \log 10$ (Ds) ;

\#==ニ=== Cáclulo de efectos de IEEE802.15.4 ======

\# Cálculo de C2 y C3

C2154=2/Liper154;

C3154=(Ls-Li154)/Liper154;

\# Cálculo de potencia recibida IEEE802.15.4 <=== REVISAR

tmp $=$ Pt 154-40.2-20* $\log 10($ Di154); \#Potencia recibida en DB

Tb154=1/bps154; \#Tiempo de bits en segundos

Eb154=(10^(tmp/10) $) *(2.8 e 4) * T b 154 ; \#$ Energía de bit recibida en Joules <== No

entiendo por que tengo que multiplicarlo por 28.000

Sb154=4*Eb154* $\log 2(M 154) * \operatorname{sinc}(2 * T b 154 * \log 2(M 154) * f) . \wedge 2 ; \quad$ \#Espectro de potencia en $W$ tmp $=\operatorname{sum}(\mathrm{Sb} 154,10)$;

\#Potencia recibida en $W$ después del filtro. El

filtro sobre las potencias negativas (*2) se compensa con la amplitud en las frecuencias negativas $(/ 2)$.

$\operatorname{Pr} 154=10 . * \log 10(\mathrm{tmp})$;

\#Potencia recibida en DB después del filtro

\# Cálculo de relaciones de potencias recibidas

SIR154=Pr-Pr154;

tmp $=$ SIR154+10* $\log 10(\mathrm{Bw} / \mathrm{Rs})$;

EbNo154=10.^(tmp./10);

p154=(0.5). * exp ( -EbNo154);

\# Calculo de PER

PER154=(C2154 ./p154) .* (K154 .*p154-1+(1-p154).^K154)+C3154 * (1-(1-p154).^K154);

\# ====== Cálculo de efectos de IEEE802.11 ======

\# Cálculo de C2 y C3

C211=2/Liper11;

C311=(Ls-Li11)/Liper11;

\# Cálculo de potencia recibida IEEE802.11 Tb11=1/bps11;

tmp $=$ Pt $11-40.2-20 * \log 10(\mathrm{Di} 11)$

\#Tiempo de bits en segundos

entiendo por que tengo que multiplicarlo por 51.000

Sb11=2*Eb11* $\log 2(M 11) * \operatorname{sinc}(T b 11 * \log 2(M 11) * f) . \wedge 2 ; \quad$ \#Espectro de potencia en $W$ tmp=sum(Sb11,10); \#Potencia recibida en $W$ después del filtro. El filtro

sobre las potencias negativas (*2) se compensa con la amplitud en las frecuencias negativas $(/ 2)$. 
$\operatorname{Pr} 11=10 \cdot{ }^{*} \log 10(\mathrm{tmp})$

\#Potencia recibida en DB después del filtro \# Cálculo de relaciones de potencias recibidas

SIR11 $=\operatorname{Pr}-\operatorname{Pr} 11$

tmp $=S I R 11+10 * \log 10($ Bw/Rs $)$;

EbNo11 $=(10) \cdot \wedge($ tmp. $/ 10)$;

$\mathrm{p} 11=(0.5) \cdot{ }^{*} \exp (-\mathrm{EbNo11})$

\# Calculo de PER

PER11 $=(C 211 . / p 11) . *\left(K 11 .{ }^{*} p 11-1+(1-p 11) \cdot{ }^{\wedge K 11}\right)+C 311 . *\left(1-(1-p 11) \cdot{ }^{\wedge}\right.$ K11 $)$

\# ====== Ploteo de los gráficos ======

hold on;

figure (1):

$\operatorname{plot}(f, P E R 11)$;

plot ( $f$, PER154);

legend( ' IEEE802.11' , ' IEEE802.15.4' ');

title('Packet Error Rate')

xlabel('Separación de canales $\left.(\mathrm{MHz}){ }^{\prime}\right)$;

hold off;

figure (2):

subplot $(2,1,1)$;

hold on;

$\operatorname{plot}(f, P E R 11)$;

plot ( $f, P E R 154)$;

legend( ' IEEE802.11' , ' IEEE802.15.4' );

title('Packet Error Rate');

hold off;

subplot $(2,1,2)$;

hold on;

$\operatorname{plot}(f, S b 11)$;

$\operatorname{plot}(f, S b 154)$

xlabel('Separación de canales $(\mathrm{MHz})$ ');

title('Densidad Espectral de Potencias');

hold off 
Anexo B - Archivos de configuración de simulación Castalia

B.1 - Omnet.ini para simulación de interferencia IEEE802.15.4

\#\#\# Generando una interferencia IEEE 802.15.4 como un pulso constante de señales [General]

include .../Parameters/Castalia.ini

sim-time-limit $=300 \mathrm{~s}$

\# ESCENARIO DE SIMULACIÓN

SN.field_x $=200 \quad \#$ meters

SN.field_y $=200 \quad$ \# meters

SN. numNodes $=3$

SN.wirelessChannel.onlyStaticNodes $=$ trueSN.node[ ${ }^{*}$. Communication. Radio.CollisionModel $=$

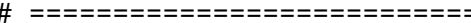

$\#======$ NODO DE SEÑAL ======

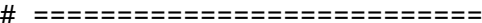

SN.node [0].xCoor $=100$

SN. node [0].yCoor $=100$

SN. node [1].xCoor $=100.5$

SN. node $[1] \cdot$ yCoor $=100$

\# MÓDULO DE RADIO

SN. node [..1]. Communication. Radio. RadioParametersFile $=$

".../Parameters/Radio/Radio802156.txt"

SN.node[..1].Communication.Radio.mode = "low"

SN.node[..1].Communication. Radio.TxOutputPower $="-10 \mathrm{dBm} " \#(-40 \mathrm{~dB})$ Debe ponerse en $\mathrm{dBm}$ porque así está definido en los parámetros de radio

\#SN.node[..1].Communication.Radio.signalDeliveryThreshold = "-92" \# Sensibilidad de la entrada del nodo para $121.4 \mathrm{kbps}$. (Ver norma IEEE802.15.6)

SN.node[..1].Communication.Radio.carrierFreq $=2440 \quad$ \# Frecuencia de transmisión en $\mathrm{MHz}$ del nodo.

SN.node[..1].Communication. Radio.state = "RX" \# El módulo debe empezar la

simulación en modo listening

\# Módulo MAC

SN.node [..1].Communication.MACProtocolName = "BaselineBANMac"

SN.node[0].Communication.MAC.isHub = true \# El nodo 0 es el hub. El 1

será el transmisor.

SN. node [..1]. Communication. MAC. phyDataRate $=121.4$

\# MÓDULO DE RUTEO

SN.node[..1].Communication.RoutingProtocolName = "BypassRouting"

SN. node [..1]. Communication. Routing. netDataFrame0verhead $=0$

\# MODULO DE APLICACIÓN

SN.node[..1].ApplicationName $=$ "ThroughputTest"

SN.node[..1].Application. packet_rate $=1$

SN.node[..1]. Application. constantDataPayload $=260$

SN. node[..1]. Application. packetHeaderOverhead $=9$

2 de $\mathrm{fCS}$

\# En paketes/segundos

\# En Bytes

\# 7 bytes de cabecera PSDU +

\# ===========================

$\#==$ NODO DE INTERFERENCIA $=$

\# =============================

\# MÓDULO DE RADIO

SN. node [2]. Communication. Radio. RadioParametersFile $=$

". ./Parameters/Radio/Radio802154.txt"

SN.node[2].Communication. Radio.mode = "normal"

SN.node[2]. Communication. Radio.TxOutputPower $=$ "0dBm"

\#SN.node[2]. Communication. Radio. maxPhyFrameSize $=145$

agrega

\#SN. node[2]. Communication. Radio. phyFrameOverhead $=1$

+ SFD ( 1 byte)

\# MÓDULO MAC

SN.node [2].Communication.MACProtocolName = "BypassMAC"

SN. node [2]. Communication. MAC. macPacketOverhead $=1$

\# PHR de 1 byte

\# MÓDULO DE RUTEO 
SN.node[2].Communication. RoutingProtocolName $=$ "BypassRouting"

SN. node [2]. Communication. netDataFrameOverhead $=0$

\# MODULO DE APLICACIÓN

SN.node[2].ApplicationName = "ThroughputTest"

SN.node[2]. Application. constantDataPayload $=120$

120 bytes y una cabecera de apliciación de 8 bytes (128 bytes)

SN.node [2].Application. packetHeaderOverhead $=8$

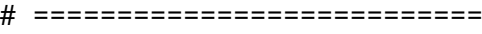

\# $=$ \#=ニ= NODO RECEPTOR =ニ=ニ==

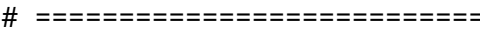

\# Definición del nodo receptor en donde se estudian los parámetros de interes.

SN. node [0]. Application. collectTraceInfo = true

$\mathrm{SN}$.node [0].Communication.MAC.collectTraceInfo = true

SN.node[0].Communication. Radio.collectTraceInfo $=$ true

SN.wirelessChannel.collectTraceInfo = true

[Config Distancia]

SN. node[2]. Communication. Radio. carrierFreq $=2440$

Frecuencia de transmisión en $\mathrm{MHz}$ del nodo.

$\mathrm{SN}$. node [2].xCoor $=100$

SN.node [2].yCoor $=\$\{y$ Coor $=100.5,101.5,101.6,101.7,101.77,101.8,101.9,102$,

$102.1,102.2,102.3,102.4,102.5,103.5,104.5\}$

SN.node[2]. Application. packet_rate $=33.33$

[Config Frecuencia]

SN.node[2].Communication.Radio.carrierFreq $=\$\{$ Frec $=2437,2438,2439,2439.5,2439.6$, $2439.7,2439.8,2439.9,2440,2440.1,2440.2,2440.3,2440.4,2440.5,2441,2442,2443\}$ \# Frecuencia de transmisión en $\mathrm{MHz}$ del nodo.

SN. node [2].xCoor $=100$

$\mathrm{SN}$. node[2].yCoor $=101$

SN.node[2]. Application. packet_rate $=33.33$

[Config Slots]

SN.node[2].Communication. Radio.carrierFreq $=2440$ \#Frecuencia de transmisión en $\mathrm{MHz}$ del nodo.

SN. node [2].xCoor $=100$

SN. node [2].yCoor $=101$

SN.node[2]. Application. packet rate $=\$\{$ IntAppPacketRate $=25,23.33,21.33,20,19.33$ $17.33,15.33,15,13.33,11.33,10,9.33,7.33,5.33,5,4.99,4.66,4.33,3.33,1.33\}$

B.2 - Archivo Radio802154.txt de configuración de parámetros de radio IEEE802.15.4 RX MODES

\# Name, dataRate(kbps), modulationType, bitsPerSymbol, bandwidth(MHz),

noiseBandwidth $(\mathrm{KHz})$, noiseFloor $(\mathrm{dBm})$, sensitivity $(\mathrm{dBm})$, powerConsumed $(\mathrm{mW})$

normal, 250, PSK, 4, 20, 194, $-100,-95,62$

IDEAL， 250， IDEAL， 4, 20, 194, $-100,-95,62$

TX LEVELS

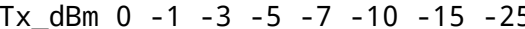

Tx_mW $57.42 \quad 55.18 \quad 50.69 \quad 46.2 \quad 42.24 \quad 36.3 \quad 32.67 \quad 29.04$

DELAY TRANSITION MATRIX

\# State switching times (time to switch from column state to row state, in msec)

\# $\quad$ RX $\quad$ TX $\quad$ SLEEP

$\begin{array}{lll}\mathrm{RX} \quad- & 0.01 & 0.194\end{array}$

$\begin{array}{lllll}\text { TX } & 0.01 & - & 0.194\end{array}$

SLEEP $0.05 \quad 0.05 \quad-$

POWER TRANSITION MATRIX

\# RX TX SLEEP

$\begin{array}{llll}R X & - & 62 & 62\end{array}$

$\begin{array}{llll}T X & 62 & - & 62\end{array}$

SLEEP $1.4 \quad 1.4 \quad-$

SLEEP LEVELS

idle 1.4, - , - , - , - 
B.3 - Omnet.ini para simulación de interferencia IEEE802.11b

\#\#\# Generando una interferencia IEEE 802.11b como un pulso constante de señales

[General]

include .../Parameters/Castalia.ini

sim-time-limit $=300 \mathrm{~s}$

\# ESCENARIO dE SimULACión

SN.field_x $=200 \quad$ \# meters

SN.field_y $=200 \quad$ \# meters

SN. numNodes $=3$

SN.wirelessChannel.onlyStaticNodes $=$ true

SN.node [*]. Communication. Radio. CollisionModel $=2$

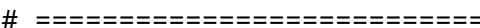

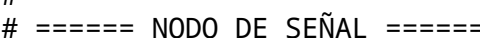

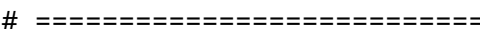

SN. node $[0] . x$ Coor $=100$

SN. node [0] $\cdot$ yCoor $=100$

SN.node $[1] \cdot x$ Coor $=100.5$

SN.node [1] $\cdot$ yCoor $=100$

\# MÓDULO DE RADIO

SN.node [..1].Communication. Radio. RadioParametersFile =

". . /Parameters/Radio/Radio802156.txt"

SN.node [..1].Communication. Radio.mode = "low"

SN.node[..1]. Communication. Radio.TxOutputPower = "-10dBm" \# (-40dB) Debe ponerse en $\mathrm{dBm}$ porque así está definido en los parámetros de radio

\#SN.node[..1].Communication.Radio.signalDeliveryThreshold = "-92" \# Sensibilidad de la entrada del nodo para 121.4 kbps. (Ver norma IEEE802.15.6)

SN.node[..1].Communication. Radio.carrierFreq $=2442 \quad$ \# Frecuencia de transmisión en $\mathrm{MHz}$ del nodo. Tuve que modificar la frecuencia porque $802.11 \mathrm{~b}$ no lo afectaba en otra portadora

SN.node[..1].Communication.Radio.state = "RX" \# El módulo debe empezar la

simulación en modo listening

\# Módulo MAC

SN.node [..1].Communication.MACProtocolName = "BaselineBANMac"

SN.node[0].Communication.MAC.isHub = true \# El nodo 0 es el hub. El 1 será el transmisor.

SN.node [..1].Communication.MAC.phyDataRate $=121.4$

\# MÓDULO DE RUTEO

SN.node[..1].Communication.RoutingProtocolName = "BypassRouting"

SN.node [..1]. Communication. Routing. netDataFrameOverhead $=0$

\# MODULO DE APLICACIÓN

SN.node[..1].ApplicationName = "ThroughputTest"

SN.node [..1].Application. packet rate $=1$

SN.node[..1].Application. constantDataPayload $=260$

SN.node[..1]. Application. packetHeaderOverhead $=9$

2 de $\mathrm{fCS}$

\# En paketes/segundos

\# En Bytes

\# 7 bytes de cabecera PSDU +

\# =ニニニ=ニニニニニニニニニニニニニニニニニニニニ=ニ

$\#==$ NODO DE INTERFERENCIA $==$

\# =ニ=ニ=ニ=ニ=ニ=ニ=ニ=ニ=ニ=ニ=ニ=ニ=ニ=

\# MÓDULO DE RADIO

SN.node[2]. Communication. Radio. RadioParametersFile =

". . /Parameters/Radio/Radio80211.txt"

SN.node[2].Communication. Radio.mode = "low"

SN . node [2]. Communication. Radio. TxOutputPower $=" 20 \mathrm{dBm} "$

SN.node[2]. Communication. Radio. maxPhyFrameSize $=2576$

bytes. Configuré una trama que dure 936,72uSeg

SN.node[2]. Communication. Radio.phyFrame0verhead $=518$

\# Largo de la trama en

durar $192 \mathrm{uSeg}$. Es por ello que pongo 518 bytes + 10 bytes que supongo que viene del

preambulo.

\# MÓDULO MAC

SN.node[2].Communication.MACProtocolName = "BypassMAC"

SN. node [2]. Communication. MAC. macPacketOverhead $=1024$

SN.node [2]. Communication. MAC. phyDataRate $=11000$ 
\# MÓDULO DE RUTEO

SN.node[2].Communication. RoutingProtocolName = "BypassRouting"

SN. node [2]. Communication. netDataFrameOverhead $=0$

\# MODULO DE APLICACIÓN

SN.node[2].ApplicationName = "ThroughputTest"

SN. node [2]. Application. constantDataPayload $=1024$

SN.node[2].Application. packetHeaderOverhead $=0$

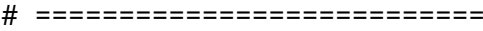

\# $=====$ NODO RECEPTOR $======$

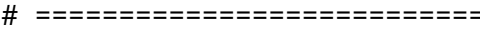

\# Definición del nodo receptor en donde se estudian los parámetros de interés.

SN.node [0]. Application. collectTraceInfo = true

SN.node[0]. Communication.MAC. collectTraceInfo = true

SN.node[0].Communication. Radio.collectTraceInfo $=$ true

SN.wirelessChannel.collectTraceInfo = true

[Config Distancia]

SN. node[2]. Communication. Radio. carrierFreq $=2442$

\# Frecuencia de transmisión en $\mathrm{MHz}$ del nodo.

SN. node [2].xCoor $=100$

SN.node $[2]$. CCoor $=\$\{$ yCoor $=100.5,101.5,102.5,103.5,104.5,105.5,106.5,107.5$ $108.5,109.5,110.5,111.5,111.8,112.5,113.5,114.5,115.5,116.5\}$

SN.node[2]. Application. packet_rate $=50$

[Config Frecuencia]

SN.node[2].Communication. Radio.carrierFreq $=\$$ Frec $=2438,2439,2440,2441,2441.5$ $2441.6,2441.7,2441.8,2441.9,2442,2442.1,2442.2,2442.3,2442.4,2442.5,2443$, $2444,2445,2446\}$

$\mathrm{SN}$. node [2].xCoor $=100$

$\mathrm{SN}$. node [2].yCoor $=102$

SN.node[2]. Application. packet_rate $=50$

[Config Slots]

SN.node[2].Communication.Radio.carrierFreq $=2442 \quad$ \# Frecuencia de

transmisión en $\mathrm{MHz}$ del nodo.

SN. node[2].xCoor $=100$

SN.node [2].yCoor $=102$

SN . node [2]. Application packet rate $=\$\{$ IntAppPacketRate $=25,23.33,21.33,20,19.33$, $17.33,15.33,15,13.33,11.33,10,9.33,7.33,5.33,5,4.99,4.66,4.33,3.33,1.33\}$

B.4 - Archivo Radio80211.txt de configuración de parámetros de radio IEEE802.11b RX MODES

\# Name, dataRate(kbps), modulationType, bitsPerSymbol, bandwidth(MHz),

noiseBandwidth $(\mathrm{KHz})$, noiseFloor $(\mathrm{dBm})$, sensitivity $(\mathrm{dBm})$, powerConsumed $(\mathrm{mW})$

low, 11000, DIFFQPSK, 2, 11, 22000, $-104,-92,3.1$

TX LEVELS

Tx_dBm $\begin{array}{lllllllllll}20 & 10 & 0 & -1 & -3 & -5 & -7 & -10 & -15 & -25\end{array}$

Tx_mW $65.63 \quad 61.52 \quad 57.42 \quad 55.18 \quad 50.69 \quad 46.2 \quad 42.24 \quad 36.3 \quad 32.67 \quad 29.04$

DELAY TRANSITION MATRIX

\# State switching times (time to switch from column state to row state, in msec)

\# $\quad$ RX $\quad$ TX SLEEP

$\begin{array}{llll}\text { RX } & - & 0.01 & 0.194\end{array}$

$\begin{array}{llll}\text { TX } & 0.01 & - & 0.194\end{array}$

SLEEP $\quad 0.05-0.05$

POWER TRANSITION MATRIX

$\begin{array}{llll}\# & \text { RX } & \text { TX } & \text { SLEEP } \\ \text { RX } & - & 3.0 & 3.0 \\ \text { TX } & 3.0 & - & 3.0 \\ \text { SLEEP } & 1.5 & 1.5 & -\end{array}$

SLEEP LEVELS

idle $0.05,-,-,-,-$ 


\section{Anexo C - Abreviaturas}

$A$

ACPR: Adjacent Channel Power Ratio

ACR: Adjacent Channel Rejection

AES: Advanced Encryption Standard

AIFS: Acknowledgment Interframe Spacing

AWGN: Additive White Gaussian Noise

AWN: Affected Wireless Network.

B

BI: Beacon Interval

BSS: Basic Service Set

BSSID: Basic Service Set Identifier

C

CAP: Contention Access Phase

CBC: Cipher Block Chaining

CCA: Clear channel assessment.

CFP: Contention-Free Period

CP: Contention Period

CP: Contention Probability

CSK: Chirp-Shift Keying

CSMA/CA: Carrier Sense Multiple Access with Collision Avoidance

CRC: Cyclic Redundancy Code

CSS: Chirp Spread Spectrum.

CTS: Clear To Send.

CW: Contention Window

D

DCF: Distributed Coordination Function

DIFS: DCF Interframe Space.

DQCSK: Differential Quadrature Chirp-Shift Keying

DQPSK: Differential Quadrature Phase-Shift Keying.

DSSS: Direct Sequence Spread Spectrum.

$\boldsymbol{E}$

EAP: Exclusive Access Pase

EIFS: Extended Interframe Space.

EIRP: Effective Isotropic Radiated Power

ESSID: Extended Service Set Identifier

$\boldsymbol{F}$

FCS: Frame Check Sequence

FM-UWB: Frequency Modulated Ultra-Wideband

FSK: Frequency Shift Keying

$\boldsymbol{H}$

HARQ: Hybrid Automatic Repeat request

HBC: Human Body Communication

HRP: High Rate Pulse repetition frequency 


\section{I}

IE: Information Element

IFS: Interfame Space

ISM: Industrial, Scientific and Medica

IWN: Interfering Wireless Network.

$\boldsymbol{L}$

LECIM: Low Energy Critical Infrastructure Monitoring.

LIFS: Long Interframe Spacing.

LP/LDC: Low Power/Low Duty Cycle.

LSB: Least Significant Bit

\section{M}

MAP: Managed Access Phase

macDsn: Número de secuencia agregado a la trama de datos IEEE 802.15.4 transmitida o al comando MAC.

MICS: Medical Implant Communication System

MK: Master Key

MSB: Most Significant Bit

MSK: Minimum Shift Keying.

$N$

NAV: Network Allocation Vector

NB: Narrow Band

$O$

OFDM: Orthogonal Frequency Division Multiplexing.

O-QPSK: Offset Quadrature Phase-Shift Keying

$\boldsymbol{P}$

PAN: Personal Area Network

PC: Point Coordinator

PCF: Point Coordination Funcion

PER: Packet Error Rate

PIFS: PCF Interframe Space.

PLCP: Physical-Layer Convergence Protocol

PLR: Packet Loss Rate

PMD: Physical Medium Dependent

PN: Pseudo-random Noise

PPDU: Physical-layer protocol data unit

PSD: Power Spectral Density

PSDU: Physical-layer service data unit

$\boldsymbol{R}$

RAP: Random Access Pase

RCC: Rail Communications and Control.

RTS: Request To Send. 
$S$

SD: Superframe Duration.

SER: Symbol Error Rate

SIFS: Short Interframe Spacing.

SIR: Signa-Interference Ratio

SLRC: STA Long Retry Count

SUN: Smart Utility Network.

SSID: Service Set Identifier.

SSRC: STA Short Retry Count

$T$

TVWS: Televisión White Space.

$\boldsymbol{U}$

UP: User Priorities

UWB: Ultra-Wideband

$\boldsymbol{W}$

WMTS: Wireless Medical Telemetry Services 


\section{Anexo D - Bibliografía.}

[1] "IEEE Standard for Local and metropolitan area networks - Part 15.6: Wireless Body Area Networks," en IEEE Std 802.15.6-2012, 29 de febrero de 2012

[2] "IEEE Standard for Low-Rate Wireless Networks" in IEEE Std 802.15.4-2015 (Revision of IEEE Std 802.15.4-2011), 22 de abril de 2016

[3] Ullah, Sana \& Mohaisen, Manar \& A. Alnuem, Mohammed. (2013). "A review of IEEE 802.15.6 MAC, PHY, and security specifications." International Journal of Distributed Sensor Networks. Abril de 2013.

[4] R. Natarajan, P. Zand y M. Nabi, "Analysis of coexistence between IEEE 802.15.4, BLE and IEEE 802.11 in the $2.4 \mathrm{GHz}$ ISM band," IECON 2016 - 42nd Annual Conference of the IEEE Industrial Electronics Society, Florence, 23-26 de octubre de 2016.

[5] Mile, A., Okeyo, G. and Kibe, A. "Hybrid IEEE 802.15.6 Wireless Body Area Networks Interference Mitigation Model for High Mobility Interference Scenarios." Wireless Engineering and Technology, Vol.9 No.2, 2018.

[6] Kaschel, Hector \& Alvarado, Johanna \& Torres, Victor. "Redes de Area Corporal Inalámbricos: Requisitos, Desafíos e Interferencias.” XV Congreso internacional de Telecomunicaciones, Chile, 12-14 de noviembre de 2014

[7] Alam, M.M. y Hamida, E.B. "Performance Evaluation of IEEE 802.15.6-Based WBANs under Co-Channel Interference." International Journal of Sensor Networks, Volumen 24, enero 2017

[8] Xiaonan Su, Changle Li y Xiaoming Yuan. "IEEE 802.15.6-based Prototype System for WBAN: Design and Implementation”, arXig.org, 10 de enero de 2017.

[9] Johana Estafanía Averos Vargas. "Estudio del estándar IEEE 802.15.6 y simulación de los parámetros de transmisión de una red de área corporal en la banda de frecuencia de 2,4GHz.", Facultad de Ingenniería Eléctrica y Electrónica - Escuela Politécnica Nacional, San Francisco de Quito, Ecuador. Enero de 2017.

[10] Hector Kaschel Carcamo, Johanna Valeria Alvarado Neira y Víctor Manuel Torres Valderrama. "Redes de área corporal inalámbricas: Requisitos, desafios e interferencia", XV Congreso Internacional De Telecomunicaciones Senacitel, Noviembre de 2014

[11] Simon Haykin “Communications Systems”, 3ra edición.

[12] S. J. Shellhammer, "Estimation of Packet Error Rate Caused by Interference usin Analytic Techniques - A Coexistence Assurance Metodology", in IEEE 802.19 Wireless Coexistene, 28 de septiembre de 2005

[13] Marco Zuniga, Bhaskar Krishnamachari, "Analyzing the Transitional Region in Low Power Wireless Links", Primer IEEE International Conference on Sensor and Ad hoc Communications and Networks (SECON), Santa Clara, CA, October 2004. 
[14] Athanassios Boulis, "Castalia: A simulator for Wireless Sensor Networks and Body Area Networks", NICTA, mayo del 2013

[15] "Part 11: Wireless LAN Medium Access Control (MAC) and Physical Layer (PHY) Specifications" in ANSI/IEEE Std 802.11, Edición de 1999

[16] "Part 11: Wireless LAN Medium Access Control (MAC) and Physical Layer (PHY) specifications: Higher-Speed Physical Layer Extension in the $2.4 \mathrm{GHz}$ Band", Supplement to ANSI/IEEE Std 802.11, Edición 1999.

[17] Página web de GNU Octave (https://www.gnu.org). Último acceso 29/07/2020

[18] Página web de OMNeT++ (https://omnetpp.org/). Último Acceso 01/08/2020

[19] "IEEE Recommended Practice for Information technology - Local and metropolitan area networks - Specific requirements - Part 15.2: Coexistence of Wireless Personal Area Networks with Other Wireless Devices Operating in Unlicensed Frequency Bands," IEEE Std 802.15.2-2003, 2003.

[20] Kwak, K. y Ullah, N., "An overview of IEEE 802.15.6 standard." 1 - 6. 10.1109/ISABEL.2010.5702867, diciembre de 2010.

[21] "Information technology — Telecommunications and information exchange between systems - Local and metropolitan area networks - Part 15-6: Wireless body area network" en ISO/IEC/IEEE 8802-15-6, Octubre 2017

[22] Hernandez, Marco y Mucchi, Lorenzo. "Body Area Networks using IEEE 802.15.6: Implementing the Ultra Wide Band Physical Layer", enero de 2014. 


\section{Anexo E - Fuentes de figuras}

Figura 1 - "IEEE Standard for Local and metropolitan area networks - Part 15.6: Wireless Body Area Networks," in IEEE Std 802.15.6-2012, 29 de febrero de 2012.

Figura 2 - "IEEE Standard for Local and metropolitan area networks - Part 15.6: Wireless Body Area Networks," in IEEE Std 802.15.6-2012, 29 de febrero de 2012.

Figura 3 - "IEEE Standard for Local and metropolitan area networks - Part 15.6: Wireless Body Area Networks," in IEEE Std 802.15.6-2012, 29 de febrero de 2012.

Figura 4 - "IEEE Standard for Local and metropolitan area networks - Part 15.6: Wireless Body Area Networks," in IEEE Std 802.15.6-2012, 29 de febrero de 2012.

Figura 5 - "IEEE Standard for Local and metropolitan area networks - Part 15.6: Wireless Body Area Networks," in IEEE Std 802.15.6-2012, 29 de febrero de 2012.

Figura 6 - "IEEE Standard for Local and metropolitan area networks - Part 15.6: Wireless Body Area Networks," in IEEE Std 802.15.6-2012, 29 de febrero de 2012.

Figura 7 - "IEEE Standard for Local and metropolitan area networks - Part 15.6: Wireless Body Area Networks," in IEEE Std 802.15.6-2012, 29 de febrero de 2012.

Figura 8 - "IEEE Standard for Local and metropolitan area networks - Part 15.6: Wireless Body Area Networks," in IEEE Std 802.15.6-2012, 29 de febrero de 2012.

Figura 9 - "IEEE Standard for Local and metropolitan area networks - Part 15.6: Wireless Body Area Networks," in IEEE Std 802.15.6-2012, 29 de febrero de 2012.

Figura 10 - "IEEE Standard for Local and metropolitan area networks - Part 15.6: Wireless Body Area Networks," in IEEE Std 802.15.6-2012, 29 de febrero de 2012.

Figura 11 - "IEEE Standard for Local and metropolitan area networks - Part 15.6: Wireless Body Area Networks," in IEEE Std 802.15.6-2012, 29 de febrero de 2012.

Figura 12 - "IEEE Standard for Local and metropolitan area networks - Part 15.6: Wireless Body Area Networks," in IEEE Std 802.15.6-2012, 29 de febrero de 2012.

Figura 13 - "IEEE Standard for Local and metropolitan area networks - Part 15.6: Wireless Body Area Networks," in IEEE Std 802.15.6-2012, 29 de febrero de 2012.

Figura 14 - "IEEE Standard for Local and metropolitan area networks - Part 15.6: Wireless Body Area Networks," in IEEE Std 802.15.6-2012, 29 de febrero de 2012.

Figura 15 - "IEEE Standard for Local and metropolitan area networks - Part 15.6: Wireless Body Area Networks," in IEEE Std 802.15.6-2012, 29 de febrero de 2012.

Figura 16 - "IEEE Standard for Local and metropolitan area networks - Part 15.6: Wireless Body Area Networks," in IEEE Std 802.15.6-2012, 29 de febrero de 2012.

Figura 17 - "IEEE Standard for Local and metropolitan area networks - Part 15.6: Wireless Body Area Networks," in IEEE Std 802.15.6-2012, 29 de febrero de 2012.

Figura 18 - "IEEE Standard for Local and metropolitan area networks - Part 15.6: Wireless Body Area Networks," in IEEE Std 802.15.6-2012, 29 de febrero de 2012.

Figura 19 - "IEEE Standard for Local and metropolitan area networks - Part 15.6: Wireless Body Area Networks," in IEEE Std 802.15.6-2012, 29 de febrero de 2012.

Figura 20 - "IEEE Standard for Local and metropolitan area networks - Part 15.6: Wireless Body Area Networks," in IEEE Std 802.15.6-2012, 29 de febrero de 2012.

Figura 21 - "IEEE Standard for Local and metropolitan area networks - Part 15.6: Wireless Body Area Networks," in IEEE Std 802.15.6-2012, 29 de febrero de 2012.

Figura 22 - "IEEE Standard for Local and metropolitan area networks - Part 15.6: Wireless Body Area Networks," in IEEE Std 802.15.6-2012, 29 de febrero de 2012.

Figura 23 - "IEEE Standard for Local and metropolitan area networks - Part 15.6: Wireless Body Area Networks," in IEEE Std 802.15.6-2012, 29 de febrero de 2012.

Figura 24 - "IEEE Standard for Local and metropolitan area networks - Part 15.6: Wireless Body Area Networks," in IEEE Std 802.15.6-2012, 29 de febrero de 2012. 
Figura 25 - "IEEE Standard for Local and metropolitan area networks - Part 15.6: Wireless Body Area Networks," in IEEE Std 802.15.6-2012, 29 de febrero de 2012.

Figura 26 - "IEEE Standard for Local and metropolitan area networks - Part 15.6: Wireless Body Area Networks," in IEEE Std 802.15.6-2012, 29 de febrero de 2012.

Figura 27 - "IEEE Standard for Local and metropolitan area networks - Part 15.6: Wireless Body Area Networks," in IEEE Std 802.15.6-2012, 29 de febrero de 2012.

Figura 28 - "IEEE Standard for Local and metropolitan area networks - Part 15.6: Wireless Body Area Networks," in IEEE Std 802.15.6-2012, 29 de febrero de 2012.

Figura 29 - "IEEE Standard for Local and metropolitan area networks - Part 15.6: Wireless Body Area Networks," in IEEE Std 802.15.6-2012, 29 de febrero de 2012.

Figura 30 - "IEEE Standard for Local and metropolitan area networks - Part 15.6: Wireless Body Area Networks," in IEEE Std 802.15.6-2012, 29 de febrero de 2012.

Figura 31 - "IEEE Standard for Local and metropolitan area networks - Part 15.6: Wireless Body Area Networks," in IEEE Std 802.15.6-2012 , 29 de febrero de 2012.

Figura 32 - "IEEE Standard for Local and metropolitan area networks - Part 15.6: Wireless Body Area Networks," in IEEE Std 802.15.6-2012, 29 de febrero de 2012.

Figura 33 - "IEEE Standard for Local and metropolitan area networks - Part 15.6: Wireless Body Area Networks," in IEEE Std 802.15.6-2012, 29 de febrero de 2012.

Figura 34 - Kaschel, Hector \& Alvarado, Johanna \& Torres, Victor. "Redes de Area Corporal Inalámbricos: Requisitos, Desafíos e Interferencias." XV Congreso internacional de Telecomunicaciones, Chile, 12-14 de noviembre de 2014.

Figura 35 - Kwak, K. y Ullah, N., “An overview of IEEE 802.15.6 standard.” 1 - 6. 10.1109/ISABEL.2010.5702867, diciembre de 2010.

Figura 36 - "IEEE Standard for Local and metropolitan area networks - Part 15.6: Wireless Body Area Networks," in IEEE Std 802.15.6-2012, 29 de febrero de 2012.

Figura 37 - "IEEE Standard for Local and metropolitan area networks - Part 15.6: Wireless Body Area Networks," in IEEE Std 802.15.6-2012, 29 de febrero de 2012.

Figura 38 - "IEEE Standard for Local and metropolitan area networks - Part 15.6: Wireless Body Area Networks," in IEEE Std 802.15.6-2012, 29 de febrero de 2012.

Figura 39 - "IEEE Standard for Local and metropolitan area networks - Part 15.6: Wireless Body Area Networks," in IEEE Std 802.15.6-2012, 29 de febrero de 2012.

Figura 40 - "IEEE Standard for Local and metropolitan area networks - Part 15.6: Wireless Body Area Networks," in IEEE Std 802.15.6-2012, 29 de febrero de 2012.

Figura 41 - "IEEE Standard for Local and metropolitan area networks - Part 15.6: Wireless Body Area Networks," in IEEE Std 802.15.6-2012, 29 de febrero de 2012.

Figura 42 - "IEEE Standard for Local and metropolitan area networks - Part 15.6: Wireless Body Area Networks," in IEEE Std 802.15.6-2012, 29 de febrero de 2012.

Figura 43 - "IEEE Standard for Local and metropolitan area networks - Part 15.6: Wireless Body Area Networks," in IEEE Std 802.15.6-2012, 29 de febrero de 2012.

Figura 44 - "IEEE Standard for Local and metropolitan area networks - Part 15.6: Wireless Body Area Networks," in IEEE Std 802.15.6-2012, 29 de febrero de 2012.

Figura 45 - "IEEE Standard for Low-Rate Wireless Networks" in IEEE Std 802.15.42015 (Revision of IEEE Std 802.15.4-2011), 22 de abril de 2016.

Figura 46 -"IEEE Standard for Low-Rate Wireless Networks" in IEEE Std 802.15.42015 (Revision of IEEE Std 802.15.4-2011), 22 de abril de 2016. 
Figura 47 -"IEEE Standard for Low-Rate Wireless Networks" in IEEE Std 802.15.42015 (Revision of IEEE Std 802.15.4-2011), 22 de abril de 2016.

Figura 48 -"IEEE Standard for Low-Rate Wireless Networks" in IEEE Std 802.15.42015 (Revision of IEEE Std 802.15.4-2011), 22 de abril de 2016.

"IEEE Standard for Low-Rate Wireless Networks" in IEEE Std 802.15.4-2015 (Revision of IEEE Std 802.15.4-2011), 22 de abril de 2016.Figura 49 -

Figura 50 -"IEEE Standard for Low-Rate Wireless Networks" in IEEE Std 802.15.42015 (Revision of IEEE Std 802.15.4-2011), 22 de abril de 2016.

Figura 51 - "IEEE Standard for Low-Rate Wireless Networks" in IEEE Std 802.15.42015 (Revision of IEEE Std 802.15.4-2011), 22 de abril de 2016.

Figura 52 -"IEEE Standard for Low-Rate Wireless Networks" in IEEE Std 802.15.42015 (Revision of IEEE Std 802.15.4-2011), 22 de abril de 2016.

Figura 53 -"IEEE Standard for Low-Rate Wireless Networks" in IEEE Std 802.15.42015 (Revision of IEEE Std 802.15.4-2011), 22 de abril de 2016.

Figura 54 -"IEEE Standard for Low-Rate Wireless Networks" in IEEE Std 802.15.42015 (Revision of IEEE Std 802.15.4-2011), 22 de abril de 2016.

Figura 55 -"IEEE Standard for Low-Rate Wireless Networks" in IEEE Std 802.15.42015 (Revision of IEEE Std 802.15.4-2011), 22 de abril de 2016.

Figura 56 -"IEEE Standard for Low-Rate Wireless Networks" in IEEE Std 802.15.42015 (Revision of IEEE Std 802.15.4-2011), 22 de abril de 2016.

Figura 57 -"IEEE Standard for Low-Rate Wireless Networks" in IEEE Std 802.15.42015 (Revision of IEEE Std 802.15.4-2011), 22 de abril de 2016.

Figura 58 -"IEEE Standard for Low-Rate Wireless Networks" in IEEE Std 802.15.42015 (Revision of IEEE Std 802.15.4-2011), 22 de abril de 2016.

Figura 59 -"IEEE Standard for Low-Rate Wireless Networks" in IEEE Std 802.15.42015 (Revision of IEEE Std 802.15.4-2011), 22 de abril de 2016.

Figura 60 -"IEEE Standard for Low-Rate Wireless Networks" in IEEE Std 802.15.42015 (Revision of IEEE Std 802.15.4-2011), 22 de abril de 2016.

Figura 61 - "IEEE Standard for Low-Rate Wireless Networks" in IEEE Std 802.15.42015 (Revision of IEEE Std 802.15.4-2011), 22 de abril de 2016.

Figura 62 -"IEEE Standard for Low-Rate Wireless Networks" in IEEE Std 802.15.42015 (Revision of IEEE Std 802.15.4-2011), 22 de abril de 2016.

Figura 63 -"IEEE Standard for Low-Rate Wireless Networks" in IEEE Std 802.15.42015 (Revision of IEEE Std 802.15.4-2011), 22 de abril de 2016.

Figura 64 -"IEEE Standard for Low-Rate Wireless Networks" in IEEE Std 802.15.42015 (Revision of IEEE Std 802.15.4-2011), 22 de abril de 2016.

Figura 65 -"IEEE Standard for Low-Rate Wireless Networks" in IEEE Std 802.15.42015 (Revision of IEEE Std 802.15.4-2011), 22 de abril de 2016.

"IEEE Standard for Low-Rate Wireless Networks" in IEEE Std 802.15.4-2015 (Revision of IEEE Std 802.15.4-2011), 22 de abril de 2016.

Figura 66 -"IEEE Standard for Low-Rate Wireless Networks" in IEEE Std 802.15.42015 (Revision of IEEE Std 802.15.4-2011), 22 de abril de 2016.

Figura 67 -"IEEE Standard for Low-Rate Wireless Networks" in IEEE Std 802.15.42015 (Revision of IEEE Std 802.15.4-2011), 22 de abril de 2016.

Figura 68 -"IEEE Standard for Low-Rate Wireless Networks" in IEEE Std 802.15.42015 (Revision of IEEE Std 802.15.4-2011), 22 de abril de 2016.

Figura 69 -"IEEE Standard for Low-Rate Wireless Networks" in IEEE Std 802.15.42015 (Revision of IEEE Std 802.15.4-2011), 22 de abril de 2016.

Figura 70 -"IEEE Standard for Low-Rate Wireless Networks" in IEEE Std 802.15.42015 (Revision of IEEE Std 802.15.4-2011), 22 de abril de 2016. 
Figura 71 - "IEEE Standard for Low-Rate Wireless Networks" in IEEE Std 802.15.42015 (Revision of IEEE Std 802.15.4-2011), 22 de abril de 2016.

Figura 72 -"IEEE Standard for Low-Rate Wireless Networks" in IEEE Std 802.15.42015 (Revision of IEEE Std 802.15.4-2011), 22 de abril de 2016.

Figura 73 -"IEEE Standard for Low-Rate Wireless Networks" in IEEE Std 802.15.42015 (Revision of IEEE Std 802.15.4-2011), 22 de abril de 2016.

"IEEE Standard for Low-Rate Wireless Networks" in IEEE Std 802.15.4-2015 (Revision of IEEE Std 802.15.4-2011), 22 de abril de 2016.

Figura 74 -"IEEE Standard for Low-Rate Wireless Networks" in IEEE Std 802.15.42015 (Revision of IEEE Std 802.15.4-2011), 22 de abril de 2016.

Figura 75 -"IEEE Standard for Low-Rate Wireless Networks" in IEEE Std 802.15.42015 (Revision of IEEE Std 802.15.4-2011), 22 de abril de 2016.

Figura 76 -"IEEE Standard for Low-Rate Wireless Networks" in IEEE Std 802.15.42015 (Revision of IEEE Std 802.15.4-2011), 22 de abril de 2016.

Figura 77 -"IEEE Standard for Low-Rate Wireless Networks" in IEEE Std 802.15.42015 (Revision of IEEE Std 802.15.4-2011), 22 de abril de 2016.

Figura 78 - "Part 11: Wireless LAN Medium Access Control (MAC) and Physical Layer (PHY) specifications: Higher-Speed Physical Layer Extension in the 2.4GHz Band", Supplement to ANSI/IEEE Std 802.11, Edición 1999.

Figura 79 - "Part 11: Wireless LAN Medium Access Control (MAC) and Physical Layer (PHY) specifications: Higher-Speed Physical Layer Extension in the 2.4GHz Band", Supplement to ANSI/IEEE Std 802.11, Edición 1999.

Figura 80 - "Part 11: Wireless LAN Medium Access Control (MAC) and Physical Layer (PHY) specifications: Higher-Speed Physical Layer Extension in the 2.4GHz Band", Supplement to ANSI/IEEE Std 802.11, Edición 1999.

Figura 81 - "Part 11: Wireless LAN Medium Access Control (MAC) and Physical Layer (PHY) specifications: Higher-Speed Physical Layer Extension in the 2.4GHz Band", Supplement to ANSI/IEEE Std 802.11, Edición 1999.

Figura 82 - "Part 11: Wireless LAN Medium Access Control (MAC) and Physical Layer (PHY) specifications: Higher-Speed Physical Layer Extension in the 2.4GHz Band", Supplement to ANSI/IEEE Std 802.11, Edición 1999.

Figura 83 - "Part 11: Wireless LAN Medium Access Control (MAC) and Physical Layer (PHY) specifications: Higher-Speed Physical Layer Extension in the 2.4GHz Band", Supplement to ANSI/IEEE Std 802.11, Edición 1999.

Figura 84 - "Part 11: Wireless LAN Medium Access Control (MAC) and Physical Layer (PHY) specifications: Higher-Speed Physical Layer Extension in the 2.4GHz Band", Supplement to ANSI/IEEE Std 802.11, Edición 1999.

Figura 85 - S. J. Shellhammer,"Estimation of Packet Error Rate Caused by Interference usin Analytic Techniques - A Coexistence Assurance Metodology", in IEEE 802.19 Wireless Coexistene, 28 de septiembre de 2005.

Figura 87 - R. Natarajan, P. Zand y M. Nabi, "Analysis of coexistence between IEEE 802.15.4, BLE and IEEE 802.11 in the $2.4 \mathrm{GHz}$ ISM band," IECON 2016 - 42nd Annual Conference of the IEEE Industrial Electronics Society, Florence, 23-26 de octubre de 2016. 